\title{
PREPARAÇÃO E CARACTERIZAÇÃO DE VIDROS ALUMINATO DE CÁLCIO COM BAIXA CONCENTRAÇÃO DE SÍLICA DOPADOS COM Nd $\mathrm{O}_{3} \mathrm{O} \mathrm{Er}_{2} \mathrm{O}_{3}$
}

\section{Juraci Aparecido Sampaio}

Tese apresentada ao Instituto de Física de São Carlos, da Universidade de São Paulo, para a obtenção do título de Doutor em Ciências: Física Aplicada.

Orientador: Prof. Dr. Tomaz Catunda

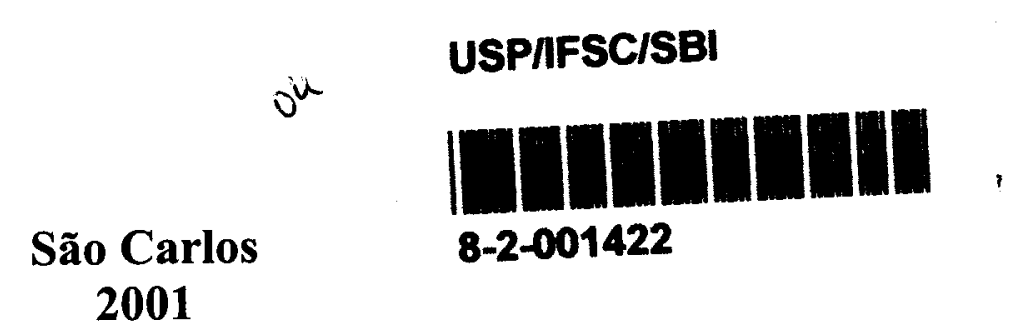

IFSC-USP SERVIÇO DE BIBLLOTECA 
Sampaio, Juraci Aparecido

"Preparação e Caracterização de Vidros Aluminato de Cálcio com Baixa Concentração de Sílica dopados com $\mathrm{Nd}_{2} \mathrm{O}_{3}$ e $\mathrm{Er}_{2} \mathrm{O}_{3}$ "/ Juraci Aparecido Sampaio São Carlos, 2001

Tese (Doutorado) - Instituto de Física de São Carlos da Universidade de São Paulo, 2001 - páginas: 176

Área: Física Aplicada

Prof. Dr. Tomaz Catunda

1. Vidros, 2. Laser, 3. Íons das terras raras

I. Título 
UNIVERSIDADE

DE SÃO PAULO

Caixa Postal 369

13560-970 São Carlos, SP

Av. Trabalhador São-carlense, 400 ,

Instituto de Física de São Carlos

13566-590 São Carlos, SP

Fone/Fax 162739777

www.if.sc.usp. br

wladerezaif.sc.usp.br

MEMBROS DA COMISSÃO JULGADORA DA TESE DE DOUTORADO DE IURACI APARECIDO SAMPAIO, APRESENTADA AO INSTITUTO DE FÍSICA DE SÃO CARLOS, UNIVERSIDADE DE SÃO PAULO, EM 11-10-2001.

COMISSÃO JULGADORA:

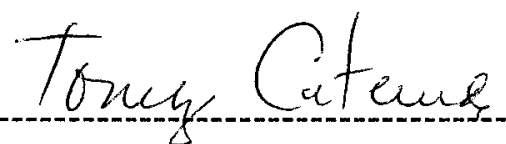

Drot. Dr. TOMAZ CATUNDA (Orientador e Presidente) - IFSC / USP
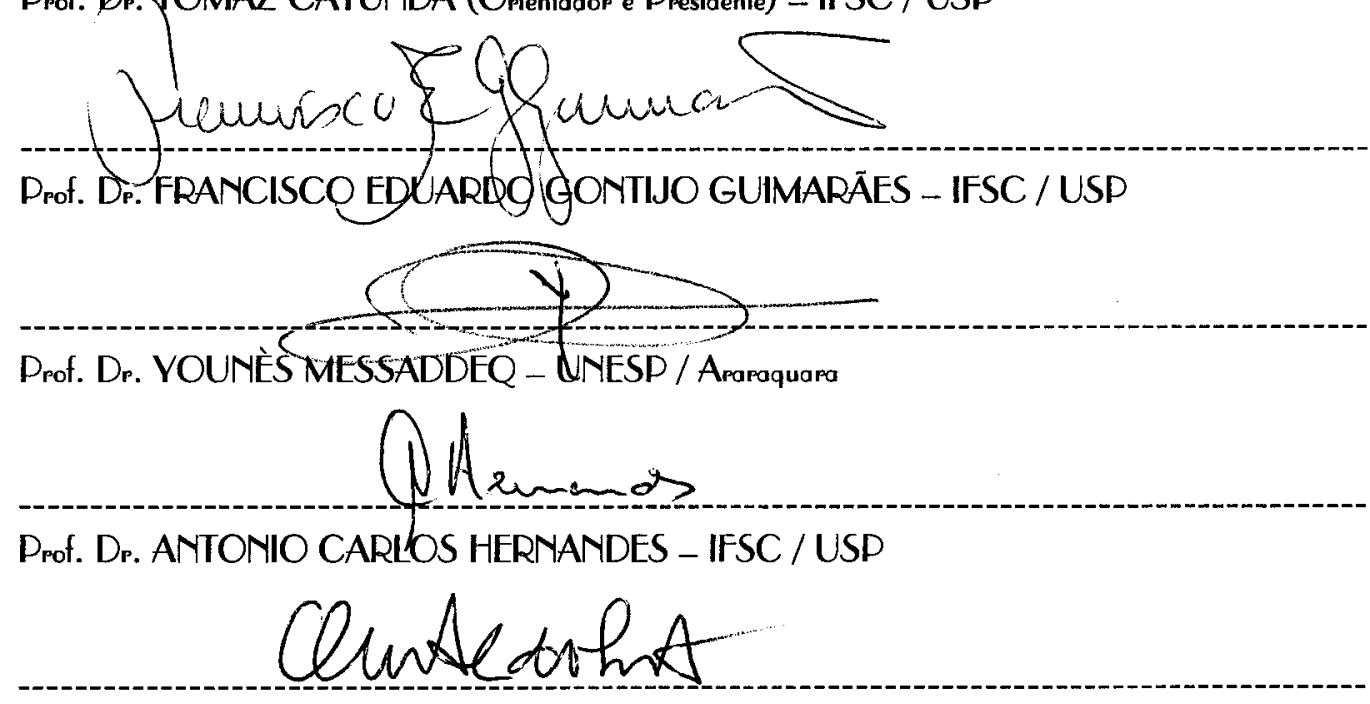

Drof. D. OSWALDO LUIZ ALVES - UNICAMP 
A meus pais. 


\section{Agradecimentos}

Ao Prof. Dr. Tomaz Catunda (IFSC-USP), pela sua orientação e discussões dos resultados .

Ao Prof. Dr. Mauro Luciano Baesso (DFI-UEM), pela sua orientação, incentivo, sugestões, e discussões dos resultados.

Ao Prof. Dr. Sergio Gama (IFGW-UNICAMP), pela sua orientação, incentivo, discussões nos resultados, e por ter permitido realizar grande parte desse trabalho em seu laboratório.

Ao Dr. Adelino de Aguiar Coelho (IFGW-UNICAMP), pela sua valiosa contribuição na construção do forno, com quem muito aprendi sobre tecnologia de vácuo.

Ao Dr. José Miguel Zelaya Bejarano (CT-UNICAMP), pela sua ajuda nos experimentos de dureza Vickers e discussões dos resultados.

Ao Daniel Rojas Pupo e ao Prof. Dr. Flávio César Guimarães Gandra, pelo auxílio nas medidas de calor específico.

Ao Eng. Antonio Carlos da Costa (IFGW-UNICAMP), pela ajuda na parte de espectrometria e refratometria.

Ao Amigo Ivair Aparecido dos Santos e ao Prof. Dr. José Antonio Eiras (DFI-UFSCar), pelas medidas das velocidades ultra-sônicas.

Ao Orival Florindo da Silva pelo trabalho de usinagem dos flanges para a construção do forno.

Ao Nelson pela usinagem das resistências de grafite. 
A Cleusa Barnabé, pela ajuda na parte de polimento e microscopia óptica.

Ao João Alimiro Lopes, pelo trabalho de solda e teste de vácuo durante a construção do forno.

Ao André Romero, pela ajuda no laboratório durante os experimentos de lente térmica.

Ao Sandro Márcio de Lima, pela ajuda no laboratório e discussões dos dados de lente térmica.

Ao Acácio Aparecido Andrade, pela ajuda no laboratório e discussões dos dados de lente térmica.

A Wladerez, sempre prestativa e eficiente na parte burocrática junto a CPG-IFSC.

Ao pessoal do grupo: Dione, Andrea, Samuel, Daniel, Glaúcia, Alessandra, Tânia e Prof. Luiz Antonio.

Ao pessoal do LMBT/GPCM: Célia, Valter, Marilsa, Cleber, Clotilde.

A minha família pelo apoio e compreensão.

A CAPES pelo bolsa de estudos.

A todos que, direta ou indiretamente, coadjuvaram para o desenvolvimento dessa tese. 


\section{Sumário}

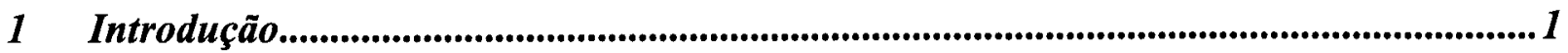

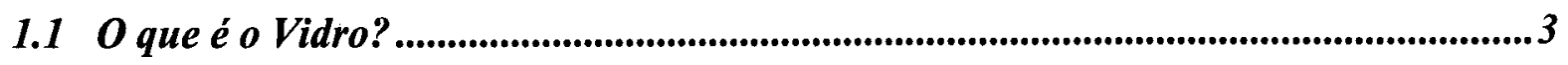

1.2 Vidros como matrizes de íons terras raras.............................................................13

$2 \quad$ O sitema vítreo aluminato de cálcio............................................................................. 14

2.1 Terras raras em vidros aluminato de cálcio ............................................................35

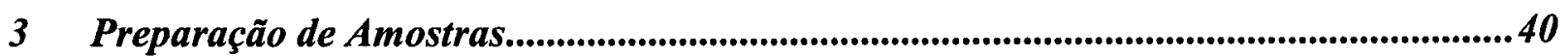

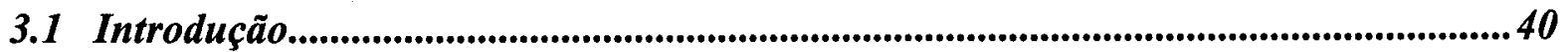

3.2 Construção de câmara de vácuo para fusão de amostras de vidros .......................... 40

3.3 Tipos de cadinhos .............................................................................................................46

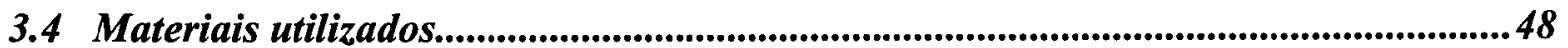

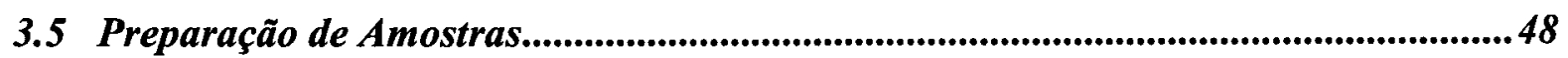

4 Técnicas de Caracterização..................................................................................................57

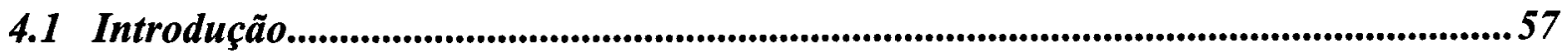

4.2 Difração de raios- $X$...........................................................................................................57

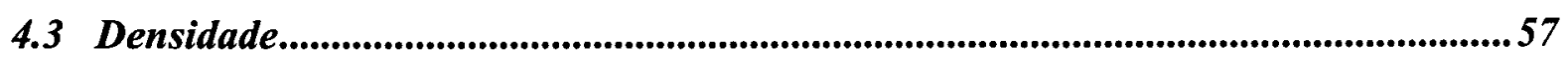

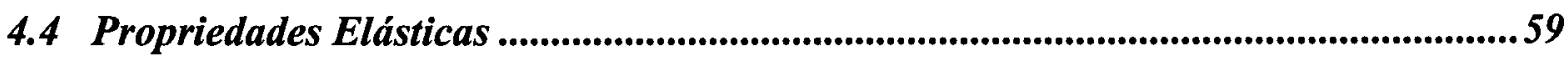

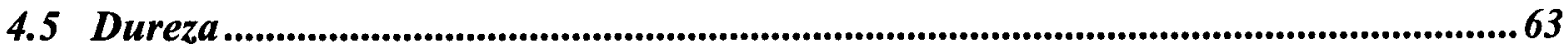

4.6 Tenacidade à Fratura.....................................................................................................65

4.7 Análise Térmica Diferencial ............................................................................67

4.8 Calor Especifico

4.9 Índice de Refração.......................................................................................... 71

4.10 Transmitância Óptica ............................................................................................... 75

4.11 Espectroscopia de Lente Térmica ....................................................................... 78

$4.12 O$ arranjo experimental da espectroscopia de lente térmica.................................... 79

4.13 Determinação da cintura do feixe do laser..........................................................80

4.14 Determinação do coeficiente de absorção óptica $(\alpha)$...................................................87 87 
4.15 O efeito de lente térmica no estado estacionário.....................................................88

4.16 Resistência ao Choque Térmico.......................................................................92

4.17 Eficiência Quântica..................................................................................................... 94

4.18 Tempo de Vida da fluorescência .....................................................................99

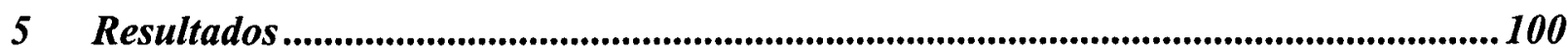

5.1 Difração de Raios- $X$...........................................................................................100

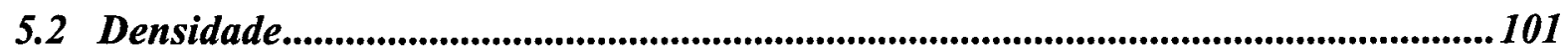

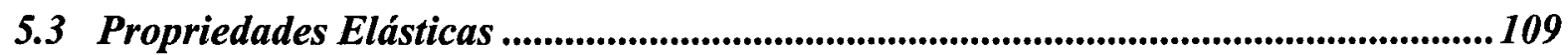

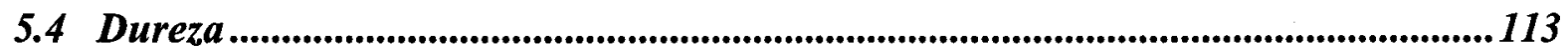

5.5 Tenacidade à Fratura ........................................................................................... 116

5.6 Análise Térmica Diferencial .........................................................................117

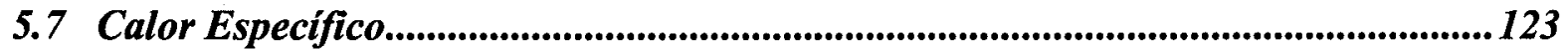

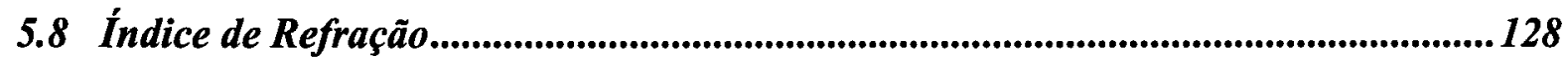

5.9 Transmitância Óptica ............................................................................................. 139

5.10 Propriedades Termo-Ópticas........................................................................... 145

5.11 Resistência ao choque térmico.................................................................................. 157

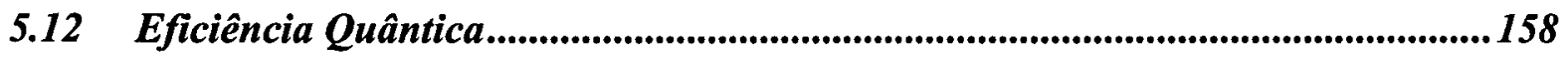

5.13 Tempo de Vida da fluorescência .............................................................................163

6 Conclusĩes e Perspectivas de trabalhos futuros....................................................... 165

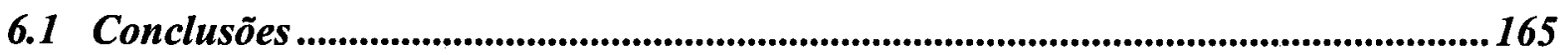

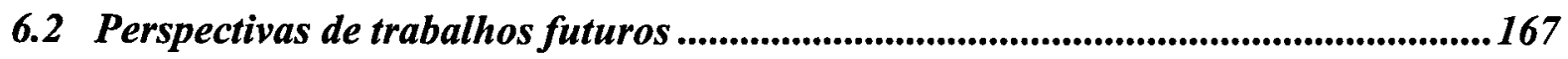

$7 \quad$ Referências Bibliográficas .............................................................................................169 


\section{Lista de Tabelas}

Tabela 3.1 - Materiais utilizados

Tabela 3.2 - Composições dos vidros aluminato de cálcio preparados a vácuo.

Tabela 3.3 - Composições dos vidros aluminato de cálcio fundidos a vácuo.

Tabela 3.4 - Composições vidros aluminato de cálcio dopados com $\mathrm{Nd}_{2} \mathrm{O}_{3}$ e $\mathrm{Er}_{2} \mathrm{O}_{3}$ fundidos ao ar.

Tabela 3.5 - Composições vidros fosfatos e boratos fundidos ao ar.......................................54

Tabela 3.6 - Composições vidros silicatos fundidos ao ar....................................................54

Tabela 4.1 - Índice de refração do prisma VoF5 em função do comprimento de onda........... 74

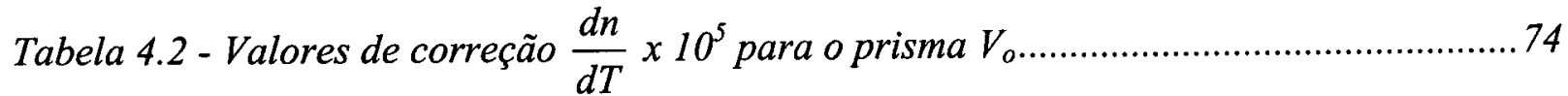

Tabela 4.3 - Parâmetros experimentais para determinação da cintura do laser. 83

Tabela 4.4 - Parâmetros experimentais usados na ELT para as amostras dopadas com $\mathrm{Er}_{2} \mathrm{O}_{3}$.

Tabela 4.5 - Parâmetros experimentais usados na ELT para as amostras dopadas com $\mathrm{Nd}_{2} \mathrm{O}_{3}$.

Tabela 4.6 - Propriedades espectroscópicas de vidros aluminato de cálcio dopados com $\mathrm{Nd}_{2} \mathrm{O}_{3}$. Comparação com os resultados reportados por Pecoraro et al. (1999).

Tabela 5.1 - Al/Ca é a razão molar $\mathrm{Al}_{2} \mathrm{O}_{3}$ entre $\mathrm{CaO}$; $\rho$ é a densidade do vidro; $\bar{n}_{M}$ éo número médio de cátions; $\bar{n}_{0}$ é o número médio de oxigênios; $\bar{W}_{\mathrm{g}}$ peso molar do vidro; $V_{M}$ é o volume molar do vidro, $V_{1 \mathrm{~g}}$ é o volume molar de oxigênios.

Tabela 5.2 - $\mathrm{Al} / \mathrm{Ca}$ é a razão molar $\mathrm{Al}_{2} \mathrm{O}_{3}$ entre $\mathrm{CaO}$; $\rho$ é a densidade do vidro ;; $\bar{n}_{M}$ éo número médio de cátions; $\bar{n}_{0}$ é o número médio de oxigênios; $\bar{W}_{g}$ peso molar do vidro; $V_{M}$ é o volume molar do vidro, $V_{1 g}$ é o volume molar de oxigênios.

Tabela 5.3- $\mathrm{Al} / \mathrm{Ca}$ é a razão molar $\mathrm{Al}_{2} \mathrm{O}_{3}$ entre $\mathrm{CaO}$; $\rho$ é a densidade do vidro; $\bar{n}_{M}$ éo número médio de cátions; $\bar{n}_{0}$ é o número médio de oxigênios; $\bar{W}_{g}$ peso molar do vidro; $V_{M}$ é o volume molar do vidro, $V_{1 g}$ é o volume molar de oxigênios. 103 
Tabela 5.4 - Al/Ca é a razão molar $\mathrm{Al}_{2} \mathrm{O}_{3}$ entre $\mathrm{CaO} ; \rho$ é a densidade do vidro; $\bar{n}_{M}$ éo número médio de cátions; $\bar{n}_{0}$ é o número médio de oxigênios; $\bar{W}_{\mathrm{g}}$ peso molar do vidro; $V_{M}$ é o volume molar do vidro, $V_{1 g}$ é o volume molar de oxigênios.

Tabela 5.5 Propriedades elásticas do sistema $\mathrm{Al}_{2} \mathrm{O}_{3}-\mathrm{CaO}-\mathrm{MgO}-\mathrm{SiO}_{2}$ dopado com íons terras raras.

Tabela 5.6 - Dados comparativos dos módulos de elasticidade de alguns sistemas vitreos (Volf et al., 1995)

Tabela 5.7 - Módulo de Young, E; Módulo de cisalhamento, G; Coeficiente de Poisson em função da temperatura para o vidro aluminato de cálcio $41.2 \mathrm{Al}_{2} \mathrm{O}_{3}, 42 \mathrm{CaO}, 16.8 \mathrm{BaO}$ (\% peso) (Florence et al., 1955)

Tabela 5.8 - Dureza Vickers para os vidros aluminato de cálcio dopados com óxidos terras raras.

Tabela 5.9 - Resultados obtidos para a determinação de $K_{I C}$. P é a carga, $H_{V}$ é a dureza Vickers, a é o raio da diagonal da indentação, c é o raio da diagonal da indentação +o comprimento da trinca, e lé o comprimento da trinca, E é o módulo de Young e $K_{I C} e ́$ a tenacidade à ruptura.

Tabela 5.10 - Eventos térmicos vidros aluminato de cálcio dopados com óxidos terras raras. $T_{g}$ (temperatura de transição vitrea), $T_{x}$ (temperatura de cristalização)........119

Tabela 5.11 - dados experimentais da capacidade térmica do substrato.

Tabela 5.12 - dados experimentais para obtenção calor especifico vidros aluminato dopados $\operatorname{com~} \mathrm{Nd}_{2} \mathrm{O}_{3}$.

Tabela 5.13 - dados experimentais para obtenção do calor específico para vidros aluminato de cálcio dopados com diferentes concentrações de Yb e Er.

Tabela 5.14 - Índice de refração em função da concentração de terra rara e comprimento de onda.

Tabela 5.15 - Índice de refração em função da concentração de terra rara e comprimento de onda.

Tabela 5.16 - Variação do índice de refração em função da temperatura, dn/dT, de vidros aluminato de cálcio fundidos ao ar. 
Tabela 5.17 Dados experimentais do efeito de lente térmica no estado estacionário para amostra de vidro aluminato de cálcio dopado com $4 \%$ de $\mathrm{Er}_{2} \mathrm{O}_{3}$, fundida a vácuo. Laser de excitação em $804 \mathrm{~nm}$ e laser de prova em $632.8 \mathrm{~nm}$.

Tabela 5.18 - dados experimentais obtidos através do transiente para amostra de vidro aluminato de cálcio dopado com $4.0 \%$ de $\mathrm{Er}_{2} \mathrm{O}_{3}$.

Tabela 5.19 - Dados vidros aluminato de cálcio dopados com $\mathrm{Er}_{2} \mathrm{O}_{3} \mathrm{em} 488 \mathrm{~nm}$-amostras fundidas ao vácuo

Tabela 5.20 - Dados vidros aluminato de cálcio dopados com $\mathrm{Er}_{2} \mathrm{O}_{3}$ em $488 \mathrm{~nm}$-amostras fundidas ao ar.

Tabela 5.21 - dados vidros aluminato de cálcio dopados com $\mathrm{Er}_{2} \mathrm{O}_{3} \mathrm{em} 804 \mathrm{~nm}$-amostras fundidas ao vácuo

Tabela 5.22 - dados vidros aluminato de cálcio dopados com $\mathrm{Er}_{2} \mathrm{O}_{3} \mathrm{em} 804 \mathrm{~nm}$-amostras fundidas ao ar

Tabela 5.23 - Dados vidros aluminato de cálcio dopados com $\mathrm{Er}_{2} \mathrm{O}_{3}$ em $788.5 \mathrm{~nm}$-amostras fundidas a vácuo.

Tabela 5.24 - dados vidros aluminato de cálcio dopados com $\mathrm{Er}_{2} \mathrm{O}_{3} \mathrm{em} 800 \mathrm{~nm}$-amostras fundidas ao ar.

Tabela 5.25 - Dados vidros aluminato de cálcio dopados com $\mathrm{Nd}_{2} \mathrm{O}_{3}$ em $514 \mathrm{~nm}$-amostras fundidas ao ar.

Tabela 5.26 - Dados vidros aluminato de cálcio dopados com $\mathrm{Nd}_{2} \mathrm{O}_{3} \mathrm{em} 810 \mathrm{~nm}$-amostras fundidas a vácuo.

Tabela 5.27 - Dados vidros aluminato de cálcio dopados com $\mathrm{Nd}_{2} \mathrm{O}_{3}$ em $514 \mathrm{~nm}$-amostras fundidas a vácuo (Sampaio, 1997)

Tabela 5.28 comparação da resistência ao choque térmico de vários sistemas vitreos. 


\section{Lista de Figuras}

Figura 1.1 - Relação entre os estados líquido, vitreo e cristalino (Paul, 1990: 3).

Figura 1.2 - Mudança do comprimento de um vidro borosilicato com aumento da temperatura: A) resfriamento lento, B) resfriamento rápido, C) resfriamento extremamente rápido, fibra de 6 нm diâmetro (Salmang, 1957).

Figura 1.3 - Distribuição da intensidade do espalhamento de raios-X com dependência ao ângulo rasante para substâncias em vários estados de agregação (Vogel, 1994:29)........8

Figura 1.4 - Padrão raios-X Debye-Scherrer de a) vidro e b) cristal (Vogel, 1994:29)...........9

Figura 1.5 - Representação esquemática bidimensional da estrutura de (a) um composto cristalino hipotético $\mathrm{A}_{2} \mathrm{O}_{3}$ e (b) a forma vitrea do mesmo composto (Zachariasen, 1932).

Figura 1.6 - Representação esquemática de várias espécies de silicato $Q^{n}$ em vidros silicatos.

a) Tetraedro elementar $Q^{3}$ com 3 oxigênios bridging e 1 oxigênio non-bridging. b) Exemplo de oxigênios non-bridging aparelhados e isolados. c) Vidro composicionalmente ordenado. d) Rede aleatória. (Zarzycki, 1991).

Figura 2.1 - Região de vitrificação do sistema binário $\mathrm{CaO}: \mathrm{Al}_{2} \mathrm{O}_{3}$ (Rawson, 1967) .15

Figura 2.2 - Representação esquemática da mudança de coordenação de um íon de $\mathrm{Al}^{3+}$ sobre o efeito de contra polarização dos ions de $\mathrm{Ca}^{2+}$. As esferas representam os oxigênios (Vogel, 1994:258).

Figura 2.3 - Transmitância na região do infravermelho para o vidro aluminato de cálcio:

$41.2 \mathrm{Al}_{2} \mathrm{O}_{3}-42 \mathrm{CaO}-6.8 \mathrm{BaO}-5.0 \mathrm{BeO}-5.0 \mathrm{La}_{2} \mathrm{O}_{3}$ (\% em peso). a) espessura 2.04 $\mathrm{mm}$, b) espessura $4.16 \mathrm{~mm}$ (Florence et al., 1955).

Figura 2.4 - curvas de transmitância de vários vidros aluminato de cálcio na região do visivel e infravermelho. A) $\left.58.5 \mathrm{CaO}, 27.5 \mathrm{Al}_{2} \mathrm{O}_{3}, 8.4 \mathrm{MgO}, 5.6 \mathrm{SiO}_{2} . \mathrm{B}\right) 32.5 \mathrm{CaO}, 57.5 \mathrm{Al}_{2} \mathrm{O}_{3}$, $2 \mathrm{MgO}, 2 \mathrm{BaO}, 2 \mathrm{La}_{2} \mathrm{O}_{3}, 7.5 \mathrm{Na}_{2} \mathrm{O}, 2.5 \mathrm{~K}_{2} \mathrm{O}, 0.5 \mathrm{Fe}_{2} \mathrm{O}_{3}$. C) $32.5 \mathrm{CaO}, 57.5 \mathrm{Al}_{2} \mathrm{O}_{3}, 2 \mathrm{MgO}$, $\left.2 \mathrm{BaO}, 2 \mathrm{La}_{2} \mathrm{O}_{3}, 7.5 \mathrm{Na}_{2} \mathrm{O}, 2.5 \mathrm{~K}_{2} \mathrm{O}, 2 \mathrm{Fe}_{2} \mathrm{O}_{3} \mathrm{D}\right) 32.5 \mathrm{CaO}, 57.5 \mathrm{Al}_{2} \mathrm{O}_{3}, 2 \mathrm{MgO}, 2 \mathrm{BaO}, 2 \mathrm{La}_{2} \mathrm{O}_{3}$, $7.5 \mathrm{Na}_{2} \mathrm{O}, 2.5 \mathrm{~K}_{2} \mathrm{O}, 5 \mathrm{Fe}_{2} \mathrm{O}_{3}$, porcentagens em mol \% (Hafner et al., 1958). 18

Figura 2.5 - Região de fácil vitrificação no sistema $\mathrm{CaO}: \mathrm{Al}_{2} \mathrm{O}_{3}: \mathrm{SiO}_{2}$ com baixa concentração de sílica, mostrada na área em cinza (Onoda e Brown, 1970). 
Figura 2.6 Comparação das curvas de transmitância de vários vidros de $2 \mathrm{~mm}$ de espessura.

a) $45 \mathrm{Al}_{2} \mathrm{O}_{3}-36.9 \mathrm{CaO}, 13.4 \mathrm{BaO}$ (\% peso, fundido a vácuo); b) $40.8 \mathrm{Al}_{2} \mathrm{O}_{3}-49 \mathrm{CaO}$,

$6.1 \mathrm{SiO}_{2}-4.1 \mathrm{MgO}$ (\% peso, fundido a vácuo); c) aluminato fundido ao ar; d) silicato fundido ao ar (Davy, 1978).

Figura 2.7 - Mudança no espectro de transmissão de um vidro 60 $\mathrm{CaO}: 40 \mathrm{Al}_{2} \mathrm{O}_{3}$ (mol\%), com

$1.5 \mathrm{~mm}$ de espessura, devido à radiação ultravioleta (número nas curvas representa o tempo de iluminação) (Hosono et al., 1985).

Figura 2.8 - Mecanismo proposto para a fotosensibilidade (Hosono e Abe, 1987a).

Figura 2.9 - Curva de decaimento da fosforescência após a retirada da fonte de excitação, em $254 \mathrm{~nm}$, monitorada em $542 \mathrm{~nm}$. O tempo no detalhe denota os minutos decorridos após a retirada da fonte excitadora em $254 \mathrm{~nm}$. A seta indica o pico de emissão em $542 \mathrm{~nm}$ devido a transição ${ }^{5} \mathrm{D}_{4} \rightarrow{ }^{7} \mathrm{~F}_{5}$ do $\mathrm{Tb}^{3+}$ (Kinoshita et. al, 1999).

Figura 2.10 - A) Efeito da razão $\mathrm{CaO} / \mathrm{Al}_{2} \mathrm{O}_{3}$ sobre $\mathrm{T}_{\mathrm{g}}$ para várias concentrações de sílica. B)

Efeito da concentração de silica sobre $T_{g}$ para $\mathrm{CaO} / \mathrm{Al}_{2} \mathrm{O}_{3}$ constante. Linhas desenhadas para guiar os olhos (Higby et. al, 1990). 32

Figura 2.11 - A) Efeito da concentração de sílica sobre o indice de refração com várias razões de $\mathrm{CaO} / \mathrm{Al}_{2} \mathrm{O}_{3}$ (linhas desenhadas para guiar os olhos). B) Viscosidade para várias

Figura 2.12 - fotoluminescência dos ions de $\mathrm{Er}^{3+}$ de uma amostra de vidro $\mathrm{CaO}: \mathrm{Al}_{2} \mathrm{O}_{3} \mathrm{Co}-$ dopado com 2 peso $\%$ de $\mathrm{Yb}^{3+}$ e 4 peso $\%$ de $\mathrm{Er}^{3+}$. Os niveis de energia associados e $\mathrm{o}$ processo de transferência de energia são indicados na figura. A distorção observada no pico próximo a 2.8 um é atribuida a presença de vapor de água do meio ambiente (Souza et al., 1999).

Figura 3.1 - Representação esquemática do forno usado na preparação de amostras feitas a vácuo.

Figura 3.2 - Fotografia da tampa superior do forno em funcionamento através de uma das janelas de quartzo para a observação da amostra

Figura 3.3 - Fotografia da tampa do forno. Entrada de mangueiras para refrigeração da parte superior do forno, inclusive a câmara para choque térmico. 
Figura 3.4 - Fotografia do forno aberto. Podemos verificar ai a haste que serve para puxar a amostra da área quente para a região de temperatura fria, para o choque térmico./..... 44

Figura 3.5 - Fotografia da parte interna do forno. No centro encontra-se o resistor; em seu entorno pode ser visto os elementos que compõem a blindagem de calor composta por um tubo de grafite, manta de grafite, carcaça de tântalo ou níquel.

Figura 3.6 - Fotografia da parte inferior do forno mostrando a entrada de eletricidade, $e$ refrigeração dos eletrodos de cobre. O tubo de cobre (grande) é a saida para a bomba de vácuo.

Figura 3.7-Fotografia da resistência de grafite usada no forno para a fusão de amostras. Em A temos a visão do ângulo de cima, enquanto que em $B$ temos a visão lateral do resistor.

Figura 3.8 - Cadinhos de grafite usados para a preparação de vidros aluminato de cálcio. .46 Figura 3.9 - Fotografia de algumas das amostras de vidros aluminato de cálcio....................56

Figura 4.1 - Deformação por tração.....................................................................................61

Figura 4.2 - Deformação por cisalhamento.........................................................................61

Figura 4.3 - Deformação por compressão.............................................................................62

Figura 4.4 - Fotomicrografia das indentações Vickers em uma amostra de vidro aluminato de cálcio, CASM00, usando cargas de $A=100 \mathrm{~g}, B=200 \mathrm{~g}$ e $C=300 \mathrm{~g}$. Tempo 30s. Aumento de 200 vezes.

Figura 4.5 - Comprimentos caracteristicos das indentações Vickers 66

Figura 4.6 - Diagrama esquemático de um calorímetro ilustrando um substrato preso a um reservatório térmico $(R)$. Os fios de sustentação $(F)$ também conduzem corrente para o aquecedor $(H)$ e o calor para o reservatório $(R)$. O suporte de amostra $(S)$ juntamente com o sensor de temperatura (T) e o aquecedor formam o substrato, que permanece em vácuo e fechado por um capa externa (C). Todo este sistema está em banho de He líquido. O vácuo é designado por (V) (Azechi et al. 1995).

Figura 4.7 - Representação esquemática da transmissão da luz pelo vidro (Shand, 1958:57).

Figura 4.8-Representação esquemática da luz atravessando Vo e uma amostra hipotética. $O$ ângulo ré obtido com o auxílio de um goniômetro. 
Figura 4.9 - Arranjo experimental do sistema de lente térmica no modo descasado.

Figura 4.10 - Posição da cintura do laser de Argônio em $488 \mathrm{~nm}$ sendo focalizado por uma lente de $f=20 \mathrm{~cm}$.

Figura 4.11 - Quadrado do diâmetro do feixe de laser de He-Ne em função da distância da lente convergente de foco, $f=20 \mathrm{~cm}$.

Figura 4.12 - Quadrado do diâmetro do feixe de He-Ne em $632.8 \mathrm{~nm}$, com o centro da parábola em $x=0$.

Figura 4.13 - Transmitância vidro aluminato de cálcio dopado com $4 \% \mathrm{Er}_{2} \mathrm{O}_{3}$. Amostras fundida a vácuo.

Figura 4.14 - Vista da evolução temporal do efeito de lente térmica em uma amostra de vidro com ds/dT positivo

Figura 4.15 - Resolução temporal de lente térmica para uma amostra de vidro aluminato de cálcio dopada com $4.0 \% \mathrm{Er}_{2} \mathrm{O}_{3}$ - Fundida a vácuo - Espessura $0.283 \mathrm{~cm}$. Potência incidente na amostra de $104 \mathrm{~mW}$.

Figura 4.16 - Espectro de fluorescência de uma amostra de vidro aluminato de cálcio dopado com $2 \%$ de $\mathrm{Nd}_{2} \mathrm{O}_{3}$, com laser de excitação em $514 \mathrm{~nm}$, a $300 \mathrm{~K}, \lambda_{e}$ em $514.5 \mathrm{~nm}$. (Pecoraro, 1999).

Figura 5.1 - Difratogramas das amostras de vidros aluminato de cálcio dopados com ions terras raras, obtidos através de difração de raios- $X$.

Figura 5.2 - Densidade dos vidros aluminato de cálcio em função da concentração de óxidos terras raras. A reta não está associada a nenhum ajuste teórico, foi desenhada apenas para guiar os olhos.

Figura 5.3 - Volume de oxigênios para vidros aluminato de cálcio dopados com $\mathrm{Nd}_{2} \mathrm{O}_{3} \mathrm{e}$ $\mathrm{Er}_{2} \mathrm{O}_{3}$. Amostras fundidas a vácuo.

Figura 5.4 volume de oxigênios para o vidro aluminato de cálcio dopados com $\mathrm{Er}_{2} \mathrm{O}_{3}$ fundidos ao ar.

Figura 5.5 - Razão molar $\mathrm{Al}_{2} \mathrm{O}_{3} / \mathrm{CaO}$ dos vidros aluminato de cálcio dopados com ions terras raras.

Figura 5.6 - Comportamento do volume molar dos vidros aluminato de cálcio dopados com diferentes concentrações de óxidos terras raras. 
Figura 5.7 - Dureza Vickers para os vidros aluminato de cálcio em função da concentração de óxidos terras raras.

Figura 5.8 - Curva de DTA para amostra de vidro aluminato de cálcio dopada com $2 \%$ de $\mathrm{Er}_{2} \mathrm{O}_{3}$

Figura 5.9 - curvas de DTA mostrando o deslocamento dos eventos térmicos, $T_{g}$ e $T_{x}$ na direção de temperaturas menores.

Figura 5.10 - Variação dos parâmetros térmicos $T_{g}$ e $T_{x}$ dos vidros aluminato de cálcio dopados em função da concentração de óxido terras raras.

Figura 5.11 - Tendência à cristalização dos vidros aluminato de cálcio em função do aumento da concentração de $\mathrm{Er}_{2} \mathrm{O}_{3}$

Figura 5.12 - Diagrama parcial do sistema $\mathrm{CaO}: \mathrm{Al}_{2} \mathrm{O}_{3}$ (Rawson, 1967).

Figura 5.13 - curva de decaimento da diferença de temperatura entre o substrato de silício e o reservatório térmico em função do tempo. Os pontos abertos representam os dados experimentais e a linha contínua o ajuste teórico obtido. A ordem de grandeza do erro é de $1 \%$

Figura 5.14 - Curva de decaimento da diferença de temperatura entre o substrato de silício + amostra de vidro aluminato de cálcio dopado com $4.0 \%$ (peso) $\mathrm{Nd}_{2} \mathrm{O}_{3}$. A curva contínua representa o ajuste. Potência dissipada foi de $P=637.8 \mu \mathrm{W}$, com $\Delta T=0.097 \mathrm{~K}$ e $\tau=$

$13.63 \mathrm{~s}$

Figura 5.15 - Calor específico dos vidros aluminato de cálcio em função da concentração de óxidos terras raras.

Figura 5.16 - Índice de refração para vidros aluminato de cálcio em função da concentração com óxido terras raras. Os dopantes são indicados na figura.

Figura 5.17 - Índice de refração dos vidros aluminato de cálcio dopados com óxidos terras raras (indicado na figura) em função da razão molar $\mathrm{Al}_{2} \mathrm{O}_{3} / \mathrm{CaO}$.

Figura 5.18 - Índice de refração de vidros aluminato de cálcio em função do comprimento de onda na região visivel do espectro eletromagnético.

Figura 5.19 - Índice de refração de vidros aluminato de cálcio em função do comprimento de onda. $\mathrm{IA} 5908) 58.5 \mathrm{CaO}, 27.5 \mathrm{Al}_{2} \mathrm{O}_{3}, 8.4 \mathrm{MgO}, 5.6 \mathrm{SiO}_{2}$. $\mathrm{IA5916)} 32.5 \mathrm{CaO}, 57.5 \mathrm{Al}_{2} \mathrm{O}_{3}$, $2 \mathrm{MgO}, 2 \mathrm{BaO}, 2 \mathrm{La}_{2} \mathrm{O}_{3}, 7.5 \mathrm{Na}_{2} \mathrm{O}, 2.5 \mathrm{~K}_{2} \mathrm{O}, 0.5 \mathrm{Fe}_{2} \mathrm{O}_{3}$. $\mathrm{IA5846)} 32.5 \mathrm{CaO}, 57.5 \mathrm{Al}_{2} \mathrm{O}_{3}, 2 \mathrm{MgO}$, 
$\left.2 \mathrm{BaO}, 2 \mathrm{La}_{2} \mathrm{O}_{3}, 7.5 \mathrm{Na}_{2} \mathrm{O}, 2.5 \mathrm{~K}_{2} \mathrm{O}, 2 \mathrm{Fe}_{2} \mathrm{O}_{3} \mathrm{IA} 5561\right) 32.5 \mathrm{CaO}, 57.5 \mathrm{Al}_{2} \mathrm{O}_{3}, 2 \mathrm{MgO}, 2 \mathrm{BaO}$, $2 \mathrm{La}_{2} \mathrm{O}_{3}, 7.5 \mathrm{Na}_{2} \mathrm{O}, 2.5 \mathrm{~K}_{2} \mathrm{O}, 5 \mathrm{Fe}_{2} \mathrm{O}_{3}$ (Hafner et al, 1958).

Figura 5.20 - Espaço livre no vidro em relação a todos os íons no vidro, em função da concentração de íons terras raras. Os íons são considerados de uma forma simplificada, como esferas sólidas.

Figura 5.21 - Índice de refração em função da temperatura para uma amostra de vidro aluminato de cálcio dopado com $3 \%$ de $\mathrm{Nd}_{2} \mathrm{O}_{3}$-amostra fundida a vácuo (CASM34).

Figura 5.22 - dn/dT em função da concentração de $\mathrm{Nd}_{2} \mathrm{O}_{3}$ em vidros aluminato de cálcio preparados ao ar.

Figura 5.23 - Curvas de transmitância óptica na região do visivel e infravermelho próximo do vidro aluminato de cálcio puro fundido em diferentes atmosferas. A curva pontilhada refere-se a uma amostra com $0.25 \mathrm{~cm}$ de espessura fundida ao ar, enquanto que a curva sólida refere-se a amostra com $0.15 \mathrm{~cm}$ de espessura fundida á vácuo.

Figura 5.24 - Curvas de transmitância óptica na região do infravermelho médio para o vidro aluminato de cálcio em diferentes atmosfera de fusão. A curva pontilhada refere-se a uma amostra com $0.25 \mathrm{~cm}$ de espessura, cuja atmosfera de fusão foi ao ar e a curva sólida refere-se a uma amostra com $0.15 \mathrm{~cm}$ de espessura fundida a vácuo.

Figura 5.25 - Curvas de transmitância óptica na região do visível e infravermelho próximo para amostras de vidro aluminato de cálcio dopado com $2 \%$ (em peso) de $\mathrm{Nd}_{2} \mathrm{O}_{3}$ fundidas em atmosferas diferentes. A curva pontilhada refere a uma amostra com 0.327 cm de espessura fundida ao ar, enquanto que a curva sólida refere-se a uma amostra com $0.347 \mathrm{~cm}$ de espessura fundida a vácuo.

Figura 5.26-Curvas de transmitância óptica na região do visivel e infravermelho próximo para amostras de vidro aluminato de cálcio dopado com $2 \%$ (em peso) de $\mathrm{Er}_{2} \mathrm{O}_{3}$ fundidas em atmosferas diferentes. A curva pontilhada refere-se a uma amostra com $0.248 \mathrm{~cm}$ de espessura fundida ao ar, enquanto que a curva sólida refere-se a uma amostra com 0.320 cm de espessura fundida a vácuo.

Figura 5.27 - Curvas de transmitância óptica na região do infravermelho próximo/médio de duas amostras de vidro aluminato de cálcio fundidas a vácuo. A curva sólida refere-se a 
amostra com $0.320 \mathrm{~cm}$ de espessura dopada com $2 \%$ (em peso) de $\mathrm{Er}_{2} \mathrm{O}_{3} ; \mathrm{A}$ curva pontilhada refere-se a uma amostra com $0.255 \mathrm{~cm}$ de espessura dopada com $2 \%$ (em peso) de $\mathrm{Er}_{2} \mathrm{O}_{3}$ e co-dopada com $2 \%$ (em peso) de $\mathrm{Yb}_{2} \mathrm{O}_{3}$

Figura 5.28 - Curvas de transmitância óptica na região do infravermelho médio para várias amostras de vidro aluminato de cálcio dopadas com $\mathrm{Er}_{2} \mathrm{O}_{3}, \mathrm{Nd}_{2} \mathrm{O}_{3}$ e $\mathrm{Yb}_{2} \mathrm{O}_{3}$. Na figura são indicadas as espessuras e a atmosfera de fusão para cada amostra.

Figura 5.29 - Obtenção do valor de OP para amostra de vidro aluminato de cálcio dopado com $4 \% \mathrm{Er}_{2} \mathrm{O}_{3}$. Amostra fundida a vácuo. Laser prova em $632.8 \mathrm{~nm}$ e laser excitação em $804 \mathrm{~nm}$.

Figura 5.30 - Difusividade em função da concentração de $\mathrm{Er}_{2} \mathrm{O}_{3}$. Amostras preparadas a vácuo e ao ar. Comprimento de onda da medida é indicada na figura.

Figura 5.31 - Condutividade térmica de vidros aluminato de cálcio em função da concentração de terra rara. Curva desenhada para guiar os olhos.

Figura 5.32 - Comparação da condutividade térmica entre vários sistemas vítreos.

Figura 5.33 - Comportamento da eficiência quântica dos vidros aluminato de cálcio em função da concentração de $\mathrm{Nd}_{2} \mathrm{O}_{3}$.

Figura 5.34 - Efeito de lente térmica normalizado em função do comprimento de onda do laser de excitação. A reta representa o ajuste através da Eq. 6.19.

Figura 5.35 - Níveis de energia do érbio

Figura 5.36 - Eficiência quântica dos vidros aluminato de cálcio em função da concentração de $\mathrm{Er}_{2} \mathrm{O}_{3}$.

Figura 5.37 - Decaimento exponencial do tempo de vida de uma amostra de vidro aluminato de cálcio dopado com $0.5 \%$ de $\mathrm{Er}_{2} \mathrm{O}_{3}$.

Figura 5.38 - Tempo de vida da fluorescência em função da concentração de $\mathrm{Er}_{2} \mathrm{O}_{3}$. Curva desenhada para guiar os olhos. 


\section{Produção bibliográfica durante o desenvolvimento da tese}

SAMPAIO, J. A., CATUNDA, T., GAMA, S., BAESSO, M. L. Thermo-optical properties of OH-free erbium doped low silica calcium aluminosilicate glasses measured by thermal lens technique. Journal of Non-Crystalline Solids. Amsterdam: v.284, n.1-3, p.210 - 216, 2001.

BAESSO, M. L., PELISSON, E., ROHLING, J. H., MEDINA NETO, A., BENTO, A. C., MIRANDA, L. C. M., LIMA, S. M., SAMPAIO, J. A., CATUNDA, T. Temperature dependence of thermo-optical properties of optical glasses determined by thermal lens spectrometry. Analytical Sciences. Tóquio: , v.17, n.SI2001, p.S106 - S109, 2001.

SAMPAIO, J. A., CATUNDA, T., COELHO, A. A., GAMA, S., BENTO, A. C., MIRANDA, L. C. M., BAESSO, M. L. Thermo-mechanical and optical properties of calcium aluminosilicate glasses doped with $\mathrm{Er}^{3+}$ and $\mathrm{Yb}^{3+}$. Journal of Non-Crystalline Solids. , v.273, n.2-3, p.239 - 245, 2000.

SOUZA, D. F., SAMPAIO, J. A., NUNES, L. A. O., BAESSO, M. L., BENTO, A. C., MIRANDA, L. C. M. Energy transfer and the 2.8-um emission of $\mathrm{Er}^{3+}$ - and $\mathrm{Yb}^{3+}$ - doped low silica content calcium aluminate glasses. Physical Review B - Condensed Matter. USA: , v.62, n.5, p.3176 - 3180, 2000.

PECORARO, É., NUNES, L. A. O., SAMPAIO, J. A., GAMA, S., BAESSO, M. L. Estudo Espectroscópico de Vidros a Base de Aluminato de Cálcio Contendo $\mathrm{Nd}^{3+}$. Química Nova. São Paulo: , v.23, n.2, p.161 - 166, 2000.

LIMA, S. M., SAMPAIO, J. A., CATUNDA, T., BENTO, A. C., MIRANDA, L. C. M., BAESSO, M. L. Mode-Mismatched thermal lens spectrometry for thermo-optical properties measurements in optical glasses: a review. Journal of Non-Crystalline Solids. Amsterdam: , v.273, n.2-3, p.215 - 227, 2000.

xvii 
BAESSO, M. L., BENTO, A. C., MIRANDA, L. C. M., SOUZA, D. F., SAMPAIO, J. A., NUNES, L. A. O. Rare-earth doped low silica calcium aluminosilicate glasses for near and mid infrared applications. Journal of Non-Crystalline Solids. Amsterdam: , v.276, n.2, p.8 18, 2000.

PECORARO, É., SAMPAIO, J. A., NUNES, L. A. O., GAMA, S., BAESSO, M. L. Spectroscopic properties of water free $\mathrm{Nd}_{2} \mathrm{O}_{3}$-doped low silica calcium aluminosilicate glasses. Journal of Non-Crystalline Solids. Amsterdam: , v.277, n.2-3, p.73 - 81, 2000.

BAESSO, M. L., BENTO, A. C., DUARTE, A. R., MEDINA NETO, A., MIRANDA, L. C. M., SAMPAIO, J. A., CATUNDA, T., GAMA, S., GANDRA, F. C. G. $\mathrm{Nd}_{2} \mathrm{O}_{3}$ doped low silica calcium aluminosilicate glasses: Thermomechanical properties. Journal of Applied Physics. USA: , v.85, n.12, p.8112 - 8118, 1999.

SOUZA, D. F., ZONETTI, L. F. C., BELL, M. J. V., SAMPAIO, J. A., NUNES, L. A. O., BAESSO, M. L., BENTO, A. C., MIRANDA, L. C. M. On the Observation of $2.8 \mathrm{~mm}$ emission from diode-pumped $\mathrm{Er}^{3+}$ and $\mathrm{Yb}^{3+}$ doped low silica calcium $\mu$ glasses. Applied Physics Letters. USA: , v.74, n.7, p.908 - 910, 1999.

SAMPAiO, J. A., CATUNDA, T., GANDRA, F. C. G., GAMA, S., BENTO, A. C., MIRANDA, L. C. M., BAESSO, M. L. Structure and properties of water free $\mathrm{Nd}_{2} \mathrm{O}_{3}$ doped low silica calcium aluminate glasses. Journal of Non-Crystalline Solids. Amsterdam: , v.247, n.1, p.196 - 202, 1999.

SANTOS, I. A., ARAUJO, E. B., EIRAS, J. A., SAMPAIO, J. A., CATUNDA, T. A DTA study of activation energy for crystallization in low silica content calcium aluminosilicate glasses. Aceito para publicação Journal of Materials Science. , (Julho de 2001). 
SAMPAIO, J. A., BAESSO, M. L., GAMA, S., COELHO, A. A., EIRAS, J. A., SANTOS, I. A. Rare earth doping effect on the elastic moduli of low silica calcium aluminosilicate glasses. Submetido ao Journal of Non-Crystalline Solids (agosto 2001).

\section{Outros trabalhos}

LIMA, S. M., SAMPAIO, J. A., CATUNDA, T., LEBULLENGER, R., HERNANDES, A. C., BAESSO, M. L., BENTO, A. C., GANDRA, F. C. G. Time-resolved thermal lens measurements of thermo-optical properties of fluoride glasses. Journal of Non-Crystalline Solids. Amsterdam: , v.256, n.1, p.337 - 342, 1999.

LIMA, S. M., SAMPAIO, J. A., CATUNDA, T., CAMARGO, A. S. S., NUNES, L. A. O., BAESSO, M. L., HEWAK, D. W. Spectroscopy, Thermo-optical and Physical Properties of $\mathrm{Nd} 3+$ doped chalcogenide glasses. Journal of Non-Crystalline Solids. Amsterdam: , v.284, n.1-3, p.274 - 281, 2001.

SAMPAIO, J. A., LIMA., S.M., CATUNDA, T., MEDINA, A. N., BENTO, A. C., BAESSO, M. L. Thermal lens versus DTA measurements for glass transition analysis of fluoride glasses. Submetido ao Journal of Non-Crystalline Solids (Agosto de 2001).

MEdinA, A. N., CALdEIRA, A. M., BENTO, A. C., BAESSO, M. L., SAMPAiO, J. A., LIMA., S.M., CATUNDA., T., GANDRA, F. C. G. Thermal relaxation method to determine the specific heat of optical glasses. Submetido ao Jounal of Non-Crystalline Solids (Agosto de 2001).

\section{Patente}

BAESSO, M. L., BENTO, A. C., SOUZA, D. F., SAMPAIO, J. A., Vidro aluminato de cálcio com baixa concentração de silica como fonte fluorescente na região do infravermelho médio PI 9903163, 1999. 


\section{Resumo}

O desenvolvimento de laseres de estado sólido compactos operando na região do infravermelho médio, entre $2-5 \mu \mathrm{m}$, tem recebido considerável atenção nos últimos anos. Esses dispositivos oferecem grande potencial como fonte de luz para uma infinidade de aplicações, como por exemplo laseres para medicina e sensores químicos remotos. Laseres operando na região de $2.8 \mu \mathrm{m}$ tem interesse particular na medicina devido à forte banda de absorção da água nessa região espectral.

Para se conseguir forte emissão laser próximo a $2.8 \mu \mathrm{m}$ têm sido investigadas famílias de vidros não-óxidos, como por exemplo vidros fluoretos de metais pesados e vidros chalcogenetos, dopados com $\mathrm{Er}^{3+}$. Entretanto esses vidros são caros, dificeis de serem feitos, além de serem tóxicos. Por essa razão o desenvolvimento de um vidro óxido seria ideal, já que são mais baratos, relativamente fáceis de serem produzidos, além de não serem tóxicos. A desvantagem dos vidros óxidos é a sua alta energia de fônons, quando comparada aos vidros haletos e chalcogenetos, que aumenta a taxa de transição não radiativa. Seria interessante investigar um sistema vitreo que tivesse propriedades otimizadas, ou seja, boas propriedades ópticas, térmicas e mecânicas, e baixa energia de fônons. $O$ sistema vítreo aluminato de cálcio seria um candidato para essas aplicações, já que preenche essas exigências. Porém não há na literatura informações a respeito da influência de pequenas quantidades de elementos terras raras nas propriedades desses vidros, e qual é a concentração ideal desses íons.

O objetivo dessa tese foi investigar composições de vidros aluminato de cálcio $(48,1$ $\mathrm{CaO}: 40.8 \mathrm{Al}_{2} \mathrm{O}_{3}: 4.1 \mathrm{MgO}: 7.0 \mathrm{SiO}_{2}$ ) dopados com $\mathrm{Nd}_{2} \mathrm{O}_{3}, \mathrm{Er}_{2} \mathrm{O}_{3}$ ou $\mathrm{Yb}_{2} \mathrm{O}_{3}$, e verificar qual a influência desses íons nas propriedades ópticas, térmicas, mecânicas e termo-ópticas. Investigou-se também qual a influência da atmosfera de fusão. Com esse objetivo as amostras foram fundidas em cadinhos de grafite sob vácuo, e em cadinhos de platina, ao ar, ambas as fusões ocorreram a $1400^{\circ} \mathrm{C}$.

As amostras foram investigadas através de difração de raios- $X$ e microscopia óptica, cujos resultados confirmaram o estado amorfo das amostras preparadas. As amostras não apresentaram estrias e tiveram boa transparência óptica. 
Os espectros de transmitância mostraram que o processo de fusão a vácuo eliminou completamente a forte banda de absorção próxima a $3 \mu \mathrm{m}$ devida à água. $O$ corte da transmitância na região do infravermelho ocorreu em $5.5 \mu \mathrm{m}$, sendo independente do tipo do ín terra rara presente na composição do vidro.

$O$ índice de refração em $546.1 \mathrm{~nm}$ aumentou de 1.6702 (amostra base) para 1.6876 (amostra dopada com $8 \%$ de $\mathrm{Er}_{2} \mathrm{O}_{3}$ ). Este acréscimo no índice de refração é atribuído a um aumento da polarizabilidade eletrônica do vidro devido ao aumento de oxigênios nonbridging. A densidade aumenta de $2.92 \mathrm{~g} / \mathrm{cm}^{3}$ (amostra base) para $3.12 \mathrm{~g} / \mathrm{cm}^{3}$ (amostra dopada com $8 \%$ de $\mathrm{Er}_{2} \mathrm{O}_{3}$ ), esse aumento é explicado levando em consideração a massa dos átomos terras raras, que são maiores em relação ao $\mathrm{Al}_{2} \mathrm{O}_{3}$.

A dureza dos vidros aluminato de cálcio diminuiu de $865 \mathrm{~kg} / \mathrm{mm}^{2}$ (amostra base) para $781 \mathrm{~kg} / \mathrm{mm}^{2}$ (amostra dopada com 8\% de $\mathrm{Er}_{2} \mathrm{O}_{3}$ ), ou seja aproximadamente $11 \%$ de decréscimo. No caso da temperatura de transição vítrea, $T_{g}$, esse decréscimo é de aproximadamente $8 \%$, sendo $841{ }^{\circ} \mathrm{C}$ para a amostra base e $782{ }^{\circ} \mathrm{C}$ para a amostra dopada com $8 \%$ de $\mathrm{Er}_{2} \mathrm{O}_{3}$. Para o vidro base, a difusividade térmica foi de $5.75 \times 10^{-3} \mathrm{~cm}^{2} / \mathrm{s}$ e a condutividade térmica foi de $15.5 \times 10^{-3} \mathrm{~W} \mathrm{~cm}^{-1} \mathrm{~K}^{-1}$. Tanto a difusividade quanto a condutividade térmica decresceram na mesma proporção da dureza e $\mathrm{T}_{\mathrm{g}}$, conforme substitui-se a alumina pelo óxido terra rara. Esta é uma indicação de que os átomos terras raras atuam como modificadores de rede, abrindo a estrutura do vidro, diminuindo a resistência mecânica e atuando como barreiras térmicas no material.

A resistência ao choque térmico dos vidros aluminato de cálcio é de $339 \mathrm{~W} / \mathrm{m}$, semelhante aos vidros silicatos que é de $358 \mathrm{~W} / \mathrm{m}$, e aproximadamente quatro vezes maior que a dos vidros fluoretos, $86 \mathrm{~W} / \mathrm{m}$. Este resultado confirma a hipótese de que os vidros aluminato de cálcio podem suportar variações abruptas de temperatura.

Através da espectroscopia de lente térmica foram obtidas a eficiência quântica dos vidros aluminato de cálcio dopados com $\mathrm{Nd}_{2} \mathrm{O}_{3}$ e $\mathrm{Er}_{2} \mathrm{O}_{3}$. No caso das amostras dopadas com concentrações menores de $3 \%$ de $\mathrm{Nd}_{2} \mathrm{O}_{3}$ a eficiência quântica foi de aproximadamente $80 \%$.

Esses resultados indicam que os vidros aluminato de cálcio são excelentes candidatos para laseres de estado sólido e demais aplicações ópticas na região do infravermelho médio. 


\begin{abstract}
The development of compact solid state lasers operating in the midinfrared wavelength region $(2-5 \mu \mathrm{m})$ has been an area of considerable activity in the last few years. These devices offer great potencial as light sources for applications as medical lasers as well as in remote chemical sensing devices. Light sources in the $2.8 \mu \mathrm{m}$ region are of particular interest for medical applications due to the strong water absorption in this spectral region. Apart from allowing extremely precise cutting and ablation of water-containing tissues, the other advantages of using light sources operating at $2.8 \mu \mathrm{m}$ are related to the possibilities of reducing skin burning in surgeries, decrease in the use of anesthesia and shortening of recovery time, especially in skin surgeries and in the cutting and removal of hard tissues, such as tooth enamel and bone.
\end{abstract}

In order to achieve strong laser emission around $2.8 \mu \mathrm{m}$ the effort so far has been concentrated on the family of $\mathrm{Er}^{3+}$ doped non-oxide glasses such as heavy metal fluorides and chalcogenides. However the production of these glasses is expensive, and it is difficult to make them, besides they are toxic. On the other hand, the oxide glasses are cheaper, atoxic and easy to produce them. The disadvantaged, however, is its the relative high phonon energy that promote high nonradiative transiton rates.

Since calcium aluminate glasses are formed with non-network formes, $\mathrm{CaO}$ and $\mathrm{Al}_{2} \mathrm{O}_{3}$, they have high tendence towards devitrification. The addition of smalll amounts of alkali and alkaline earth elements enrlarges the glass forming region. Several calcium aluminate glasses compostions containing $\mathrm{SiO}_{2}, \mathrm{BaO}$ and $\mathrm{MgO}$ are now reported in the literature.

In this thesis, low silica calcium aluminosilicate glasses doped with $\mathrm{Nd}_{2} \mathrm{O}_{3}$ and $\mathrm{Er}_{2} \mathrm{O}_{3}$ were prepared. Since the sample compositions were close to the phase diagram glass formation, the rare earth doping was performed up to $8 \mathrm{wt} . \%$. The samples was melted under vacuum condition in a graphite crucible at $1500{ }^{\circ} \mathrm{C}$, and in air in a platinum crucible.

The influence of the rare earth doping on the thermal diffusivity, thermal conductivity and Vickers hardness was such that all these physical parameters decreased by roughly the same amount, namely $8 \%$, between the undoped and $5 \mathrm{wt} \%$ of $\mathrm{Nd}_{2} \mathrm{O}_{3}$. The dependence of 
these parameters, as a function of the $\mathrm{Nd}_{2} \mathrm{O}_{3}$ doping, strongly supports the ideia that the $\mathrm{Nd}^{3+}$ or $\mathrm{Er}^{3+}$ act as network modifiers.

Elastic moduli $(E, G, K, v)$ of calcium aluminosilicate glasses with $<10$ mole $\%$ of $\mathrm{SiO}_{2}$ doped with $\mathrm{Er}_{2} \mathrm{O}_{3}$ and $\mathrm{Yb}_{2} \mathrm{O}_{3}$, melted in air and under vacuum conditions, have been measured using the pulse echo ultrasonic technique. There was a decrease of the elastic properties, about $5 \%$, as rare earth doping increases from 0.2 to $1.5 \mathrm{~mol} \%$ (about $8 \mathrm{wt} \%$ ). The Young's modulus did not vary within errors of measurements. The Debye temperature varied between $(369 \pm 9) \mathrm{K}$ and $352 \pm 9 \mathrm{~K}$, which is explained assuming that the rare earth ions acts as network modifiers disrupting the glasses structure. The undoped calcium aluminate glasses fracture toughness is (1.4 \pm 0.3$) \mathrm{MPa} \mathrm{m}^{1 / 2}$ and the thermal shock resistance is (339 \pm 102$) \mathrm{W} / \mathrm{m}$.

The fluorescence quantum efficiency determined by thermal lens spectroscopy, was found be about $80 \%$ for the $2 \mathrm{wt} \% \mathrm{Nd}_{2} \mathrm{O}_{3}$ doped calcium aluminosilicate glass. The fluorescence quenching was observed to doping higher than $2 \mathrm{wt} \% \mathrm{Nd}_{2} \mathrm{O}_{3}$. The variation of the refractive index as a function of the temperature, $\mathrm{dn} / \mathrm{dT}$, was found be $8.0 \times 10^{-6} \% \mathrm{c}$.

Among the various glass system investigated, CA glasses presented greater mechanical properties and larger thermal shock resistance, indicating that these materials are canditates for solid state laser applications and other infrared applications. 


\section{Introdução}

A tese aqui apresentada faz parte de um trabalho que vem sendo desenvolvido há aproximadamente seis anos, por grupos de pesquisas pertencentes a três universidades, duas do Estado de São Paulo e uma do Estado do Paraná, a saber: a Universidade de São Paulo USP, através do instituto de Física de São Carlos (Grupo de Espectroscopia de Sólidos); Universidade Estadual de Campinas - UNICAMP, através do Instituto de Física Gleb Wataghin (Grupo de Preparação e Caracterização de Materiais - GPCM) e finalmente a Universidade Estadual de Maringá - UEM, através do departamento de física (Grupo de Fototérmica). Um dos objetivos desses grupos de pesquisa é a construção de laseres de estado sólido para a região do visível e infravermelho, cujo desafio maior é a obtenção de laser que opere na região do infravermelho, mais precisamente em $2.8 \mu \mathrm{m}$, que tem aplicações na medicina.

Todavia, o desenvolvimento de novos materiais para laseres não é um tarefa simples, já que cada material possui suas peculiaridades. Alguns são mais resistentes a impactos mecânicos e térmicos, porém suas propriedades ópticas não são satisfatórias; outros possuem excelentes propriedades ópticas e espectroscópicas, mas são frágeis e suas propriedades térmicas são impróprias para ambientes hostis como a cavidade de um laser. Portanto é necessário investigar todas as características desses materiais, sejam elas fisicas ou químicas, e verificar se há possibilidade ou não de usá-los para esse fim. De maneira simplória podemos dizer o que o desenvolvimento de um novo material para laser segue três passos básicos.

O primeiro consiste no desenvolvimento do material em si, ou seja, qual é a sua facilidade de produção, como produzi-lo melhor, quais são as minúcias de produção, quais são 
suas características físico-químicas básicas dependentes da composição e, como é que o dopante se dilui no material; o segundo passo se refere a investigação de como os íons dopantes (metais de transição, como por exemplo $\mathrm{Cr}^{3+}$ diluído em $\mathrm{Al}_{2} \mathrm{O}_{3}$, conhecido como rubi; terras raras, como por exemplo $\mathrm{Nd}^{3+}$ diluído no cristal YAG) interagem com a matriz, seja cristal ou vidro. As propriedades ópticas e espectroscópicas desses íons são fortemente influenciadas pelo material hospedeiro, que pode tanto diminuir como aumentar a eficiência quântica, tempo vida, entre outras. Nessa fase é que se pode dizer se esse material tem ou não potencial para servir como meio ativo para laser de estado sólido, e caso positivo, qual é a concentração ideal desses íons na composição do material. O terceiro passo é o de colocar o material à prova e verificar se realmente ele emitirá radiação laser quando colocado em uma cavidade ressonante. Cada um desses passos é decisivo para o sucesso de produção desses laseres.

O escopo da tese aqui apresentada se situa nos dois primeiros passos, sendo a ênfase maior consagrada ao primeiro. $\mathrm{O}$ material escolhido foi o vidro aluminato de cálcio que possui excelentes propriedades ópticas, mecânicas e térmicas e devido a isso temos hipótese de ser possível usá-lo como meio ativo para laser de estado sólido. Além do interesse tecnológico, esse sistema vítreo é interessante do ponto de vista acadêmico já que os óxidos $\mathrm{CaO}$ e $\mathrm{Al}_{2} \mathrm{O}_{3}$ não formadores de rede, como ocorre com o $\mathrm{SiO}_{2}$ e $\mathrm{P}_{2} \mathrm{O}_{5}$. Outro fato que chama a atenção é o baixo custo desses óxidos, uma vez que o Brasil é grande produtor, e a sua não toxidade, como ocorre por exemplo com os vidros haletos.

Vale ressaltar que as amostras preparadas durante o desenvolvimento dessa tese foram também usadas como objeto de estudo por outros alunos de mestrado (Zonetti, 1999) e doutorado (Pecoraro, 1999; Souza, 2000a), cujas investigações focalizaram propriedades complementares as que serão aqui apresentadas. Os objetivos desta tese foram desenvolver amostras de vidros aluminato de cálcio dopados com neodímio, érbio e itérbio, e estudar suas propriedades básicas tais como, densidade, dureza; propriedades mecânicas (coeficiente de Poisson, módulo de Young, módulo de cisalhamento); análise térmica diferencial (DTA), temperatura de transição vítrea, temperatura de cristalização, temperatura de fusão; propriedades ópticas: índice de refração, absorção; propriedades espectroscópicas: eficiência quântica, tempo de vida. Além dos vidros aluminato de cálcio foram também preparadas 
algumas amostras de vidros outros sistemas vítreos, tais como silicato, fosfato, borato. No caso dos vidros aluminato de cálcio foram feitas medidas em função da concentração de óxido terra rara. Desenvolveu-se também durante a tese a construção de duas camâras de vácuo para a preparação de amostras.

\section{$1.1 O$ que é o Vidro?}

$\mathrm{O}$ vidro devido à sua facilidade e versatilidade de produção e aplicações tornou-se tão comum em nosso cotidiano que basta olharmos ao nosso redor que podemos vê-lo presente em nossas cozinhas, automóveis, janelas, computadores, etc. Entretanto, para um leigo, vidro é vidro. Não há diferenças a não ser pelas cores, formas e usos... e por esta razão pode ser um tanto quanto surpreendente quando um pesquisador diz que estuda vidros, e não raro surgem algumas questões, desde as mais simples até as de cunho científico

Do ponto de vista técnico-científico há uma vasta infinidade de tipos de vidros, composições diversas e aplicações muito específicas e sofisticadas para cada tipo deles. Entre os diferentes tipos de vidros podemos citar os vidros semicondutores, os de spin, os cerâmicos, os vidros ópticos, etc. Mas $\mathrm{O}$ que é o vidro? O que caracteriza um material ser ou não vítreo? Quais as “impressões digitais” básicas de um vidro? Estas são questões presentes no dia-a-dia; e, de que maneira podemos responder essas questões de forma concisa sem que haja confusão, principalmente devido aos diferentes significados atribuidos à palavra vidro?

O uso corrente desta palavra evoluiu no decorrer dos séculos (Scholze, 1980), e por essa razão há na literatura científica, devido principalmente aos diferentes ponto de vista dos diversos autores, uma gama numerosa de definições. Um dos pioneiros da pesquisa vítrea, Tammann (1933) começa seu livro "O estado vítreo" pela frase: “Os materiais sólidos e não cristalizados se encontram no estado vítreo". Esta definição é entretanto genérica pois engloba por exemplo a sílica gel na categoria de vidros.

Várias outras definições colocam em primeiro plano o comportamento da viscosidade e as grandezas que deste se originam. As definições citadas até os dias de hoje não se limitam apenas à composição dos vidros. Um outro grupo de definição provém de autores mais próximos à tecnologia. Um exemplo é a definição da American Society for Testing and 
Materials (ASTM), que segue os moldes de uma norma alemã (DIN 1259, 1971) nos seguintes termos: "O vidro é um produto mineral obtido por fusão e que se solidifica sem cristalizar-se". $O$ sentido da palavra vidro limita-se portanto apenas aos compostos minerais, o que de forma geral é discutivel. A definição norte-americana traz alguns adendos: entre eles a designação de "vidro" a alguns objetos como vidro de garrafa, ou recipientes para guardar doces, cereais...

De certa forma é complexo darmos uma definição ao vidro em vista da multiplicidade de conotações que lhe é conferido; ao definirmos algo é necessário que essa definição contenha a essência dos seus diferentes sentidos, explicitando ou subentendendo o todo, o que não é possível para o caso do vidro, o que gera discordância e até mesmo contradição entre os diferentes autores. Por isso é possivel encontrarmos definições atribuindo ao vidro o sentido de objeto até aquelas que o classificam levando em consideração o seu estado físico-químico.

A fim de sanar essas contradições, o comitê do U. S. National Research Council propuseram uma definição mais geral para o vidro, porém não curta (Wong e Angell, 1976; p. 36) "O vidro é por difração de raios- $X$ um material amorfo que exibe a temperatura de transição vítrea, definida como o fenômeno pelo qual uma fase amorfa sólida exibe, devido à mudança de temperatura, em razão de uma variação repentina na derivada das propriedades termodinâmicas, tais como calor específico e coeficiente de expansão, em relação a suas respectivas fases cristalina e líquida".

Os vidros são caracterizados por propriedades bem definidas comuns a todos eles independente da composição e propriedades diferindo-os em relação aos líquidos e sólidos cristalinos. Diferente dos cristais, os vidros não tem ponto de fusão exato e não se dividem em direções preferidas (Paul, 1990:1). Da mesma forma que os sólidos cristalinos, os vidros possuem alta elasticidade - pode-se curvar uma fibra de vidro ao seu máximo, que ao soltá-la esta recuperará sua forma original -, como líquidos podem escoar se uma pressão muito alta for aplicada, como por exemplo no caso do teste de dureza Vickers. A forma vítrea da matéria combina portanto a rigidez característica do estado cristalino e a fluidez dos estado líquido. Da mesma forma que os líquidos, os vidros são também isotrópicos, propriedade requerida para uma infinidade de propósitos (Paul, 1990).

Um vidro é geralmente obtido pelo resfriamento do líquido abaixo do seu ponto de congelamento, condição considerada como parte da definição do estado vítreo. A explicação 
clássica para a formação do vidro é de que, quando um líquido é resfriado, sua fluidez (viscosidade recíproca) diminui, e em uma dada temperatura abaixo do ponto de congelamento, torna-se aproximadamente zero, e o líquido torna-se "rígido".

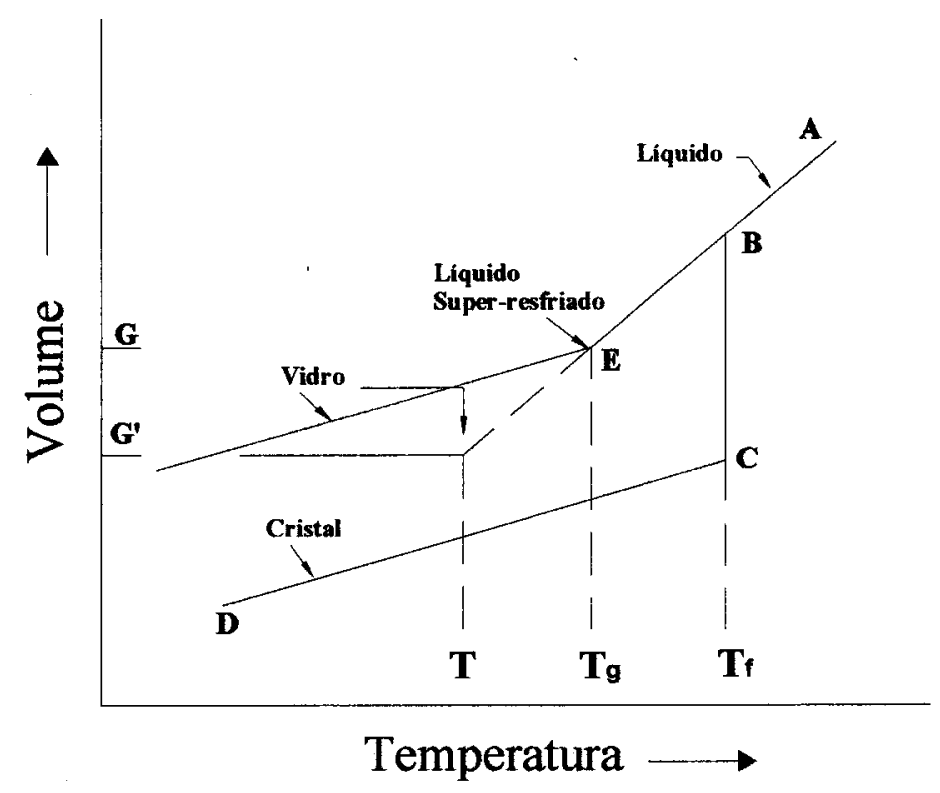

Figura 1.1 - Relação entre os estados líquido, vítreo e cristalino (Paul, 1990: 3).

A relação entre cristal, líquido e vidro pode ser explicada por meio do diagrama do volume versus a temperatura, como ilustrado na figura 1.1. Alguns autores fazem essa diferenciação ilustrando o comportamento do calor específico versus a temperatura. Ao resfriarmos o líquido do estado $\mathrm{A}$, o volume diminuirá uniformemente ao longo da linha $\mathrm{AB}$. Se a taxa de resfriamento for lenta, e os nucleantes estiverem presente, a cristalização ocorrerá na temperatura de resfriamento $T_{f}$. $O$ volume diminuirá abruptamente de $B$ até $C$; em seguida, o sólido se contrairá com a queda da temperatura ao longo do segmento $\mathrm{CD}$.

Se a taxa de resfriamento for suficientemente rápida, a cristalização não ocorrerá na posição $T_{f}$; o volume do líquido super resfriado diminuirá ao longo do segmento $B E$, que é uma continuação suave do segmento $A B$. A uma certa temperatura $T_{g}$, o volume versus a temperatura sofrerá uma mudança significativa na inclinação e continuará paralelo à contração do segmento $C D$ relativo à forma cristalina. $T_{g}$ é chamado de temperatura de transformação ou temperatura de transição vítria (do inglês: glass transition temperature). Tem-se vidro 
somente abaixo de $T_{g}$. A região compreendida entre ponto $E$, e o ponto correspondente a $T_{g}$, varia com a taxa de resfriamento - e assim é apropriado chamá-lo de intervalo de transformação ao invés de ter-se um ponto fixo. Em $\mathrm{T}_{\mathrm{g}}$ a viscosidade do material é muito alta - aproximadamente $10^{13}$ poise.

Se a temperatura do vidro for mantida constante em $T$, ponto abaixo de $T_{g}, o$ volume G continuará a decrescer lentamente, eventualmente chegando ao ponto $G^{\prime}$, linha tracejada, que é uma continuação suave da contração do segmento BE do líquido super resfriado. Outras propriedades do vidro mudam também com o tempo na vizinhança de $T_{g}$. Este processo pelo qual o vidro atinge uma condição mais estável é conhecida como estabilização. Acima de $T_{g}$ não é observada dependência temporal das propriedades. Como conseqüencia a existência de efeitos de estabilização, as propriedades do vidro depende de certa forma da taxa pelo qual ele foi esfriado, particularmente do intervalo de transformação.

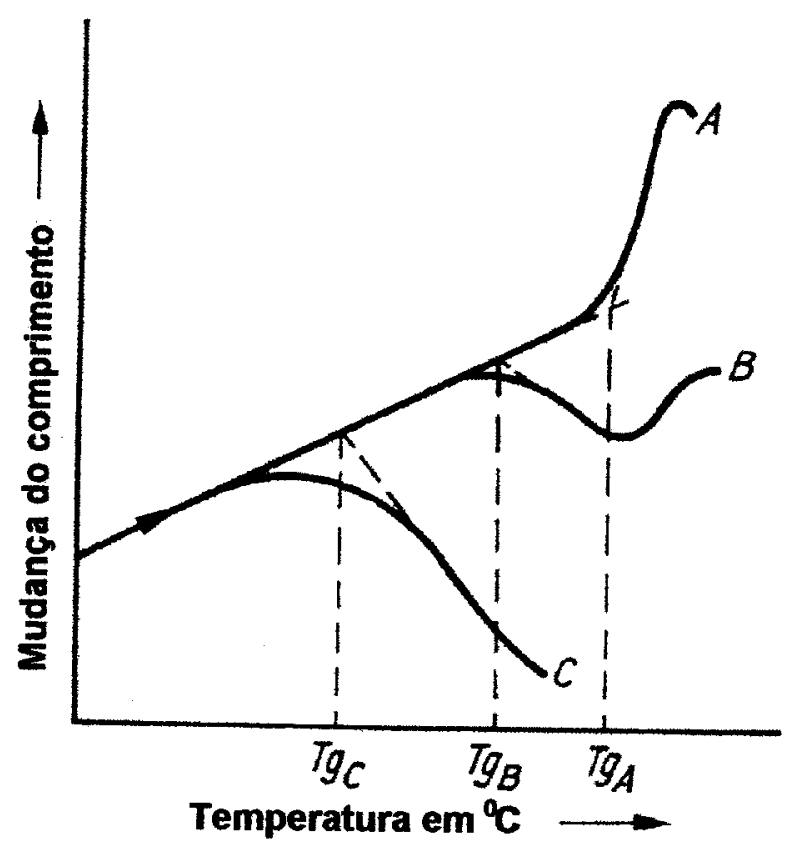

Figura 1.2 - Mudança do comprimento de um vidro borosilicato com aumento da temperatura: A) resfriamento lento, B) resfriamento rápido, C) resfriamento extremamente rápido, fibra de 6 pam diâmetro (Salmang, 1957). 
Um dos fatores que influencia a temperatura de transição vítrea é a taxa pela qual o vidro foi resfriado, conforme mostra a figura 1.2. A diferença dos valores de $T_{g}$ obtidas para amostras em diferentes taxas de resfriamento foram demonstradas por Salmang (1957).

A curva $A$ mostra o comportamento de uma amostra de vidro que foi resfriado muito lentamente. $O$ vidro contraiu-se a um volume não muito maior do que aquele do cristal, que é o volume de equilíbrio meta estável. Entretanto para um vidro que foi resfriado muito mais rápido, curva $B$, não houve tempo suficiente para a contração, tal que sobre reaquecimento é observado um intervalo de contração quando o vidro aproxima-se de seu volume de equilíbrio metaestável. Uma fibra de vidro permite taxas extremas de resfriamento que resulta na curva $C$, mostrando que o reaquecimento provoca uma contração considerável. Se tais espécimes fossem usados para determinar os valores de $T_{\mathfrak{g}}$, verificaríamos uma diferença de mais que $100{ }^{\circ} \mathrm{C}$ nessa temperatura para cada amostra investigada.

Portanto, somente um valor de $T_{g}$ obtido em condições padrão pode ser considerado como ponto de transição vítrea. Os vidros que são resfriados menos ou mais rapidamente, curvas $B$ e $C$, respectivamente, contraem-se durante o curso do processo de re-aquecimento envolvido na determinação de $T_{g}$. Quando o vidro é reaquecido na região de transição, em que mudanças na estrutura e nas outras propriedades são possíveis, os elementos da estrutura do vidro são rearranjados em sítios mais densos e energia mais baixa. Este rearranjo leva à contração. Um aumento no comprimento entretanto ocorrerá em todos os casos com um aumento maior da temperatura.

O entendimento deste complexo fenômeno é crítico para o processo de recozimento e têmpera, sendo muito importante para a produção de vidros. Uma análise superficial ou incompleta dos vários comportamentos de um vidro fundido na região de transição não é mais suficiente para a indústria vidreira moderna, sendo necessário outras técnicas para diferenciar o estado vítreo dos outros estados da matéria (Vogel, 1994:28).

A difração de raios- $X$ oferece meios de investigar a estrutura de um material, e para o vidro não é diferente. Os padrão de difração de raios- $X$ diferenciam-se de acordo com a técnica usada. A figura 1.3, mostra a dependência da difração de raios-X em função do ângulo rasante $\sin \theta / \lambda$ para gases, líquidos, vidros e cristais (A técnica aqui usada é a de espalhamento de Bragg). Para os gases, a difração é muito intensa em baixos ângulos e 
decresce continuamente $\operatorname{com} \sin \theta / \lambda$. Para líquidos a difração em baixos ângulos permanece alta mas é muito mais baixa do que para gases, aparecendo um alargamento difuso e com pontos de máximo. No caso de cristais aparecem picos bem localizados, cujas intensidades são máximas, tanto para baixos quanto para altos ângulos. Desta forma o difratograma de raios- $X$ para os vidros se assemelha aos padrões de difração dos líquidos, muito mais do que a dos cristais.

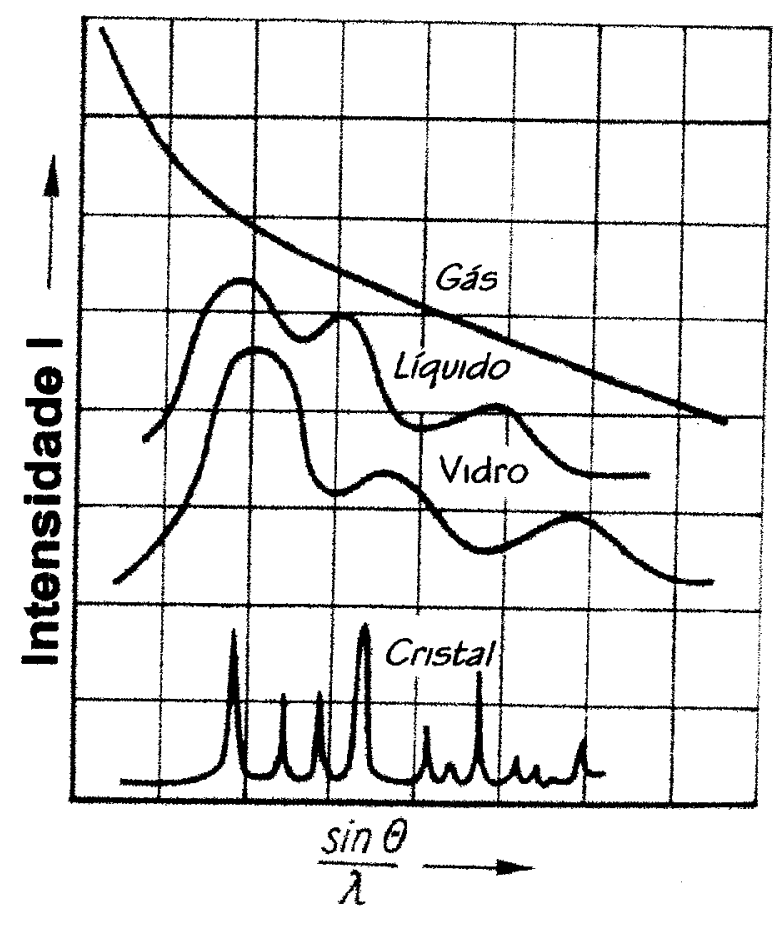

Figura 1.3 - Distribuição da intensidade do espalhamento de raios- $X$ com dependência ao ângulo rasante para substâncias em vários estados de agregação (Vogel, 1994:29).

Na figura 1.4, o padrão Debye-Scherrer é comparado entre um vidro (a) e um cristal (b). As figuras 1.3 e 1.4 mostram que líquidos e vidros possuem uma ordem de curto alcance (short-range order) enquanto que uma ordem de longo alcance não existe. No caso dos cristais há uma ordem periódica tanto para curto quanto para longo alcance. Os sólidos vítreos e cristalinos que estão ambos no estado sólido, mostram diferenças críticas em seu comportamento como demonstrado claramente pelos dois exemplos tratados nesta seção: a mudança do comportamento do volume/calor específico com a temperatura e a diferença nos padrão de raios-X. 

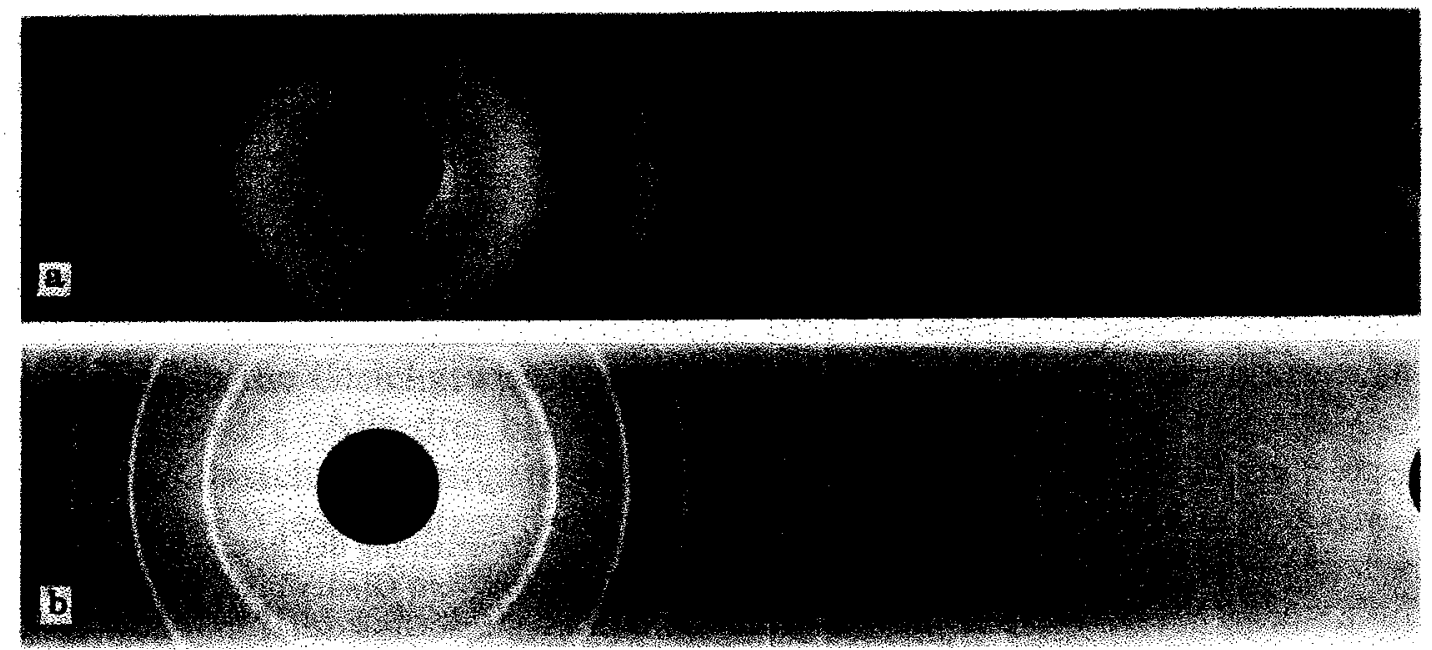

Figura 1.4 - Padrão raios-X Debye-Scherrer de a) vidro e b) cristal (Vogel, 1994:29).

E o que podemos dizer sobre a estrutura dos vidros óxidos, e por que algumas composições óxidas formam vidros enquanto outras não? Para responder essa pergunta o primeiro passo foi dado em 1932 por W. H. Zachariasen, cristalógrafo, muito familiarizado com os primeiros estudos de difração de raios- $X$ da estrutura da sílica cristalina. $O$ trabalho de aspecto tanto especulativo quanto quantitativo é singular pelo impacto que teve sobre a compreensão da estrutura e das propriedades dos vidros óxidos.

A hipótese central deste trabalho é que a forma vitrea de um óxido deve ter uma energia interna não muito maior do que à forma cristalina. Desta maneira, ele sugeriu que ambas as formas deveriam conter o mesmo tipo de oxigênio poliédrico e estes deveriam estar ligados de maneira semelhante, exceto que na forma vítrea os ângulos e comprimentos entre as ligações químicas estariam compreendidos em um intervalo de valores e não fixos como ocorre para os cristais. Somente substâncias em que os poliedros estão ligados pelos seus vértices possuem estruturas que são suficientemente flexíveis para incorporar a desordem, característica do estado vítreo, sem que a energia da estrutura de rede seja significativamente aumentada.

Neste tipo de material o "poliedro" base é o triângulo $\mathrm{AO}_{3}$. Em ambas as formas, os triângulos estão ligados somente nos seus vértices pelas pontes de oxigênio. No vidro silicato, 
o poliedro básico é o $\mathrm{SiO}_{4}$ tetraédrico. Novamente, cada tetraedro é ligado aos vértices de um outro vizinho tetraédrico. O uso conveniente do termo "rede aleatória" é óbvio quando observamos o diagrama esquemático da figura 1.5, que mostra a estrutura de um óxido hipotético $\mathrm{A}_{2} \mathrm{O}_{3}$ em ambas as formas, cristalina e vítrea.

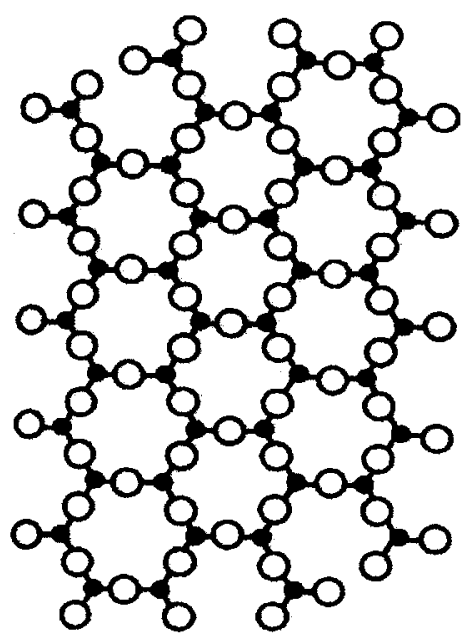

(a)

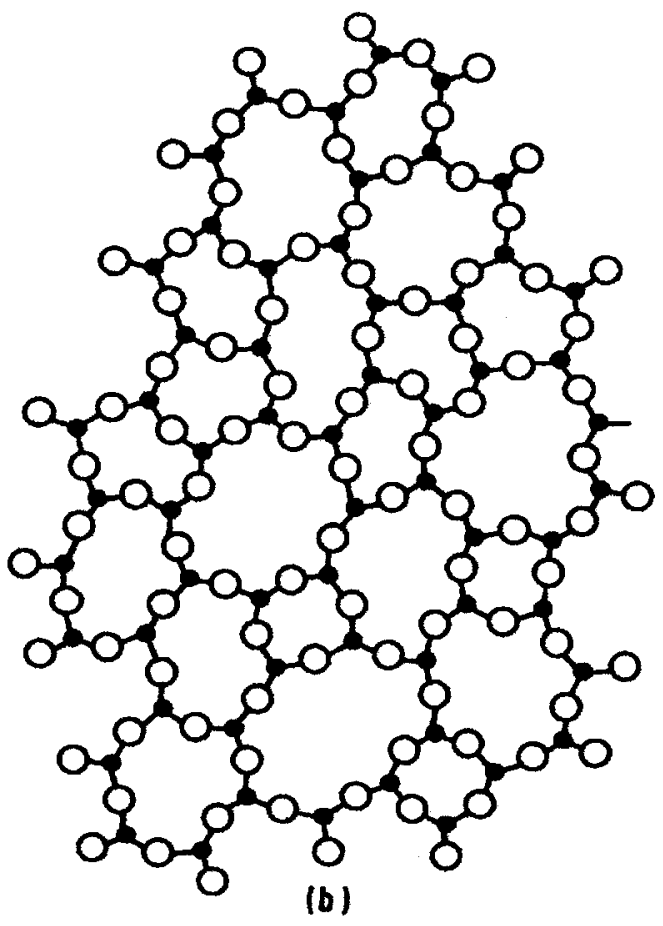

(b)

Figura 1.5 - Representação esquemática bidimensional da estrutura de (a) um composto cristalino hipotético $\mathrm{A}_{2} \mathrm{O}_{3}$ e (b) a forma vítrea do mesmo composto (Zachariasen, 1932).

Zachariasen argüiu que, para não aumentar a energia interna do sistema, os óxidos formadores de rede deveriam obedecer às seguintes condições:

- O átomo de oxigênio não pode estar ligado a mais de dois átomos $\mathrm{A}$.

- O número de átomos de oxigênio em torno dos átomos $\mathrm{A}$ deve ser pequeno.

- O oxigênio compartilha vértices, mas não faces e lados.

- Pelo menos três vértices em cada poliedro deve ser compartilhado.

Todos os óxidos formadores de vidros então conhecidos obedecem às regras de Zachariasen. De acordo com Zachariasen, o ingrediente essencial de um vidro óxido é o óxido 
formador de rede. A sílica, $\mathrm{SiO}_{2}$, é o óxido mais usado como formador de rede, mas o $\mathrm{GeO}_{2}$, $\mathrm{As}_{2} \mathrm{O}_{5}$ e $\mathrm{P}_{2} \mathrm{O}_{5}$, são também conhecidos por formar unidades estruturais tetraédricas que compartilham elétrons nos compostos cristalinos e em todos os tipos de vidros. $\mathrm{O}_{\mathrm{B}_{2}} \mathrm{O}_{3}$ forma unidades triangulares, mas mesmo assim pode formar vidro.

As outras classes de óxidos usados na fabricação de vidros são classificados como modificadores quando estes desorganizam a continuidade da rede, e intermediários quando estes podem tanto juntar-se ou ocupar os buracos da rede. Os óxidos alcalinos e os óxidos alcalinos-terrosos são classificados como modificadores de rede.

Uma série de estudos sobre a estrutura dos vidros silicatos usando difração de raios- $X$ foi feita por Warren (1941). Estes trabalhos foram interpretados em termos do modelo de rede aleatória, e importantes informações foram obtidas em relação à maneira pela qual os íons alcalinos e alcalinos-terrosos são incorporados na estrutura vítrea. As características de maior significado são:

- Os cátions ficam situados nas lacunas relativamente largas da estrutura.

- Para cada ânion oxigênio adicional introduzido, uma ligação A-O-A é quebrada, de maneira que dois oxigênios non-bridging são formados. A carga positiva introduzida é localmente neutralizada pela carga negativa dos oxigênios na formação nonbridging (oxigênios non-bridging é jargão usado para se referir a oxigênios não ligados).

Há diversos modelos para a estrutura de sólidos amorfos que levam em consideração a forma das funções de distribuição, simetria local, descrição geométrica, relação orientacional, distribuição dos espécimes químicos, etc. Discutiremos brevemente a ordem composicional destes materiais em termos dos átomos bridging e non-bridging. Como exemplo consideremos o silicato de lítio cristalino, que possuiu ânions silício-oxigênio de cargas formais (a carga formal representa, num sentido idealizado, o número de elétrons que um átomo ganha ou perde quando ele entra numa ligação perfeitamente covalente com outros átomos) que variam de acordo com a concentração de lítio. Consideremos ainda a mistura de óxidos $\left(\mathrm{Li}_{2} \mathrm{O}\right)_{x}\left(\mathrm{SiO}_{2}\right)_{1-x} ;$ a composição em $x=0$ corresponde à estrutura na qual todos os quatro oxigênios estão na forma bridging, isto é, estão ligados a dois átomos de silício. $\mathrm{Na}$ 
terminologia de Ressonância Magnética Nuclear isto é usualmente especificado pela notação $\mathrm{Q}^{4}$ representando quatro átomos bridging em torno dos átomos tetraédricos (Quaternário). Quando o teor de $x$ aumenta, o número de oxigênios non-briding é rearranjado de tal forma que a fração de átomos $\mathrm{Q}^{4}$ diminua com o correspondente aumento em $\mathrm{Q}^{n}(n<4)$. A figura 1.6 mostra a representação esquemática de vários "espécimes" de silicatos $Q^{\mathrm{n}}$ em vidros silicatos.

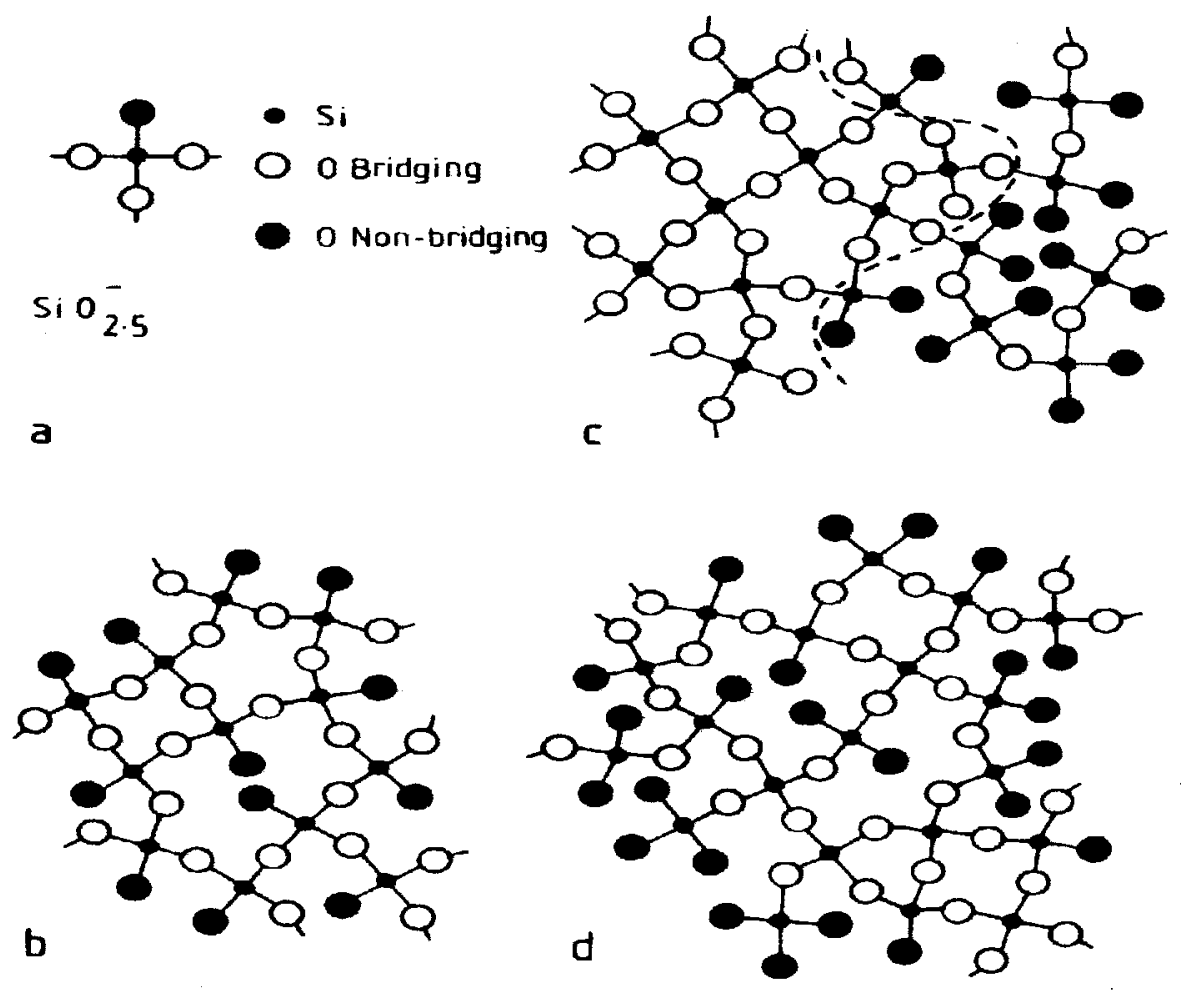

Figura 1.6 - Representação esquemática de várias espécies de silicato $Q^{n}$ em vidros silicatos. a) Tetraedro elementar $Q^{3}$ com 3 oxigênios bridging e 1 oxigênio non-bridging. b) Exemplo de oxigênios non-bridging aparelhados e isolados. c) Vidro composicionalmente ordenado. d) Rede aleatória. (Zarzycki, 1991).

No modelo aleatório todos os espécimes são esperados estar presentes em proporções governadas pela composição média, energia e temperatura, etc. 
Os vidros óxidos, de maneira geral, contêm uma variedade de óxidos diferentes, e o modelo de rede aleatória foi utilizado para caracterizar os papéis que estes desempenham na estrutura dos mesmo.

\subsection{Vidros como matrizes de íons terras rarạs}

Um grande número de matrizes cristalinas foram investigadas desde à descoberta do laser de rubi. Laseres de matrizes cristalinas oferecem geralmente como vantagem em relação aos vidros, alta condutividade térmica, linhas de fluorescencia estreitas e, em alguns casos, alta dureza. Entretanto, a qualidade óptica e homogeneidade do dopante nas matrizes cristalinas são freqüentemente pobres e as linhas de absorção mais estreitas e como os vidros não possuem um campo cristalino definido, suas bandas de absorção são alargadas, o que melhora a eficiência de bombeio desses materiais. Uma outra vantagem dos vidros em relação aos cristais é a facilidade de produção.

Nas últimas décadas grande esforço foi concentrado na área de pesquisa de materiais para laseres, principalmente vidros ópticos. Muitos íons ativadores foram investigados. Os mais estudados são o $\mathrm{Nd}$, Er e $\mathrm{Yb}$; combinações de diferentes íons ativadores também foram usados. $\mathrm{O}$ melhor ativador é ainda o $\mathrm{Nd}$, que foi o primeiro a ser usado. As matrizes dos vidros estudados são formadas por compostos óxidos, como por exemplo $\mathrm{SiO}_{2}, \mathrm{~B}_{2} \mathrm{O}_{3}, \mathrm{GeO}_{2}, \mathrm{P}_{2} \mathrm{O}_{5}$ e $\mathrm{TeO}_{2}$, por haletos, entre eles, $\mathrm{BeF}_{2}, \mathrm{CdF}_{2}, \mathrm{AlF}_{3}, \mathrm{ZrF}_{4}, \mathrm{HfF}_{4}, \mathrm{ThF}_{4}, \mathrm{BiCl}_{3}, \mathrm{ThCl}_{4}$ e $\mathrm{BiBr}_{3}$ e pelos chalcogenetos $\mathrm{As}_{2} \mathrm{~S}_{3}, \mathrm{As}_{2} \mathrm{Se}_{3}$ e $\mathrm{La}_{2} \mathrm{~S}_{3}$. Também é de interesse outros vidros mistos, incluindo os vidro fluoro-fosfatos e os cloro-fosfatos.

No caso de laseres usados para usinagem e para medidas que requerem alta taxa de repetição é necessário que o vidro tenha baixa expansão térmica, baixo módulo de elasticidade, boa resistência mecânica e boa resistência ao choque térmico. A variação do coeficiente de temperatura do comprimento do caminho óptico, ds/dT deve ser zero. Outro fator importante é possuir baixo índice de refração não linear $n_{2}$. Embora a composição básica do vidro determina a maioria das propriedades do vidro, a concentração do íon terra rara deve ser levado em consideração. 


\section{O sistema vítreo aluminato de cálcio}

O sistema vítreo aluminato de cálcio é interessante tanto do ponto de vista tecnológico quanto acadêmico. Embora a descoberta deste sistema vítreo tenha ocorrido no ínicio do século próximo passado (Sherperd et. al, 1909), ainda hoje desperta interesse no que diz respeito a sua estrutura (Petkov et al., 2000). A descoberta de formação de vidro no sistema binário $\mathrm{CaO}-\mathrm{Al}_{2} \mathrm{O}_{3}$ ocorreu durante estudos do diagrama de fase do sistema ternário MgO$\mathrm{CaO}-\mathrm{Al}_{2} \mathrm{O}_{3}$, porém era possível obter-se apenas poucos miligramas de vidro. Foi necessário esperar aproximadamente até a metade do século $\mathrm{XX}$ para descobrir que a introdução de pequenas quantidades, aproximadamente $5 \%$ em peso, de $\mathrm{SiO}_{2}$ no sistema binário aumentava o intervalo de vitrificação. Um exemplo de composição nos trabalhos reportados por Stanworth (1948) e Sun (1949) é em peso \%, $48.6 \mathrm{Al}_{2} \mathrm{O}_{3}, 44.8 \mathrm{CaO}, 6.6 \mathrm{SiO}_{2}$. Um dos principais desafios para os cientistas nesse início de investigação era conseguir composições estáveis e que não prejudicasse a transmitância na região do infravermelho, cujo corte é aproximadamente $5 \mu \mathrm{m}$. A adição de grandes quantidades de sílica faz com que esse corte seja deslocado para comprimentos de ondas mais curtos. Além desse fator outro desafio era a eliminação da forte banda de absorção na região entre 3 e $4 \mu \mathrm{m}$ devido aos radicais $\mathrm{OH}^{-}$.

De acordo com Rawson (1967) o intervalo de formação de vidro no sistema CaO$\mathrm{Al}_{2} \mathrm{O}_{3}$ está entre 38 e $65 \%$ (em peso) de $\mathrm{Al}_{2} \mathrm{O}_{3}$, coincidindo com a região onde a temperatura líquidus é relativamente mais baixa, $\cong 1380{ }^{\circ} \mathrm{C}$, enquanto que o ponto de fusão dos óxidos 
puros é de $\cong 2600{ }^{\circ} \mathrm{C}$ para o $\mathrm{CaO}$ e $\cong 2010{ }^{\circ} \mathrm{C}$ para o $\mathrm{Al}_{2} \mathrm{O}_{3}$. Em outros sistemas aluminato binário a temperatura do eutético é bem mais alta: $\mathrm{BeO}: \mathrm{Al}_{2} \mathrm{O}_{3} \rightarrow 1835^{\circ} \mathrm{C}$ (Lang et. al., 1952); $\mathrm{MgO}: \mathrm{Al}_{2} \mathrm{O}_{3} \rightarrow 2105{ }^{0} \mathrm{C}$ (Alper et al., 1962); $\mathrm{SrO}: \mathrm{Al}_{2} \mathrm{O}_{3} \rightarrow 1505{ }^{\circ} \mathrm{C}$ (Massazza, 1959); $\mathrm{BaO}: \mathrm{Al}_{2} \mathrm{O}_{3} \rightarrow 1620{ }^{\circ} \mathrm{C}$ (Purt, 1960). Supostamente, esta temperatura mais alta do eutético explica porque a formação de vidro está confinada no sistema $\mathrm{Al}_{2} \mathrm{O}_{3}: \mathrm{CaO}$. Uma temperatura líquidus mais baixa favorece uma viscosidade mais alta, que é a condição fundamental para a formação de vidro. Na figura 2.1 é mostrado o diagrama de fase do sistema binário $\mathrm{CaO}: \mathrm{Al}_{2} \mathrm{O}_{3}$. A região de formação de vidro é indicada na figura pelas setas.

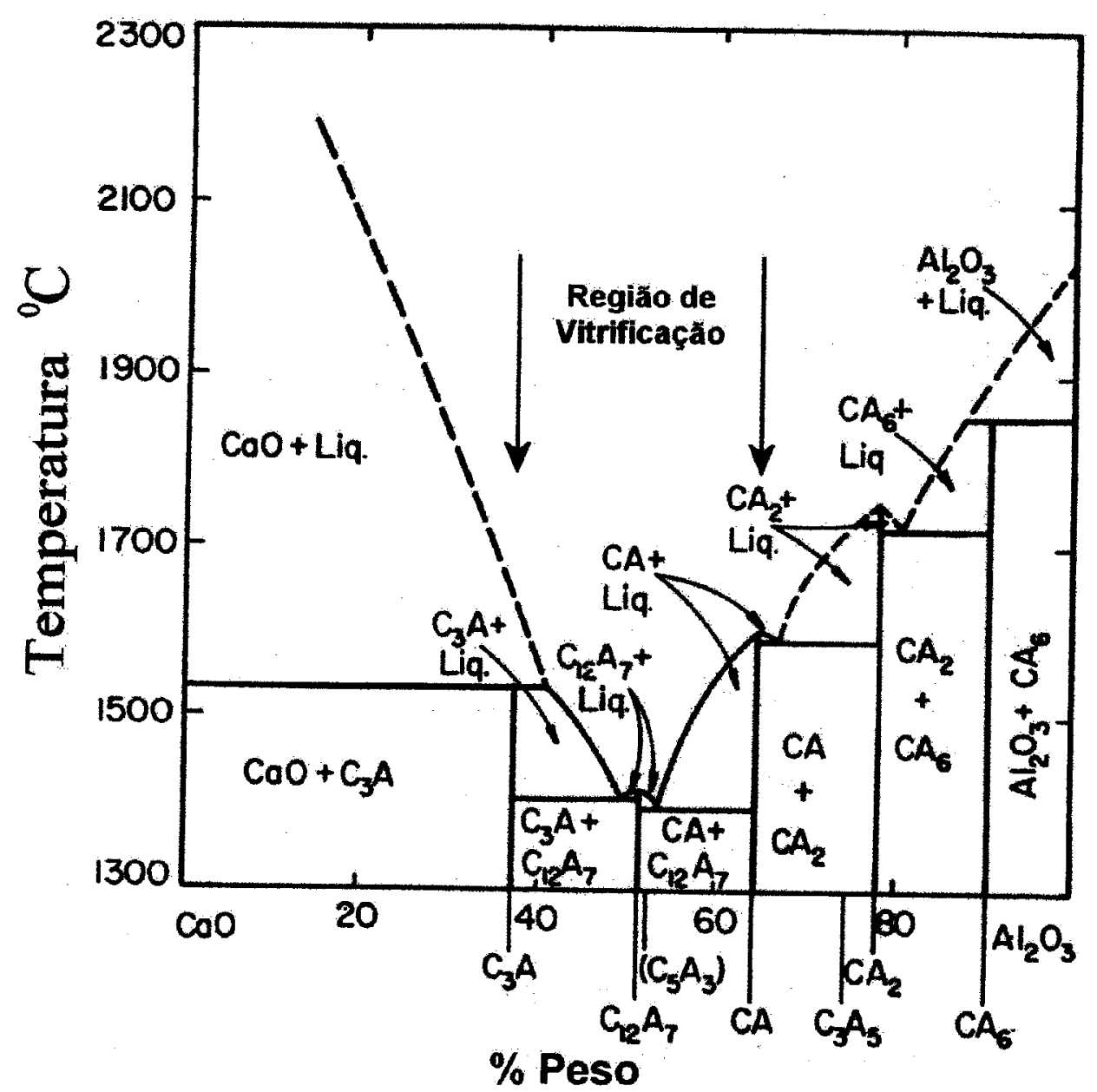

Figura 2.1 - Região de vitrificação do sistema binário $\mathrm{CaO}: \mathrm{Al}_{2} \mathrm{O}_{3}$ (Rawson, 1967) 
O vidro aluminato de cálcio é interessante do ponto de vista estrutural, já que tanto o $\mathrm{CaO}$ quanto o $\mathrm{Al}_{2} \mathrm{O}_{3}$ não são formadores de vidro, como ocorre por exemplo, com o $\mathrm{SiO}_{2}$ e o $\mathrm{P}_{2} \mathrm{O}_{5}$. Eles são classificados como intermediários pois sob certas condições tendem a juntar-se à rede do vidro. É suposto na literatura que a formação de vidro deve-se ao efeito de contrapolarização do íon Ca sobre o complexo $\mathrm{AlO}_{6}$, promovendo uma tranformação do grupo $\mathrm{AlO}_{4}$, que neste caso desempenharia papel similar ao $\mathrm{SiO}_{4}$, ou seja um formador de rede (Vogel, 1994:257). Aparentemente o efeito do óxido alcalino é insuficiente para tal transformação e por esta razão os vidros aluminato alcalinos não são obtidos nos processos convensionais de fusão. Essa mudança de coordenação é representada esquematicamente na figura 2.2.

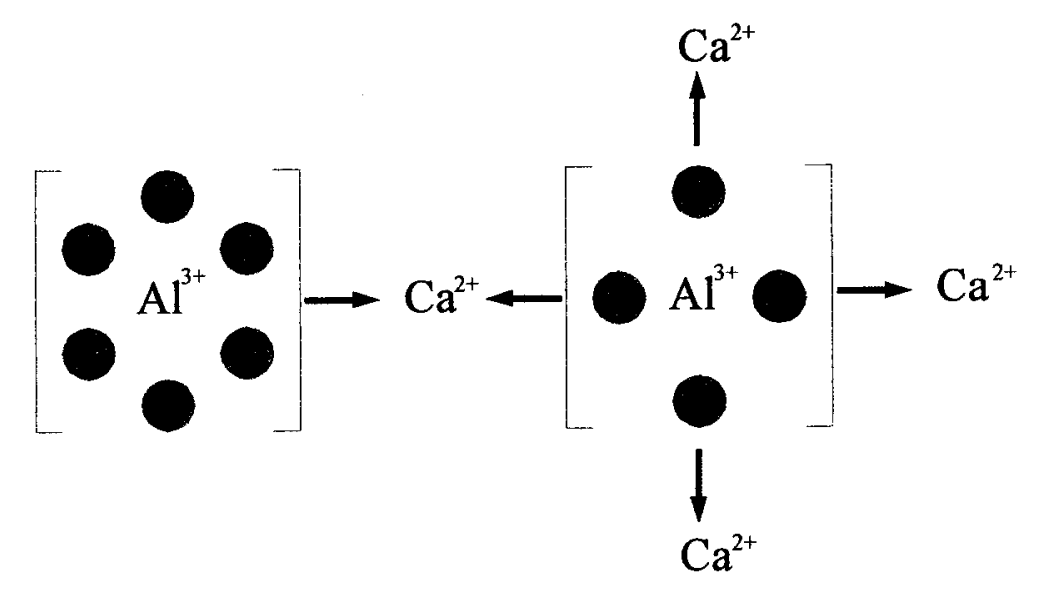

Figura 2.2 - Representação esquemática da mudança de coordenação de um íon de $A l^{3+}$ sobre o efeito de contra polarização dos íons de $\mathrm{Ca}^{2+}$. As esferas representam os oxigênios (Vogel, 1994:258).

Stanworth sugeriu que embora o alumínio tenha numa coordenação octaédrica no $\mathrm{Al}_{2} \mathrm{O}_{3}$, quando no vidro sua coordenação passa a ser tetraédrica, esta conclusão é baseada nas investigações de Bussem e Eitel (1936) que encontrou esse tipo de coordenação no composto $12 \mathrm{CaO} .7 \mathrm{Al}_{2} \mathrm{O}_{3}$. Portanto a regra de Zachariasen poderia ser usada para explicar porque forma-se vidro no sistema $\mathrm{CaO}-\mathrm{Al}_{2} \mathrm{O}_{3}$, enquanto que o $\mathrm{Al}_{2} \mathrm{O}_{3}$ por si só não.

A literatura acerca dos vidros aluminato de cálcio até o início da década dos anos 50 é escassa. Porém desde então esse sistema vítreo começou a chamar a atenção devido a sua alta transmitância na região do infravermelho, que chega até $6 \mu \mathrm{m}$, maior se comparada aos vidros silicatos que transmitem até $4 \mu \mathrm{m}$. Os vidros germanatos possuem transmitância semelhante 
aos aluminatos, porém são de alto custo de produção. A transmitância na região do infravermelho dos vidros em geral é reduzida drasticamente pela absorção da água, mais precisamente, radicais $\mathrm{OH}^{-}$. A fim de contornar esse problema Florence et al. (1955) investigaram várias composições de vidros aluminato de cálcio e vidros germanatos. $\mathrm{O}$ enfoque do artigo de Florence é dado à utilização de óxidos anidros e hidratados na preparação das amostras. São investigadas ao todo 23 amostras, das quais apenas 2 são de vidros germanatos. Algumas composições de vidros aluminato de cálcio continham baixa concentração de $\mathrm{SiO}_{2}, \mathrm{MgO}, \mathrm{La}_{2} \mathrm{O}_{3}$; a maior parte destas amostras continham concentrações de $\mathrm{BaO}, \mathrm{BeO}$ variando entre 5 e 20 peso\%. Esses vidros podem ser usados amplamente em aplicações na região do infravermelho, em que a banda de absorção da água entre 2.9 e $4.0 \mu \mathrm{m}$ seja irrelevante. $\mathrm{Na}$ realidade os métodos por eles utilizados na preparação dos vidros não eliminam de maneira eficiente a banda de absorção da água. A figura 2.3 mostra as curvas de transmitância de uma amostra de vidro aluminato de cálcio, cuja composição é $41.2 \mathrm{Al}_{2} \mathrm{O}_{3}$ $42 \mathrm{CaO}-6.8 \mathrm{BaO}-5.0 \mathrm{BeO}-5.0 \mathrm{La}_{2} \mathrm{O}_{3}$ (\% em peso).

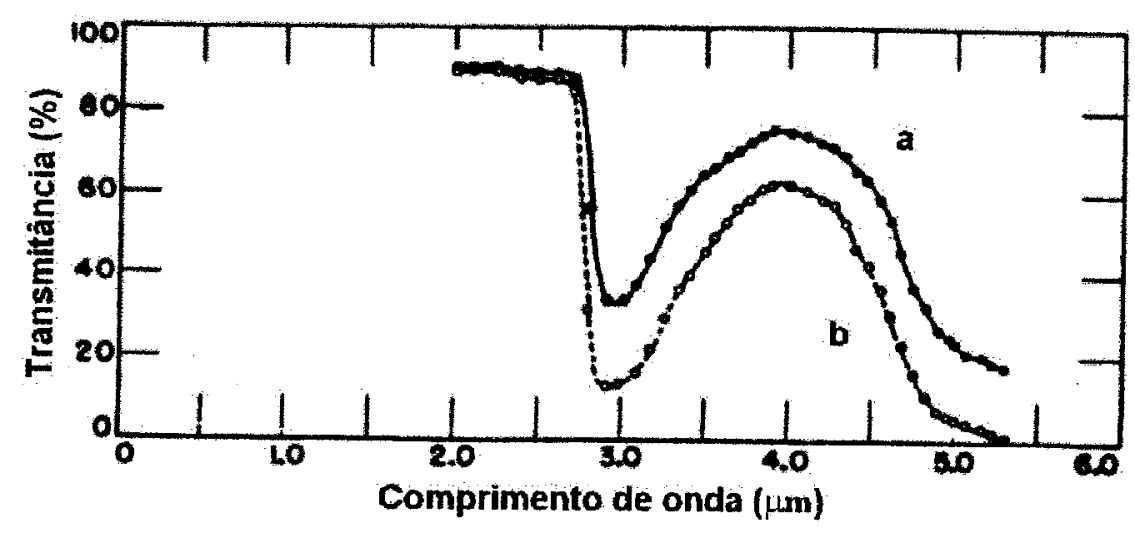

Figura 2.3 - Transmitância na região do infravermelho para o vidro aluminato de cálcio: $41.2 \mathrm{Al}_{2} \mathrm{O}_{3}-42 \mathrm{CaO}-6.8 \mathrm{BaO}-5.0 \mathrm{BeO}-5.0 \mathrm{La}_{2} \mathrm{O}_{3}$ (\% em peso). a) espessura $2.04 \mathrm{~mm}$, b) espessura $4.16 \mathrm{~mm}$ (Florence et al., 1955).

Hafner e colaboradores (1958) investigaram as propriedades ópticas e física de alguns vidros aluminato de cálcio. $O$ objetivo deste trabalho foi o de encontrar composições mais estáveis. Os estudos preliminares foram feitos usando $100 \mathrm{~g}$ de matéria prima, em seguida $500 \mathrm{~g}$, e depois de avaliada a formação de vidro, foram preparadas amostras com $5.5 \mathrm{Kg}$. Os estudos foram feitos ao ar, usando cadinhos de platina. $\mathrm{O}$ que chama a atenção nesse trabalho 
é o número de amostras feitas, ao todo 573. A maioria das referências citadas são dificeis de serem encontradas já que referem-se a contratos firmados com a força aérea dos Estados Unidos. Nesse trabalho apenas composições que puderam ser obtidas em $5.5 \mathrm{Kg}$ são reportadas. Os autores listam uma relação de óxidos que podem ser adicionados aos sistema binário, $\mathrm{CaO}: \mathrm{Al}_{2} \mathrm{O}_{3}$, sem que ocorra a cristalização: $1 \% \rightarrow \mathrm{ZrO}_{2} ; 2 \% \rightarrow \mathrm{La}_{2} \mathrm{O}_{3}, \mathrm{Ta}_{2} \mathrm{O}_{5}$ e $\mathrm{TiO}_{2}$; $4 \% \rightarrow \mathrm{Li}_{2} \mathrm{O}, \mathrm{MgO}, \mathrm{K}_{2} \mathrm{O}, \mathrm{ZnO}, \mathrm{SrO}, \mathrm{BaO}, \mathrm{SnO}_{2}$ e $\mathrm{Nb}_{2} \mathrm{O}_{5} ; 8 \% \rightarrow \mathrm{Na}_{2} \mathrm{O} ; 16 \% \mathrm{Fe}_{2} \mathrm{O}_{3}$ e $\mathrm{GeO}_{2}$ (porcentagens em mole). Outros óxidos não são recomendados para ser adicionados à composição dos vidros aluminato de cálcio devido a vários fatores: a) os que promovem devitrificação $\rightarrow \mathrm{Cu}_{2} \mathrm{O}, \mathrm{Rb}_{2} \mathrm{O}, \mathrm{CdO}, \mathrm{PbO}, \mathrm{Nd}_{2} \mathrm{O}_{3}, \mathrm{Sb}_{2} \mathrm{O}_{3}, \mathrm{CeO}_{2}, \mathrm{MnO}_{2}, \mathrm{~V}_{2} \mathrm{O}_{3}$; b) os que envolvem duas fases de formação $\rightarrow \mathrm{Cr}_{2} \mathrm{O}_{3}, \mathrm{WO}_{3}, \mathrm{MoO}_{3}$; c) os que atacam os cadinhos de platina $\rightarrow \mathrm{Bi}_{2} \mathrm{O}_{3}, \mathrm{TeO}_{2}, \mathrm{Ag}_{2} \mathrm{O}$; d) os que diminuem a transmitância no infravermelho $\rightarrow \mathrm{CoO}$, $\mathrm{As}_{2} \mathrm{O}_{3}, \mathrm{~B}_{2} \mathrm{O}_{3}, \mathrm{P}_{2} \mathrm{O}_{5}, \mathrm{BeO}$. De maneira geral estas investigações indicam que o sistema binário pode ser estabilizado através da adição de até $15 \%$ de óxidos alcalinos e de até $8 \%$ de óxidos alcalinos terrosos (porcentagens em mol). $\mathrm{O}$ óxido de ferro, $\mathrm{Fe}_{2} \mathrm{O}_{3}$ pode ser adicionado até $15 \%$ porém degrada a transmitância na região do visível. Na figura 2.4 podemos observar o efeito da concentração de $\mathrm{Fe}_{2} \mathrm{O}_{3}$ na transmitância de vários vidros aluminato de cálcio.

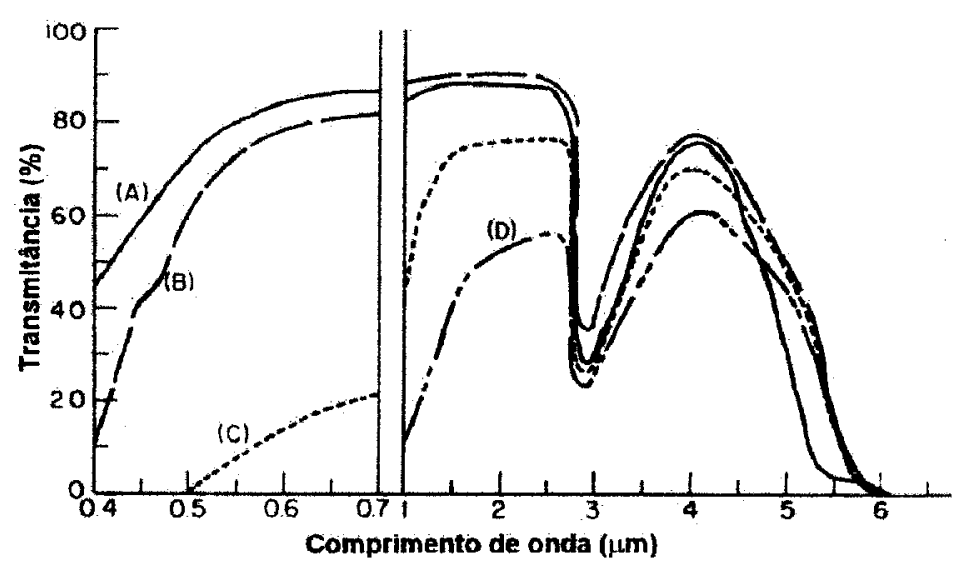

Figura 2.4 - curvas de transmitância de vários vidros aluminato de cálcio na região do visivel e infravermelho. A) $58.5 \mathrm{CaO}, 27.5 \mathrm{Al}_{2} \mathrm{O}_{3}, 8.4 \mathrm{MgO}, 5.6 \mathrm{SiO}_{2}$. B) $32.5 \mathrm{CaO}, 57.5 \mathrm{Al}_{2} \mathrm{O}_{3}, 2 \mathrm{MgO}$, $2 \mathrm{BaO}, 2 \mathrm{La}_{2} \mathrm{O}_{3}, 7.5 \mathrm{Na}_{2} \mathrm{O}, 2.5 \mathrm{~K}_{2} \mathrm{O}, 0.5 \mathrm{Fe}_{2} \mathrm{O}_{3} \mathrm{C}$ ) $32.5 \mathrm{CaO}, 57.5 \mathrm{Al}_{2} \mathrm{O}_{3}, 2 \mathrm{MgO}, 2 \mathrm{BaO}, 2 \mathrm{La}_{2} \mathrm{O}_{3}$, $\left.7.5 \mathrm{Na}_{2} \mathrm{O}, 2.5 \mathrm{~K}_{2} \mathrm{O}, 2 \mathrm{Fe}_{2} \mathrm{O}_{3} \mathrm{D}\right) 32.5 \mathrm{CaO}, 57.5 \mathrm{Al}_{2} \mathrm{O}_{3}, 2 \mathrm{MgO}, 2 \mathrm{BaO}, 2 \mathrm{La}_{2} \mathrm{O}_{3}, 7.5 \mathrm{Na}_{2} \mathrm{O}, 2.5 \mathrm{~K}_{2} \mathrm{O}$, $5 \mathrm{Fe}_{2} \mathrm{O}_{3}$, porcentagens em mol \% (Hafner et al., 1958) 
A soma das composições dos vidros da figura 2.4 excede $100 \%$. Isso deve-se a introdução de $2 \mathrm{~mol} \%$ de $\mathrm{MgO}, \mathrm{BaO}$ e $\mathrm{La}_{2} \mathrm{O}_{3}$ além da concentração variável de $\mathrm{Fe}_{2} \mathrm{O}_{3}$ adicionada ao vidro base $32.5 \mathrm{CaO}, 57.5 \mathrm{Al}_{2} \mathrm{O}_{3}, \mathrm{Na}_{2} \mathrm{O}, 2.5 \mathrm{~K}_{2} \mathrm{O}$. Além da investigação quanto a formação de vidros os autores reportam algumas propriedades físicas. $\mathrm{O}$ módulo de Young varia de 104 a $106 \mathrm{GPa}$, a densidade de 2.95 a $3.07 \mathrm{~g} / \mathrm{cm}^{3}$; a dureza Knoop varia de 5.7 a 6.2 $\mathrm{GPa}$, a expansão térmica de $8.1-10 \times 10^{-6}{ }^{0} \mathrm{C}^{-1}$, resistência ao impacto $49.6-51.8 \mathrm{GPa}$.

G. Y. Onoda e S. D. Brown (1970) investigaram a formação de vidro de vidros aluminato de cálcio com baixa concentração de sílica. Cerca de 300 composições diferentes foram preparadas, tanto no sistema binário, ternário e quaternário. A temperatura liquidus usada foi abaixo de $1500{ }^{\circ} \mathrm{C}$. Além da formação de vidros são reportadas também propriedades mecânicas e viscosidade. Neste artigo conclui-se que o óxido de cálcio é necessário para a vitrificação. Quantidades limitadas (em alguns casos até $30 \mathrm{~mol} \%$ ) de outros óxidos tais como $\mathrm{Li}_{2} \mathrm{O}, \mathrm{MgO}, \mathrm{BaO}, \mathrm{ZnO}, \mathrm{Na}_{2} \mathrm{O}, \mathrm{K}_{2} \mathrm{O}, \mathrm{BeO}, \mathrm{B}_{2} \mathrm{O}_{3}$ podem estar presentes no vidro. Uma condição necessária, embora insuficiente, para a fácil formação de vidro é que a proporção de íons de oxigênio em relação aos cátions formadores $\left(\mathrm{Al}^{3+}\right.$ e $\left.\mathrm{Si}^{4+}\right)$ esteja entre 2.35 e 2.6. Em vista desse fato os autores discorrem que todos os $\mathrm{Al}^{3+}$ estando na posição tetraedral o número médio de oxigênios ligados/tetraedro está compreendido entre 2.8 e 3.3. Conseqüentemente, como no caso dos vidros do sistema binário, os vidros multicomponentes são formados, provavelmente, apenas quando houver aproximadamente três ou quatro íons de oxigênios ligados a um tetraedro alumínio-oxigênio. A importância dos íons modificadores na formação de vidro nos sistemas aluminato é acentuado em virtude de que apenas os íons de $\mathrm{Ca}^{2+}$ permitir que o $\mathrm{Al}^{3+}$ seja um formador de rede no sistema binário. Composições com

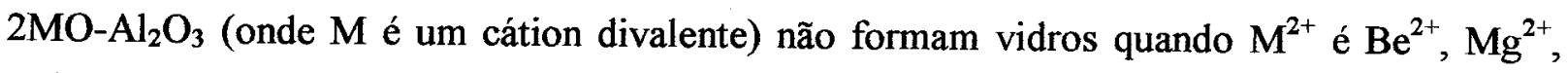
$\mathrm{Zn}^{2+}$ ou $\mathrm{Ba}^{2+}$. A substiuição gradual de outros cátions formadores no vidro base, $\mathrm{CaO}: \mathrm{Al}_{2} \mathrm{O}_{3}$, leva à instabilidade vítrea.

De particular interesse é a observação que podemos fazer no sistema ternário com pouca sílica $\mathrm{Al}_{2} \mathrm{O}_{3}: \mathrm{CaO}: \mathrm{SiO}_{2}$. Na figura 2.5 podemos observar que a região que permite a formação de vidro está restrita a uma área em torno do eutético ternário $\left(30.4 \mathrm{Al}_{2} \mathrm{O}_{3}-8.2 \mathrm{SiO}_{2}\right.$ - $61.4 \mathrm{CaO}$ ). Esta é a única região em que a temperatura líquidos está abaixo de $1400{ }^{\circ} \mathrm{C}$ em toda a parte do lado de baixa concentração de sílica. Estes resultados são consistentes com a 
observação geral de que o vidro é usualmente formado em materiais que possuam uma temperatura líquidos abaixo de $1500{ }^{\circ} \mathrm{C}$. Em temperaturas mais altas tem-se uma energia maior disponível para ativar o processo de nucleação ou crescimento de cristais.

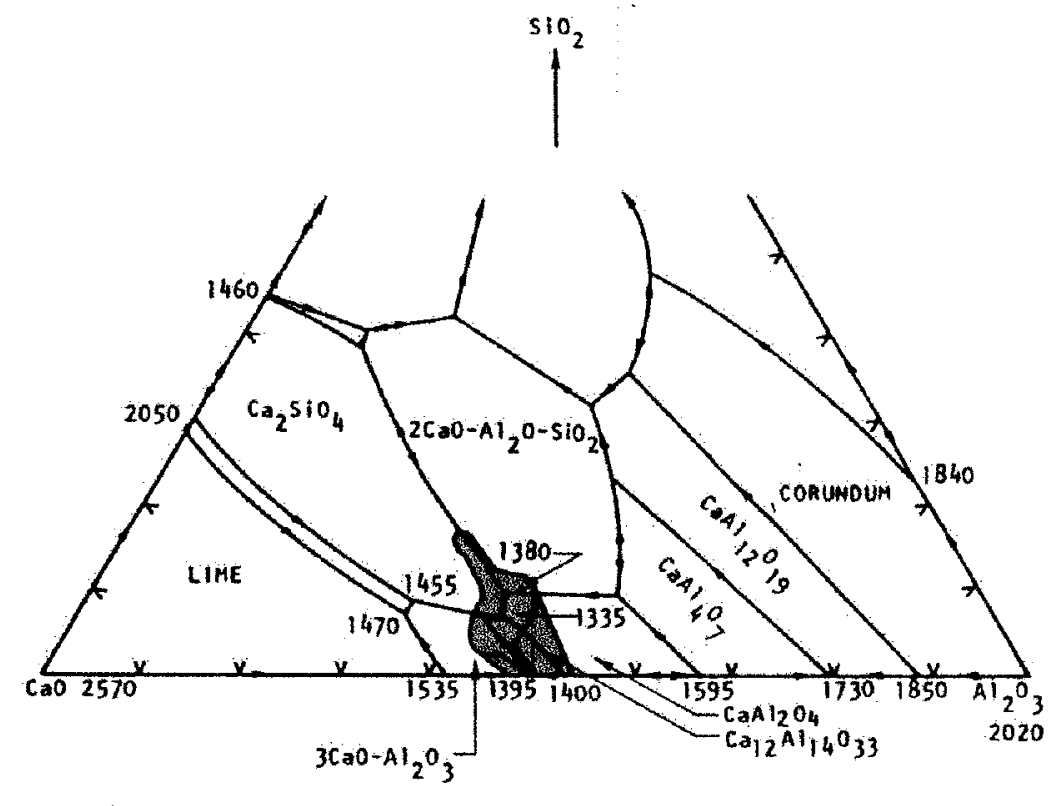

Figura 2.5 - Região de fácil vitrificação no sistema $\mathrm{CaO}: \mathrm{Al}_{2} \mathrm{O}_{3}: \mathrm{SiO}_{2}$ com baixa concentração de silica, mostrada na área em cinza (Onoda e Brown, 1970).

G. Y. Onoda e S. D. Brown (1970) fizeram também um estudo quantitativo sobre a nucleação e o crescimento de cristais. A temperatura líquidos do vidro foi de $1450{ }^{\circ} \mathrm{C}$, determinadas por um aquecedor de irídio. O líquido foi sub-resfriado até $1200{ }^{\circ} \mathrm{C}$ e mantido nessa temperatura por 30 minutos sem que ocorresse cristalização. Em $1200{ }^{\circ} \mathrm{C}$ e abaixo, surgiram núcleos o suficiente para a formação de cristais individuais. Uma vez que os cristais nucleados cresceu rapidamente, a taxa de crescimento em $1300{ }^{\circ} \mathrm{C}$ foi estimada através da introdução de uma semente dentro do material sub-resfriado. A taxa de crescimento foi de 42 $\mathrm{mm} / \mathrm{h}$, comparada as taxas máximas de um vidro silicato típico que é menor que $1 \mathrm{~mm} / \mathrm{h}$.

A cristalização depende de alguns outros fatores: no caso do sistema ternário $\mathrm{CaO}: \mathrm{Al}_{2} \mathrm{O}_{3}: \mathrm{SiO}_{2}$, somente $1 / 5$ dos íons de $\mathrm{Ca}^{2+}$ podem ser susbstituídos por $\mathrm{Ba}^{2+}$ ou $\mathrm{Mg}^{2+}$ antes de ocorrer devitrificação. Uma concentração maior de $\mathrm{Ca}^{2+}$ pode ser susbtituída se um 
íon alcalino for adicionado. A mais alta substituição possível é com o $\mathrm{Zn}^{2+}$ que pode substituir até $1 / 2$ dos íons de $\mathrm{Ca}^{2+}$.

A nucleação e a cristalização de vidros aluminato de cálcio binários, $46.5 \mathrm{CaO}, 53.5$ $\mathrm{Al}_{2} \mathrm{O}_{3}$ (em peso \%), foram investigadas recentemente por $\mathrm{Li}$ e Mitchell (1999). As medidas de análise térmica foram realizadas usando várias taxas de aquecimento. A temperatura de cristalização primária ocorre entre $940{ }^{\circ} \mathrm{C}$ a $1040{ }^{\circ} \mathrm{C}$. Análise por difração de raios-X revela que as amostras com diferentes tipos de partículas e condições de aquecimento possuem as mesmas fases cristalinas $\mathrm{Ca}_{12} \mathrm{Al}_{14} \mathrm{O}_{33}\left(\mathrm{C}_{12} \mathrm{~A}_{7}\right)$ e $\mathrm{CaAl}_{2} \mathrm{O}_{4}$ (CA), cujo tamanho de grão médio dos cristais é de $35 \mathrm{~nm}$. Estudos de cristalização sob condições não isotermas foram realizadas, a energia de ativação do crescimento de cristal foi de $739 \pm 4 \mathrm{~kJ} / \mathrm{mol}$ pelo método de Kissinger ou $694 \pm 4 \mathrm{~kJ} / \mathrm{mol}$ pelo método de Augis-Bennet.

Investigações em relação ao puxamento de fibras de vidros aluminato de cálcio também são também reportadas. A viscosidade dos vidros aluminato de cálcio na região de temperatura líquidos (TL) é baixa e aumenta-se a medida que diminui-se a temperatura. A velocidade para puxamento de fibra é de 182 Poise a $20{ }^{\circ} \mathrm{C}$ acima de TL, 720 Poise a $50{ }^{\circ} \mathrm{C}$ abaixo de TL e 10.000 Poise a $200{ }^{\circ} \mathrm{C}$ abaixo de TL (limite superior para o puxamento de fibra). Neste trabalho é concluído que apesar de ser possível a formação de vidros em algumas composições sem sílica, ou do sistema binário, $51.4 \mathrm{Al}_{2} \mathrm{O}_{3}: 48.6 \mathrm{CaO}$, não é possível o puxamento de fibras desses vidros.

O desenvolvimento de vidros aluminato de cálcio para uso na região do infravermelho até $5 \mu \mathrm{m}$ foi reportado por Davy (1978). Esse trabalho é muito interessante, principalmente para quem está principiando na arte de fazer vidros aluminato de cálcio. Nesse trabalho o autor descreve detalhadamente a preparação destes vidros, os êxitos e problemas que podem ocorrer. Pela primeira vez é reportada uma curva de transmitância óptica do vidro aluminato de cálcio semelhante à da safira, cuja transmissão óptica chega a $6 \mu \mathrm{m}$. A figura 2.6 mostra as curvas de transmitância dos vidros aluminato fundidos a vácuo e ao ar, e compara com um vidro silicato preparado ao ar. A transmitância sem as indesejáveis bandas de absorção devidas a presença de água é conseguida através da fusão das amostras a vácuo. Duas composições são de destaque nesse trabalho: 1) $45 \mathrm{Al}_{2} \mathrm{O}_{3}-36.9 \mathrm{CaO}, 13.4 \mathrm{BaO}$ e 2) $40.8 \mathrm{Al}_{2} \mathrm{O}_{3}-49 \mathrm{CaO}, 6.1 \mathrm{SiO}_{2} \mathrm{e}$ 
4.1MgO (\% em peso). A composição 1 possui transmissão óptica próxima à da safira, porém a composição 2 é mais estável.

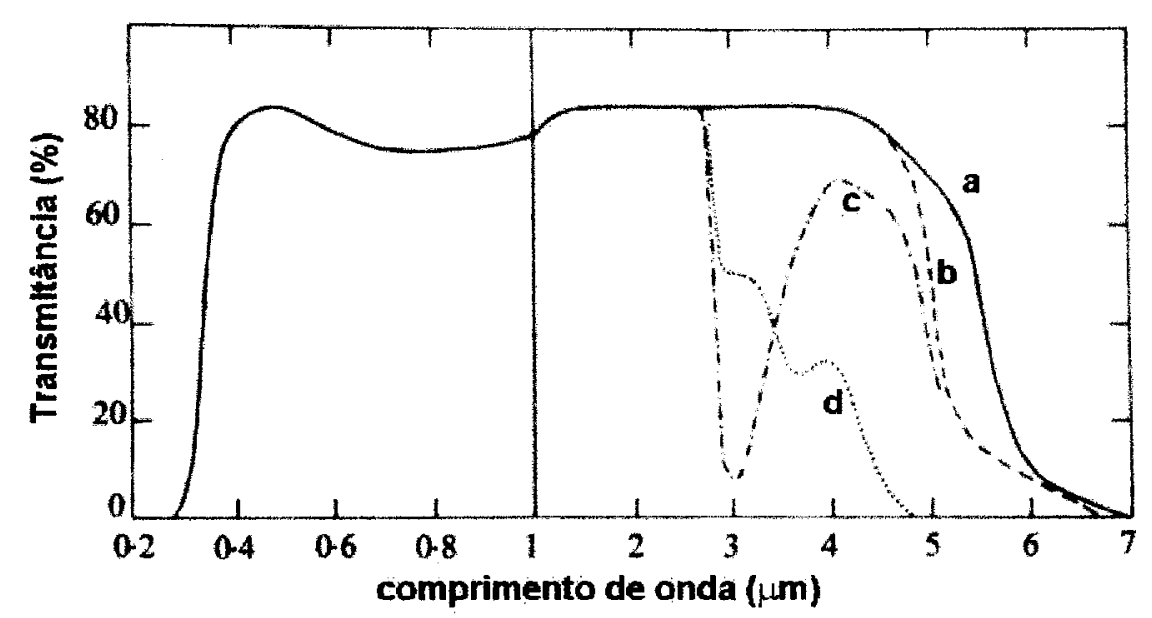

Figura 2.6 Comparação das curvas de transmitância de vários vidros de $2 \mathrm{~mm}$ de espessura. a) $45 \mathrm{Al}_{2} \mathrm{O}_{3}-36.9 \mathrm{CaO}, 13.4 \mathrm{BaO}$ (\% peso, fundido a vácuo); b) $40.8 \mathrm{Al}_{2} \mathrm{O}_{3}-49 \mathrm{CaO}$, 6.1 $\mathrm{SiO}_{2}$ $4.1 \mathrm{MgO}$ (\% peso, fundido a vácuo); c) aluminato fundido ao ar; d) silicato fundido ao ar (Davy, 1978).

F. T. Wallenberger, N. E. Weston e S. Brown (1991) investigaram o puxamento de fibras ópticas de vidros aluminato de cálcio super resfriados. Neste artigo é reportado que é possível puxar fibras de vidros aluminato de cálcio em um amplo intervalo de composições. Pode-se variar a concentração de $\mathrm{Al}_{2} \mathrm{O}_{3}$ de 35 a $50 \mathrm{~mol} \%$, sendo possível também o puxamento de fibras de composições quaternárias, como por exemplo $46.1 \mathrm{Al}_{2} \mathrm{O}_{3}, 36.1 \mathrm{CaO}$, $4.0 \mathrm{MgO}$ e $13.8 \mathrm{BaO}$ (em peso\%). As fibras reportadas nesse trabalho tinham até $2 \mathrm{~m}$ de comprimento, cujas preformas iniciais possuiam $25.4 \mathrm{~mm}$ de diâmetro por $2.54 \mathrm{~mm}$ de espessura.

A resistência mecância de fibras de vidros aluminato de cálcio variam de acordo com a técnica de puxamento. As fibras puxadas em forno de indução possuem o mais alto valor de resistência mecância, $8.27 \mathrm{GPa}$ (Schroeder et al., 1969), por outro lado fibras com a mesma composição, só que puxadas em forno de oxy-acetileno possui uma menor resistência, 4.13 GPa (Brown e Onoda Jr., 1966, 1968, 1970). Puxamento manual proporciona fibras com 2.76 $\mathrm{GPa}$. 
Foram reportados pouquíssimos trabalhos em relação às propriedades elétricas dos vidros aluminato de cálcio. Leedecke e Ballard (1980) reportam a condutividade elétrica de vários vidros aluminato de cálcio, entre $150^{\circ} \mathrm{C}$ e $800^{\circ} \mathrm{C}$, medidos na freqüência de $50-10^{5}$ $\mathrm{Hz}$. A condutividade ac possui uma fraca dependência com a temperatura, sendo mais dependente da frequência. Em $500{ }^{\circ} \mathrm{C}$ a condutividade dc é $<10^{-9} \Omega^{-1} \mathrm{~cm}^{-1}$, com energia de ativação de $1.7 \mathrm{eV}$. Shelby et al. (1989) reportam que a condutividade elétrica, a $500{ }^{\circ} \mathrm{C}$, de vidros $(63-x) \mathrm{CaO}, x \mathrm{CaF}_{2}, 37 \mathrm{Al}_{2} \mathrm{O}_{3}$ (em mol\%) é muito baixa, $\approx 8 \times 10^{-9} \Omega^{-1} \mathrm{~cm}^{-1}$. A adição de $\mathrm{CaF}_{2}$, cerca de $15 \mathrm{~mol} \%$ no sistema binário aumenta a condutividade por um fator de $20 . \mathrm{A}$ explicação para tais resultados é o fato desses vidros não ter cátions monovalentes, supostamente, a adição de novos portadores, i. e., íons de flúor, faz com que a condutividade elétrica aumente.

Uma outra versatilidade dos vidros aluminato de cálcio é a sua sensibilidade à radiação ultravioleta, tornando-os atraentes para dispositivos de amarzenamento de informações acessados pela luz. Os vidros empregados para tais fins são, geralmente, dopados com íons metálicos pesados ou nobres e/ou íons haletos. Um exemplo típico é o vidro silicato fotosensível ativado com a co-dopagem de $\mathrm{Au}^{+} \mathrm{e} \mathrm{Ce}^{3+}$ (Stookey, 1949). No caso dos vidros aluminato de cálcio não é necessária a introdução de elementos dopantes em sua composição. Hosono et al. (1985) reportam a fotosensibilidade em vidros aluminato de cálcio do sistema binário $\mathrm{CaO}: \mathrm{Al}_{2} \mathrm{O}_{3}$ sem dopantes. A concentração de $\mathrm{CaO}$ nas amostras variam entre 60 e 65 mol\%. Um dos cuidados tomados nos experimentos foi a utilização de cadinhos de alumina ao invés de cadinhos de platina que dissolvem íons $\mathrm{Pt}^{4+}$ no material fundido que conseqüentemente podem mascaram os resultados, principalmente no que concerne ao ínicio da banda de absorção. Nestes experimentos as amostras foram iluminadas por uma lâmpada de ultravioleta, UV, de $500 \mathrm{~W}$, cuja energia dissipada foi de $530 \mathrm{~mJ} / \mathrm{cm}^{2}$.

A figura 2.7 mostra as mudanças no espectro de transmissão óptica de um vidro 60 $\mathrm{CaO}: 40 \mathrm{Al}_{2} \mathrm{O}_{3}$ em função da duração da iluminação UV. Podemos observar o aparecimento de uma nova banda próxima a $400 \mathrm{~nm}$ conforme aumenta-se o tempo de exposição da amostra à radiação ultravioleta. $\mathrm{O}$ vidro inicialmente é transparente tornando-se marrom amarelado ao ser exposto a radiação UV e ao ser aquecido a temperatura entre 100 a $250{ }^{\circ} \mathrm{C}$ retorna a sua cor original. Este um processo é reversível. 


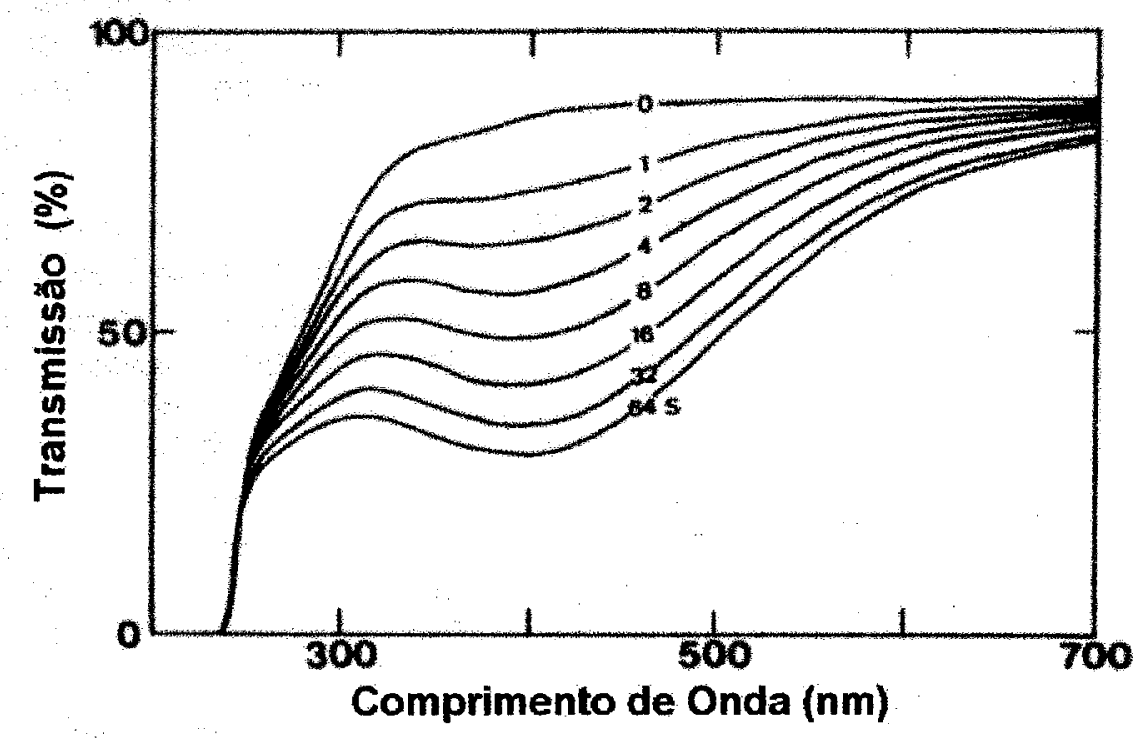

Figura 2.7 - Mudança no espectro de transmissão de um vidro $60 \mathrm{CaO}: 40 \mathrm{Al}_{2} \mathrm{O}_{3}$ (mol\%), com $1.5 \mathrm{~mm}$ de espessura, devido à radiação ultravioleta (número nas curvas representa o tempo de iluminação) (Hosono et al., 1985).

A sensibilidade à radiação ultravioleta é reduzida de forma acentuada pela adição de $\mathrm{SiO}_{2}$ ou $\mathrm{GeO}_{2}$ nos vidros aluminato de cálcio. Essa queda é mais forte para composições cuja concentração de $\mathrm{SiO}_{2}$ é maior que $40 \mathrm{~mol} \%$. Esse resultado corrobora com a literatura uma vez que a fotosensibilidade não é observada em vidros aluminosilicatos convencionais. Entretando os autores ressaltam a dificuldade de obtenção dos vidros aluminato de cálcio binários, uma vez que estes tendem facilmente à cristalização, e concluem que uma baixa concentração de sílica, $<10$ mol\%, não influenciaria de maneira significativa a sensibilidade à radiação ao ultravioleta, ou seja é possível otimizar a preparação destes vidros para obter-se um melhor ganho.

Além disso, Hosono et al. (1985) reportam sobre a dependência da sensibilidade pelo comprimento de onda da iluminação UV. Quando o comprimento de onda diminui, as bandas induzidas aparecem em comprimentos de onda abaixo de $270 \mathrm{~nm}$, aumentando rapidamente até atingir um máximo e subseqüentemente diminuindo. Esta queda é atribuída a um fenômeno aparente, devido ao efeito de filtro interno, ou seja, a iluminação dos raios UV são quase todos absorvidos na superficie do vidro devido ao coeficiente de absorção que aumenta 
rapidamente na região de comprimento de ondas abaixo da aresta da transmissão óptica. $O$ comprimento de onda que dá a sensibilidade máxima corresponde ao início da absorção.

Hosono e Abe (1987a) propuseram um mecanismo químico para explicar a fotosensibilidade dos vidros aluminato de cálcio à radiação ultravioleta. Este mecanismo é baseado nas características dos sinais de ESR (eletron spin ressonance) induzidos pela radiação UV e nas bandas de absorção óptica e na validade da correlação do ESR óptico, dois defeitos paramagnéticos, um centro de buraco alumínio-oxigênio (Al-OHC) e um ozônide $\mathrm{O}_{3}^{-}$ que são considerados ser a origem da coloração induzida pelo UV. Os autores supõem existir a presença de unidades estruturais sensíveis a radiação UV no vidro. A formação de ozoneto $\mathrm{O}_{3}^{-}$, que é um trímero do átomo de oxigênio, sugere a presença de um oxigênio relacionado aos defeitos tais como uma ligação peroxi e/ou oxigênio molecular.

$\mathrm{O}$ mecanismo de fotosensibilidade baseado nos centros de cores resultantes é ilustrado na figura 2.8 .

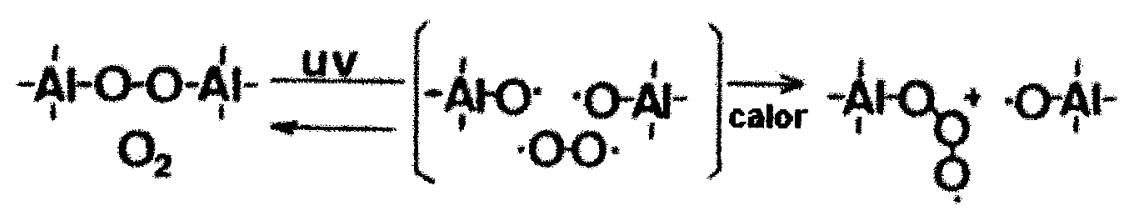

Figura 2.8 - Mecanismo proposto para a fotosensibilidade (Hosono e Abe, 1987a).

Neste modelo, supõem-se que uma ligação peroxi (-O-O-) conectada a dois $\mathrm{Al}$ coordenados tetraedricamente e um oxigênio molecular dissolvido estejam presentes como defeitos estruturais no vidro. Uma ligação peroxi é dissociada homoliticamente pela absorção dos quanta de UV, dando um par de Al-OHC's, que é um dos dois centros de cor. Subsequentemente, um dos pares Al-OHC resultantes combinam com um oxigênio molecular próximo para formar um ozônide, que é um outro centro de cor. A formação do ozoneto previne a recombinação dos pares Al-OHC resultantes, estabilizando a cor induzida em temperatura ambiente. Uma das características dos peróxidos é a sua cisão homolítica por raios UV e sua alta eficiência quântica (Ogata et al., 1983), nos quais o potencial dos estados excitados relevantes é respulsivo (Evleth, 1976). De acordo com esse modelo, o clareamento do vidro devido ao aquecimento corresponde a uma decomposição térmica dos ozônides. 
A fotosensibilidade dos vidros aluminato de cálcio é também dependente da atmosfera de fusão. Hosono e Abe (1988) reportam o fotocromismo de vidros aluminato de cálcio fundidos em cadinhos de grafite e em atmosfera reduzida, quando estes são expostos à radiação ultravioleta. Porém a larga banda de absorção que ocorre é centrada em $570 \mathrm{~nm}$, diferente dos vidros fundidos em atmosfera oxidante, $400 \mathrm{~nm}$. No caso das amostras fundidas em atmosfera oxidante essas absorções permanecem estáveis após a interrupção da iluminação, ao contrário do que ocorre com as amostras fundidas em atmosfera reduzida, que decai após a interrupção da iluminação, mesmo em temperatura ambiente. $O$ fotocromismo é atribuído a um defeito estrutural devido à deficiência de oxigênio, ao contrário dos vidros fundidos em atmosfera oxidante que apresentam excesso de oxigênio.

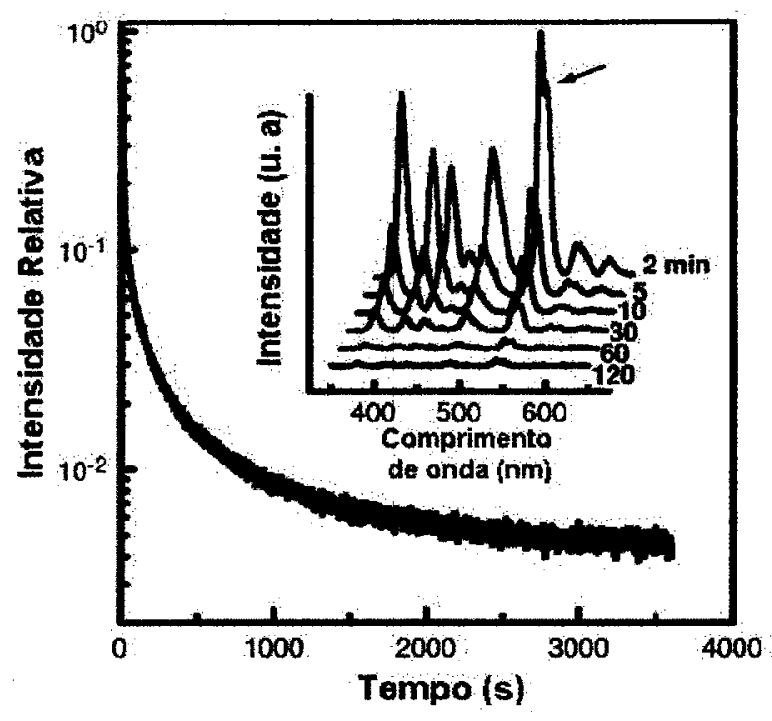

Figura 2.9 - Curva de decaimento da fosforescência após a retirada da fonte de excitação, em $254 \mathrm{~nm}$, monitorada em $542 \mathrm{~nm}$. O tempo no detalhe denota os minutos decorridos após a retirada da fonte excitadora em $254 \mathrm{~nm}$. A seta indica o pico de emissão em $542 \mathrm{~nm}$ devido a transição ${ }^{5} \mathrm{D}_{4} \rightarrow{ }^{7} \mathrm{~F}_{5}$ do $\mathrm{Tb}^{3+}$ (Kinoshita et. al, 1999).

A fosforescência de longa duração em vidros aluminato de cálcio, $59 \mathrm{CaO}-27 \mathrm{Al}_{2} \mathrm{O}_{3}-$ $7 \mathrm{MgO}-7 \mathrm{SiO}_{2}-0.1 \mathrm{~Tb}_{4} \mathrm{O}_{7}$ (mole \%), foi recentemente reportada por Kinoshita et al. (1999). As amostras foram excitadas por 10 minutos com luz ultravioleta, $254 \mathrm{~nm}$. A emissão em $542 \mathrm{~nm}$ persistiu por 2 horas após a retirada da fonte de excitação. Hosono et al. (1998) reporta que que os vidros fundidos em atmosfera reduzida possuem uma fosforescência de longa duração 
devido aos íons de $\mathrm{Tb}^{3+}$ referente à transição ${ }^{5} \mathrm{D}_{4} \rightarrow{ }^{7} \mathrm{~F}_{5}$. A intensidade da fosforescência dos vidros fundidos em atmosfera reduzida é duas ordens de magnitude maior do que os vidros preparados em atmosfera oxidante. A figura 2.9 mostra a curva de decaimento da fosforescência em função do tempo monitorada em $542 \mathrm{~nm}$. No detalhe da figura 2.9 é mostrada a evolução temporal do espectro após a retirada da fonte de excitação.

Um dos trabalhos mais completos sobre a estrutura dos vidros aluminato de cálcio é reportado por McMillan (1981) em sua tese de doutoramento, e publicados posteriormente (McMillan, 1982, 1983). McMillan mediu os espectros Raman de uma ampla série de vidros aluminato de cálcio binários, contendo entre 19 e $81 \mathrm{~mol} \%$ de $\mathrm{CaO}$. Estes vidros foram produzidos em pequenas quantidades fundidas em um forno solar cuja temperatura era superior a $2000{ }^{0} \mathrm{C}$. O resfriamento rápido, $10^{6} \mathrm{~K} / \mathrm{s}$, foi feito usando uma prensa de aço, obtendo-se amostras muito finas. Apenas foram realizadas medidas de Raman e nenhuma outra propriedade foi investigada.

Como resultado da sua investigação, McMillan (1981) propôs que a estrutura dos vidros aluminato de cálcio na proporção 50/50 consiste de uma rede contínua de $\left(\mathrm{AlO}_{4}\right)^{-}$, sem oxigênios nobridging na estrutura, ou seja, a estrutura é análoga à da sílica vítrea, com os íons de $\mathrm{Ca}^{2+}$ ocupando os intertícios na rede e atuando como compensador de carga para os tetraedros alumínio/oxigênio negativamente carregados. Conforme adiciona-se $\mathrm{CaO}$ à composição do vidro, oxigênios nonbridging são formados. Vidros cuja composição tenha entre 60 e $70 \mathrm{~mol} \%$ de $\mathrm{CaO}$ será consistituído de uma rede de tetraedros $\left(\mathrm{AlO}_{4}\right)^{-} \mathrm{com}$ um ou dois oxigênios nonbridging por tetraedro.

McMillan (1983) sugere que a adição de $\mathrm{CaO}$ na estrutura completamente polimerizada dos tetraedros $\mathrm{CA}$ resulta em uma despolimerização da rede do aluminato com a formação de unidades $\equiv \mathrm{AlO}$. A adição de $\mathrm{CaO}$ pode resultar em uma rede expandida dos grupos aluminato tetraédrico despolimerizados, $\mathrm{e}$ as unidades aluminato distorcidas pode desta forma aceitar uma coordenação média um pouco maior a fim de acomodar o excesso de átomos de oxigênios. Em concentrações maiores de $\mathrm{CaO}$, átomos de oxigênios estão suficientemente disponíveis para formar pequenas unidades altamente despolimerizada tais como os anéis $\mathrm{Al}_{6} \mathrm{O}_{18}$ presentes no aluminato tricálcico. 
Morikawa et al. (1983) investigaram a estrutura de curto alcance do vidro $12 \mathrm{CaO} 7 \mathrm{Al}_{2} \mathrm{O}_{3}(63 \mathrm{~mol} \%$ de $\mathrm{CaO})$ usando a função distribuição radial. A conclusão é de que todos os íons de alumínio no vidro estão na coordenação tetraédrica. $O$ número de coordenação dos átomos de $\mathrm{Al}$ e $\mathrm{Ca}$ é 4.2 e 5.6 respectivamente. Baseados nos cálculos sobre os vários modelos cristalinos é concluído que a estrutura contém camadas de tetraedros de alumínio/oxigênio, com os íons de $\mathrm{CaO}$ ocupando os interstícios na estrutura. Embora não façam menção de oxigênios nonbridging, a sua ilustração esquemática da estrutura do modelo cristalino indica que oxigênios nonbridging ocorre entre as camadas da estrutura.

Huang e Behrman (1991) reportam sobre a estrutura e propriedades dos vidros aluminosilicatos de cálcio. Nesse trabalho são preparados vidros em diferentes intervalos de composições ( 0 - $39 \mathrm{~mol} \% \mathrm{Al}_{2} \mathrm{O}_{3}, 13-65 \mathrm{~mol} \% \mathrm{CaO}, 10-75 \mathrm{~mol} \%$ de $\mathrm{SiO}_{2}$ ), cujo enfoque é dado à razão $\mathrm{Al}_{2} \mathrm{O}_{3} / \mathrm{CaO}$, em que a concentração de $\mathrm{SiO}_{2}$ é mantida constante. Com base nos resultados de volume molar de oxigênios, densidade, índice de refração e espectro de infravermelho os autores explicam a estrutura desses vidros. Os autores supõem que a coordenação do alumínio é tetraédrica, e os íons de $\mathrm{Ca}$ estão associados ao tetraedro $\left(\mathrm{AlO}_{4}\right)^{-}$ para compensar o excesso de carga. Para os íons de $\mathrm{Ca}$ estarem associados ao tetraedo alumínio-oxigênio, durante o processo de formação do vidro, os íons de cálcio devem estar difusos nas proximidades dos íons de alumínio. Se a razão molar $\mathrm{Al}_{2} \mathrm{O}_{3} / \mathrm{CaO}$ for menor que 1 é possível que alguns tetraedros alumínio-oxigênio não estejam associados aos íons de cálcio. $O$ excesso de carga pode ser compensado pela formação de oxigênios ligados triplamente e/ou vacâncias de oxigênio. Se a razão de $\mathrm{Al}_{2} \mathrm{O}_{3} / \mathrm{CaO}$ for baixa, haverá maior excesso de $\mathrm{Ca}$ no vidro quando aumentar-se o teor de sílica. Se esta razão aumentar, a quantidade de Ca diminuirá consequentemente. A idéia fundamental é de que o óxido de cálcio quebra a rede do vidro e fornece oxigênios "livres" para "intermediar" o óxido de alumínio, a fím de que o óxido de alumínio seja coordenado tetraedralmente.

Dutt et al (1992) reportam um modelo estrutural para vidros aluminosilicatos de cálcio com baixa concentração de sílica a fím de explicar o valor máximo em $\mathrm{T}_{\mathrm{g}}$ observado em composições com 5 a $15 \mathrm{~mol} \%$ de $\mathrm{SiO}_{2}$. Os autores sugerem que a adição de $\mathrm{SiO}_{2}$ ao vidro diminui o número de oxigênios non-bridging, [NBO], por tetraedro $\left(\mathrm{AlO}_{4}\right)^{-}[\mathrm{T}]$, dado por: 


$$
\frac{[\mathrm{NBO}]}{T}=\frac{2[\mathrm{Ca}]-[\mathrm{Al}]}{[\mathrm{Si}]+[\mathrm{Al}]}
$$

As quantidades em colchetes indicam o número de constituintes. Outro fato que os autores levam em consideração é a intensidade média das ligações que aumenta, já que a ligação Si-O é mais forte do que a ligação $\mathrm{Al}-\mathrm{O}$ e portanto $\mathrm{T}_{\mathrm{g}}$ inicialmente aumenta devido a uma maior intensidade média das ligações e uma maior média da polimerização, isto é, número médio de oxigênios por tetraedro. Referindo-se ao artigo reportado por Hosono et al. (1987a) os autores assumem que a adição de $\mathrm{SiO}_{2}$ tende a reduzir o número de ligações peroxi ou íons peróxidos, e por esta razão os íons rejeitados podem inicialmente aparecer na forma de radicais superoxidos $O_{2}^{-}$. Levando isso em consideração os autores concluem que a concentração de $O_{2}^{-}$pode ser um indicador para a mudança estrutural que aparece no vidro, cujo comportamento pode pode estar relacionado a $\mathrm{T}_{\mathrm{g}}$. Além disso as condições de preparo das amostras influenciam a concentração de $O_{2}^{-}$, sendo menor para as amostras que foram previamente sinterizadas antes da fusão.

McMillan et al. (1996) investigaram a estrutura dos vidros aluminato de cálcio via ${ }^{27} \mathrm{Al}$ MAS-NMR. As amostras preparadas em um forno solar com taxas resfriamento de $10^{6}-10^{7}$ ${ }^{0} \mathrm{C} / \mathrm{s}$, e $200-300{ }^{0} \mathrm{C} / \mathrm{s}$. Os vidros resfriados rapidamente e cuja razão $\mathrm{CaO}: \mathrm{Al}_{2} \mathrm{O}_{3}<1$, além da coordenação do $\mathrm{Al}$ que é tetraédrica, possuem também $\mathrm{Al}$ que são coordenados por cinco e seis oxigênios. Os vidros cuja composição é $\mathrm{CaO}-\mathrm{CaAl}_{2} \mathrm{O}_{4}$ são coordenados apenas tetraedricamente. É sugerido que o deslocamento químico isotrópico médio destes vidros, que aumenta com a concentração de $\mathrm{CaO}$, pode ser devido ao estado de despolimerização das unidades aluminato. Os vidros resfriados rapidamente mostram uma estrutura menos ordenada e mais distorcida.

Kens et al. (1998) reportam um trabalho complementar ao de McMillan et al. (1996) investigando a coordenação de vidros aluminato de cálcio preparados pelo método de fusão convencional e pelo método sol-gel. Usando também a técnica de ${ }^{27} \mathrm{Al}$ MAS-NMR, os autores encontraram resultados iguais aos de Mcmillan para os vidros preparados por fusão, ou seja, os átomos de Al são coordenados tetraedricamente. Por outro lado, as amostras preparadas via sol-gel, possui átomos de $\mathrm{Al}$ coordenados tanto tetraedricamente quanto octaedricamente. No 
caso da coordenação octraédrica é observada uma dependência com o teor de hidroxila, ou seja, a medida em que diminui-se o teor de $\mathrm{OH}$ a coordenação octaédrica tende a zero. É concluído que a alta coordenação dos átomos de alumínio nos derivados sol-gel deve-se ao teor de hidroxila, e conseqüentemente, não existe diferença substancial entre os vidros preparados por fusão convencional, daqueles preparados pelo método sol-gel.

Hannon e Parker (2000) investigaram a estrutura dos vidros aluminato por meio de difração de nêutrons. Duas componsições do sistema binário $\mathrm{CaO}-\mathrm{Al}_{2} \mathrm{O}_{3}$ foram preparadas com 30 e $38 \mathrm{~mol} \%$, respectivamente. Conclui-se que o alumínio é tretraedralmente coordenado pelo oxigênio. Não há evidência da presença de átomos de $\mathrm{Al}$ em coordenações mais altas. Os átomos de cálcio são coordenados por quatro átomos de oxigênio em distâncias bem definidas de $2.34 \AA$. Há também uma coordenação adicional a longa distância, e um número de coordenação seis para o $\mathrm{Ca}-\mathrm{O}$ parece ser provável.

A estrutura e propriedades de vidros aluminosilicato de cálcio com baixa concentração de silica são reportadas por Cormier et al. (2000). este trabalho complementa o reportado por Hannon e Parker (2000) já que são utilizadas difração de raios-X e difração de nêutrons, com a diferença que neste trabalho as amostras investigadas contém $\mathrm{SiO}_{2}$. É concluído que a rede vítrea é baseada no tetraedro $\mathrm{SiO}_{4}$ e $\mathrm{AlO}_{4}$, e que os átomos de $\mathrm{Ca}$ estão em sítios octaedrais promovendo a compensação de cargas próximo ao $\mathrm{Al}$. Com a adição de sílica não há mudança estrutural abrupta para os vidros que possuem um $\mathrm{T}_{\mathrm{g}}$ mais alto, o que indica que a variação nas propriedades destes vidros com a adição de sílica não é devida as mudanças do ambiente em torno dos átomos de Si. Encontrou-se coordenação 4.7 para os átomos de Ca com os átomos de oxigênio situados a uma distância de $2.35 \AA$.

Recentemente Petkov et al. (2000) investigaram a conectividade de rede de vários vidros aluminosilicato de cálcio, com composição $\mathrm{Ca}_{x / 2} \mathrm{Al}_{x} \mathrm{Si}_{1-x} \mathrm{O}_{2}(x=0,0.25,0.5,0.67)$. Os autores reportam que a conectividade do tetraedro da rede, $\mathrm{Si} / \mathrm{Al}-\mathrm{O}$, diminui com o aumento de $x$ devido aos oxigênios nonbridging localizados no tetraedro $\mathrm{Si}-\mathrm{O}$. Os átomos de cálcio mantêm a coordenação esférica para todos os valores de $x$, e de certa forma desempenham papel determinante na estrutura do vidro. Os resultados da análise do número de coordenação médio do $\mathrm{Si}-\mathrm{O}$ e $\mathrm{Al}-\mathrm{O}$, indicam que tanto os átomos de $\mathrm{Si}$ quanto os de $\mathrm{Al}$ possuem quatro oxigênios na sua vizinhança quando a razão $\mathrm{Al} / \mathrm{Ca}$ é baixa $(x=0,0.25)$. Para $x=0.5$ a rede 
começa a "quebrar" quando uma leve diminuição no número de coordenação médio do Si ocorre. Este resultado suporta a idéia de que oxigênios nonbridging podem estar presentes nos vidros aluminosilicatos mesmo se não exigidos pela estequiometria. Quando mais da metade dos íons de Si são substituídos pelo $\mathrm{Al}(x=0.67)$ o número de oxigênios nonbridging na primeira esfera de coordenação do Si aumenta ainda mais, fazendo com que a coordenação média do Si-O seja menor que 3.2. O tetraedro Al-O, entretanto, permanece livre de oxigênios nonbridging. Os resultados sugerem que a desintegração dos tetraedros da rede deve-se principalmente pela criação de ligações Si-O-Ca e não de ligações Al-O-Ca. Além disso os autores afirmam que os resultados não implicam que os tetraedros Si-O sejam deficientes de oxigênios, mesmo em altas concentrações de cálcio.

Shelby et al. (1989) investigaram a adição de fluoreto de cálcio no sistema binário $\mathrm{CaO}: \mathrm{Al}_{2} \mathrm{O}_{3}$, cujo objetivo era verificar a possibilidade do fluoreto reagir com o hidrogênio presente na fusão e formar HF, que evapora, e consequentemente diminui a concentração de radicais $\mathrm{OH}^{-}$. A composição do vidro base variou de 59 a $70 \mathrm{~mol} \%$ de $\mathrm{Cao}$, com o $\mathrm{CaF}_{2}$ substituindo o $\mathrm{CaO}$. É concluído que a adição de fluoreto nos vidros promove apenas uma pequena redução na concentração de $\mathrm{OH}^{-}$, não o suficiente para produzir vidros livres de hidroxilas. A substituição de $\mathrm{CaF}_{2}$ pelo $\mathrm{CaO}$ resulta em um decréscimo na viscosidade, indice de refração e $T_{g}$ e um aumento da expansão térmica.

Shelby et al. (1990) investigaram a adição de gálio no sistema binário aluminato de cálcio com o objetivo de deslocar o corte na transmitância do infravermelho para comprimentos de ondas mais longos, já que os íons de gálio são mais pesados e possuem uma intensidade de campo maior que as dos íons de alumínio. A adição de $\mathrm{Ga}_{2} \mathrm{O}_{3}$ no sistema aluminato de cálcio binário promove um deslocamento no corte de transmitância na região do infravermelho de 5.95 para $6.5 \mu \mathrm{m}$, a temperatura de transformação vítrea, $T_{\mathrm{g}}$, diminui, enquanto que o coeficiente de expansão térmica, índice de refração, densidade aumentam.

Shelby e Wierzbicki (1995) investigaram a adição de $\mathrm{Na}_{2} \mathrm{O}$ nos vidros aluminato de cálcio com composições variando de 0 a $10 \mathrm{~mol} \%$ de $\mathrm{Na}_{2} \mathrm{O}, 50$ a $70 \mathrm{~mol} \%$ de $\mathrm{CaO}$ e 30 a 44 mol\% de $\mathrm{Al}_{2} \mathrm{O}_{3}$. Os resultados dessa investigação indicam que a habilidade de formação de vidro neste sistema é independente da concentração de soda até diminuir rapidamente próximo a $10 \mathrm{~mol} \%$ de $\mathrm{Na}_{2} \mathrm{O}$. A cristalização nos vidros contendo menos que 10 mol\% de soda resulta 
na formação de fases idênticas às encontradas no sistema aluminato de cálcio binário. A substituição de $\mathrm{CaO}$ por $\mathrm{Na}_{2} \mathrm{O}$ diminui $\mathrm{T}_{\mathrm{g}}$ por aproximadamente $100 \mathrm{~K}$, com decréscimo menores na densidade e índice de refração, e um pequeno aumento na expansão térmica.

King e Shelby (1996) reportam sobre os vidros aluminato de cálcio com estrôncio. A conclusão deste trabalho é óxido de Sr promove uma modesta melhora na tendência de formação de vidro. A temperatura de transição vítrea diminui suavemente com o aumento da concentração de SrO.

Fonder e Mitchel (1998) investigaram os efeitos dos método de preparação dos vidros aluminato de cálcio próximos à temperatura solidus e na presença de tensão mecânica. Usando espectroscopia de refletância é possível verificar que não ocorre distorção do tetraedro $\mathrm{AlO}_{4}$ quando as amostras são resfriadas pelo método de splat-quenching, e por outro lado ocorre distorção desses tetraedros quando as amostras são resfriadas em ar fibras são puxadas.
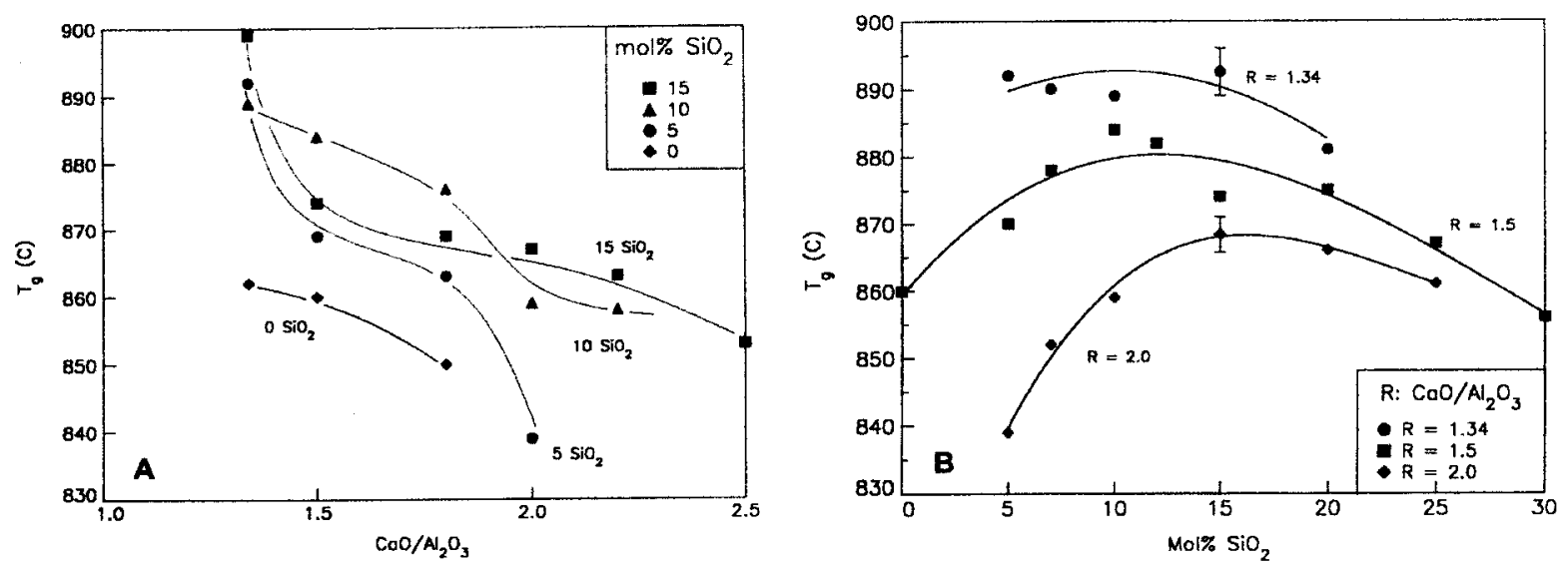

Figura 2.10 - A) Efeito da razão $\mathrm{CaO} / \mathrm{Al}_{2} \mathrm{O}_{3}$ sobre $\mathrm{T}_{\mathrm{g}}$ para várias concentrações de sílica. B) Efeito da concentração de sílica sobre $\mathrm{T}_{\mathrm{g}}$ para $\mathrm{CaO} / \mathrm{Al}_{2} \mathrm{O}_{3}$ constante. Linhas desenhadas para guiar os olhos (Higby et. al, 1990).

A possibilidade de melhorar a habilidade de formação de vidros aluminato de cálcio através da adição de óxidos alcalinos e alcalinos terrosos na composição do sistema binário foi investigada por Uhlmann et al. (1993). As composições desse estudo não continham sílica. $O$ corte na transmissão na região do infravermelho foi de $6.25 \mu \mathrm{m}$. A adição de elementos alcalinos e alcalinos terrosos na composição dos vidros pode melhorar bastante a habilidade de formação de vidro e estabilizá-los evitando a cristalização. 
A formação e propriedades térmicas de vidros aluminatos de cálcio com baixa concentração de sílica, < $25 \mathrm{~mol} \%$, foram investigadas por Higby et al. (1990). O enfoque deste trabalho é dado aos vidros cujas composições a razão molar $\mathrm{CaO} / \mathrm{Al}_{2} \mathrm{O}_{3}$ é mantida constante e varia-se a concentração de $\mathrm{SiO}_{2}$. No caso da temperatura de transição vítrea é verificado que para uma dada concentração de silica, e um aumento da razão $\mathrm{CaO} / \mathrm{Al}_{2} \mathrm{O}_{3}$ ocorre uma diminuição em $\mathrm{T}_{\mathrm{g}}$. Por outro lado quando adiciona-se sílica ao sistema binário, ocorre um máximo em $\mathrm{T}_{\mathrm{g}}$ em aproximadamente $15 \mathrm{~mol} \%$ de $\mathrm{SiO}_{2}$. Esses dados são mostrados na figura 2.10, enquanto que na figura 2.11 é mostrado o comportamento do índice de refração e da viscosidade em função da razão de $\mathrm{CaO} / \mathrm{Al}_{2} \mathrm{O}_{3}$ e concentração de $\mathrm{SiO}_{2}$.
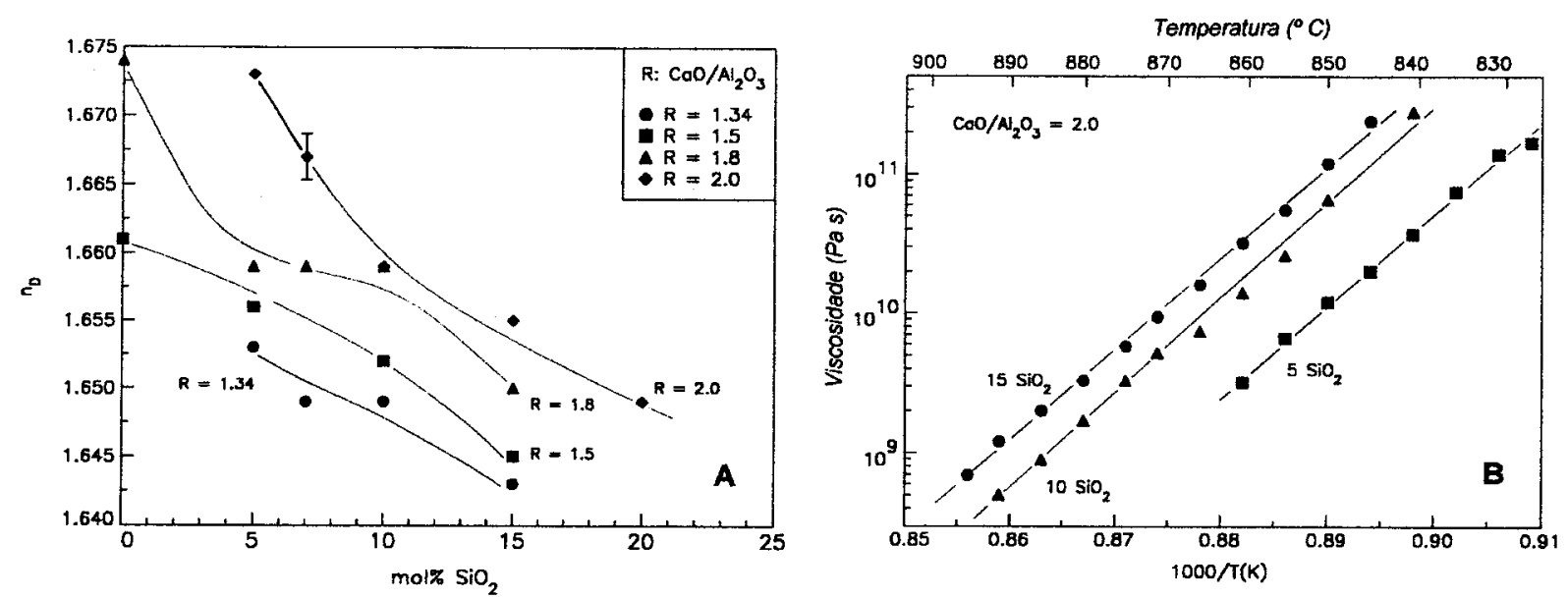

Figura 2.11 - A) Efeito da concentração de sílica sobre o índice de refração com várias razões de $\mathrm{CaO} / \mathrm{Al}_{2} \mathrm{O}_{3}$ (linhas desenhadas para guiar os olhos). B) Viscosidade para várias concentrações de $\mathrm{SiO}_{2}$ com a razão $\mathrm{CaO} / \mathrm{Al}_{2} \mathrm{O}_{3}=2.0$. As linhas são ajustes lineares Arrhenian determinado pelo ajuste dos quadrados mínimos dos dados mostrados (Higby et al., 1990).

Através do ajuste linear da viscosidade, valores entre $10^{12}$ e $10^{8}$ Poise, determinou-se o valor da energia de ativação do fluxo viscoso, que varia de 1300 a $1700 \mathrm{~kJ} / \mathrm{mol}$, muito maior do que os vidros com alta concentração de sílica, como por exemplo no vidro borosilicato NBS 717 que tem uma energia de ativação de $525 \mathrm{~kJ} / \mathrm{mol}$.

Com base no artigo de MacMillan e Pirou (1983), conclui-se que com o aumento da razão $\mathrm{CaO} / \mathrm{Al}_{2} \mathrm{O}_{3}$ ocorre também um aumento da concentração de oxigênios non-bridging, o que causa um decréscimo em $T_{g}$ e um aumento no índice de refração. $O$ papel da sílica na 
estrutura dos vidros aluminato de cálcio depende da concentração de $\mathrm{SiO}_{2}$ e da razão $\mathrm{CaO} / \mathrm{Al}_{2} \mathrm{O}_{3}$.

Shelby (1985) investiga a formação de vidros aluminato de cálcio, bem como a expansão térmica, $T_{g}$, temperatura de amolecimento dilatométrico, $T_{d}$, e índice de refração. $O$ autor discute os resultados em termos do modelo de estrutural e inclui a possibilidade de separação de fases em certas regiões do diagrama ternário. São preparados vidros com alta e baixa concentração de sílica, com temperatura de fusão entre $1400{ }^{\circ} \mathrm{C}$ e $1600{ }^{\circ} \mathrm{C}$. A expansão térmica para vidros com baixa concentração de sílica, $<10 \mathrm{~mol} \%$, é de $8-10 \times 10^{-6} /{ }^{0} \mathrm{C}$, resultado que se repete quando mantém-se a concentração de sílica constante e varia-se a razão molar $\mathrm{CaO} / \mathrm{Al}_{2} \mathrm{O}_{3}$ de 0.66 para 1.5 . Shelby observa um mínimo em $\mathrm{T}_{\mathrm{g}}$ para vidros com aproximadamente $5 \mathrm{~mol} \%$ de $\mathrm{SiO}_{2}$ e sugere que esta seja uma indicação de mudança abrupta na estrutura ou morfologia do vidro quando a concentração de $\mathrm{SiO}_{2}$ está entre 0 e 5 mol\%. A temperatura de transformação vítrea, $T_{g}$, de duas composições binárias são aproximadamente iguais, $804{ }^{\circ} \mathrm{C}$. A diferença $\left(\mathrm{T}_{\mathrm{d}}-\mathrm{T}_{\mathrm{g}}\right.$ ) aumenta abruptamente próximo a $5 \mathrm{~mol} \%$ de $\mathrm{SiO}_{2}$. Baseado em outros sistemas vítreo, Shelby, afirma que este comportamento é frequentemente uma indicação de separação de fases. Finalmente o autor sugere que os vidros com concentrações menores que $5 \mathrm{~mol} \%$ de $\mathrm{SiO}_{2}$ situa-se em uma região de imiscibilidade.

Lines et al. (1989) investigaram a pontencialidade dos vidros aluminato de cálcio como materiais ópticos com perdas ultra baixas. As perdas totais (Rayleigh, Brillouin e Raman) foi de aproximadamente $0.04 \mathrm{~dB} / \mathrm{km}$ em $1.5 \mu \mathrm{m}$, com uma atenuação mínima projetada para as amostras sem sílica menor que $0.015 \mathrm{~dB} / \mathrm{km}$ em $1.9 \mu \mathrm{m}$. Os autores discutem ainda sobre as possibilidades de produzir preformas usando métodos convencionais de deposição por vapor e concluem que ainda há necessidade de muitos estudos até obter fibras dos vidros aluminato de cálcio. Complementar a esse trabalho, Hwa (1998), investiga uma série de vidros aluminato de cálcio variando a concentração de $\mathrm{SiO}_{2}$, e verifica também que as perdas desses vidros é menor do que os observados na sílica fundida, variando de 0.020 a $0.036 \mathrm{~dB} / \mathrm{km}$, em $1.9 \mu \mathrm{m}$, enquanto que do $\mathrm{SiO}_{2}$ é de $0.144 \mathrm{~dB} / \mathrm{km}$. 


\subsection{Terras raras em vidros aluminato de cálcio}

Ao analisarmos os vários trabalhos publicados sobre vidros aluminato de cálcio, notaremos que há pouco mais de uma dezena deles referindo-se a estes vidros dopados com elementos terras raras. $\mathrm{O}$ primeiro artigo tratando de $\mathrm{Nd}^{3+}$ em vidros aluminato de cálcio (52 $\mathrm{CaO}, 32 \mathrm{Al}_{2} \mathrm{O}_{3}, 11 \mathrm{SiO}_{2}, 5 \mathrm{BaO}$, em mol\%) foi reportado por Jacobs e Weber (1976). Nesse artigo é investigada a dependência da seção transversal de emissão induzida do nível ${ }^{4} \mathrm{~F}_{3 / 2} \rightarrow$ ${ }^{4} I_{11 / 2}$ de vários sistemas vítreos, inclusive o aluminato de cálcio, porém a discussão é enfatizada apenas nos resultados de vidros silicatos e fosfatos. Apenas no início da década de 90 é que foi dada uma maior atenção a esse sistema vítreo dopados com íons terras-raras. Zou e Izumitami (1993a) reportam sobre a transferência de energia de excitação do $\mathrm{Nd}^{3+}-\mathrm{Yb}^{3+}-\mathrm{Er}^{3+}$ em vários sistemas vítreos. $\mathrm{O}$ processo de transferência de energia entre os íons de $\mathrm{Nd}^{3+}, \mathrm{Yb}^{3+}$ e $\mathrm{Er}^{3+}$ são investigados através do espectro de fluorescência e decaimento do tempo de vida. Os resultados são interpretados com base no modelo cinético que descreve as interações entre os íons terra raras em termos dos microparâmetros caracterizando as probabilidades de migração de energia. A eficiência de transferência de energia do $\mathrm{Nd}^{3+} \rightarrow \mathrm{Yb}^{3+}$ aumenta na seguinte ordem: fosfatos $<$ fluorofosfatos $<$ germanatos $<$ silicatos $<$ aluminatos. As características espectroscópicas e a dinâmica da transferência de energia do $\mathrm{Nd}^{3+} \rightarrow \mathrm{Yb}^{3+} \mathrm{e}$ $\mathrm{Yb}^{3+} \rightarrow \mathrm{Er}^{3+}$ em vidros aluminato $\left(36 \mathrm{CaO}, 48 \mathrm{Al}_{2} \mathrm{O}_{3}-8 \mathrm{MgO}-8 \mathrm{BaO}, \mathrm{x} \mathrm{Nd}_{2} \mathrm{O}_{3}, \mathrm{y} \mathrm{Yb}_{2} \mathrm{O}_{3}, \mathrm{z}\right.$ $\mathrm{Er}_{2} \mathrm{O}_{3}$, em mol\%) é reportada por Zou e Izumitami (1993b). A conclusão é de que a alta eficiência de transferência de energia, próxima a $100 \%$, do $\mathrm{Nd}^{3+}$ para o $\mathrm{Yb}^{3+}$ pode ser devido a uma boa superposição espectral da fluorescência do $\mathrm{Nd}^{3+}$ e da absorção do $\mathrm{Yb}^{3+}$. A eficiência da fluorescência dos vidros dopados com $\mathrm{Yb}^{3+}$ sensibilizado pelo $\mathrm{Nd}^{3+}$ é maior do que o vidro

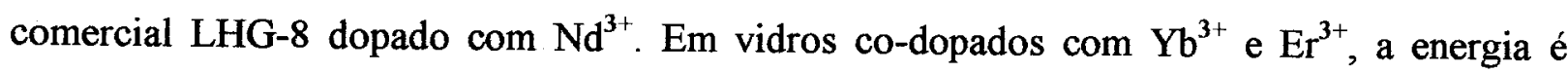
transferida em ambas as direções $\mathrm{Yb}^{3+} \leftrightarrow \mathrm{Er}^{3+}$. A energia de volta transferida do $\mathrm{Er}^{3+}$ para o $\mathrm{Yb}^{3+}$ esvazia a população dos estados excitados ${ }^{4} \mathrm{~S}_{3 / 2},{ }^{4} \mathrm{I}_{11 / 2} \mathrm{e}^{4} \mathrm{I}_{13 / 2}$. A conclusão desse estudo é de que os vidros dopados com $\mathrm{Er}^{3+}$ e sensibilizados por $\mathrm{Yb}^{3+}$ e $\mathrm{Nd}^{3+}$ não são bons candidatos para laser de érbio em $1.54 \mu \mathrm{m}$. Em complemento a esses trabalhos Zou e Izumitani (1993c) estudaram as propriedades espectroscópicas e os mecanismos de absorção do estado excitado 
(ESA) e a transferência de energia por conversão ascendente de vidros dopados com $\mathrm{Er}^{3+}$, a discusão é enfatizada nos resultados de vidros aluminato de cálcio e galatos. As intensidades da fluorescência por conversão ascendente originam-se do nível ${ }^{4} \mathrm{~S}_{3 / 2}$ e ${ }^{4} \mathrm{~F}_{9 / 2}$ e a fluorescência Stokes das transições ${ }^{4} \mathrm{I}_{11 / 2} \rightarrow{ }^{4} \mathrm{I}_{15 / 2}$ e ${ }^{4} \mathrm{I}_{11 / 2} \rightarrow{ }^{4} \mathrm{I}_{13 / 2}$ são principalmente dominadas por relaxações multi-fônons que são determinadas pela energia de fônons do vidro matriz, que aumenta da seguinte forma: Fluoretos $\left(500 \mathrm{~cm}^{-1}\right)<$ Galatos $\left(660 \mathrm{~cm}^{-1}\right)<$ Aluminatos $\left(780 \mathrm{~cm}^{-}\right.$ $\left.{ }^{1}\right)<$ Fluorofosfatos $\left(630-1060 \mathrm{~cm}^{-1}\right)<$ Germanatos $\left(820 \mathrm{~cm}^{-1}\right)<$ Silicato $\left(1100 \mathrm{~cm}^{-1}\right)<$ fosfatos $\left(1300 \mathrm{~cm}^{-1}\right)$. As fluorescências anti-Stokes no verde e vermelho provenientes dos níveis ${ }^{4} \mathrm{~S}_{3 / 2}$ e ${ }^{4} \mathrm{~F}_{9 / 2}$, obtidas por excitação no infravermelho do nível ${ }^{4} \mathrm{I}_{9 / 2}$ do $\mathrm{Er}^{3+}$, são principalmente atribuídas, no caso dos vidros aluminatos e galatos, ao estado excitado de absorção do nível ${ }^{4} \mathrm{I}_{13 / 2}$ e a transferência de energia por conversão ascendente do nível ${ }^{4} \mathrm{I}_{13 / 2}$, respectivamente. Quando a excitação é produzida no nível ${ }^{4} \mathrm{I}_{11 / 2}$, entretanto, a fluorescência por conversão ascendente dos níveis ${ }^{4} \mathrm{~S}_{3 / 2}$ e ${ }^{4} \mathrm{~F}_{9 / 2}$ são resultantes principalmente da transferencia de energia por conversão ascendente dos níveis ${ }^{4} \mathrm{I}_{11 / 2}$ e ${ }^{4} \mathrm{I}_{13 / 2}$, respectivamente.

Tanabe et al. (1993) discutem a respeito da conversão ascendente e estrutura local de vidros aluminato dopados com $\mathrm{Er}^{3+}$. Entre os três parâmetros de intensidade Judd-Ofelt $\Omega_{2} \mathrm{e}$ $\Omega_{4}$ mostram valores maiores comparados a outros vidros óxidos dopados com $\mathrm{Er}^{3+}$ indicando uma probabilidade de transição maior da absorção em $650 \mathrm{~nm}$. Através da técnica de espectroscopia Mössbauer encontrou-se que o número de coordenação dos íons terras raras neste vidro é de aproximadamente 7 com baixa simetria. A energia de fồnons de $800 \mathrm{~cm}^{-1}$ foi atribuída à vibração dos grupos $\mathrm{AlO}_{4}$ ligados aos íons terras raras no vidro, o resulta em uma menor taxas de decaimento multi-fồnons em relação aos vidros silicatos. A fluorescência em $550 \mathrm{~nm}$ por conversão ascendente foi observada através de um laser de bombeio operando em $650 \mathrm{~nm}$. A observação da conversão ascendente no verde é possível devido a uma larga probabilidade de transição do nível ${ }^{4} \mathrm{~F}_{9 / 2} \leftarrow{ }^{4} \mathrm{I}_{15 / 2}$ e também devido a um mecanismo de absorção do estado excitado do nível ${ }^{4} \mathrm{I}_{13 / 2}$ para o nível ${ }^{4} \mathrm{~F}_{5 / 2}$.

As propriedades espectroscópicas de vidros aluminato de cálcio dopados com $\mathrm{Nd}^{3+}$ foram investigadas por Uhlmann et al. (1994), os quais concluem que estes vidros são candidatos interessantes como novos materiais para laser devido a sua alta eficiência quântica e alta probabilidade de transição total, o que sugere que a ação laser efetiva seja possível. 
Uma vez que as amostras investigadas tinham apenas uma concentração fixa de $\mathrm{Nd}_{2} \mathrm{O}_{3}, 0.5$ mol\%, e a fusão ocorreu ao ar, os autores sugerem investigações para determinar o "quenching" da fluorescência e estudar o efeito da remoção de OH dos vidros. Esse estudo foi feito posteriormente por Pecoraro et al. (2000).

$\mathrm{A}$ análise da fluorescência de vidro aluminato de cálcio na razão $50 \% \mathrm{CaO}-50 \% \mathrm{Al}_{2} \mathrm{O}_{3}$ dopado com $\mathrm{Nd}^{3+}$ foi investigada por Paradis et al. (1997). O processo de preparação de amostras é um tanto quanto complexo já que envolve sinterização, prensagem e fundição através de laser de $\mathrm{CO}_{2}$ operando em $10.6 \mu \mathrm{m}$. As amostras são obtidas na forma de esferas de 2-4 $\mathrm{mm}$ de diâmetro. Os resultados indicam que os vidros aluminato de cálcio $50 \% \mathrm{CaO}$ $50 \% \mathrm{Al}_{2} \mathrm{O}_{3}$ possuem uma fluorescência máxima, para a transição ${ }^{4} \mathrm{~F}_{3 / 2} \rightarrow{ }^{4} \mathrm{I}_{11 / 2}$, em $1067 \mathrm{~nm}$ quando excitado por um laser de diodo em $810 \mathrm{~nm}$. O decaimento da fluorescência do nível ${ }^{4} \mathrm{~F}_{3 / 2}$ é muito curto, $<0.3 \mathrm{~ms}$. Uma das possíveis aplicações para os vidros esféricos produzidos seria usá-los como laseres esféricos.

$\mathrm{O}$ fenômeno de fosforescência de longa duração em vidros baseados em $\mathrm{CaO}-\mathrm{Al}_{2} \mathrm{O}_{3}$ $\mathrm{B}_{2} \mathrm{O}_{3}$ dopado com $\mathrm{Eu}^{2+}$ foi reportado por Qiu e Hirao (1998). O papel do $\mathrm{B}_{2} \mathrm{O}_{3}$ nas amostras foi apenas para melhorar a vitrificação. As amostras após serem irradiadas por lâmpada fluorescente, luz branca, com uma densidade de potência de $2 \times 10^{4} 1 \times$ por $30 \mathrm{~min}$, emitem luz visível cujo pico em $510 \mathrm{~nm}$ pode ser visto a olho nu, no escuro durante $8 \mathrm{~h}$ após a remoção da fonte de luz ativadora. Essa fosforescência de longa duração é atribuída à recombinação dos elétrons e buracos presentes na rede vítrea que podem ser termicamente liberados em temperatura ambiente.

O mecanismo de conversão ascendente de vidros aluminato de cálcio dopados com $\mathrm{Tm}^{3+} \mathrm{e} \mathrm{Nd}^{3+}$, no azul, foi investigado por Chung et al. (1997). A fluorescência por conversão ascendente no azul (480nm) do $\mathrm{Tm}^{3+}$ da transição ${ }^{1} \mathrm{G}_{4} \rightarrow{ }^{3} \mathrm{H}_{6}$ foi observada quando as amostras co-dopadas com $\mathrm{Tm}^{3+} \mathrm{Nd}^{3+}$ foram excitadas em $791 \mathrm{~nm}$. A fluorescência por conversão ascendente é mais eficiente para concentrações de $0.2 \mathrm{~mol} \%$ de $\mathrm{Tm}_{2} \mathrm{O}_{3}$ com 0.1 mol\% de $\mathrm{Nd}_{2} \mathrm{O}_{3}$. A relação entre a intensidade de fluorescência e potência de bombeio sugere que um processo de absorção de dois fótons é requirida para a conversão ascendente, o qual começa com uma excitação simultânea do $\mathrm{Tm}^{3+}$ e $\mathrm{Nd}^{3+}$ para o nível ${ }^{3} \mathrm{H}_{4}$ e ${ }^{4} \mathrm{~F}_{5 / 2}$, respectivamente, pela absorção da luz de bombeio que tem um comprimento de $791 \mathrm{~nm}$. O 
mecanismo é seguido pela absorção do estado excitado do $\mathrm{Tm}^{3+}:{ }^{3} \mathrm{H}_{4} \rightarrow{ }^{1} \mathrm{G}_{4}$ ao absorver a emissão em $1060 \mathrm{~nm}$ da transição $\mathrm{Nd}^{3+}:{ }^{4} \mathrm{~F}_{3 / 2} \rightarrow{ }^{4} \mathrm{I}_{11 / 2}$. A transferência de energia do $\mathrm{Nd}^{3+}$ para o $\mathrm{Tm}^{3+}$ foi confirmada pela diminuição da intensidade da emissão em $1060 \mathrm{~nm}$ e o tempo de vida do nível $\mathrm{Nd}^{3+}:{ }^{4} \mathrm{~F}_{3 / 2}$.

À parte do desenvolvimento da presente tese, foram feitas também algumas investigações paralelas a cerca das propriedades espectroscópicas dos vidros aluminato de cálcio dopados com neodímio, bem como érbio, érbio-itérbio. Pecoraro (1999) em sua tese de doutorado investigou as propriedades espectroscópicas desses vidros dopados com $\mathrm{Nd}^{3+}$, tais como espectro de absorção óptica no ultravioleta, vísivel e infravermelho próximo, espectro de luminescência na região do infravermelho, e decaimento do tempo de vida da fluorescência. $O$ modelo de Judd-Ofelt é usado para a determinação dos parâmetros de intensidade $\left(\Omega_{2}, \Omega_{4}\right.$, e $\Omega_{6}$ ), seção transversal de emissão, tempo de vida radiativo, razão de ramificação (branching ratios), e a eficiência quântica da fluorescência. A eficiência quântica variou de 95 para amostra dopada com 0.5 peso $\%$ de $\mathrm{Nd}_{2} \mathrm{O}_{3}$ até 0.45 para a mostra dopada com 5 peso $\%$ de $\mathrm{Nd}_{2} \mathrm{O}_{3}$ (Pecoraro et al., 2000).

Um dos resultados mais importantes obtido, pelos vários grupos envolvidos, até o presente momento, foi a observação da emissão de luminescência de luz em $2.8 \mu$ m (Souza et al., 1999), abrindo a possibilidade de fazer laseres para aplicações médicas, como cirurgias, ablação, remoção de técidos duros (esmalte de dentes). Laseres nesse comprimento de onda é desejável devido à forte banda de absorção da água em $2.8 \mu \mathrm{m}$, fazendo com que o trauma devido à cirurgia e tempo convalescência seja o menor possível. Souza et al. (2000a) em sua

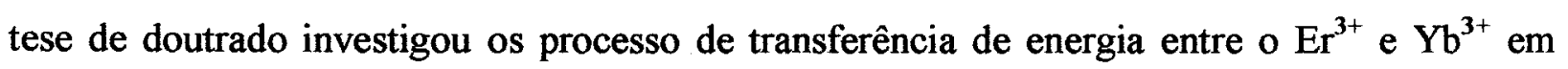
vidros aluminato de cálcio fundidos a vácuo. Concluiu-se desse trabalho que a transferência de energia entre esses íons ocorre em ambas as direções, a constante de transferência de energia para o processo $\mathrm{Yb}^{3+} \rightarrow \mathrm{Er}^{3+}$ é duas vezes maior que o processo inverso devido ao mecanismo dipolo-dipolo (Souza, 2000a). A figura 2.12 mostra o sinal de fotoluminescência do $\mathrm{Er}^{3+} \mathrm{em}^{-1}$ vidros aluminato de cálcio codopado com 2 peso\% de $\mathrm{Yb}_{2} \mathrm{O}_{3}$ e 4 peso $\%$ de $\mathrm{Er}_{2} \mathrm{O}_{3}$. 


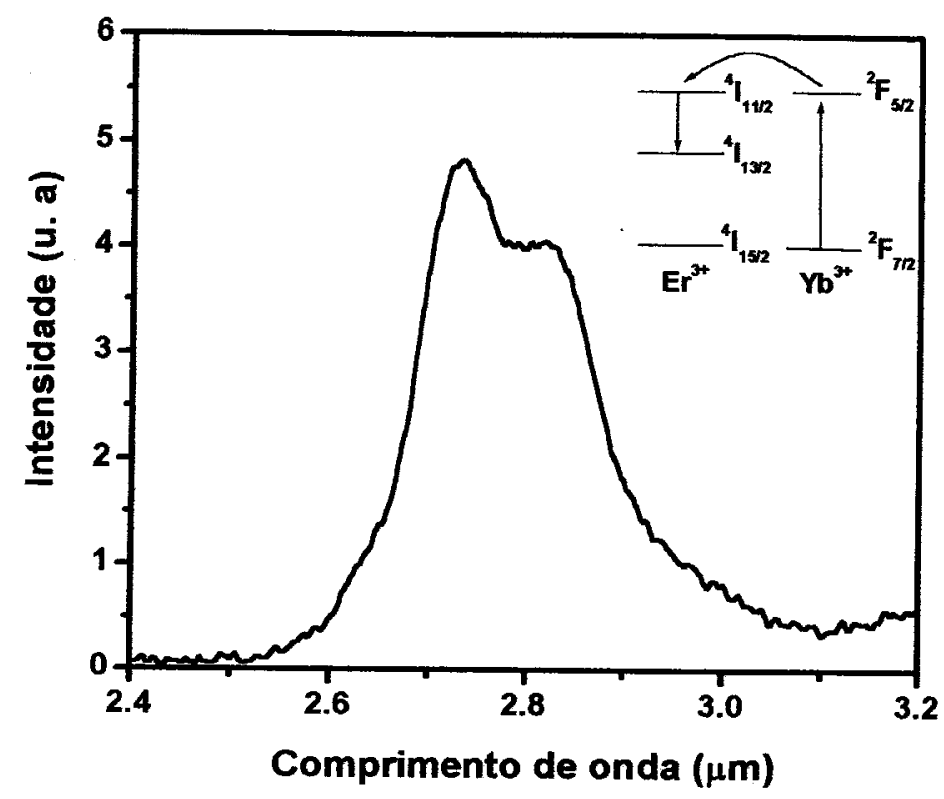

Figura 2.12 - fotoluminescência dos ions de $\mathrm{Er}^{3+}$ de uma amostra de vidro $\mathrm{CaO}: \mathrm{Al}_{2} \mathrm{O}_{3} \mathrm{CO}_{-}$ dopado com 2 peso\% de $\mathrm{Yb}^{3+}$ e 4 peso \% de $\mathrm{Er}^{3+}$. Os niveis de energia associados e o processo de transferência de energia são indicados na figura. A distorção observada no pico próximo a 2.8 um é atribuida a presença de vapor de água do meio ambiente (Souza et al., 1999).

A emissão de luminescência de luz em $2.8 \mu \mathrm{m}$ é atribuída a dois fatores, primeiramente devido ao processo de preparação, já que as amostras foram fundidas a vácuo, o que eliminou a forte banda de absorção que vai desde 2.5 até aproximadamente $4 \mu \mathrm{m}$, e em segundo lugar a energia de fồnons relativamente baixa em relação aos outros sistemas vítreos óxidos, que é de aproximadamente $800 \mathrm{~cm}^{-1}$. Esse resultado é um importante passo para a fabricação de laseres em $2.8 \mu \mathrm{m}$ (Baesso et al., 2001). 


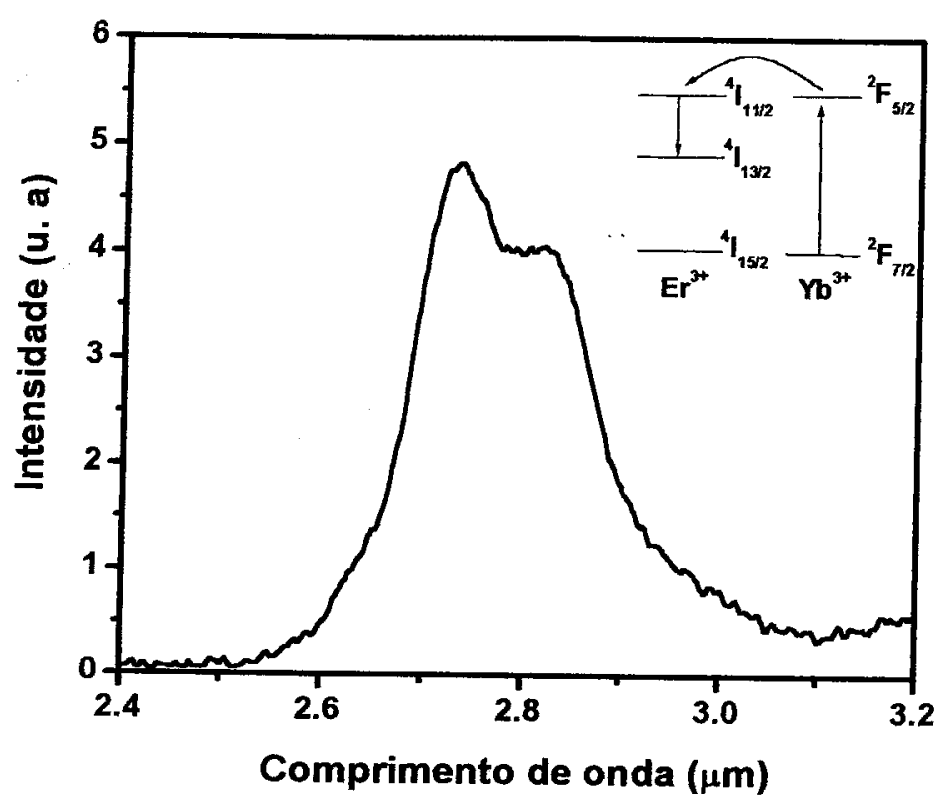

Figura 2.12 - fotoluminescência dos ions de $\mathrm{Er}^{3+}$ de uma amostra de vidro $\mathrm{CaO}: \mathrm{Al}_{2} \mathrm{O}_{3}$ codopado com 2 peso\% de $\mathrm{Yb}^{3+}$ e 4 peso \% de $\mathrm{Er}^{3+}$. Os níveis de energia associados $e$ o processo de transferência de energia são indicados na figura. $A$ distorção observada no pico próximo a 2.8 em é atribuida a presença de vapor de água do meio ambiente (Souza et al.,
1999).

A emissão de luminescência de luz em $2.8 \mu \mathrm{m}$ é atribuída a dois fatores, primeiramente devido ao processo de preparação, já que as amostras foram fundidas a vácuo, o que eliminou a forte banda de absorção que vai desde 2.5 até aproximadamente $4 \mu \mathrm{m}$, e em segundo lugar a energia de fônons relativamente baixa em relação aos outros sistemas vítreos óxidos, que é de aproximadamente $800 \mathrm{~cm}^{-1}$. Esse resultado é um importante passo para a fabricação de laseres em $2.8 \mu \mathrm{m}$ (Baesso et al., 2001). 


\section{Preparação de Amostras}

\subsection{Introdução}

Para obtermos reprodutibilidade de amostras é necessário que a qualidade da matériaprima seja de alta pureza, e as condições de pressão, temperatura e tempo sejam controladas. Descreveremos a seguir os motivos que levaram à construção de uma câmara de vácuo e os procedimentos adotados na preparação das amostras dos vidros aluminato de cálcio dopados

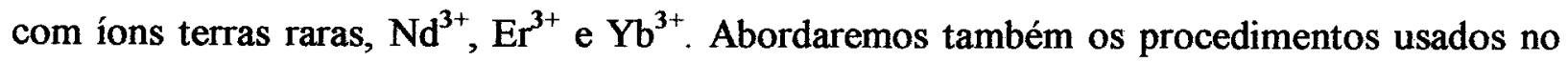
corte e o polimento das amostras.

\subsection{Construção de câmara de vácuo para fusão de amostras de vidros}

O motivo de construírmos um forno com uma câmara a vácuo é a possibilidade de podermos controlar as condições de atmosfera, pressão e temperatura. Nessas condições de fusão podemos conseguir amostras livres de água, que é responsável por uma forte e larga banda de absorção na região do infravermelho, entre 2.8 e $3.5 \mu \mathrm{m}$, fazendo com que qualquer emissão nesse comprimento de onda seja anulada. É justamente nessa região do espectro eletromagnético que se encontra a banda de fluorescência do $\mathrm{Er}^{3+}$, cuja emissão laser é de interesse na medicina. 
Um forno comercial com uma câmara a vácuo é de alto custo financeiro, aproximadamente US $\$ 200,000.00$, enquanto que para construírmos um forno que atendesse às nossas necessidades esse valor foi reduzido à aproximadamente US\$15,000.00.

Como já mencionado anteriormente, o projeto desta tese envolve três grupos de pesquisas, de três universidades diferentes, USP-UNICAMP-UEM. O desenvolvimento de vidros aluminato de cálcio para aplicações na região do infravermelho já é feito no Grupo de Preparação e Caracterização de Materiais desde a década de 80 (Baesso, 1987). E no caso destes vidros dopados com íons terras raras começou em meados dos anos 90 durante a tese de mestrado de Sampaio (1997), no qual foram preparadas amostras de vidros aluminato de cálcio dopadas com $\mathrm{Nd}_{2} \mathrm{O}_{3}$. Naquela ocasião conseguiu-se produzir amostras com boa qualidade óptica até 5\% desse óxido. Entretanto a câmara usada para preparação de amostras estava com muitos problemas de controle de atmosfera, uma vez que esse forno tinha mais de 25 anos de uso, necessitando portanto de uma reforma. Além disso, a câmara existente era projetada para crescimento de cristais para operar até $1000{ }^{\circ} \mathrm{C}$, sendo adaptada para a preparação de amostras de vidro, com alta temperatura de fusão.

Optou-se por fazer uma nova câmara para este forno, marca Varian $\mathrm{NRC}$, modelo 2835 , série 0001 , e ao mesmo tempo construir um outro forno para preparação de amostras na Universidade Estadual de Maringá, de maneira que tivéssemos dois fornos para preparação de amostras. $O$ trabalho de desenvolver esses fornos demandou um tempo relativamente demorado, pois tínhamos que reprojetá-lo de maneira de forma problemas rotineiros fossem sanados.

Um dos grandes problemas era a parte de refrigeração desse forno que era feito basicamente por serpentinas, a não ser pela tampa da parte superior que era feita por uma camisa de água. Decidiu-se fazer paredes duplas para que a refrigeração fosse feita de maneira uniforme, tanto na tampa, quando na parte em torno da câmara e na parte inferior. As janelas para observação foram reduzidas. Nas figuras a seguir serão apresentadas as fotos da câmara de vácuo e as peças de grafite. 


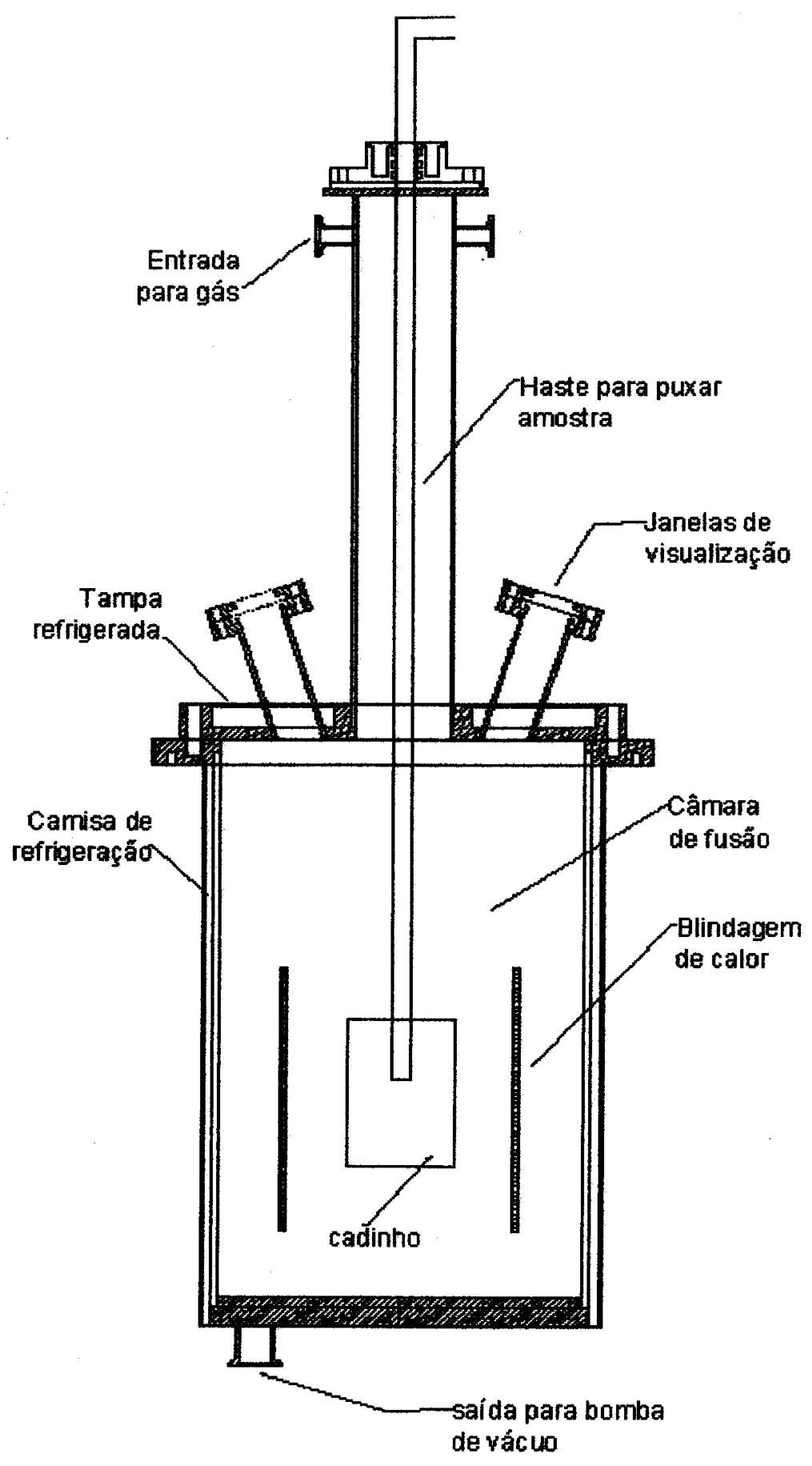

Figura 3.1 - Representação esquemática do forno usado na preparação de amostras feitas a vácuo. 


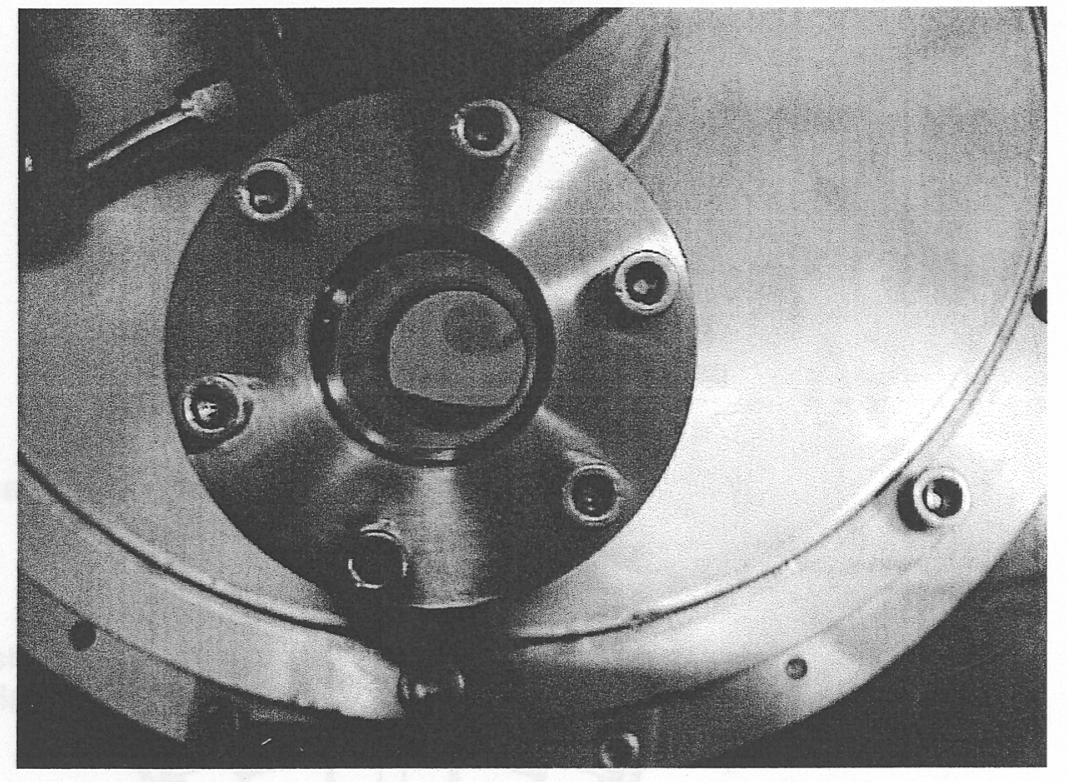

Figura 3.2 - Fotografia da tampa superior do forno em funcionamento através de uma das janelas de quartzo para a observação da amostra

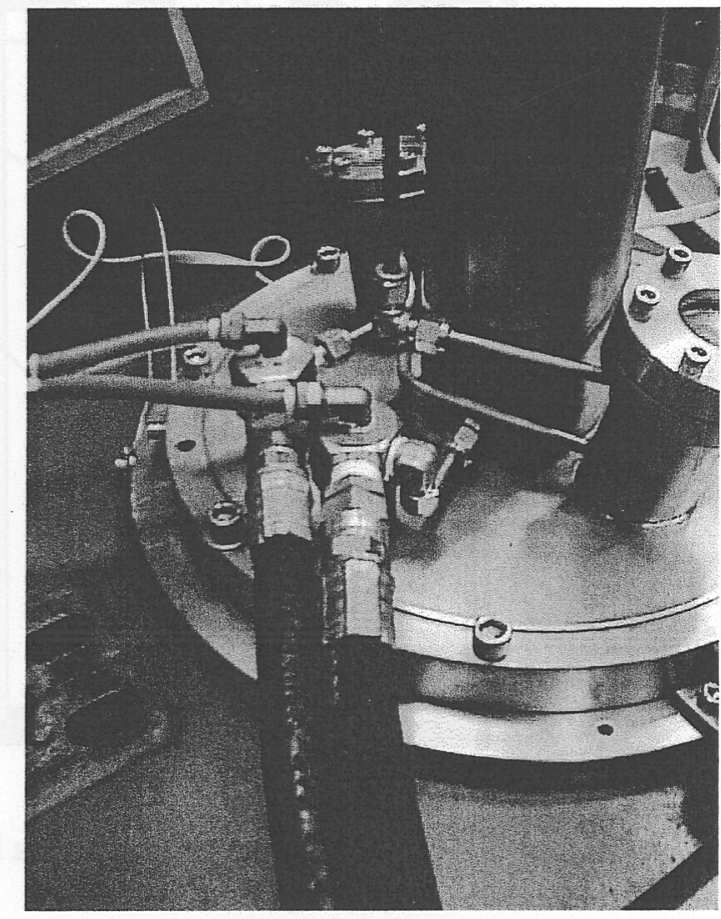

Figura 3.3 - Fotografia da tampa do forno. Entrada de mangueiras para refrigeração da parte superior do forno, inclusive a câmara para choque térmico. 


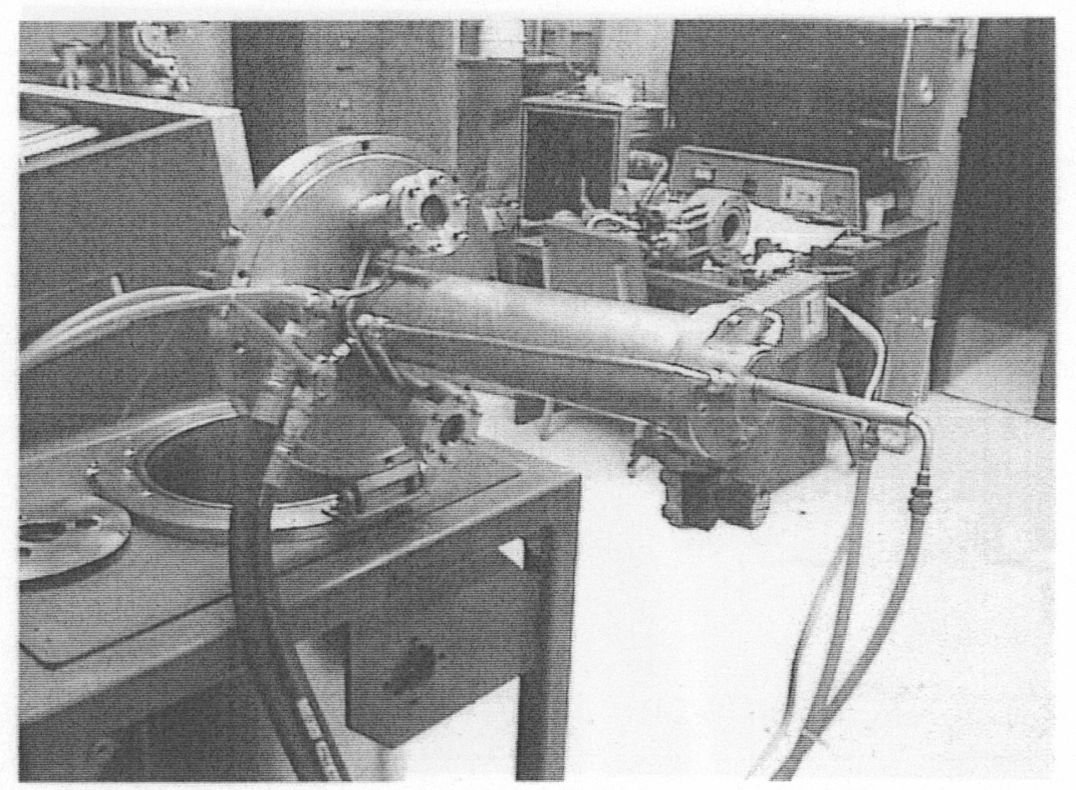

Figura 3.4 - Fotografia do forno aberto. Podemos verificar ai a haste que serve para puxar a amostra da área quente para a região de temperatura fria, para o choque térmico./

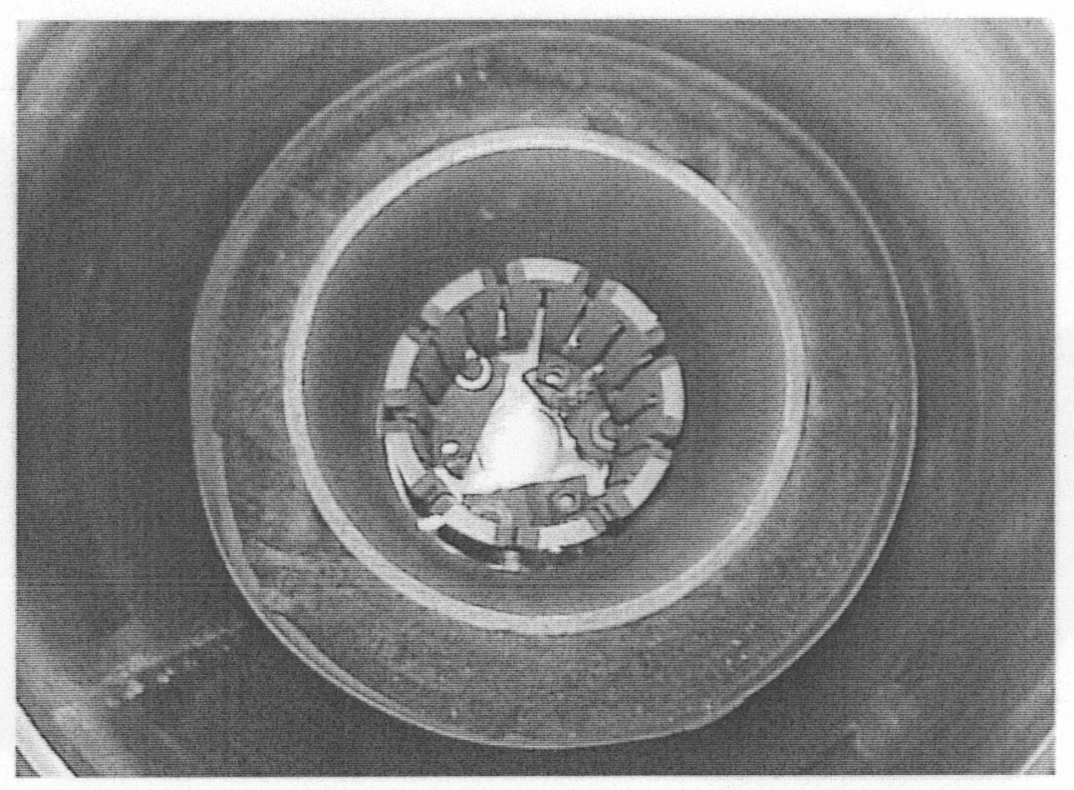

Figura 3.5 - Fotografia da parte interna do forno. No centro encontra-se o resistor; em seu entorno pode ser visto os elementos que compóem a blindagem de calor composta por um tubo de grafite, manta de grafite, carcaça de tântalo ou níquel. 


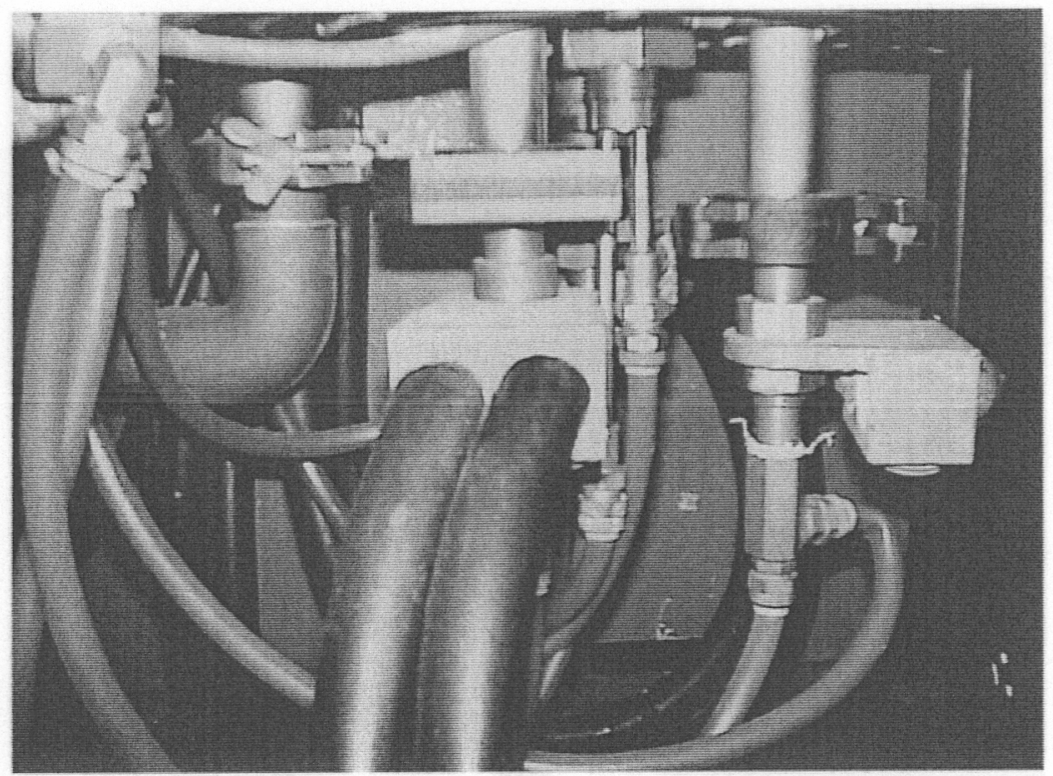

Figura 3.6 - Fotografia da parte inferior do forno mostrando a entrada de eletricidade, $e$ refrigeração dos eletrodos de cobre. O tubo de cobre (grande) é a saída para a bomba de vácuo.

A.

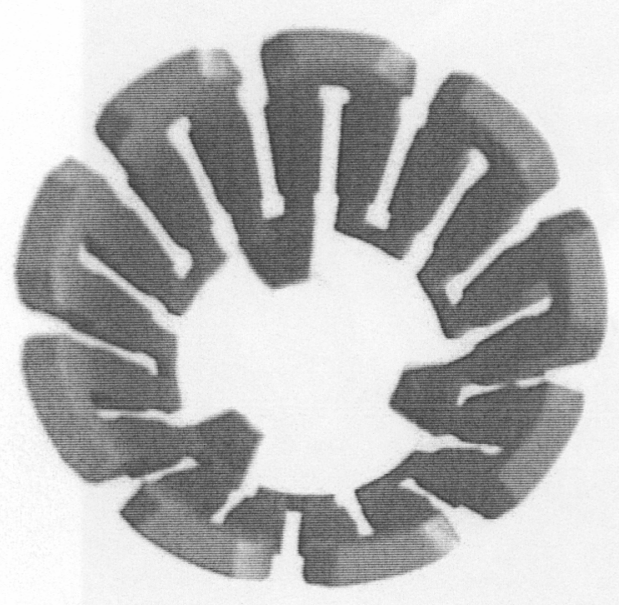

$\mathbf{B}$

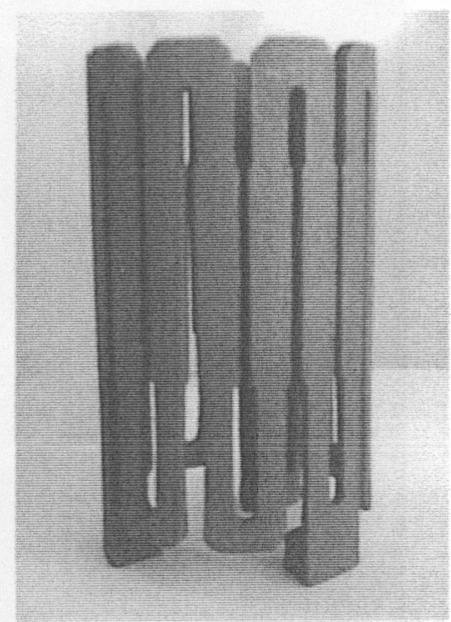

Figura 3.7 -Fotografia da resistência de grafite usada no forno para a fusão de amostras. Em A temos a visão do ângulo de cima, enquanto que em $B$ temos a visão lateral do resistor. 


\subsection{Tipos de cadinhos}

Os cadinhos usados na preparação de vidros são escolhidos de acordo com a temperatura de trabalho, e as possíveis reações que podem ocorrer entre o fundido e o cadinho. Usamos na preparação das nossas amostras cadinhos de platina, no caso das fundidas ao ar, e cadinhos de grafite, no caso das fundidas a vácuo. A fusão de vidros aluminato de cálcio em cadinhos de alumina deve ser evitada já que a alumina reage com o carbonato de cálcio e a sílica, e que tem como conseqüência a mudança da estequiometria da composição, além de furar o cadinho e provocar o vazamento do material no forno. As características dos cadinhos utilizados no preparo de nossas amostras são discutidas a seguir (Ohlweiler, 1982:121).

\section{- Grafite pirolítico}

A principal vantagem de uso do grafite pirolítico é a sua natureza refratária, seu ponto de fusão é de $3737^{\circ} \mathrm{C}$, por este motivo é uma das escolhas para cadinhos de altas temperaturas. Entretanto só pode ser usado a vácuo ou atmosfera inerte, uma vez que ocorre a formação de $\mathrm{CO}_{2}$ quando este entra em contato com o ar, levando à contaminação das amostras e a perda do mesmo. Na figura 2.7 são mostrados alguns dos cadinhos de grafite usados na preparação de nossas amostras.
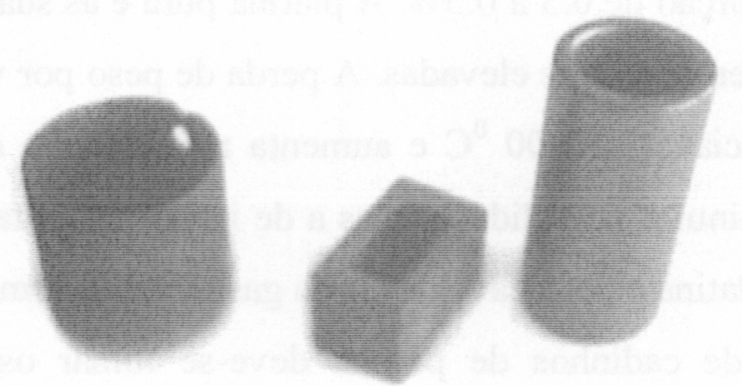

Figura 3.8 - Cadinhos de grafite usados para a preparação de vidros aluminato de cálcio.

No caso do uso de cadinhos de grafite deve-se tomar um cuidado extra, uma vez que a contaminação pelo grafite é acentuada se não forem tomadas as devidas precauções. Resíduos de grafite podem misturar-se à frita provocando escurecimento no vidro. Os seguintes passos 
devem ser levados em consideração ao utilizarmos esse tipo de cadinho: primeiramente o cadinho deve ser lixado com uma lixa de aproximadamente 400 mesh para tirar possiveis resíduos de amostras, e em seguida diminuir gradativamente a grana da lixa para que a superfície fique polida, uma lixa de 1200 mesh é suficiente para esse fim. O polimento final é feito com lenço de papel, ou papel higiênico macio. O papel deve ser passado na cadinho até que este fique o menos escuro possivel e a superficie do cadinho fique espelhada. Desta forma garantimos que a frita não reagirá com o cadinho e não ocorrerá aderência do vidro ao mesmo. Para que o cadinho de grafite não absorva umidade do ar é interessante deixá-los guardados em vácuo, já que isso facilita o processo de degaseificação.

\section{- Platina}

A platina funde a uma temperatura muito alta, $1769^{\circ} \mathrm{C}$. É um metal muito bom condutor de calor. Não adsorve umidade em extensão apreciável, não sofre alteração química quando aquecida ao ar a temperaturas elevadas, e não é atacada pela maior parte dos reagentes. É um metal que possui a capacidade de resistir à ação de carbonatos alcalinos em fusão e do ácido fluorídrico. Por tudo isso, a platina é um material muito apropriado para a confecção de cápsulas (evaporação de soluções) e cadinhos (fusões e calcinações).

A platina por ser um metal bastante mole, é, às vezes, endurecida mediante a adição de pequenas quantidades de metais platínicos, como irídio e ródio. Especialmente usado para este fim é o irídio na proporção de 0.3 a $0.5 \%$. A platina pura e as suas ligas com irídio e ródio são levemente voláteis a temperaturas elevadas. A perda de peso por volatização não é sensivel até $900{ }^{\circ} \mathrm{C}$, torna-se apreciável a $1000{ }^{\circ} \mathrm{C}$ e aumenta rapidamente a temperaturas mais altas. A presença de ródio diminui a volatilidade, mas a de iridio aumenta a perda por aquecimento. A altas temperaturas a platina é permeável a vários gases, especialmente hidrogênio.

No caso de uso de cadinhos de platina deve-se tomar os mesmo cuidados quanto a contaminação. Uma vez que o vidro adere a superficie do cadinho de platina, a possibilidade de contaminação por dopantes é grande. Os cadinhos de platina são freqüentemente limpos usando ácido fluorídrico (ácido altamente corrosivo). Entretanto esse processo é demorado, às vezes meses, dependendo do tipo de vidro. Uma das maneiras encontradas para reduzir este 
tempo é usar potássio bissulfato, $\mathrm{KHSO}_{4}$, no cadinho, levando ao forno próximo à temperatura de fusão do vidro e deixa-lo nestas condições por 30 minutos. Após esse tempo deve-se verter o material do cadinho, e em seguida lavá-lo com água quente para tirar o resíduo mais grosso, uma lavagem com HF elimina os resíduos de $\mathrm{KHSO}_{4}$. É interessante também deixá-lo um certo tempo em ultra-som para a limpeza final.

\subsection{Materiais utilizados}

A qualidade óptica de um vidro é influenciada pela qualidade da matéria-prima utilizada. Em nossos estudos utilizamos óxidos/carbonatos comerciais, cuja procedência e pureza são abaixo relacionadas:

Tabela 3.1-Materiais utilizados

\begin{tabular}{lcc}
\hline \multicolumn{1}{c}{ Material } & Fabricante & Pureza \\
$\mathrm{Al}_{2} \mathrm{O}_{3}$ & J. T. Baker & $99,1 \%$ \\
$\mathrm{CaCO}_{3}$ & Ecibra & $99,0 \%$ \\
$\mathrm{MgO}$ & Quimibras & $97,0 \%$ \\
$\mathrm{SiO}_{2}$ & Riedel de Haën & $98,0 \%$ \\
$\mathrm{Nd}_{2} \mathrm{O}_{3}$ & Alfa & $99,99 \%$ \\
$\mathrm{Er}_{2} \mathrm{O}_{3}$ & Aldrich & $99,9 \%$ \\
$\mathrm{Yb}_{2} \mathrm{O}_{3}$ & Aldrich & $99,9 \%$ \\
\hline
\end{tabular}

\subsection{Preparação de Amostras}

As amostras de vidros aluminato de cálcio foram preparadas de acordo com as composições dadas nas tabelas 3.2 a 3.4. Os óxidos/carbonatos foram pesados uma balança analítica, cuja precisão é de 5 casas, marca Mettler, modelo H20T, que em seguida foram misturados em um moinho de bolas por 12 horas para homogeneizar. Em seguida foram levados ao forno para fusão. O lote de cada amostra foi de 15 gramas. 


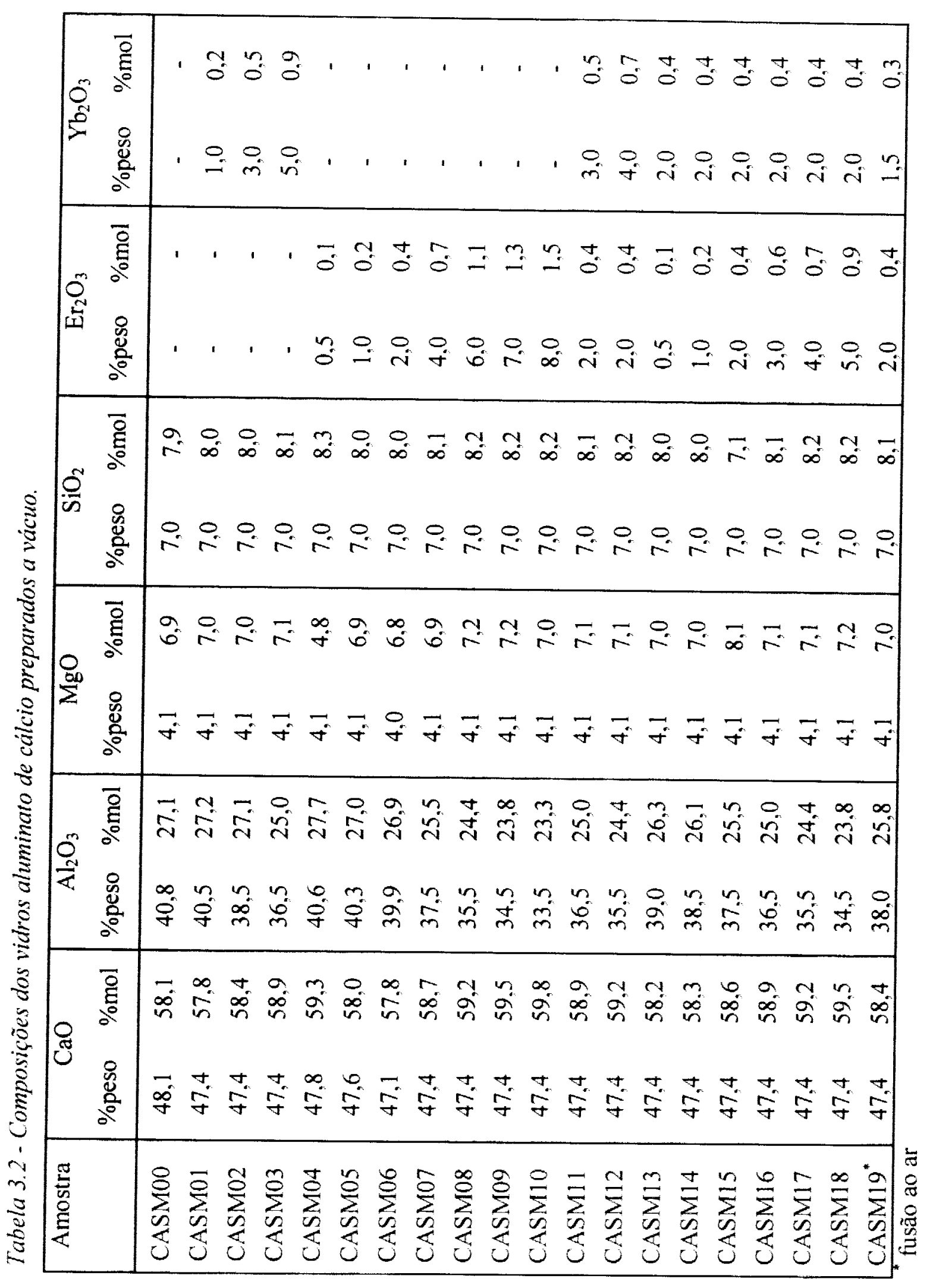




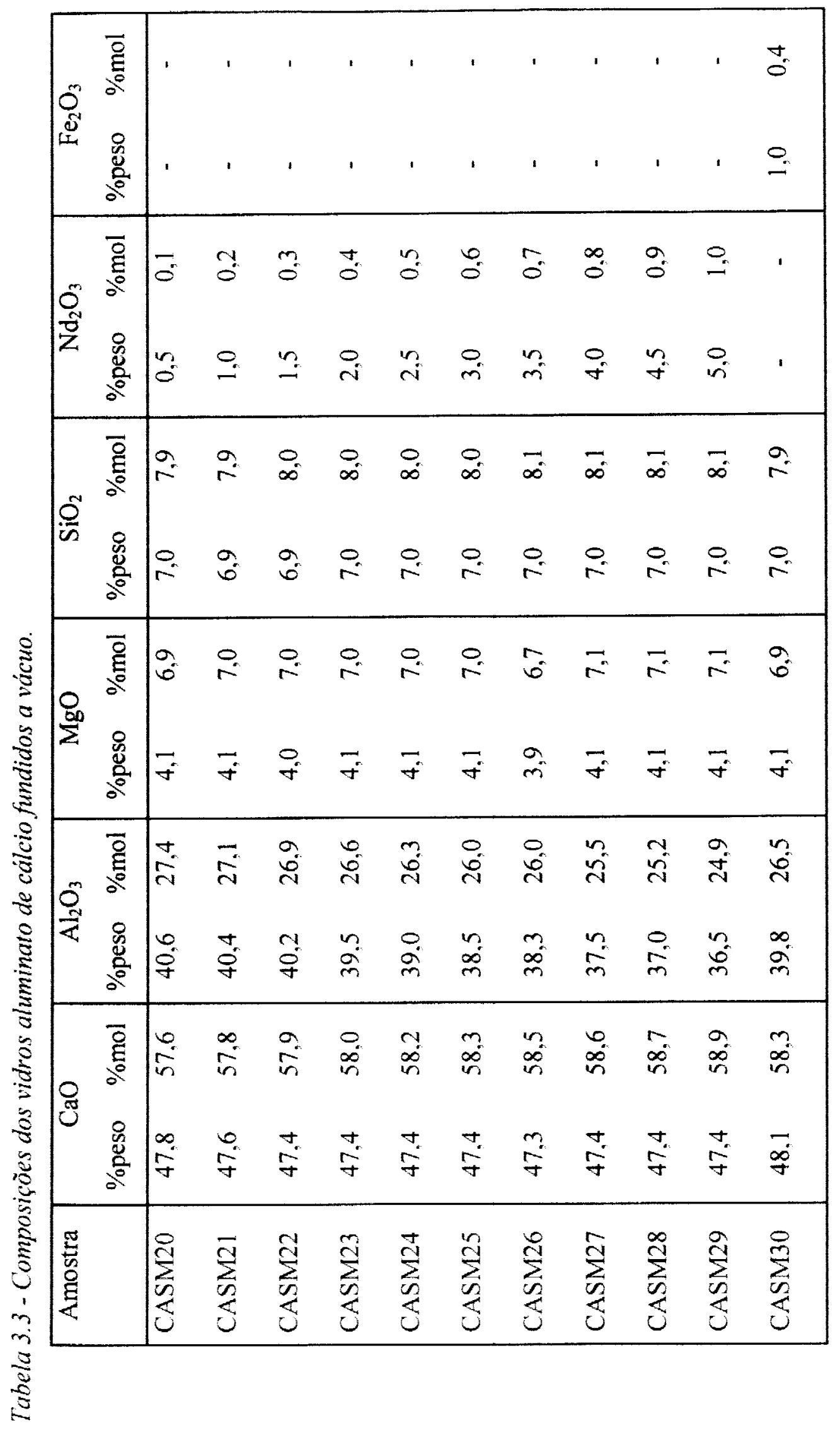




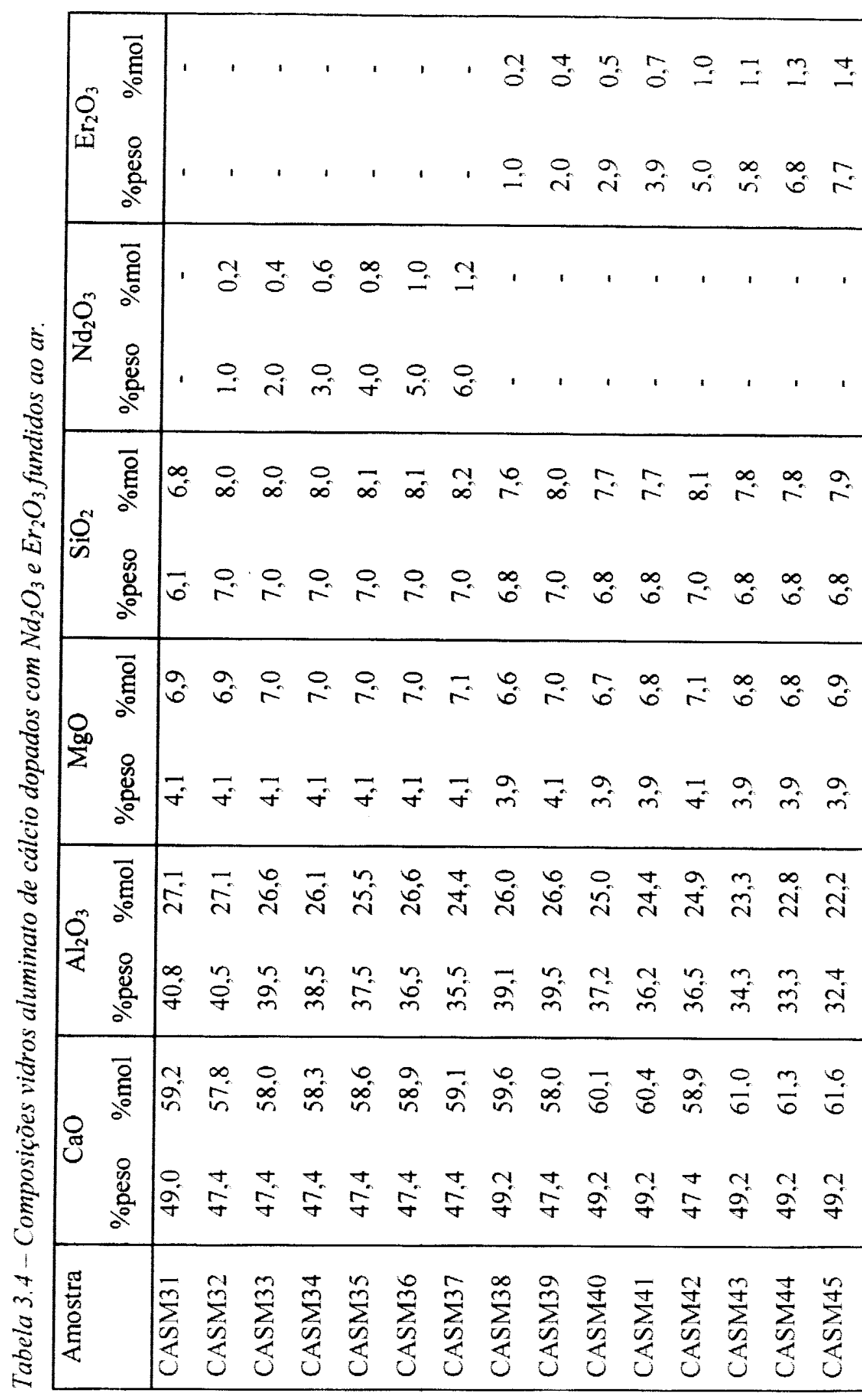


A composição dos vidros aluminato de cálcio teve como composição inicial $48,1 \mathrm{CaO}$, $40.8 \mathrm{Al}_{2} \mathrm{O}_{3}, 4.1 \mathrm{MgO}$ e $7.0 \% \mathrm{SiO}_{2}$ (em peso \%). Esta composição é segundo a literatura uma das mais estáveis e otimizadas para a transmissão no infravermelho (Davy, 1978).

Quando iniciamos o estudo de preparação dos vidros aluminato de cálcio dopados com terras raras, primeiramente com óxido de neodímio em 1996, seguimos o procedimento que era adotado anteriormente no grupo, no qual consistia em fazer uma quantidade grande de vidro matriz, cerca de 200 gramas, que posteriormente era quebrado, e em seguida dividido em lotes de $10 \mathrm{~g}$ e moído. A dopagem era feita adicionando o óxido terra rara na porcentagem desejada. Esse método foi utilizado para fazer amostras dopadas com até $2 \%$ de $\mathrm{Nd}_{2} \mathrm{O}_{3}$ e até $2 \%$ de $\mathrm{Er}_{2} \mathrm{O}_{3}$.

À primeira vista as amostras estavam homogêneas, havia um aumento na gradação de cores perceptível a olho nu. No entanto quando cortamos e polimos opticamente as amostras verificou-se que não havia homogeneidade do terra rara na amostra. No caso das amostras dopadas com neodímio, tinha-se uma parte mais azul na borda e no centro uma parte mais clara, dando a impressão que o óxido terra rara tira migrado do centro para as bordas. $O$ mesmo ocorreu com as amostras dopadas com érbio. Esses resultados de má homogeneização confirmaram-se depois através da determinação do coeficiente de absorção óptica, pois havia uma variação muito grande dessa propriedade para diferentes pontos da mesma amostra. Portanto esse método de preparação não é aconselhável pois não garante a estequiometria devido falta de homogeneidade.

A solução encontrada para este problema foi fazer a fusão da matéria-prima juntamente com o dopante. A dúvida que surgiu inicialmente foi de qual óxido devíamos substituir para colocarmos o dopante. Resolvemos começar pelos componentes de maior porcentagem. A primeira tentativa (frustrada!) foi substituir no óxido de cálcio, porém as amostras com mais de $2 \%$ de dopante cristalizavam facilmente. Outra tentativa foi feita, desta vez substituindo o óxido de alumínio por $\mathrm{Nd}_{2} \mathrm{O}_{3}$, o que resultou em êxito. No caso dos vidros dopados com $\mathrm{Nd}_{2} \mathrm{O}_{3}$ conseguimos substituir até $5 \%$ de $\mathrm{Al}_{2} \mathrm{O}_{3}$ por $\mathrm{Nd}_{2} \mathrm{O}_{3}$. As amostras com mais de $4 \%$ desse óxido necessitaram de um taxa de choque térmico maior. O choque térmico consiste em desligar o forno e ao mesmo tempo puxar o cadinho com a amostra para a câmara superior na tampa do forno que encontra-se também a vácuo, que é refrigerada por água gelada. sua 
temperatura é de aproximadamente $200{ }^{\circ} \mathrm{C}$, principalmente devido à radiação proveniente da área quente inferior. Seguindo esse procedimento começamos os estudos com o érbio. Aparentemente, os vidros dopados com érbio fundem-se mais facilmente do que os dopados com neodímio. Uma prova deste fato é a maior concentração desse dopante inserida no vidro, cerca de $8 \%$ de $\mathrm{Er}_{2} \mathrm{O}_{3}$. Co-dopagens de $\mathrm{Er}_{2} \mathrm{O}_{3}$ e $\mathrm{Yb}_{2} \mathrm{O}_{3}$ tiveram comportamento semelhante. Até $5 \%$ de $\mathrm{Er}_{2} \mathrm{O}_{3}$ o procedimento para choque térmico foi o descrito acima. No entanto as amostras também começaram a cristalizar-se acima dessa concentração, foi quando resolvemos aumentar a taxa de resfriamento através da introdução de gás argônio, no momento em que desligamos o resistor e puxamos a amostra para a câmara superior, isso em fração de segundos. Esse procedimento foi satisfatório uma vez que conseguimos uma alta concentração de óxido terra rara na matriz. Com esse procedimento conseguimos amostras com homogeneidade e qualidade óptica satisfatória. Esse tipo de choque térmico não foi suficiente para conseguirmos amostras com mais de $5 \%$ de $\mathrm{Nd}_{2} \mathrm{O}_{3}$.

Foram também preparadas durante esta tese amostras de outros tipos de vidros, tais como silicato, borato e fosfato. Estes vidros foram fundidos ao ar em cadinhos de platina. As composições desses vidros são dadas nas tabelas 3.5 e 3.6.

Os vidros silicatos foram fundidos a $1400{ }^{\circ} \mathrm{C}$, ao ar, durante 3 horas. As amostras foram vertidas em moldes de grafite pré-aquecidos, a temperatura de $400{ }^{\circ} \mathrm{C}$.

Os vidros boratos foram fundidos a $1050^{\circ} \mathrm{C}$, ao ar, durante 5 horas. Em seguida foram vertidos em moldes de grafite e levados a temperatura de $600{ }^{\circ} \mathrm{C}$ e deixados resfriar até a temperatura ambiente.

Os vidros fosfatos foram fundidos a $920{ }^{\circ} \mathrm{C}$, ao ar, durante 10 horas. Em seguida foram vertidos em moldes de grafite preaquecido

Usamos para a fusão dessas amostras um forno da marca Harper, modelo HOU9715M28SD, cuja temperatura máxima de trabalho é de $1450{ }^{\circ} \mathrm{C}$. 

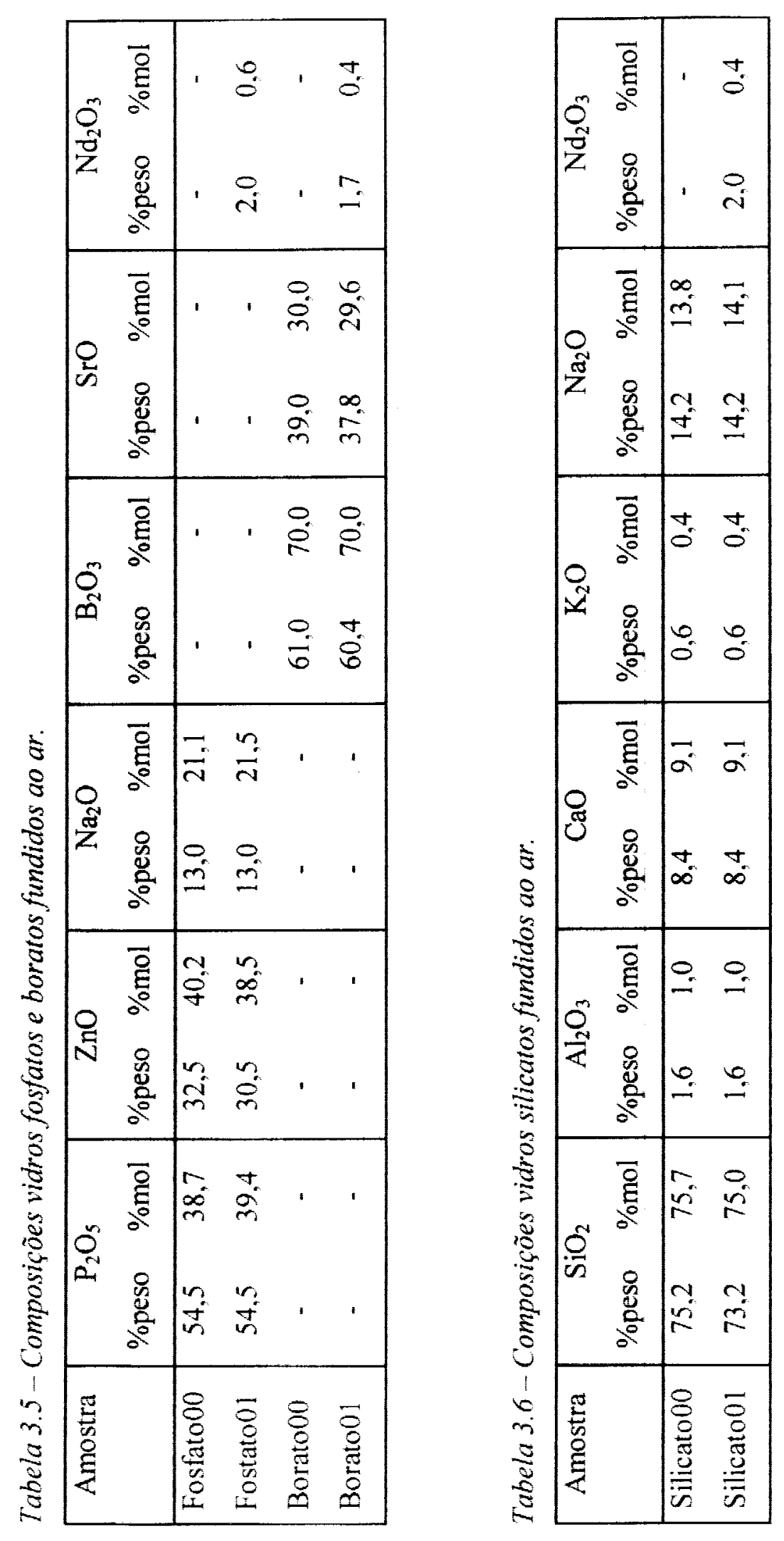


\subsection{Corte e polimento}

Após a fusão da amostra é necessário cortá-la e fazer o polimento. Dependendo da exigência do experimento a ser realizado esse corte e polimento pode ser menos ou mais sofisticado. Alguns experimentos como por exemplo DTA não necessita de polimento uma vez que a amostra pode ser usada na forma de "bulk" ou em pó. Porém, a maioria das outras técnicas necessita de um polimento especial; uma das técnicas que exige mais cuidados é a refratometria pois as superficies da amostra que entra em contato com o prisma do refratômetro devem ser planas e com ângulos de $90^{\circ}$ entre si. Como na maioria das vezes trabalha-se com amostras muito pequenas, é necessário usar uma serra de corte fino, de aproximadamente $0.2-0.5 \mathrm{~mm}$, evitando dessa forma perda do material.

As amostras investigadas nesta tese foram cortadas usando uma serra de baixa rotação, modelo ISOMET, marca Buehler, cujo disco de corte adiamantado possui espessura de $0.5 \mathrm{~mm}$. Para lixamento preliminar das amostras foi usada uma lixadeira da marca Panambra, modelo DP9a, cuja velocidade é de $300 \mathrm{rpm}$. Para o acabamento final de polimento utilizou-se uma politriz da marca Panambra, modelo DP9U2, cuja velocidade de rotação pode ser ajustada: panos de polimento de 6 e $3 \mu \mathrm{m}$ utilizou-se $250 \mathrm{rpm}$ durante 3 minutos, enquanto que para o pano de $1 \mu \mathrm{m}$ utilizou-se $150 \mathrm{rpm}$ durante 3 minutos. $O$ processo de polimento possui basicamente três passos: $O$ primeiro é o desbaste grosso, usando lixa que vai desde granulação 100 até 320 mesh, o segundo é o desbaste fino usando lixa de 400 até 2400 mesh, e finalmente o terceiro passo é o polimento em si, usando panos de polimentos apropriados com pasta de diamante de 6, 3 e $1 \mu \mathrm{m}$. Entre uma granulometria e outra a amostra é girada em $90^{\circ}$ a fím de eliminar os riscos da lixa precedente.

O método tradicional usado em nosso grupo para polimento de amostras consiste em embutir a amostra em resina acrílica (embutimento a frio), e em seguida fazer o lixamento e o polimento. A resina acrílica pode ser dissolvida em clorofórmio, e assim é possivel polir a superficie da amostra de dois lados. Por esse método, embora, o polimento seja satisfatório do ponto de vista metalográfico, muitas vezes não é possivel obter faces planas e paralelas, podendo a amostra ter a forma de cunha. Isso é mais crítico para amostras moles, como por exemplo, vidros fluoretos ou chalcogenetos. Como o vidro aluminato de cálcio é duro, com uma certa experiência é possivel obter um polimento 
satisfatório. Pode-se iniciar o polimento também a partir da lixa com grana 800 mesh, eliminando o passo com as lixas de grana inferior. Nesse caso a amostra não deve ser embutida, e deve ser razoavelmente grande a fím de ser possível segurá-la na mão.

Vale ressaltar a necessidade de um bom recozimento do vidro, pois embora a amostra tenha ficado boa visualmente, pode ocorrer a fragmentação total da amostra durante o corte devido à tensões internas proveniente do choque térmico dado durante o preparo da amostra.

Nop-trystalline Solids 000 (2000) $000 \cdot 00$

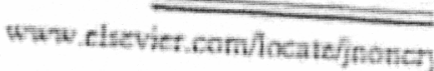

cal and optical properties calcil.m glaspes doped with $\mathrm{Er}^{3+}$ ana a ffit unda ${ }^{a}$, A.A. Coelho ${ }^{b}$, S. Gama ${ }^{\text {b. A.C. Bento }}{ }^{c}$, M. Niranda ${ }^{\circ}$, M.L. Baesso ${ }^{\circ}$

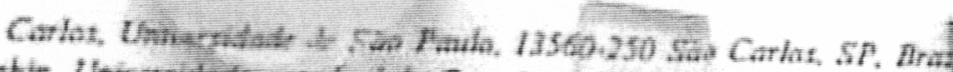

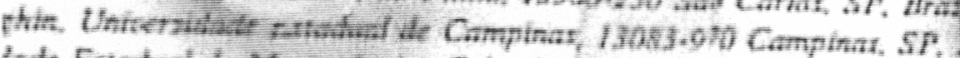

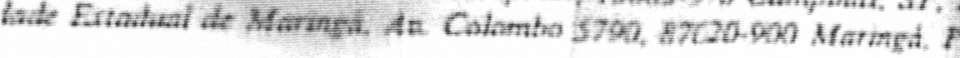

Figura 3.9 - Fotografia de algumas das amostras de vidros aluminato de cálcio..

$\mathrm{Na}$ figura 3.9 temos a fotografia das amostras de vidros aluminato de cálcio. A amostra maior (verde claro) refere-se a uma amostra dopada com $\mathrm{Fe}_{2} \mathrm{O}_{3}$ (CASM30). As amostra $\mathrm{s}$ transparentes, no meio inferior e direita superior, referem ao vidro base (CASM00). A amostra de tonalidade escura refere-se ao vidro dopado com $4 \%$ (em peso) de $\mathrm{Nd}_{2} \mathrm{O}_{3}$ fundida ao ar (CASM35). A amostra localizada no meio superior refere-se a amostra dopada com 4\% (em peso) de $\mathrm{Er}_{2} \mathrm{O}_{3}$, fundida a vácuo. Podemos verificar dessas fotografias a boa qualidade óptica das amostra, ou seja, por inspeção visual não há a presença de estrias, cordas e boa transmitância óptica. 


\section{Técnicas de Caracterização}

\subsection{Introdução}

Como pudemos verificar na revisão bibliográfica dos vidros aluminato de cálcio, no capítulo 2, há na literatura poucas informações sobre a influência dos íons terras raras nesses vidros. Para preencher essa lacuna de informações, foi um dos objetivos dessa tese investigar qual era a influência desses ions sobre as propriedades térmicas, mecânicas, ópticas e termo-ópticas nesses vidros, mais especificamente, quando substituimos na composição do vidro o óxido de aluminio pelo óxido terra-rara $\left(\mathrm{Nd}_{2} \mathrm{O}_{3}, \mathrm{Er}_{2} \mathrm{O}_{3}\right.$ e $\left.\mathrm{Yb}_{2} \mathrm{O}_{3}\right)$. A seguir discutiremos as diversas técnicas usadas para caracterizar as amostras obtidas.

\subsection{Difração de raios-X}

A técnica de difração de raios- $X$ foi empregada a fim de verificarmos possíveis traços de cristalização nas amostras. Para isso usamos o equipamento de difração de raios$\mathrm{X}$ da marca Philips, modelo 1830 , utilizando radiação $\mathrm{K} \alpha$. A intensidade da radiação foi de $45 \mathrm{kV}$ e $35 \mathrm{MA}$. As amostras foram preparadas na forma de lâminas com $(10 \times 5 \times 2)$ $\mathrm{mm}^{3}$.

\subsection{Densidade}

Do ponto de vista técnico a densidade não possui muita relevância, porém é de fundamental importância para o cálculo de outras propriedades fỉsicas tais como, volume molar, refração molar, condutividade/difusividade térmica, entre outras. Outra informação 
que a densidade/volume molar pode fornecer é se um determinado dopante, como por exemplo $\mathrm{Nd}$, entrou na estrutura do vidro. $\mathrm{O} \mathrm{Nd}$ ao substituir um átomo leve, como por exemplo $\mathrm{Al}, \mathrm{Si}$ ou $\mathrm{Ca}$, faz com que a densidade do vidro aumente.

Tanto a densidade como o volume molar nos dá informações do quão compactos os ions ou os grupos iônicos estão empacotados na estrutura do material, entretanto não mostram como as partículas estão geometricamente arranjadas ou qual é a unidade estrutural que elas formam. Para uma substância homogênea, como por exemplo o vidro, a densidade, $\rho$, é definida como a razão do peso pelo volume:

$$
\rho=\frac{m}{V}
$$

A densidade do vidro é freqüentemente dada à temperatura ambiente de $20{ }^{\circ} \mathrm{C}$. Com o aumento da temperatura a densidade diminui monotonamente, até atingir a temperatura de transição vítrea, $\mathrm{T}_{\mathrm{g}}$, e a partir daí começa a depender do coeficiente de expansão volumétrica $\beta=3 \alpha$ ( $\alpha$ é o coeficiente de expansão linear).

A densidade dos vidros é também dependente do recozimento. Os vidros que não são recozidos possuem uma densidade mais baixa em relação aos vidros bem recozidos, essa diferença é de aproximadamente 1 a $2 \%$ (Volf, $1988: 222$ ).

As medidas de densidade foram feitas utilizando o método baseado no princípio de Arquimedes, que consiste em medir o peso da amostra ao ar e em seguida dentro de um líquido cuja densidade seja conhecida. A balança utilizada para estas medições foi a mesma descrita para fazer a pesagem dos óxidos/carbonatos no preparo das amostras. Em nossos estudos foi utilizado o tetracloreto de carbono, $\mathrm{CCl}_{4}$, como líquido de imersão. A densidade do tetacloreto de carbono é $1.594 \mathrm{~g} / \mathrm{cm}^{3}$ a temperatura de $20{ }^{\circ} \mathrm{C}$. Quanto a temperatura ambiente for maior que $20^{\circ} \mathrm{C}$ é necessário fazer a correção do valor dado pela seguinte expressão:

$$
\rho_{C C_{4}}=1.594-1.9\left(T_{C_{4}}-20\right) \times 10^{-3}
$$

Tendo os valores do peso da amostra ao ar, $\mathrm{P}_{\mathrm{ar}}$, e no $\mathrm{CCL}_{4}, \mathrm{P}_{\mathrm{CCl}_{4}}$ podemos determinar a densidade do vidro através da seguinte relação:

$$
\rho_{v u d r o}=\frac{P_{a r}}{P_{a r}-P_{C l_{4}}} \times \rho_{C I_{t}}
$$


Outras duas quantidades freqüentemente usadas são o número médio de íons de oxigênios, $\bar{n}_{O}=\sum f_{i} n_{O,}$, e o número médio de cátions $\bar{n}_{M}=\sum f_{i} m_{M, t}$.

O peso molar do vidro, $\bar{W}_{g}$ (quantidade adimensional), ou, mais precisamente, o peso molar médio de todos os componentes do vidro, é calculado para um dado vidro como a soma das frações molares $f$, multiplicado pelo peso molar dos óxidos individuais.

$$
\bar{W}_{g}=\sum f W_{i}
$$

O volume molar do vidro, ou mais especificamente, o volume molar médio dos componentes do vidro é dado pela razão do peso molar médio do vidro pela sua densidade:

$$
V_{M}=\frac{\overline{W_{g}}}{\rho}
$$

Vidros nos quais os componentes são de pesos moleculares dissimilares $\left(\mathrm{Li}_{2} \mathrm{O}\right.$, $\mathrm{PbO}, \mathrm{K}_{2} \mathrm{O}, \mathrm{MgO}, \mathrm{B}_{2} \mathrm{O}_{3}$ ) é mais conveniente comparar os vidros com a base de unidade volumétrica molar $V_{1}$ relacionada por 1 átomo grama de oxigênio (Scholze, 1980: 164). Para um vidro de multicomponentes, o volume unitário $V_{1 . g}$ é dado por:

$$
V_{\mathrm{I}, g}=\frac{\bar{V}_{M, g}}{\sum n_{0} f_{i}}=\frac{V_{M, g}}{\bar{n}_{0}}=\frac{W_{g}}{\rho \bar{n}_{0}}
$$

em que $\bar{n}_{0}$ é o número médio de íons de oxigênio.

\subsection{Propriedades Elásticas}

Quando um sólido é submetido à forças mecânicas sua resposta pode tomar três formas diferentes: a deformação elástica, reversível; a deformação plástica, permanente; a fissura, ou de-coesão local, que pode ser seguida de ruptura, ou separação em fragmentos (Guillemet, 1997). Holloway (1973) define sólido, como a classe de material que exibe uma deformação recuperável quando sujeito a pequenas tensões. Um contra exemplo é o fluido quando sujeito à aplicação de tensão. Neste caso ocorre uma deformação contínua, que embora pequena, não é capaz de recuperar a sua forma original ao suprimirmos tal força. O fluído não possui rigidez. 
Se ao aplicarmos uma tensão em um sólido, e essa deformação for reversivel por supressão da força, o corpo é chamado elástico ou frágil. A lei de Hooke que exprime essa deformação $D$ é proporcional à pressão $\sigma$ aplicada, dada por:

$$
\sigma=M D
$$

A constante de proporcionalidade $M$ que aparece neste equação é chamada geralmente de módulo, que representa as constantes dos materiais. Há diferentes tipos de módulos dependendo do tipo de deformação.

Uma tração aplicada a um sólido produz um alongamento que é caracterizado pelo modulo de elasticidade E, conhecido também como módulo de Young ou módulo de alongamento. Uma força de cisalhamento conduz a um processo de cisalhamento. $O$ módulo correspondente $G$ recebe várias denominações: módulo de elasticidade ao cisalhamento, de elasticidade transversal, módulo de rijeza. Por fim, uma pressão sendo exercida sobre todas as faces do sólido conduz à compressão que é denominada módulo de compressão K. Se o corpo sofrer uma dilatação será produzida na direção perpendicular ao alongamento uma contração transversal. Se tomarmos o alongamento relativo $\Delta l / l$ e a contração transversal $\Delta d / d$ temos a seguinte relação:

$$
\frac{\Delta d d}{\Delta l l}=v
$$

que é chamada de coeficiente de Poisson, v. Os três módulos acima estão ligados entre si através da equação a seguir:

$$
E=2(1+v) G=3(1-2 v) K
$$

A compressão hidrostática ou alongamento de um sólido corresponde ao deslocamento de todos os átomos ou íons da posição de mínima energia. Em altas tensões o módulo elástico aumenta em compressão e diminuir em tensão. Para alguns materiais a deformação pode ocorrer através da reorganização dos átomos que inicialmente não mudam sua separação. A borracha, por exemplo, consiste de anéis entrelaçados formando uma cadeia longa de moléculas. Os átomos dentro de qualquer uma das moléculas estão fortemente ligados, porém há somente ligações dipolares relativamente fracas entre as moléculas. A borracha possui um módulo de alongamento muito baixo e também exibe tensão elástica muito grande. A extensão na direção de uma tensão de tração aplicada é devido ao arranjo da cadeia molecular. Eventualmente, em tensões muito altas, as cadeias 
se alinham na direção da tensão aplicada e em seguida um maior alongamento se opõem às intensas forças entre os átomos dentro de cada cadeia, e o material se torna muito mais duro (Holloway, 1973). As figuras 4.1, 4.2 e 4.3 ilustram os diferentes tipos de módulos elásticos.

a) Deformação por tensão

Força longitudinal (uniaxial) $=\mathrm{F}$

Tração longitudinal $=\delta l / l$

Tensão lateral $=\delta \omega / l$

$\mathrm{E}=$ módulo de alongamento $=$ tração/tensão (longitudinal) $=\frac{F}{\text { área }} \div \frac{\delta l}{l}=\frac{F}{l \delta l}$

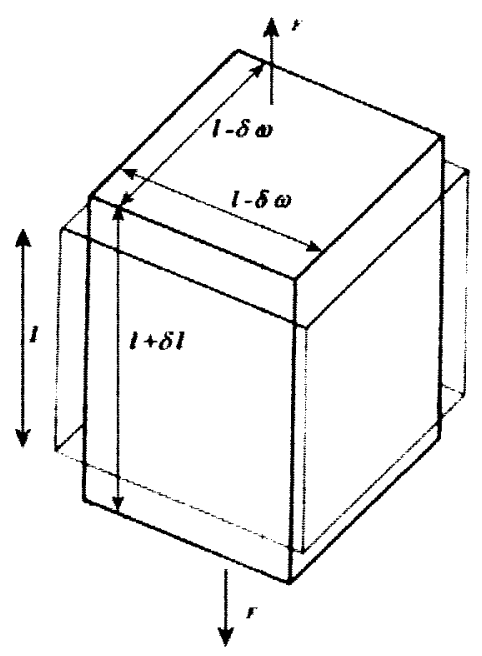

Figura 4.1 - Deformação por tração.

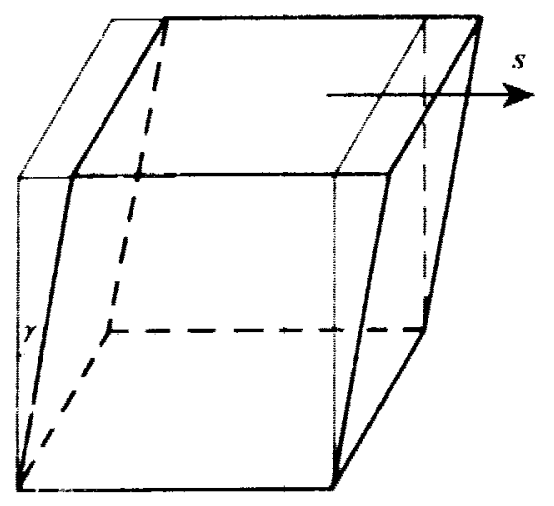

Figura 4.2 - Deformação por cisalhamento. 
b) Cisalhamento puro

A superficie inferior do cubo é mantida fixa e a força tangencial $S$ é aplicada na face superior do cubo.

Força de cisalhamento $=\mathrm{S}$

Tensão de cisalhamento $=\tan \gamma \approx \gamma$

$\mathrm{G}=$ módulo de rijeza $=$ tração/tensão (cisalhamento) $=\frac{S}{\text { área }} \frac{1}{\gamma}=\frac{S}{l^{2}} \frac{1}{\gamma}$

c) Compressão hidrostática

Neste caso as forças são iguais sobre todas as faces

$\mathrm{K}=$ módulo de compressão $=$ Pressão hidrostática/deformação volumétrica $=\frac{T}{\text { ateat }}$

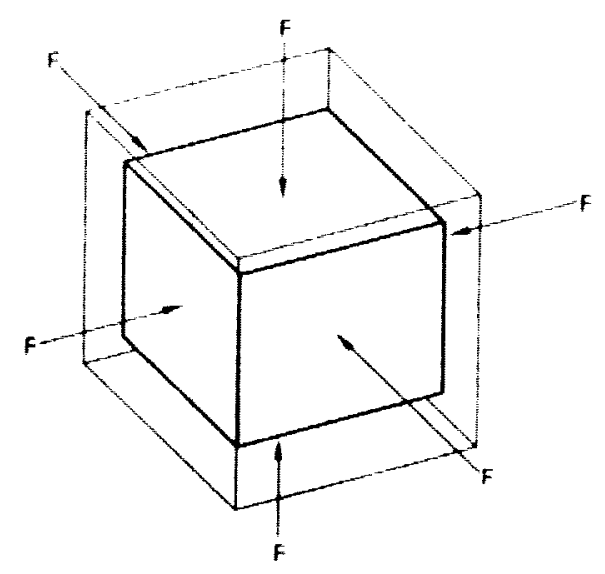

Figura 4.3 - Deformação por compressão.

As propriedades elásticas estão relacionadas com as velocidades ultra-sônicas através das seguintes equações:

Módulo longitudinal $\quad \Rightarrow L=\rho V_{i}^{2}$

Módulo de cisalhamento $\Rightarrow G=\rho V_{s}^{2}$

Constante de Lamé $\quad \Rightarrow \lambda=\rho V_{l}^{2}-2 \rho V_{s}^{2}$

Módulo de elasticidade $\Rightarrow E=\frac{G(3 \lambda+2 G)}{\lambda+G}=\rho V_{s}^{2} \frac{\left(3 V_{1}^{2}-4 V_{s}^{2}\right)}{\left(V_{l}^{2}-V_{s}^{2}\right)}$
longitudinal

Coeficiente de Poisson $\Rightarrow v=\frac{\lambda}{2(\lambda+G)}=\frac{V_{l}^{2}-2 V_{s}^{2}}{2\left(V_{l}^{2}-V_{s}^{2}\right)}$ 


$$
\begin{aligned}
& \text { Módulo de compressão } \Rightarrow K=\lambda+\frac{2}{3} G=\frac{\rho}{3}\left(3 V_{l}^{2}-4 V_{s}^{2}\right) \\
& \text { Impedância acústica } \Rightarrow Z=\rho V_{l}
\end{aligned}
$$

Das propriedades elásticas podemos ainda obter a temperatura de Debye, $\theta_{D}$, que está relacionada às velocidades longitudinais e transversais através da relação:

$$
\theta_{D}=\frac{h}{k}\left(\frac{3 N}{4 \pi}\right)^{1 / 3} V_{D}
$$

em que $V_{D}$ é a velocidade de Debye média no vidro e é dada por:

$$
V_{D}=\left[\frac{1}{3}\left(\frac{1}{V_{l}^{3}}+\frac{2}{V_{s}^{3}}\right)\right]^{-1 / 3}
$$

$\mathrm{N}$ é o número de vibrações fundamentais por unidade de volume, $h$ é a constante de Planck $\left(6.626 \times 10^{-34} \mathrm{Js}\right)$ e k é a constante de Boltzman $\left(1.381 \times 10^{-23} \mathrm{~J} \mathrm{~K}^{-1}\right)$. N é tomado como o número de átomos por unidade de volume e é dado por:

$$
N=\frac{N_{a} \rho P}{\bar{W}_{g}}
$$

$\mathrm{N}_{\mathrm{a}}$ é o número de Avogadro $\left(6.02 \times 10^{23} \mathrm{~mol}^{-1}\right), \rho$ é a densidade, $\mathrm{P}$ é o número de átomos na fórmula química, que é dado por $\bar{n}_{M}$ e $\bar{n}_{0}$ nas tabelas 2.6 e 2.8 , e $\bar{W}_{g}$ é o peso molecular.

As velocidades transversais, $V_{s}$, e longitudinais, $V_{l}$ foram obtidas usando um equipamento MATEC, modelo 6600 , na escala de $30 \mathrm{MHz}$, com transdutores de quartzo cortados na direção $\mathrm{X}$ e $\mathrm{Y}$. As amostras depois de preparadas, conforme descrito no capítulo 2, foram cortadas na forma de cubos, com $10 \mathrm{~mm}$ de espessura, em seguida foram polidas opticamente até 1500 mesh, com faces planas e paralelas, e em seguida depositado um filme fino de cobre para contato com o transdutor.

\subsection{Dureza}

Os ensaios de microdureza foram feitos a temperatura ambiente usando um durômetro da marca Leitz Wetzlar, Germany, modelo Durimet, série 5385, cuja carga usada foi de $200 \mathrm{~g}$, aplicada durante $30 \mathrm{~s}$. $\mathrm{O}$ aumento obtido na visualização das micro 
indentações foi de 40 vezes. A superfície das amostras foi de aproximadamente 15 x15 $\mathrm{mm}$. A fim de verificar as possíveis variações em diferentes pontos da amostra realizou-se pelo menos quinze indentações em cada uma delas.

No início dos ensaios de micro dureza não tínhamos idéia de qual era a carga ideal para fazer indentações nos vidros aluminato de cálcio, já que não há referências na literatura. Em vista disso, usamos cargas de 25, 50, 100, 200, 300 g. Idealmente a carga aplicada deve ser grande para obter indentações grandes, e desta forma evitar dificuldade visual na medida, reduzindo portanto os erros. Porém nem sempre isso é possível, como por exemplo, no caso dos vidros chalcogenetos que devido a sua baixa dureza, cargas acima de $50 \mathrm{~g}$ provocam fissuras na indentação. No caso dos vidros aluminato de cálcio as fissuras ocorrem para cargas a partir de $300 \mathrm{~g}$.

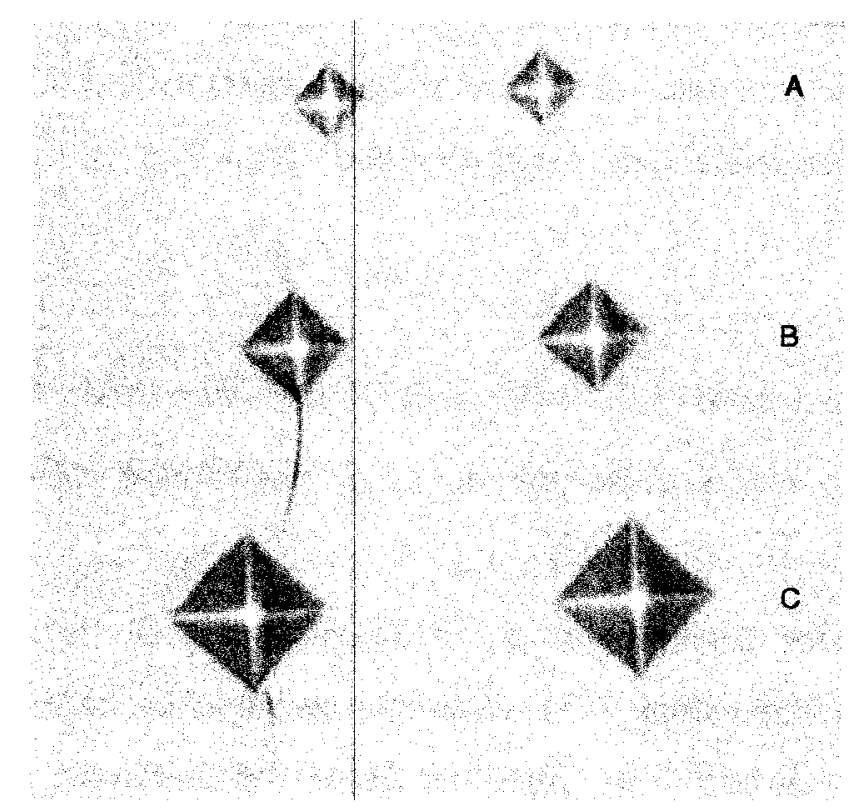

Figura 4.4 - Fotomicrografia das indentações Vickers em uma amostra de vidro aluminato de cálcio, CASM00, usando cargas de $A=100 \mathrm{~g}, B=200 \mathrm{~g}$ e C $=300 \mathrm{~g}$. Tempo $30 \mathrm{~s}$. Aumento de 200 vezes.

Na figura 4.4 são mostradas as micro indentações Vickers, em uma amostra de vidro aluminato de cálcio, CASM00, usando várias cargas. Em A foi usada uma carga de 100g, em B uma carga de $200 \mathrm{~g}$ e em C uma carga de 300g. O tempo da impressão foi de 30s. Podemos perceber que conforme aumenta-se a carga, aumenta-se também o tamanho da indentação, o que facilita bastante a visualização das diagonais e o que reduz o erro na medida. 


\subsection{Tenacidade à Fratura}

Em temperaturas bem abaixo do ponto de amolecimento do vidro e para baixas tensões, os vidros obedecem a lei de Hooke; a razão entre tração/tensão é uma constante e não é observada deformação (plástica) macroscópica permanente até a tensão na qual a fratura ocorre. Para amostras de vidros comerciais a tenacidade à fratura é aproximadamente $50 \mathrm{MPa}$, o que corresponde a uma tensão elástica de cerca de 0.1 por cento. Algumas composições de vidro podem suportar tensões de até $10 \mathrm{GPa}$ e um afastamento significativo da lei de Hooke se torna aparente. Não há entretanto escoamento plástico detectável, de forma que embora a tensão não seja exatamente proporcional à tensão, é ainda elástica: um espécime recupera sua forma e tamanho originais quando a tensão é retirada.

Se submetermos um tarugo de vidro comum a um teste de tração ou flexão, ele se deformará de maneira perfeitamente elástica até a ruptura. O ponto de início da fratura é geralmente na superfície e o plano da fratura é sempre perpendicular à pressão de intensidade máxima. Depois da ruptura, pode-se juntar os fragmentos deste tarugo, e reconstruí-lo exatamente em sua forma e dimensões iniciais. Assim vemos que o vidro oferece as marcas mais visíveis da fragilidade. Entretanto para a maioria dos materiais, a plasticidade, sobre suas diferentes formas, desempenham o papel essencial no desencadeamento da fratura.

Geralmente, os testes de resistência mecânica e a deformação elástica à ruptura variam muito, por isso é necessário tomar certos cuidados a fim de obter reprodutibilidade dos resultados: condições de temperatura, umidade, velocidade com que a carga é aplicada, e principalmente ter o vidro que está sendo testado não sofreu quedas, batidas....

A tenacidade à fratura, $\mathrm{K}_{\mathrm{IC}}$, de um material é um parâmetro importante e necessário para prever o desempenho mecânico de materiais estruturais. Tenacidade à fratura de um material é a capacidade que esse material tem de resistir à propagação de um defeito existente (trinca). Quando a tenacidade à fratura de um material é conhecida, sabe-se exatamente que valor da combinação tensão/comprimento de trinca aplicado a esse material causaria a propagação desse defeito, que na prática significa falha catastrófica. Esse parâmetro pode ser obtido utilizando-se vários métodos disponíveis na literatura, e um deles é o método da impressão de dureza, que consistem em fazer uma impressão de 
dureza Vickers em um material frágil, estimando-se a tenacidade à fratura do material a partir das dimensões das trincas geradas na impressão. O método é simples e rápido, e é bastante usado na determinação da tenacidade à fratura de materiais cerâmicos há quase duas décadas (Li, 1989). Ao se fazer a impressão cria-se uma zona, logo abaixo do indentador, deformada plasticamente, que é totalmente envolvida por uma segunda zona deformada elasticamente. Esse processo cria um campo de tensões que leva à formação de trincas no material que circunda a impressão. Alguns tipos de trinca podem surgir, sendo as mais importantes as trincas diagonais, que são aquelas saindo dos cantos da indentação. A trinca diagonal pode ser média ou semicircular, ou pode ser uma trinca de Palmqvist. A trinca de Palmqvist ocorre para os materiais de maior tenacidade à fratura enquanto que a trinca média ocorre para materiais de menor tenacidade à fratura (Lankfor, 1982) A figura 4.5 mostra os comprimentos característicos de uma impressão Vickers utilizados na determinação de $\mathrm{K}_{\mathrm{IC}}$.

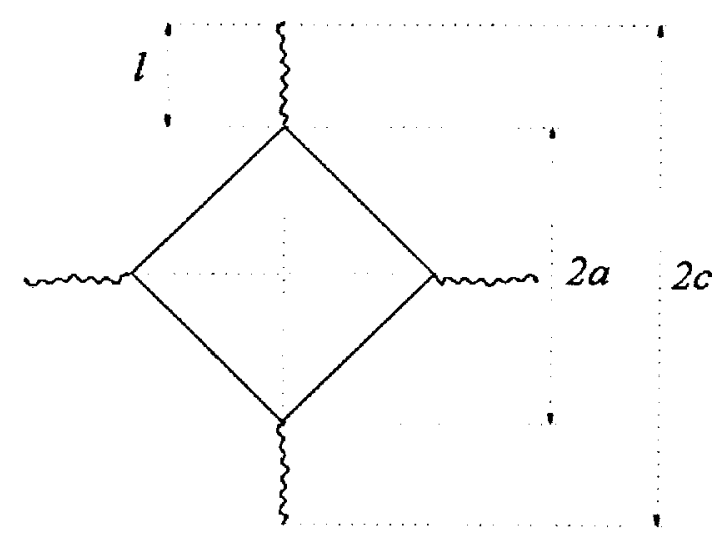

Figura 4.5-Comprimentos característicos das indentações Vickers.

Existem diversos modelos teóricos utilizados para se determinar $\mathrm{K}_{\mathrm{IC}}$ a partir das dimensões da impressão e das trincas geradas. Um modelo bastante utilizado é aquele proposto por Blendell (Ponton, 1989), que estabelece a existência de uma relação universal entre $K_{\text {IC }}$ e a razão tamanho da trinca/tamanho da impressão, que é dado por:

$$
K_{I C}=0.0303 H_{V}^{0.6} E^{0.4} a^{0.5} \log \left(8.4 \frac{a}{c}\right)
$$


onde $H_{V}$ é a dureza Vickers (GPa), E é o módulo de elasticidade (GPa), $c$, $a$ e $l$, são os comprimentos da trinca e da impressão $(\mu \mathrm{m})$, observados na figura 4.5, e P é a carga da impressão em kgf.

É reportado sempre na literatura que os vidros aluminato de cálcio possuem uma resistência mecânica alta, porém não há informação do quão considerável é essa diferença em relação a outros sistemas vítreos. E, para comparação de resultados é interessante termos valores obtidos sobre as mesmas condições. Por esta razão determinou-se $\mathrm{K}_{\mathrm{IC}}$ de sete famílias vítreas, além dos vidros aluminato de cálcio (CASM00), investigamos também amostras de vidros silicato (silicato00), borato (borato00), fosfato (fosfato00), fluoreto ( $Z B L A N)$, telureto $\left(70 \mathrm{TeO}_{2}-20 \mathrm{ZnO}-10 \mathrm{Na}_{2} \mathrm{O}\right)$ e chalcogeneto $\left(70 \mathrm{Ga}_{2} \mathrm{~S}_{3} 30 \mathrm{La}_{2} \mathrm{~S}_{3}\right)$. Algumas dessas matrizes foram preparadas em nosso grupo, e outra como fluoreto, chalcogeneto e telureto por grupos externos. Os parâmetros $\mathrm{P}, \mathrm{H}_{\mathrm{v}}, a, c, l$ são obtidos experimentalmente, enquanto que os valores de $\mathrm{E}$ foram retirados da literatura (Klocek, 1991). O erro nesse tipo de medidas é de aproximadamente $40 \%$ (Woods, 1991).

\subsection{Análise Térmica Diferencial}

Para a obtenção da temperatura de transição vitrea e temperatura de cristalização dos vidros aluminato de cálcio, utilizamos um analisador térmico diferencial, marca Netzsch, modelo STA 409 -EP, que opera até $1350{ }^{\circ} \mathrm{C}$. O termopar utilizado para medir a variação de temperatura, foi do tipo $\mathrm{S}$ (Pt -10Rh-Pt), cujo intervalo de temperatura de operação é de 0 a $1700{ }^{\circ} \mathrm{C}$. Para esses experimentos utilizou-se amostras na forma de volume (bulk). A referência utilizada foi um cadinho de alumina vazio. A taxa de aquecimento foi de $10^{\circ} \mathrm{C}$ por minuto, em atmosfera ambiente.

Uma vez que a temperatura de transição vítrea, $\mathrm{T}_{\mathrm{g}}$, e temperatura de cristalização, $T_{x}$, está abaixo de $1200{ }^{\circ} \mathrm{C}$, escolheu-se fazer as medidas até esta temperatura. Uma das vantagens é que podemos reutilizar os cadinhos de alumina para várias corridas de DTA pois até esta temperatura não há reação entre o cadinho e a amostra. Além disso, conforme resultados anteriores (Sampaio, 1997) era sabido que não havia variação significativa na temperatura de fusão, $T_{m}$, que é de aproximadamente $1320{ }^{\circ} \mathrm{C}$ na temperatura de pico. Essa não variação na temperatura de fusão, $T_{m}$, pode ser devido ao fato de que a amostra ao fundir-se reage com a $\mathrm{Al}_{2} \mathrm{O}_{3}$ do cadinho, que acaba sendo incorporada em sua composição 
e conseqüentemente mudando a estequeometria e mascarando os resultados para $T_{m}$. Para um estudo mais detalhado de $T_{m}$ seria interessante o uso de cadinhos de platina.

\subsection{Calor Específico}

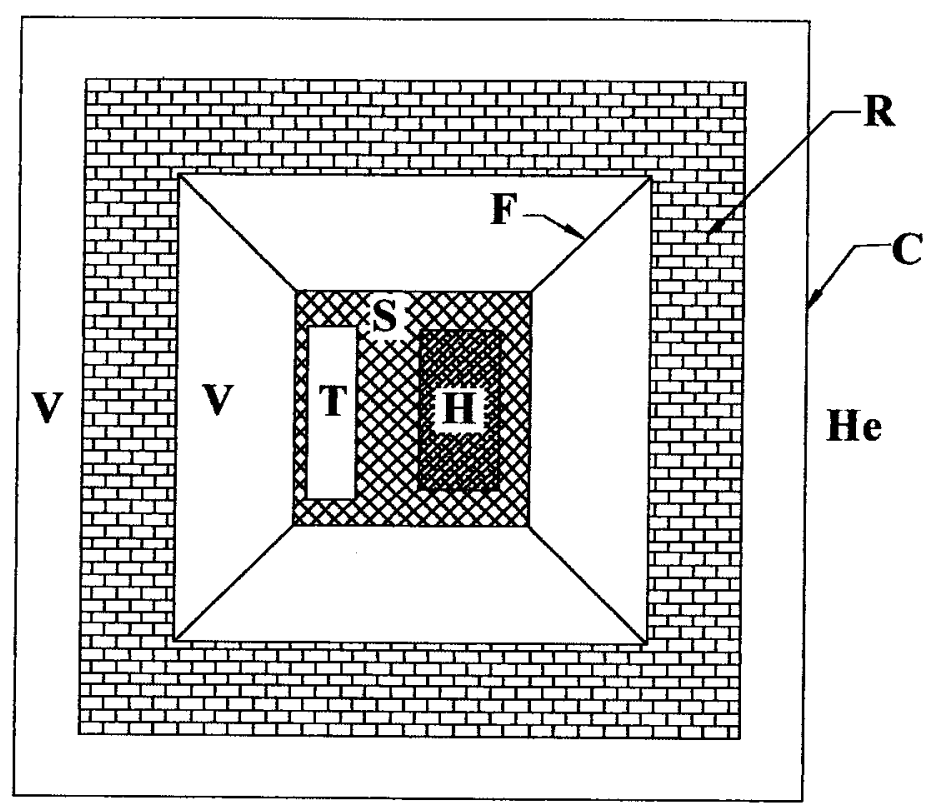

Figura 4.6 - Diagrama esquemático de um calorímetro ilustrando um substrato preso a um reservatório térmico $(R)$. Os fios de sustentação $(F)$ também conduzem corrente para o aquecedor $(H)$ e o calor para o reservatório $(R)$. O suporte de amostra (S) juntamente com o sensor de temperatura (T) e o aquecedor formam o substrato, que permanece em vácuo e fechado por um capa externa (C). Todo este sistema está em banho de He líquido. $O$ vácuo é designado por (V) (Azechi et al. 1995).

O método de relaxação térmica é conveniente para pequenas amostras (desde $5 \mathrm{mg}$ ) apresentado boa precisão em torno de $5 \%$ e além de ser possível implementá-lo para qualquer intervalo de temperatura. $O$ método de relaxação térmica substitui com vantagens a técnica adiabática convencional uma vez que esta funciona melhor em baixas temperaturas, $<40 \mathrm{~K}$, e necessita de um bom isolamento térmico, algo não muito simples de se conseguir em temperaturas criogênicas (Azechi et al., 1995).

Essencialmente o método consiste na análise da variação da temperatura da amostra em função do tempo após a aplicação de um pulso de calor. Para descrever o método consideremos o diagrama ilustrado na figura 4.6. Um substrato, composto por suporte de amostra, aquecedor e sensor de temperatura, é sustentado por fios presos a um reservatório 
térmico. Estes fios são também utilizados para conduzir corrente para o aquecedor do substrato para o reservatório. O sistema, composto pelo reservatório térmico mais substrato, encontra-se dentro de um recipiente onde se faz vácuo de isolamento. Supomos que o sistema esteja inicialmente a uma temperatura uniforme $T_{0}$. Em seguida ligamos uma corrente constante, I, a qual dissipa uma energia $\mathrm{E}$ por efeito Joule no aquecedor, que se encontra preso ao substrato. Parte desta energia será absorvida pelo substrato, $E_{a b s,}$ aquecendo-o, de modo que sua temperatura passa a ser $T(t)>T_{0}$. Devido à diferença de temperatura entre substrato e reservatório de calor, os fios passam a conduzir energia, $\mathrm{E}_{\text {con }}$. Assim, desprezando perdas de calor por convecção, pois o sistema está em vácuo, e por irradiação uma vez que $T(t)$ será sempre apenas um pouco maior que $T_{0} \cong 0.2 \mathrm{~K}$, teremos $\mathrm{E}$ $=E_{a b s}+E_{c o n}$. Derivando em relação ao tempo teremos $P=P_{a b s}+P_{c o m}$. A potência conduzida pelos fios é dada por:

$$
P_{c o n}=\sum_{i} k_{i}\left(T(t)-T_{0}\right)=k \Delta T
$$

onde $k_{i}$ é a condutância de cada fio, $k$, é a condutância térmica total e $\Delta \mathrm{T}$ é definido como sendo $T(t)-T_{0}$.

A potência absorvida pelo substrato é dada por:

$$
P_{a b s}=C \frac{d}{d t}\left(T-T_{0}\right)=C \frac{d}{d t} \Delta T
$$

onde $\mathrm{C}$ é a capacidade térmica do substrato, considerada constante durante o processo. Desta forma temos:

$$
P=C \frac{d}{d t} \Delta T+k \Delta T
$$

À medida que o substrato absorve energia, $\Delta \mathrm{T}$ aumenta e, conseqüentemente, maior é a quantidade de energia conduzida para o reservatório de calor. Após um tempo suficientemente longo, toda a energia fornecida ao substrato será conduzida pelos fios e a temperatura do substrato ficará estável. Temos assim:

$$
P=k \Delta T_{\max }
$$

Se nesse instante, definido como sendo $t=0$, desligarmos a corrente, os fios conduzirão apenas a energia que ficou acumulada no substrato. Assim a temperatura $T$ diminuirá gradativamente até que chegue $\mathrm{em} \mathrm{T}=\mathrm{T}_{0}$. Como $\mathrm{I}=0$ temos $\mathrm{P}=0$ e a equação 4.16 fica: 


$$
C \frac{d}{d t} \Delta T+k \Delta T=0
$$

A solução desta equação diferencial, com a condição $\Delta T(0)=\Delta T_{\max }$ é dada por:

$$
\Delta T=\Delta T_{\max } e^{-t / \tau}
$$

onde definimos $\tau=C / k$.

Assim, conhecendo a potência dissipada no substrato e medindo a diferença de temperatura máxima $\Delta T_{\max }$ obtemos a condutância térmica $k$ usando a equação 4.17. Uma vez de posse da curva experimental de decaimento $\Delta T(t)$ × $t$ podemos determinar o valor da constante de tempo $\tau$ pelo ajuste com a equação 4.19. Desse modo determinamos a capacidade térmica $\mathrm{C}$ do substrato dada por:

$$
C=\tau k=\frac{\tau P}{\Delta T_{\max }}
$$

As medidas da capacidade térmica das amostras de vidros aluminato de cálcio dopados com óxidos terras raras foram obtidas em temperatura ambiente. Primeiramente determinou-se o valor da capacidade térmica do substrato, $\mathrm{C}_{\text {sub }}$, e em seguida o valor da capacidade térmica do substrato mais a amostra, $\mathrm{C}_{\text {total }}$. Desta forma subtraindo o valor da capacidade térmica total menos a capacidade térmica do substrato, obtivemos o valor da capacidade térmica da amostra. Como o calor específico é definido como a razão entre a capacidade térmica pela massa da substância, podemos escrever:

$$
c_{p}=\frac{C_{\text {total }}-C_{\text {sub }}}{m}
$$

Utilizamos para obter os dados experimentais do calor específico um controlador de temperatura Lake Shore, modelo DRC 91CA; Fonte de corrente Keithley, modelo 224; Nanovoltímetro Keithley, modelo 182; Nanovoltímetro Keithley modelo 181, e um computador para fazer a aquisição de dados.

Antes de fazermos medidas em nossas amostras, fizemos a calibração do sistema determinando primeiramente o calor específico de uma amostra padrão de alumínio, pureza de $99.999 \%$ e calor específico de $0.91 \mathrm{Jg} / \mathrm{K}$. A fim de obter-se um acoplamento eficaz entre a amostra e o substrato utilizou-se pasta térmica na superfície polida da amostra. Certa precaução foi tomada a fim de evitar excesso de pasta térmica, de maneira que apenas um leve "filme" desta fosse aplicado. 


\section{9 Índice de Refração}

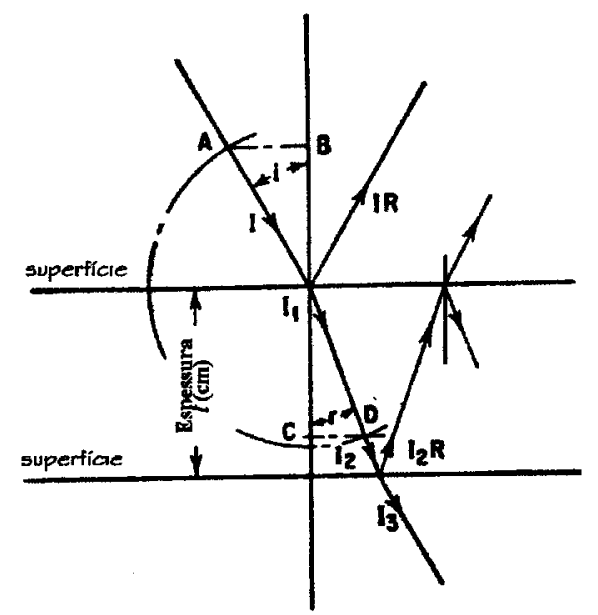

Figura 4.7 - Representação esquemática da transmissão da luz pelo vidro (Shand, 1958:57).

Na figura 4.7 I é a intensidade do feixe incidente, $R$ é a refletância da superfície do vidro, $I R$ é o feixe refletido, $I_{1}=I-I R$, é a intensidade do feixe que entra no vidro, $I_{2}=I_{1}$ $\mathrm{e}^{-\beta t}, \mathrm{I}_{2} \mathrm{R}$ é o feixe refletido da superficie imergente, $\mathrm{I}_{3}=\mathrm{I}_{2}-\mathrm{I}_{2} \mathrm{e}^{-\beta t}=\mathrm{I}(1-\mathrm{R})^{2} \mathrm{e}^{-\beta \mathrm{t}}$, i é o ângulo de incidência, $r$ é o ângulo de refração, e $n$ é o índice de refração $=\operatorname{sen} i / \operatorname{sen} r=$ $\mathrm{AB} / \mathrm{CD}$

A luz ao passar de um meio menos denso, como o ar, para um meio óptico mais denso, como o vidro, tem sua velocidade reduzida. A razão entre estas velocidades é conhecida como índice de refração, $n$, do meio mais denso.

$$
n=\frac{\text { velocidade no ar }}{\text { velocidade no vidro }}
$$

Se o feixe de luz se espalhar na superfície do vidro em ângulos não perpendiculares à superfície, o feixe no vidro será inclinado na direção perpendicular, como ilustrado na figura 4.7, onde $I$ é a intensidade do feixe incidente, $R$ é a refletância da superfície do vidro, IR é o feixe refletido, $I_{1}=I-I R$, é a intensidade do feixe que entra no vidro, $I_{2}=I_{1}$ $\mathrm{e}^{-\beta t}, \mathrm{I}_{2} \mathrm{R}$ é o feixe refletido da superfície imergente, $\mathrm{I}_{3}=\mathrm{I}_{2}-\mathrm{I}_{2} \mathrm{e}^{-\beta \mathrm{t}}=\mathrm{I}(1-\mathrm{R})^{2} \mathrm{e}^{-\beta \mathrm{t}}$, i é o ângulo de incidência, $r$ é o ângulo de refração, de forma que o índice de refração pode ser determinado a partir de dois ângulos (Shand, 1958:57).

$$
n=\frac{\text { seno do ângulo incidente }}{\text { seno do ângulo da refração }}=\frac{A B}{C D}
$$


$O$ índice de refração depende da interação do campo elétrico associado com o raio e com a camada eletrônica mais externa dos átomos que constituem o material do meio. A energia luminosa faz com que os elétrons oscilem harmonicamente, tal que os elétrons da camada mais externa possam ser visto como osciladores harmônicos.

A velocidade da luz, $c$, diminuirá proporcionalmente à polarizabilidade dos elétrons mais externos. Quando os elétrons e a freqüência da luz estão em perfeita ressonância ocorre a absorção (Fanderlik, 1983:78).

Nas medidas de índice de refração dos vidros aluminato de cálcio usamos um refratômetro do modelo Pulfrich PR2, marca Carl Zeiss. O líquido de contato usado no caso de medidas em temperatura ambiente foi di-iodo-metano terfenil hidrogenado, cujo índice de refração é $n_{d}=1.710 \pm 0.005$, a $25^{\circ} \mathrm{C}$. No caso dos vidros aluminato de cálcio é desaconselhável o uso de alfa-Bromonafetaleno, muito comum nesse tipo de medida, uma vez que o índice de refração desse líquido, $n_{e}=1.66$, é muito próximo ao do vidro aluminato, o que acaba mascarando os resultados. No caso das medidas em função da temperatura utilizamos nujol, $n_{e}=1.515$. A razão dessa escolha é que o nujol, que é um óleo natural, além de não ser volátil, não possui o odor forte característico dos líquidos inflamáveis. Alguns outros líquidos podem ser aplicados como líquido de contato.

No refratômetro de Pulfrich é possível usar vários tipos de prismas, dependendo da amostra e do tipo de medida. Com os prismas Go é possível medir índices de refração desde $n_{e}=1.46$ até $n_{e}=1.74$, entretanto é possível fazer medidas apenas em temperatura ambiente. A medida é baseada na medição do ângulo limite da refração total da luz. No caso de uso desse prisma não é necessário o uso de colimador uma vez que deve a luz seja difusa na superficie da amostra.

No caso do uso do prisma Vo, usado em nossa medidas, é possível medir índices de refração desde $n_{e}=1.29$ até $n_{e}=1.83$, sendo possível fazer medidas também em função da temperatura pois este prisma pode ser acoplado a um banho térmico, atingindo no máximo $75^{\circ} \mathrm{C}$. Entretanto para uma medição precisa é necessário que as faces da amostra que entram em contato com o prisma tenham um ângulo vivo de $90^{\circ}$. É necessário também o uso de um colimador. Diferentemente do prisma Go, que fornece o ângulo limite da reflexão total da luz, o prisma Vo fornece o ângulo de desvio da luz. 


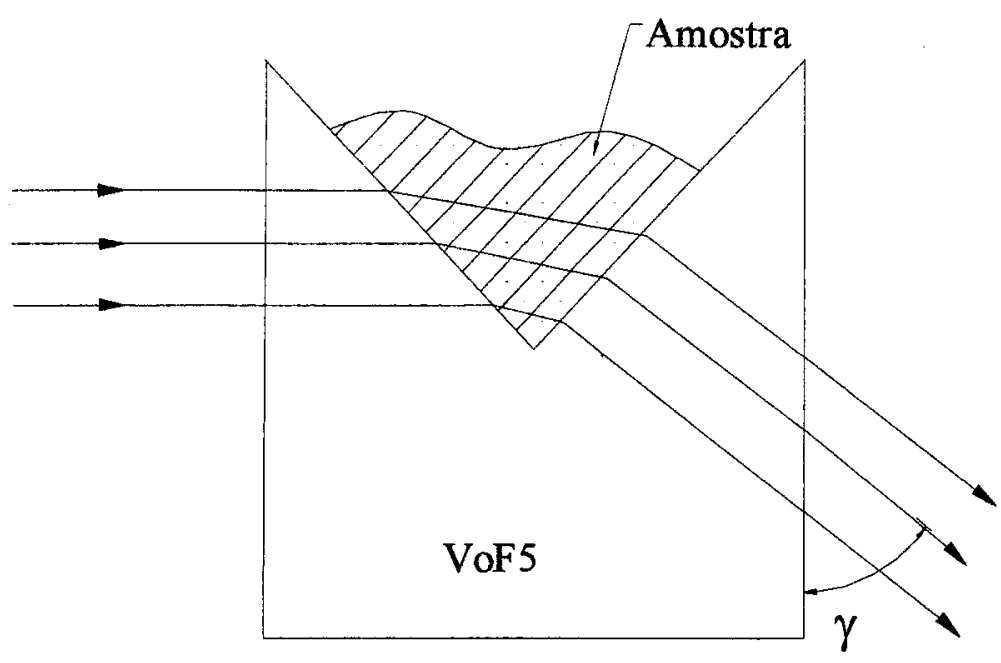

Figura 4.8 - Representação esquemática da luz atravessando Vo e uma amostra hipotética. $O$ ângulo yé obtido com o auxilio de um goniômetro.

Com a medição do desvio da luz realiza-se o chamado princípio espectrométrico. A figura 4.8 mostra esquematicamente o caminho óptico percorrido pelos raios de luz através de um prisma Vo e uma amostra hipotética. Os raios de luz saem paralelos do colimador $\mathrm{e}$ chegam ao prisma Vo, sendo refratados nas superficies inclinadas onde se encontra a amostra, saindo por fim do prisma formando um ângulo $\gamma$. Este ângulo $\gamma$ é medido com auxílio de um goniômetro acoplado ao sistema óptico do refratômetro. $\mathrm{O}$ ângulo $\gamma$ está relacionado ao índice de refração do prisma, $N$, e da amostra, $n$, através da seguinte relação.

$$
\cos \gamma=\frac{1}{\sqrt{2}}\left(\sqrt{1,5 N^{2}-n^{2}}-\sqrt{n^{2}-0.5 N^{2}}\right)
$$

para a determinação de $n_{\lambda}$, em função do comprimento de onda, temos:

$$
n_{\lambda}=\sqrt{N_{\lambda}^{2}-\cos \gamma \sqrt{N_{\lambda}^{2}-\cos ^{2} \gamma}}
$$

$\mathrm{Na}$ tabela a seguir são dados os índices de refração do prisma VoF5 em vários comprimentos de onda (valores obtidos do manual do equipamento): 
Tabela 4.1 - Índice de refração do prisma VoF5 em função do comprimento de onda.

\begin{tabular}{cccc}
\hline Linha & Lâmpada & $\begin{array}{c}\text { Comprimento } \\
\text { de onda (nm) }\end{array}$ & $\begin{array}{c}\mathrm{N} \\
\pm 1 \times 10^{-5}\end{array}$ \\
\hline $\mathrm{C}$ & hidrogênio & 656,3 & 1,733951 \\
$\mathrm{C}^{\prime}$ & cádmio & 643,8 & 1,735155 \\
$\mathrm{D}$ & sódio & 589,3 & 1,741449 \\
$\mathrm{~d}$ & hélio & 587,6 & 1,741679 \\
$\mathrm{e}$ & mercúrio & 546,1 & 1,748005 \\
$\mathrm{~F}$ & hidrogênio & 486,1 & 1,760767 \\
$\mathrm{~F}$ & cádmio & 480,0 & 1,762415 \\
$\mathrm{~g}$ & mercúrio & 435,8 & 1,777051 \\
$\mathrm{~h}$ & mercúrio & 404,7 & 1,791625 \\
\hline
\end{tabular}

O prisma usado para fazer as medidas do índice de refração, Vo F5, foi projetado para operar a $20{ }^{\circ} \mathrm{C}$, quando a temperatura for maior que esta deve-se levar em conta a variação do índice de refração dos prismas. Os valores do índice de refração encontrados através da equação 4.25 devem ser corrigidos de acordo com a tabela 4.2. Esses valores devem ser multiplicados por $\Delta T=T_{m}-T_{20}$ ( $T_{m}$ é a temperatura de medição e $T_{20}$ é a temperatura a $20^{\circ} \mathrm{C}$ ). Este valor deve ser adicionado ao índice de refração encontrado.

Tabela 4.2 - Valores de correção $\frac{d n}{d T} \times 10^{5}$ para o prisma $V_{o}$

\begin{tabular}{ccccccccc}
\hline$\gamma$ & $\mathrm{C}$ & $\mathrm{C}$ & $\mathrm{d}$ & $\mathrm{e}$ & $\mathrm{F}$ & $\mathrm{F}^{\prime}$ & $\mathrm{g}$ & $\mathrm{h}$ \\
\hline 15 & 0,62 & 0,62 & 0,68 & 0,77 & 0,92 & 0,93 & 1,08 & 1,29 \\
20 & 0,63 & 0,63 & 0,69 & 0,78 & 0,93 & 0,94 & 1,09 & 1,30 \\
30 & 0,64 & 0,65 & 0,71 & 0,80 & 0,96 & 0,97 & 1,12 & 1,33 \\
40 & 0,66 & 0,67 & 0,73 & 0,82 & 0,98 & 0,99 & 1,15 & 1,36 \\
50 & 0,67 & 0,68 & 0,74 & 0,83 & 1,00 & 1,01 & 1,17 & 1,39 \\
$60 \ldots$ & 0,68 & 0,69 & 0,75 & 0,84 & 1,01 & 1,02 & 1,18 & 1,40 \\
100 & & & & & & & &
\end{tabular}

Como exemplo tomemos o caso de uma amostra de vidro aluminato de cálcio dopada com $2 \%$ de $\mathrm{Nd}_{2} \mathrm{O}_{3}$ fundido ao ar:

O ângulo medido a $27^{\circ} \mathrm{C}$ na linha $e$ é: $\gamma=82^{\circ} 5245$

Índice de refração através da equação 5.31: $n_{\mathrm{e}}=1,67200$ 
Fator de correção segundo a tabela de temperatura $\frac{d n}{d T}=0.84 \times 10^{-5}$

Correção da temperatura: $0,84 \times 10^{-5}(27-20)=5,88 \times 10^{-5}$

Resultado Final: $n_{\mathrm{e}}=1,67205$ a $27^{\circ} \mathrm{C}$

Com base nos resultados do índice de refração obtivemos também outras propriedades correlacionadas, como a refração molar que é dada pela equação de LorentzLorenz:

$$
\Pi=\frac{N_{0} \alpha}{3 \varepsilon_{0}}=\frac{n^{2}-1}{n^{2}+2} \frac{M}{\rho}
$$

e o número de abbe, $v_{\mathrm{d}}$, que é definido pela equação:

$$
v_{d}=\frac{n_{d}-1}{n_{F}-n_{C}}
$$

A refração molar é somente influenciada pela deformabilidade dos íons. $\Pi$ é uma medida matemática do espaços opticamente preenchidos pelos íons no vidro. $O$ termo “opticamente preenchido" indica que o valor de $\Pi$ é derivado de propriedades ópticas, 0 índice de refração, $n$, e não da permissividade do meio $\varepsilon$. A diferença entre volume molar do vidro, $V_{M}$, da refração molar do vidro, $\Pi$, representa a medida do espaço que é opticamente vazio, ou mais precisamente, o espaço preenchido levemente pelos elétrons (Volf, 1988). Uma melhor idéia do espaço "livre", $V_{\phi}$ e "preenchido", $V_{f}$, no vidro pode ser obtido através das porcentagens do espaço total usando as equações

$$
V_{\phi}=100 \frac{\left(V_{M}-\Pi\right)}{V_{M}}
$$

e

$$
V_{f}=100-V_{\phi}
$$

\subsection{Transmitância Óptica}

A obtenção dos espectros de transmitância óptica foi feita usando um espectrômetro Lambda 9, série 1645, Perkin-Elmer para a região do ultravioleta até o infravermelho 
médio ( $250 \mathrm{~nm}$ até $2500 \mathrm{~nm}$ ). No caso da região do infravermelho médio (2500 até 6000 nm) foi utilizado um espectrômetro JASCO, modelo IR700, série 306457.

$O$ espectro de absorção dos vidros na região do infravermelho no espectro eletromagnético é amplamente determinado pela interação entre o material e a radiação que excita as vibrações atômicas. Estas podem envolver mudanças oscilatórias nas distâncias interatômicas (ligação de distanciamento) ou ângulos entre as ligações (ligação de curvatura). Para vidros óxidos pelo menos, há somente um ou dois casos de bandas de absorção devido à excitação de elétrons.

Para uma molécula diatômica simples, a absorção da radiação pode ocorrer na freqüência natural da vibração da molécula. Isto pode ser calculado usando mecanismos clássicos. Se $k$ for constante de força da ligação e $m_{l}$ e $m_{2}$ for a massa dos átomos da molécula, então a frequiência vibracional é dada por

$$
v=\frac{1}{2 \pi} \sqrt{\frac{k}{\mu}}, \quad \text { sendo } \mu=\frac{m_{1} m_{2}}{m_{1}+m_{2}} \quad \text { (4.30) }
$$

A absorção da radiação eletromagnética ocorre se a molécula tiver um momento de dipolo, no caso de moléculas homonucleares tais como $\mathrm{O}_{2}$ e $\mathrm{N}_{2}$ não haverá vibrações no espectro no infravermelho. Embora esta equação seja simples, ela não pode ser aplicada para materiais complexos como no caso de vidros, embora, seja regra geral que os vidros que possuem composições baseadas em átomos pesados ligados por forças relativamente fracas possuam fortes absorções na região do infravermelho em comprimentos de ondas maiores, por outro lado os vidros cujos componentes são átomos leves, e as forças das ligações sejam fortes teremos o corte na transmissão no infravermelho em comprimentos de ondas mais curtos.

A transmissão dos vidros é geralmente limitada ou inteiramente suprimida pelas autovibrações da rede (Vogel, 1994:257). Os vidros boratos e fosfatos com $5 \mathrm{~mm}$ de espessura perdem transmissão em $3.5 \mu \mathrm{m}$. Para os vidros silicatos o limite é em torno de 4.6 a $4.8 \mu \mathrm{m}$. Assim os vidros clássicos não são apropriados para uso como materiais que transmitem no infravermelho. Também pequenas concentrações de $\mathrm{H}_{2} \mathrm{O}$ influenciam significativamente na transmissão no infravermelho. Geralmente as bandas de absorção devido ao $\mathrm{H}_{2} \mathrm{O}$ nos vidros que transmitem no infravermelho devem ser esperadas nos seguintes comprimentos de onda:

2.7 até $3.0 \mu \mathrm{m} \quad$ vibração devida ao estiramento $\mathrm{O}-\mathrm{H}$ 
A medida que são introduzidos modificadores na rede do vidro ocorre a formação de oxigênios non brindgings, os grupo $\mathrm{OH}$ se formam com aqueles das ligações por ponte de hidrogênio que são a origem de uma banda em comprimento de ondas mais longos, próximo a $3.5 \mu \mathrm{m}$. Para teores mais elevados de elementos alcalinos, pode existir na estrutura do vidro tetraedros de $\left(\mathrm{SiO}_{4}\right)^{-}$mais móveis que são ligados pelas ligações de ponte de hidrogênio mais fortes, o que faz aparecer uma banda em $4.25 \mu \mathrm{m}$. A importância relativa desta banda dependerá da composição do vidro. Quando no vidro de $\mathrm{Na}_{2} \mathrm{O}_{3}-\mathrm{SiO}_{2}$, a $\mathrm{SiO}_{2}$ é substituído por $\mathrm{Al}_{2} \mathrm{O}_{3}$, o número de óxigênio não ligados diminuem em conseqüência da formação de tetraedros $\left(\mathrm{AlO}_{4}\right)^{-}$, o que caracteriza a banda em $3.5 \mu \mathrm{m}$ em favor daquela em $2.8 \mu \mathrm{m}$. Quando se atinge a razão molar $\mathrm{Na}_{2} \mathrm{O}: \mathrm{Al}_{2} \mathrm{O}_{3}=1$, não existe mais ponte de oxigênio não ligadas e a banda em $3.5 \mu \mathrm{m}$ desaparece. A partir de aproximadamente $4.5 \mu \mathrm{m}$, os vidros óxidos em sua grande maioria, mesmo com alguns milímetros de espessura, são completamente opacos a radiação infravermelha. As vibrações de estiramento Si-O são responsáveis por esta forte absorção (Scholze, 1980:203).

A posição das bandas de absorção é determinada pelo peso dos átomos, e natureza das ligações químicas M-O, que constituem o vidro, cuja influência maior é a dos átomos mais importantes. É por esta razão que a introdução de íons mais pesados, faz com que seja possível obter vidros mais transparentes na região do infravermelho como por exemplo os vidros de $\mathrm{As}_{2} \mathrm{~S}_{3}$ que possuem corte na região do infravermelho por volta de $10 \mu \mathrm{m}$. Entre os vidro óxidos temos os vidros germanatos, teluretos e os aluminato de cálcio que atingem transmissão até aproximadamente $6 \mu \mathrm{m}$.

Entretanto, nem sempre é possível introduzir elementos pesados na rede do vidro. Um exemplo é o vidro aluminato de cálcio, cujo corte na transmitância na região do infravermelho é por volta de $6 \mu \mathrm{m}$ dependendo da composição. Uma vez que a formação de vidro está limitada a uma pequena região no diagrama de fase, a introdução desses elementos pesados pode levar a devitrificação. Além disso a introdução de átomos pesados na rede do vidro faz que com as ligações químicas fiquem mais fracas e como consequência há uma degradação propriedades microscópicas e macroscópicas. 
A partir da transmitância óptica é possível obter o coeficiente de absorção óptica, que é mais preciso uma vez que o coeficiente de absorção óptica leva em consideração as perdas devido a reflexão da luz na superfície do vidro, e a espessura da amostra.

A luz ao incidir na superfície de um vidro tem uma parte de sua energia refletida $\mathrm{e}$ uma parte transmitida através do meio, de maneira que sua intensidade diminui no decorrer do caminho óptico. Por essa razão, na maioria das vezes, é necessário tomar a transmitância total da luz que é representada pela razão entre a intensidade do feixe emergente e o do feixe incidente. As perdas da intensidade inclue aquelas resultantes da reflexão e aquelas da absorção, conforme ilustrado anteriormente na figura 4.7. O resultado da transmitância total é dada por:

$$
T^{\prime \prime}=\frac{I_{3}}{I}=(1-R)^{2} e^{-a t}=\chi e^{-a t}
$$

$\chi$ é a redução da intensidade da reflexão igual a $(1-\mathrm{R})^{2}, \mathrm{R}$ é a reflexão correspondente a luz refletida de uma única superficie de vidro polida. Esta proporção depende do índice de refração do vidro, $n$, e do ângulo de incidência, ou os ângulos da perpendicular em que a luz atinge a superfície. Para incidência normal, $R$, a fração de luz refletida por uma única superfície pode ser determinada pela formula de Fresnel como sendo

$$
R=\left(\frac{n-1}{n+1}\right)^{2}
$$

Para um vidro cujo índice de refração é 1.5 a perda por refletância é de $4 \%$ enquanto que para $n=2.0$ a perda chega $11.1 \%$. Levando isso em consideração o coeficiente de absorção pode ser escrito como.

$$
\alpha=\frac{1}{l} \ln \frac{T}{(1-R)^{2}}
$$

\subsection{Espectroscopia de Lente Térmica}

Na determinação das propriedades termo-ópticas e eficiência quântica utilizamos a espectroscopia de lente térmica (ELT) no modo descasado, cujo modelo teórico foi discutido anteriormente na tese de mestrado de Sampaio (1997), e por Pereira (1997) que discute os vários modelos teóricos da ELT. A seguir é apresentada a configuração 
experimental utilizada em nossos experimentos, a obtenção dos parâmetros usados para fazer os ajustes teóricos dos dados experimentais.

\subsection{O arranjo experimental da espectroscopia de lente térmica}

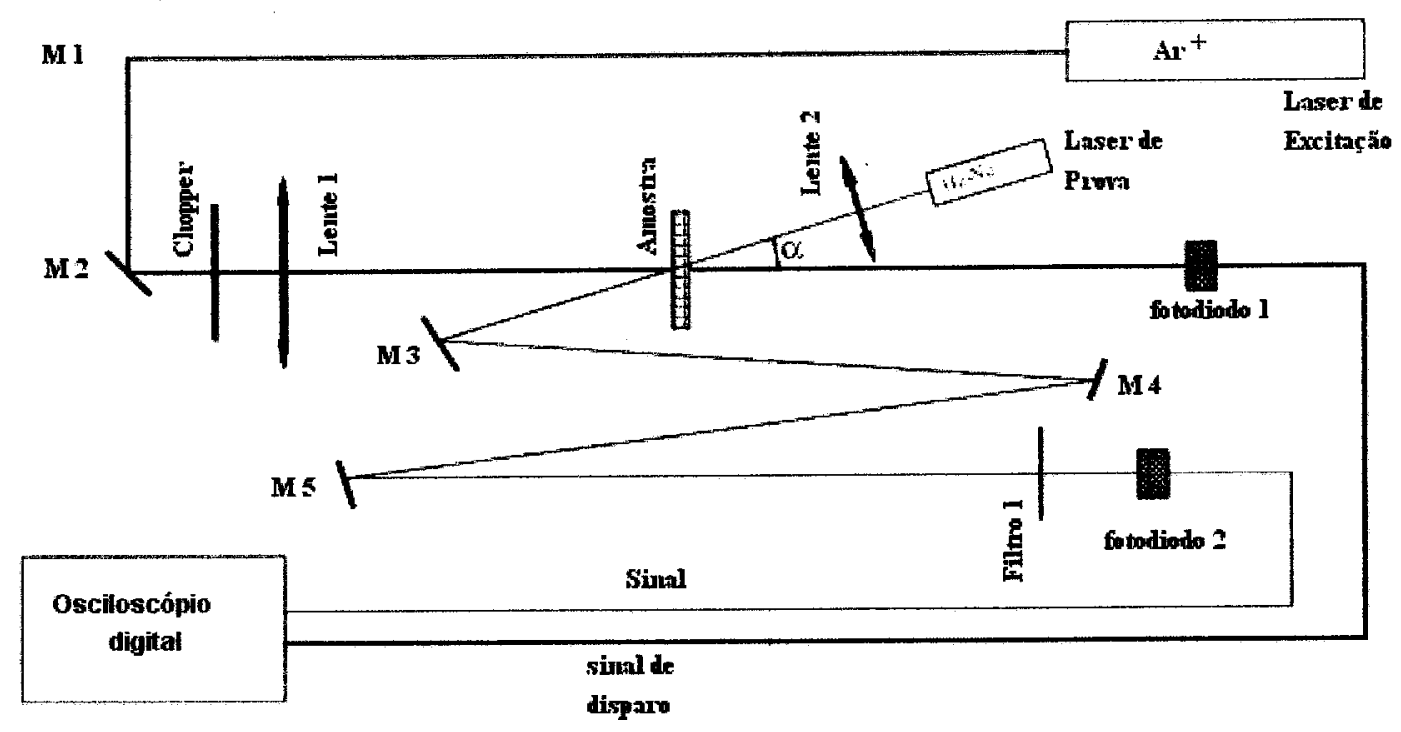

Figura 4.9 - Arranjo experimental do sistema de lente térmica no modo descasado.

O arranjo experimental da técnica de lente térmica é muito sensível, uma vez que a determinação dos parâmetros experimentais usados para fazer o ajuste teórico dos dados experimentais depende do tipo de lente usada, das distâncias entre os elementos. Na figura 4.9 é ilustrada a representação do arranjo experimental da espectroscopia de lente térmica no modo descasado. O feixe do laser de excitação é desviado pelos espelhos M1 e M2 sendo em seguida focalizado por uma lente convergente, $f=10 \mathrm{~cm}$, com o obturador colocado em seu foco, este dispositivo permite temporizar de forma precisa a exposição do feixe do laser de excitação na amostra; o feixe do laser passa novamente por outra lente convergente, $f=10 \mathrm{~cm}$, sendo focalizado por uma outra lente, que pode ser de $5,10,15,20$ ou $25 \mathrm{~cm}$. Uma lente com foco menor garante uma maior potência de excitação na amostra. Usamos em nossos experimentos uma lente de $f=20 \mathrm{~cm}$. A amostra foi posicionada na cintura do feixe de excitação, ou seja, posição onde a potência é maior. Após passar pela amostra o laser de excitação incide no fotodiodo que está conectado ao osciloscópio digital, o qual registra o sinal de disparo (trigger). Se o fotodiodo for muito sensível pode-se utilizar um filtro para minimizar o sinal. No caso do laser de $\mathrm{He}-\mathrm{Ne}$, o 
feixe é desviado pelo espelho $\mathrm{M} 3$ e focalizado por uma lente convergente, $f=20 \mathrm{~cm}$. $\mathrm{O}$ alinhamento é feito de maneira que o laser de He-Ne cruze na cintura do feixe do laser de Ar, posição em que está a amostra, com um ângulo de aproximadamente 1,5 graus. Ao passar pela amostra o feixe do laser de He-Ne é desviado pelos espelhos, M4 e M5 até atingir o fotodiodo 2 . Um caminho longo, aproximadamente $3 \mathrm{~m}$, garante que apenas o centro do feixe do laser de prova será detectado pelo fotodiodo 2 . O laser de prova na amostra encontra-se na sua região confocal.

Em nosso experimentos de ELT usamos um laser de He-Ne operando em $632.8 \mathrm{~nm}$, marca Coherente, potência de $5 \mathrm{~mW}$, como laser de prova, e, um laser de Argônio marca Cohente, potência de $5 \mathrm{~W}$ em modo multilinhas (potência máxima de $1.2 \mathrm{~W}$ em $514 \mathrm{~nm}$, como laser de excitação. Realizou-se também experimentos excitando a amostra com um laser de titânio-safira, marca coherente, o qual é bombeado por um laser de argônio, no modo multilinha, com potência de bombeio de $5 \mathrm{~W}$, sendo a potência de saída máxima de $500 \mathrm{~mW}$.

\subsection{Determinação da cintura do feixe do laser}

A montagem experimental foi feita em cima de uma mesa óptica. Para determinarmos de maneira precisa as posições das lentes, amostra e filtros, utilizamos um trilho óptico acoplado a uma régua de aproximadamente $1 \mathrm{~m}$. Usamos dois métodos para determinar a cintura do feixe do laser e seus parâmetros confocais. $O$ primeiro método consiste em usar um detector de potência e um pinhole de $4 \mu \mathrm{m}$, e verificar como varia a intensidade do feixe do laser conforme desloca-se o detector da posição próxima à lente em direção a seu foco; o segundo consiste em usar um medidor de diâmetro de feixe de laser (Omega Meter - Beam Profiler, marca Thorblass, modelo WM100). Há vantagens e desvantagens entre os dois métodos. No primeiro método a desvantagem é o tempo que se gasta para medir a potência em cada ponto, já que o feixe do laser deve passar pelo pinhole, a vantagem é que se tem um valor mais confiável dos parâmetros obtidos. $\mathrm{O}$ segundo método tem como vantagem, a rapidez com que se pode medir a posição do diâmetro do feixe, entretanto sua desvantagem é a alta sensibilidade do detector, pois não se pode incidir potências muito altas, já que ocasiona sobrecarga do sinal, este problema pode ser contornado usando filtros. Entretanto estes filtros podem deslocar a posição exata da cintura do feixe do laser. Após determinados os parâmetros experimentais, colocamos 
uma amostra padrão para determinarmos a sua difusividade térmica, e assim garantir que a cintura do feixe do laser é exatamente aquela. Caso haja alguma diferença, é feito o ajuste usando o micrômetro do XYZ em que se encontra a amostra.

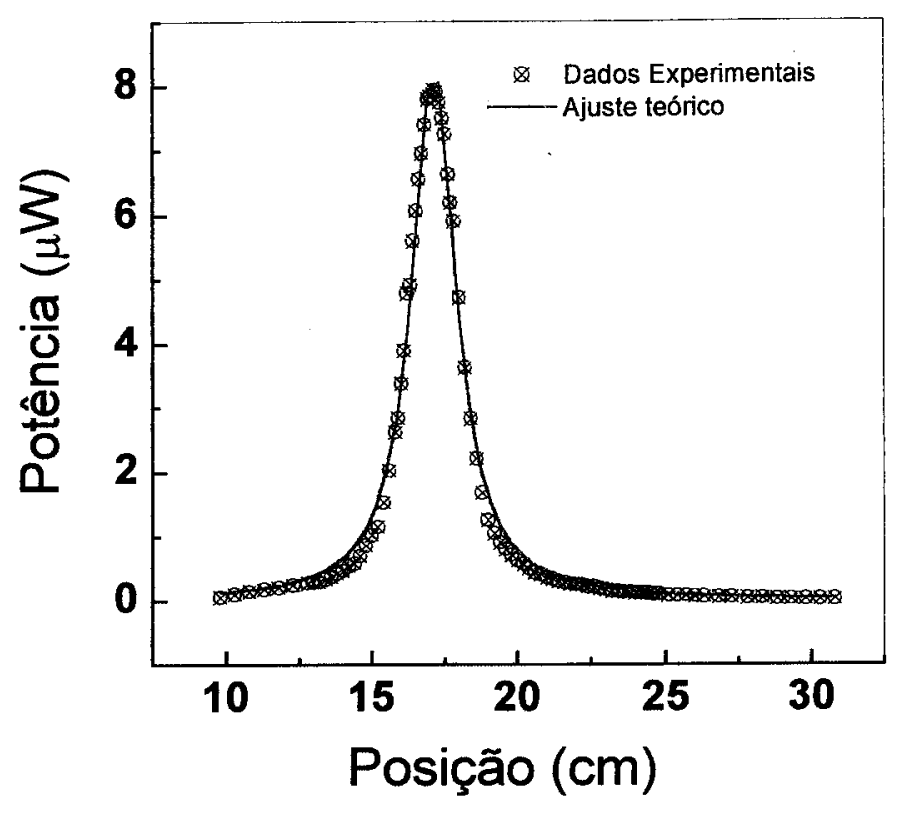

Figura 4.10 - Posição da cintura do laser de Argônio em $488 \mathrm{~nm}$ sendo focalizado por uma lente de $f=20 \mathrm{~cm}$.

Como exemplo tomemos o caso do laser de argônio em $488 \mathrm{~nm}$, e uma lente de $f=$ $20 \mathrm{~cm}$. Uma vez que sabemos que a cintura do feixe do laser estará na posição focal, podese iniciar a medida da potência aproximadamente 5 a $10 \mathrm{~cm}$ da lente. Conforme deslocamos o detector desde à lente até a sua posição focal percebermos que ocorre um aumento da intensidade do laser. Próximo à região focal é interessante diminuir o intervalo entre um ponto e outro a fim de obter-se vários pontos para um ajuste satisfatório. Ao passarmos pelo foco perceberemos que o valor da intensidade do laser começará a decair. Esse comportamento é ilustrado na figura 4.10. Esses dados devem ser anotados e tabelados de maneira que se possa fazer um gráfico para determinar os parâmetros que estamos interessados. O ajuste dos dados experimentais é feito utilizando a seguinte equação:

$$
I=I_{0} /\left(1+\sqrt{\frac{Z-Z_{o}}{Z_{c}}}\right)
$$


em que, I é a intensidade do laser (obtida experimentalmente), $Z$ é a variável das abscissas (obtida experimentalmente), $I_{0}$ é o valor máximo da potência, $Z_{0}$ é a posição da cintura do laser, $Z_{c}$ é a distância confocal. No caso do exemplo acima obtivemos $P_{o}=8.3$ Volts, $Z_{0}=$ $17.1 \mathrm{~cm} \mathrm{e} Z_{\mathrm{c}}=0.93 \mathrm{~cm}$. O diâmetro do feixe do laser de argônio em $\lambda=488 \mathrm{~nm}$ é dada por:

$$
\omega_{0}=\sqrt{\frac{Z_{c} \lambda}{\pi}}=\sqrt{\frac{0.93 \times 10^{-2} \mathrm{~m} \times 488 \times 10^{-9} \mathrm{~m}}{\pi}}=3.8 \times 10^{-3} \mathrm{~cm}(4.35)
$$

Embora pelo segundo método seja mais rápido obter a posição da cintura e o valor do diâmetro do feixe temos que calcular o parâmetro confocal $Z_{\mathrm{c}}$. Desta forma procedemos como no primeiro método, ou seja, medimos o diâmetro do feixe do laser em várias posições na frente da lente de $f=20 \mathrm{~cm}$, passando pela seu foco e indo um pouco além deste. $O$ menor tempo nessa medida deve-se ao fato de que o feixe do laser incidi diretamente no detector, não há uso de pinhole. No caso da medida da cintura do feixe do laser de He-Ne em $632.8 \mathrm{~nm}$ foram feitas 42 medições em pontos diferentes. $\mathrm{O}$ medidor de diâmetro de feixe laser fornece o valor de $\omega_{0} \mathrm{em} \mu \mathrm{m}$. Fazendo-se um gráfico do quadrado desses valores, $\omega_{0}^{2}$, em função da distância, vamos obter uma parábola, que pode ser ajustada pela equação $y=A+B x+C x^{2}$, fornecendo os parâmetro A, B e C. O centro da parábola é dada pela seguinte equação:

$$
Z_{0}=\frac{-B}{2 C}
$$

$\mathrm{Na}$ figura 4.11 temos os valores experimentais para o laser de $\mathrm{He}-\mathrm{Ne}$ em $632.8 \mathrm{~nm}$. $\mathrm{O}$ valor dos parâmetros de ajustes foram: $\mathrm{A}=0.011, \mathrm{~B}=-9.953 \times 10^{-4}, \mathrm{C}=2.33 \times 10^{-5}$. Usando a equação 4.36 obtemos $Z_{0}=21.4 \mathrm{~cm}$, que é a posição da cintura do laser de HeNe.

Para determinarmos o valores do parâmetro confocal, $Z_{c}$, fizemos o seguinte procedimento: diminui-se dos valores das abscissas o valor da posição da cintura do laser, $Z_{0}$, no caso particular acima $Z_{0}=21.4 \mathrm{~cm}$. Fizemos novamente o gráfico e ajustamos com a equação da parábola, $y=A+B x+C x^{2}$, e obtemos novamente os parâmetros $\mathrm{A}, \mathrm{B}$ e C. A posição confocal é dada pela seguinte equação: 


$$
Z_{c}=\sqrt{\frac{A}{C}}
$$

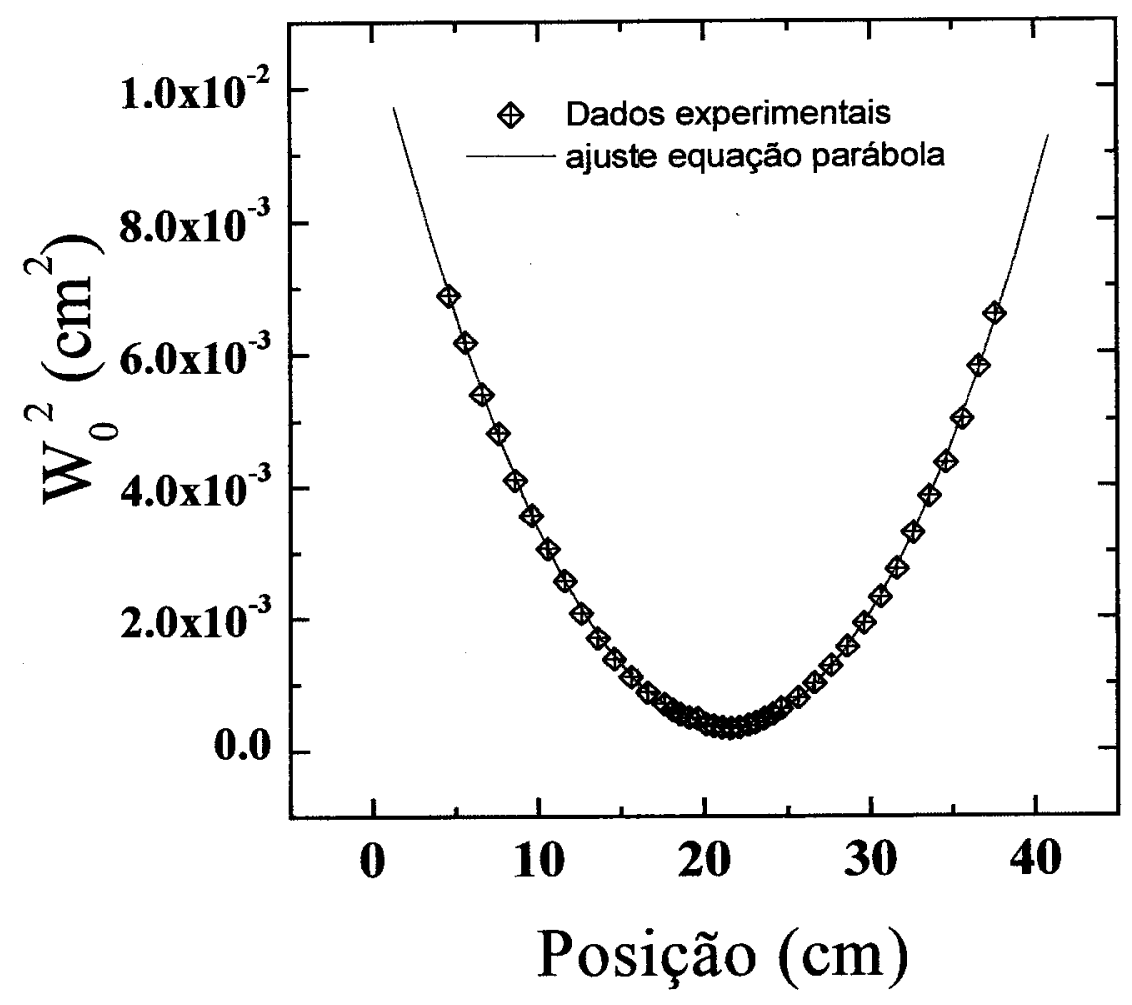

Figura 4.11 - Quadrado do diâmetro do feixe de laser de He-Ne em função da distância da lente convergente de foco, $f=20 \mathrm{~cm}$.

A figura 4.12 mostra os dados experimentais e a curva de ajuste. Para esse caso o parâmetro $\mathrm{A}=3.48 \times 10^{-4}, \mathrm{~B}=-3.72 \times 10^{-7} \mathrm{e} \mathrm{C}=2.33 \times 10^{-5}$. Usando a equação 4.37 temos que o parâmetro confocal para o laser de $\mathrm{He}-\mathrm{Ne}$ é $\mathrm{Z}_{\mathrm{c}}=3.87 \mathrm{~cm}$. Usando novamente a equação 4.35 obtemos o valor do diâmetro do feixe $\omega_{0}=8.83 \times 10^{-3} \mathrm{~cm}$.

Supondo que esses dados serão os usados para configurar nosso arranjo experimental temos resumidamente:

Tabela 4.3 - Parâmetros experimentais para determinação da cintura do laser.

\begin{tabular}{lclcc} 
& $\lambda(\mathrm{nm})$ & $\omega_{0}(\mathrm{~cm})$ & $Z_{0}(\mathrm{~cm})$ & \multicolumn{1}{c}{$Z_{\mathrm{c}}(\mathrm{cm})$} \\
$\mathrm{He}-\mathrm{Ne}$ & 632.8 & $8.83 \times 10^{-3}$ & 21.4 & 3.87 \\
$\mathrm{Ar}$ & 488.0 & $3.80 \times 10^{-3}$ & 17.1 & 0.93
\end{tabular}




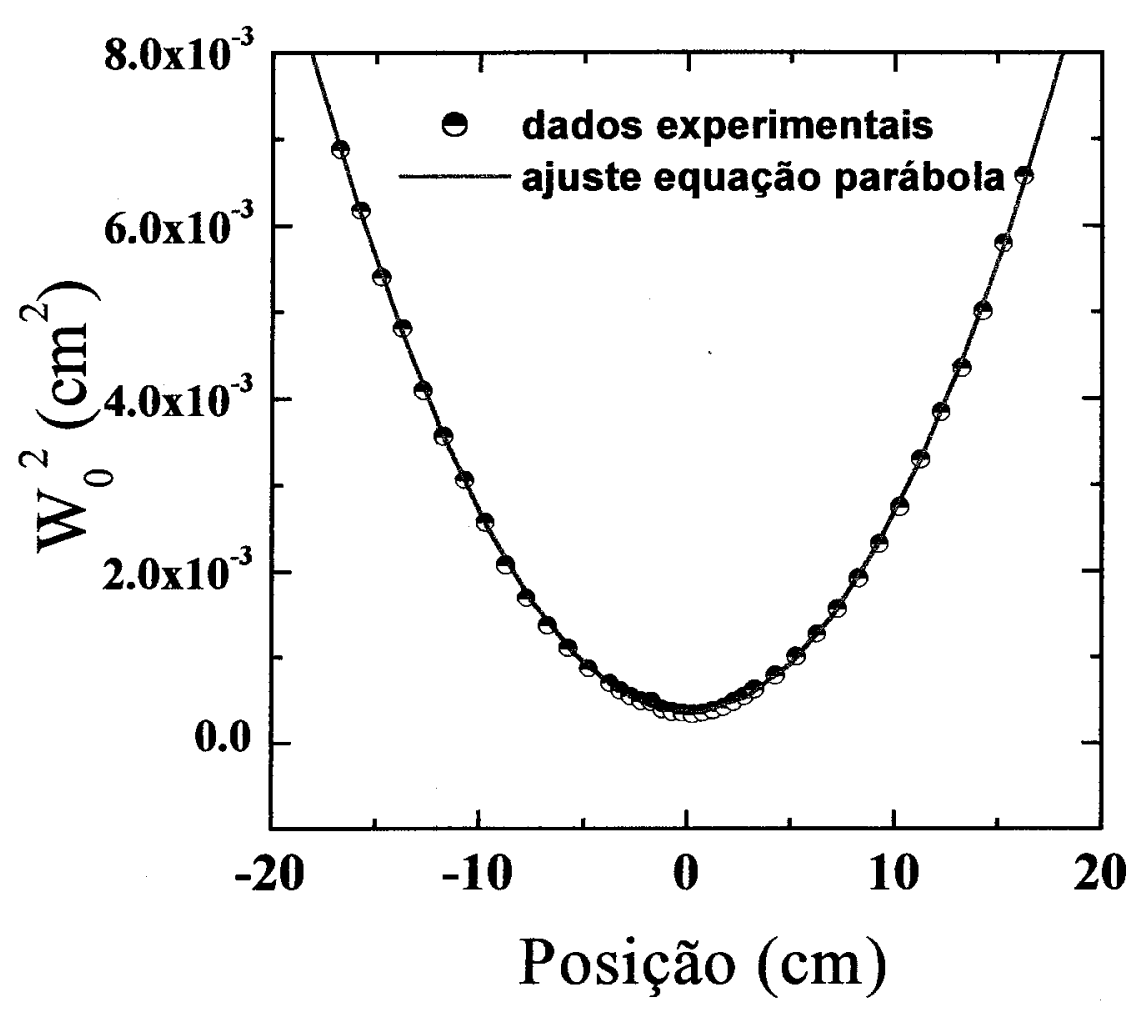

Figura 4.12 - Quadrado do diâmetro do feixe de He-Ne em $632.8 \mathrm{~nm}$, com o centro da parábola em $x=0$.

Com base nesses resultados podemos agora determinar os parâmetros experimentais, $m$ e $V$, a serem usados na equação teórica para se fazer o ajuste dos dados. O parâmetro $m=\left(\omega_{1 p} / \omega_{e}\right)^{2}$ onde $\omega_{1 p}=\omega_{0} \sqrt{1+V^{2}}$, com $V=Z_{1} / Z_{c p}$, e $Z_{1}=Z-Z_{\mathrm{op}}$, em que é $\mathrm{Z}$ a distância da lente do feixe de prova até a amostra e $Z_{\text {op }}$ a posição da cintura do feixe de prova. Supondo agora $Z=31.4 \mathrm{~cm} \mathrm{e} Z_{\text {op }}=21.4 \mathrm{~cm}$, temos que $Z_{1}=10 \mathrm{~cm}, V=$ 2.58 , conseqüentemente $\omega_{l p}=24.47 \times 10^{-3} \mathrm{~cm}$, portanto o valor de $m=41.5$. Os valores de $m$ e $V$ usados nos ajustes dos dados experimentais são dados nas tabelas 4.4 e 4.5 . 
Tabela 4.4 - Parâmetros experimentais usados na ELT para as amostras dopadas com $\mathrm{Er}_{2} \mathrm{O}_{3}$.

\begin{tabular}{|c|c|c|c|c|c|c|}
\hline Atmosfera de fusão & & vácuo & ar & vácuo e ar & ar & vácuo \\
\hline Laser de prova & & $\mathrm{He}-\mathrm{Ne}$ & $\mathrm{He}-\mathrm{Ne}$ & $\mathrm{He}-\mathrm{Ne}$ & $\mathrm{He}-\mathrm{Ne}$ & $\mathrm{He}-\mathrm{Ne}$ \\
\hline$\lambda_{\mathrm{p}}$ & $\mathrm{nm}$ & 632,8 & 632,8 & 632,8 & 632,8 & 632,8 \\
\hline$\omega_{0 p}\left(\times 10^{-3}\right)$ & $\mathrm{cm}$ & 10,4 & 9,05 & 8,824 & 8,824 & 8,824 \\
\hline$Z_{\mathrm{op}}$ & $\mathrm{cm}$ & 22,6 & 21,8 & 21,4 & 21,4 & 21,4 \\
\hline$Z_{\mathrm{cp}}$ & $\mathrm{cm}$ & 5,37 & 4,1 & 3,87 & 3,87 & 3,87 \\
\hline$\omega_{1 \mathrm{p}}\left(\mathrm{x} 10^{-3}\right)$ & $\mathrm{cm}$ & 20,1 & 18,3 & 18,54 & 18,54 & 18,54 \\
\hline $\mathrm{Z}$ & $\mathrm{cm}$ & 31,5 & 28,9 & 28,5 & 28,5 & 28,5 \\
\hline$Z_{1}=Z-Z_{\text {op }}$ & $\mathrm{cm}$ & 8,9 & 7,1 & 7,1 & 7,1 & 7,1 \\
\hline $\mathbf{V}=\mathrm{Z}_{\mathrm{l}} / \mathrm{Z}_{\mathrm{cp}}$ & & 1,657 & 1,753 & 1,848 & 1,848 & 1,848 \\
\hline Laser de excitação & & $\mathrm{Ar}$ & $\mathrm{Ar}$ & $\mathrm{Ti}: \mathrm{Al}_{2} \mathrm{O}_{3}$ & $\mathrm{Ti}: \mathrm{Al}_{2} \mathrm{O}_{3}$ & $\mathrm{Ti}: \mathrm{Al}_{2} \mathrm{O}_{3}$ \\
\hline$\lambda_{\mathrm{e}}$ & $\mathrm{nm}$ & 488 & 488 & 804 & 800 & 788,5 \\
\hline$\omega_{\mathrm{oe}}\left(\mathrm{x} 10^{-3}\right)$ & $\mathrm{cm}$ & 4,2 & 6,26 & 6,20 & 4,954 & 5,73 \\
\hline$Z_{\mathbf{o e}}$ & $\mathrm{cm}$ & 17,1 & 19,2 & 24,7 & 24,9 & 24,4 \\
\hline$Z_{\mathrm{ce}}$ & $\mathrm{cm}$ & 0,93 & 2,5 & 1,5 & 0,93 & 1,31 \\
\hline $\mathbf{M}$ & & 22,97 & 8,51 & 8,943 & 14,01 & 8,943 \\
\hline
\end{tabular}


Tabela 4.5 - Parâmetros experimentais usados na ELT para as amostras dopadas com $\mathrm{Nd}_{2} \mathrm{O}_{3}$.

\begin{tabular}{|c|c|c|c|c|c|c|c|c|c|}
\hline $\begin{array}{l}\text { Atmosfera de } \\
\text { fusão }\end{array}$ & & vácuo & vácuo & vácuo & ar & vácuo & vácuo & vácuo & ar \\
\hline Laser de prova & & $\mathrm{He}-\mathrm{Ne}$ & $\mathrm{He}-\mathrm{Ne}$ & $\mathrm{He}-\mathrm{Ne}$ & $\mathrm{He}-\mathrm{Ne}$ & $\mathrm{He}-\mathrm{Ne}$ & $\mathrm{He}-\mathrm{Ne}$ & $\mathrm{He}-\mathrm{Ne}$ & $\mathrm{He}-\mathrm{Ne}$ \\
\hline$\lambda_{\mathrm{p}}$ & $\mathrm{nm}$ & 632,8 & 632,8 & 632,8 & 632,8 & 632,8 & 632,8 & 632,8 & 632,8 \\
\hline$\omega_{0 \mathrm{p}}\left(\times 10^{-3}\right)$ & $\mathrm{cm}$ & 8,9 & 9,474 & 8,9 & 8,9 & 8,9 & 8,9 & 8,9 & 8,9 \\
\hline$Z_{\mathrm{op}}$ & $\mathrm{cm}$ & 21,638 & 14,978 & 21,6 & 21,6 & 21,638 & 21,6 & 21,638 & 21,6 \\
\hline$Z_{c p}$ & $\mathrm{~cm}$ & 3,933 & 4,456 & 3,93 & 1,15 & 3,933 & 3,93 & 3,933 & 1,15 \\
\hline$\omega_{1 p}\left(\times 10^{-3}\right)$ & $\mathrm{cm}$ & 17,78 & 18,915 & 17,78 & 17,78 & 17,78 & 17,78 & 17,78 & 17,78 \\
\hline Z & $\mathrm{cm}$ & 28,5 & 22,7 & 28,4 & 28,5 & 28,5 & 28,4 & 28,5 & 28,5 \\
\hline$Z_{1}=Z-Z_{\mathrm{op}}$ & $\mathrm{cm}$ & 7,7 & 7,7 & 6,8 & 8,7 & 6,8 & 6,8 & 6,8 & 8,7 \\
\hline$V=Z_{1} / Z_{c p}$ & & 1,064 & 1,728 & 1,73 & 1,73 & 1,73 & 1,73 & 1,73 & 1,73 \\
\hline $\begin{array}{l}\text { Laser } \\
\text { excitação }\end{array}$ & & $\mathrm{Ar}$ & $\mathrm{Ar}$ & ${ }_{3}^{\mathrm{Ti}: \mathrm{Al}_{2} \mathrm{O}}$ & $\mathrm{Ar}$ & Ti: $\mathrm{Al}_{2} \mathrm{O}$ & ${ }_{3}^{\mathrm{Ti}}: \mathrm{Al}_{2} \mathrm{O}$ & $\begin{array}{l}\mathrm{Ti}: \mathrm{Al}_{2} \mathrm{O} \\
3\end{array}$ & $\mathrm{Ar}$ \\
\hline$\lambda_{\mathrm{e}}$ & $\mathrm{nm}$ & 357,0 & 514,5 & 810 & 514,5 & 594,0 & 883,2 & 750,1 & 514,5 \\
\hline$\omega_{o e}\left(\times 10^{-3}\right)$ & $\mathrm{cm}$ & 1,83 & 6,938 & 3,82 & 3,3 & 10,02 & 5,78 & 13,51 & 3,3 \\
\hline$Z_{\mathbf{o e}}$ & $\mathrm{cm}$ & 12,6 & 20,1 & 21,1 & 19,8 & 19,089 & 22,72 & 21,09 & 19,8 \\
\hline$Z_{\mathrm{ce}}$ & $\mathrm{cm}$ & 0,295 & 2,94 & 1,31 & 0,67 & 5,31 & 1,19 & 0,5658 & 0,67 \\
\hline $\mathbf{M}$ & & 50,464 & 7,289 & 21,66 & 29,029 & 3,15 & 9,46 & 23,34 & 29,029 \\
\hline
\end{tabular}




\subsection{Determinação do coeficiente de absorção óptica $(\alpha)$}

O coeficiente de absorção óptica, $\alpha$, é um dos parâmetros mais críticos a ser determinado no experimento de lente térmica, principalmente no casos de amostras matrizes (sem dopantes) que não possuem bandas de absorção intensas. Além de parâmetro fundamental na normalização do efeito de lente térmica, o coeficiente de absorção óptica permite também verificar se a dopagem de um determinado ín foi realmente eficaz. No caso do aumento da linear na concentração de $\mathrm{Nd}^{3+}$ deveremos ter um aumento também linear no coeficiente de absorção óptica, garantido que o dopante entrou na estrutura do vidro, ou seja não houve perdas durante a fusão por volatização.

No caso dos vidros fluoretos devido a sua alta transparência, a determinação de $\alpha$ acaba sendo uma tarefa muito difícil, dificuldade que é também encontrada em menor escala para os vidros aluminato de cálcio, silicatos, fosfatos. Essa medida pode ser feita em um espectrofotômetro, porém os resultados podem ser ligeiramente diferentes dos medidos na montagem de lente térmica, já que nesse equipamento a medida é feita em uma região muito grande, quando comparada com a região iluminada pelo feixe de laser. Além disso, a vantagem de se medir o coeficiente de absorçãoóptica na montagem de lente térmica é a garantia que a posição da amostra é a mesma na qual foi feita a medida do efeito térmico. Uma outra dificuldade de se medir $\alpha$ é quando a amostra não é homogênea, o que resulta em diferentes valores de $\alpha$ para diferentes regiões da mesma amostra.

A mensuração de $\alpha$ é feita colocando a amostra na mesma posição que é feito o experimento de lente térmica, ou seja, na cintura do feixe do laser de excitação, onde a potência é máxima. A transmitância é obtida incidindo o laser de excitação em várias potências, de maneira a obter-se aproximadamente 15 pontos. Primeiramente mede-se a potência incidente, e em seguida a potência transmitida, como ilustrado na figura 4.13. Em seguida faz-se o ajuste linear destes dados, $y=a+b x$, em que $y$ é a potência transmitida $\mathrm{e}$ $x$ e a potência incidente, $a$ e uma constante e $b$ é o coeficiente angular da reta, ou seja, a transmitância da amostra. No caso da amostra de vidro aluminato de cálcio dopado com $4 \%$ de $\mathrm{Er}_{2} \mathrm{O}_{3}$ fundida a vácuo, cuja espessura é 0.283 , encontramos que a sua transmitância é 
0.788 \pm 0.003 . Entretanto na transmitância obtida não está incluso as perdas por reflatância. Ou seja é necessário ainda determinarmos a transmitância efetiva. Usando a equação de Fresnel para a reflatância $R=((n-1) /(n+1))^{2}$ e tomando $n \cong 1,674$, no caso dos vidros aluminato de cálcio, temos $\mathrm{R}=0,063$. A transmitância medida é dada por $T_{\text {medida }}=(1-R)^{2} T_{\text {efetiva }}$ ou seja $T_{\text {medida }}=0.88 T_{\text {efetiva }}$. Usando agora a lei de Beer, temos que $\alpha=(1 / l) \ln T_{\text {eftiva }}=0.390 \mathrm{~cm}^{-1}$

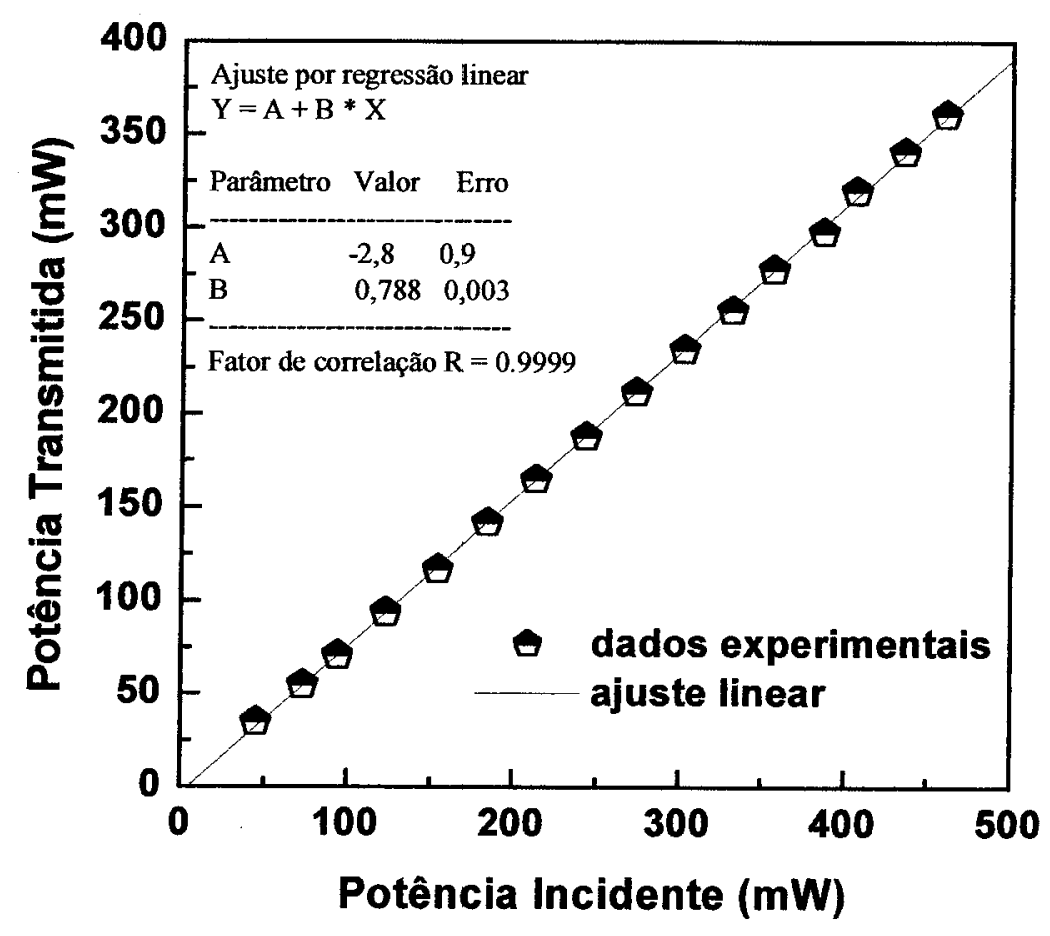

Figura 4.13 - Transmitância vidro aluminato de cálcio dopado com $4 \% \mathrm{Er}_{2} \mathrm{O}_{3}$. Amostras fundida a vácuo.

\subsection{O efeito de lente térmica no estado estacionário}

A determinação do efeito de lente térmica no estado estacionário garante obtermos um conjunto de dados que leva em consideração diferentes potências do laser de excitação. Além disso é possivel verificar se há alguma mudança abrupta com a potência de excitação. 
Para determinarmos o efeito de lente térmica no estado estacionário, a amostra é posicionada na cintura do feixe de excitação e na posição confocal do laser. É escolhida uma região da amostra na qual o feixe do laser de prova no campo distante tenha um bom sinal; amostras com estrias, mal polimento, separação de fases resulta em sinais muito ruins. Escolhida a melhor região da amostra, faz a maximização do sinal do feixe do laser de prova incidente no detector em um campo distante. Feito isso o obturador do feixe do laser de excitação é aberto de maneira que este incida na amostra. Escolhe-se uma potência razoável para se observar o sinal de lente térmica. No caso de amostras com ds/dT maior que zero é feita a maximização do sinal, amostras com ds/dT menor que zero é feita a minimização do sinal, que é feita através da focalização do feixe do laser de excitação através do dispositivo $\mathrm{XY}$ da lente. Estando o sistema maximizado, são feitas as medidas em várias potências, aproximadamente 15 pontos. Para amostras com baixo coeficiente de absorção óptica são usadas potências mais altas, enquanto que potências mais baixas são usadas para amostras com alta absorção, de maneira que o sinal máximo de lente térmica seja de $20 \%$.

O sinal de lente térmica é monitorado por um multímetro que fornece o valor da intensidade do feixe do laser de prova no detector, com e sem o laser de excitação. $O$ fotodiodo usado em nossas medidas possui sensibilidade até $1 \mathrm{~V}$. Dependendo da qualidade óptica da amostra esse valor é ultrapassado, para evitar tal problema em nossos experimentos usamos filtros na frente do detector, quando necessário.

Para determinarmos o valor de $\theta$ (sinal de lente térmica) em função da potência no estado estacionário, usamos os valores de $\mathrm{I}(0)$ e $\mathrm{I}(\mathrm{t})$, dados pelas equações abaixo:

$$
I(t)=I(0)\left\{1-\frac{\theta}{2} \operatorname{atan}\left[\frac{2 m V}{\left[(1+2 m)^{2}+V^{2}\right] \frac{t_{c}}{2 t}+1+2 m+V^{2}}\right]\right\}^{2}
$$

em que;

$$
m=\left(\frac{\omega_{1 p}}{\omega_{e}}\right)^{2} ; V=\frac{Z_{1}}{Z_{c}} \text { quando } Z_{c} \gg Z_{2} ; t_{c}=\frac{\omega_{e}^{2}}{4 D} ; \theta=-\frac{P_{e} A_{e} l_{0}}{K \lambda_{p}} \frac{d s}{d T}
$$


Sendo:

$t_{c} \rightarrow$ Constante de tempo característica da lente térmica,

$\omega_{\mathrm{e}} \quad \rightarrow \quad$ Raio do feixe laser de excitação na amostra,

$\mathrm{D} \rightarrow$ Difusividade térmica da amostra $\left(\mathrm{cm}^{2} / \mathrm{s}\right)$,

$\mathrm{K} \rightarrow$ Condutividade térmica $\left(\mathrm{W} \mathrm{cm}^{-1} \mathrm{~K}^{-1}\right)$,

$\mathrm{P}_{\mathrm{e}} \rightarrow$ Potência do feixe laser de excitação $(\mathrm{mW})$,

$A_{e} \quad \rightarrow \quad$ Coeficiente de absorção óptica no comprimento de onda da luz do feixe do laser de excitação,

$l_{0} \quad \rightarrow \quad$ Espessura da amostra,

$Z_{c} \rightarrow$ Distância confocal do feixe de prova,

$Z_{I} \quad \rightarrow \quad$ Distância entre a cintura do laser de prova e a amostra,

$Z_{2} \quad \rightarrow \quad$ Distância entre a amostra e o detector,

$\omega_{l p} \rightarrow$ Raio do feixe laser de prova na amostra,

$\theta \rightarrow$ Aproximadamente a diferença de fase do feixe de prova entre $r=0$ e $r=\sqrt{2} \omega_{e}$ induzida pela lente térmica,

$\lambda_{p} \rightarrow$ Comprimento de onda do feixe de prova,

$I(0) \rightarrow$ O valor de I $(\mathrm{t})$ quando o transiente de tempo, t, ou $\theta$, é zero.

No caso estacionário o tempo $t$ tende a infinito, sendo a equação 4.38 reduzida a:

$$
\theta=2\left[1-\sqrt{\frac{I(t)}{I(0)}}\right]\left[\operatorname{atan}\left(\frac{2 m V}{1+2 m+V^{2}}\right)\right]^{-1}
$$

Nas medidas de resolução temporal usamos um chopper, cuja freqüência foi ajustada entre 4 e $10 \mathrm{~Hz}$, dependendo do tempo de resposta da amostra; um osciloscópio digital Tektronix modelo TDS 210, duplo traço de $60 \mathrm{MHz}, 1 \mathrm{GS} / \mathrm{s}$, usado para fazer a aquisição de dados através do programa fornecido pelo fabricante do equipamento. $O$ osciloscópio foi acoplado a um computador via cabo conectado a sua porta serial. $\mathrm{Na}$ maioria dos casos o tempo do transiente foi de $80 \mathrm{~ms}$. O osciloscópio foi programado para fazer infinitas médias dos transientes. Ou seja a aquisição dos dados foi feita até que a 
curva média não apresentasse ruídos. Na figura 4.14 é ilustrada a curva obtida na tela do osciloscópio, cujos dados são transferidos para o computador.

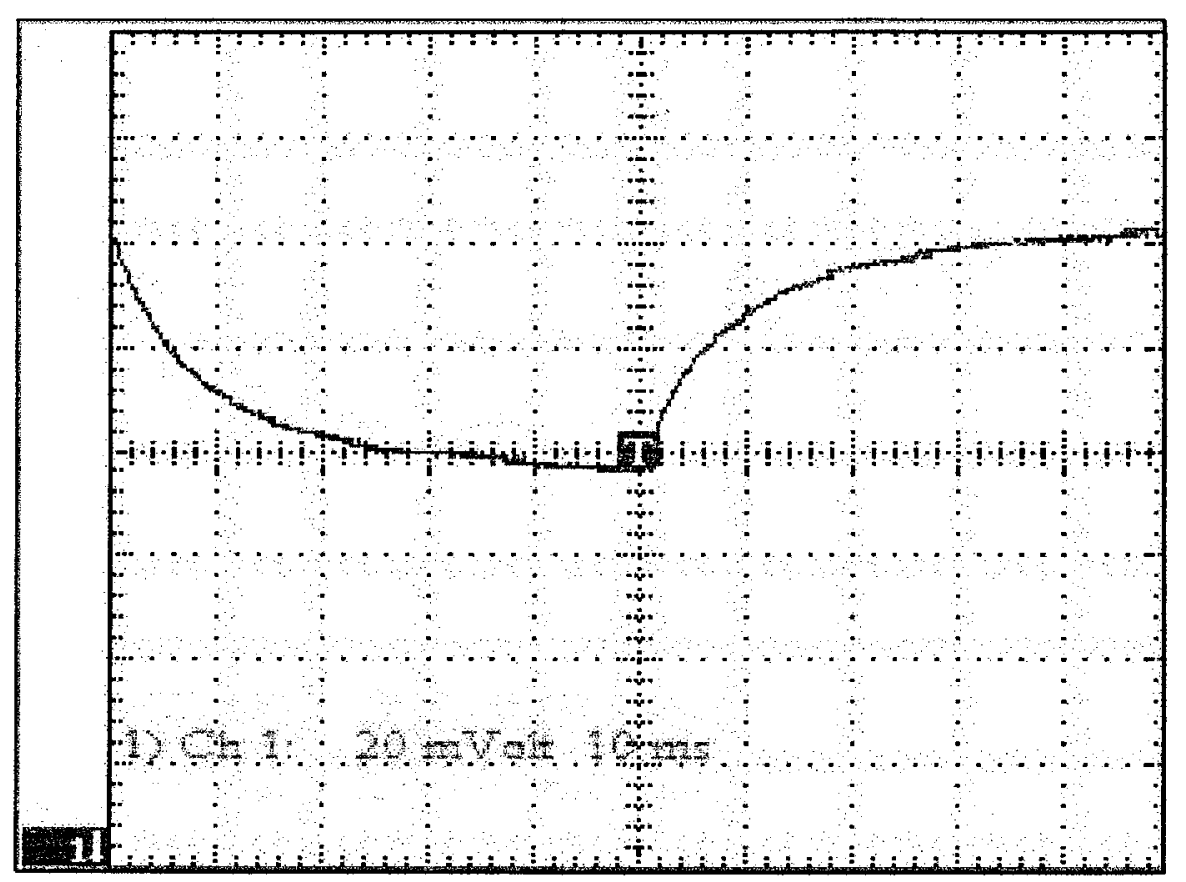

Figura 4.14 - Vista da evolução temporal do efeito de lente térmica em uma amostra de vidro com ds/dT positivo.

$\mathrm{Na}$ figura 4.15 temos a curva de resolução temporal do efeito de lente térmica para

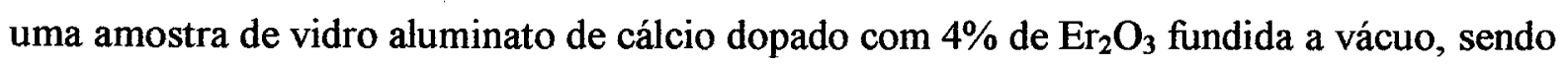
a potência do laser de excitação de $104 \mathrm{~mW}$, cujos dados são ajustados pela equação 6.5. Para cada amostra foram obtidas de três a quatro curvas e em seguida feita a média dos parâmetros para a obtenção de $\theta / \mathrm{P}$ e difusividade térmica.

A determinação da difusividade térmica, em temperatura ambiente, foi feita utilizando os resultados de $t_{c}$ através seguinte equação:

$$
D=\frac{\omega_{0}^{2}}{4 t_{c}}
$$




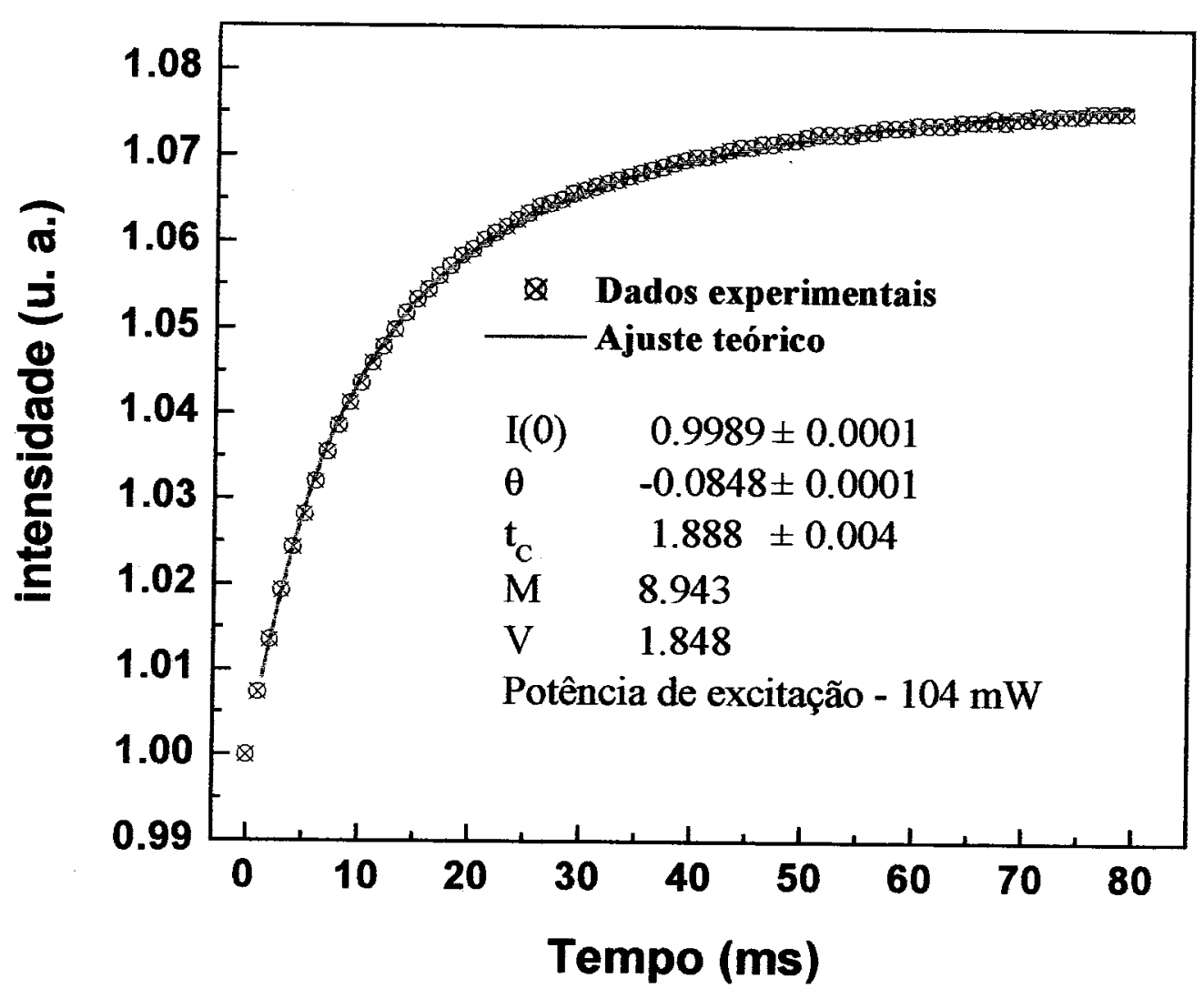

Figura 4.15 - Resolução temporal de lente térmica para uma amostra de vidro aluminato de cálcio dopada com $4.0 \% \mathrm{Er}_{2} \mathrm{O}_{3}$ - Fundida a vácuo - Espessura $0.283 \mathrm{~cm}$. Potência incidente na amostra de $104 \mathrm{~mW}$.

\subsection{Resistência ao Choque Térmico}

A resistência ao choque térmico é definida por Novotný et al. (1979) como a habilidade de um material suportar sem dano, a rápida mudança de temperatura, particularmente o resfriamento devido ao contado abrupto com um meio de menor temperatura. Na literatura, esta propriedade é também, às vezes, chamada de resistência térmica, $\mathfrak{R}$ (Volf, 1988). 
A resistência térmica $\mathfrak{R}$ depende das propriedades do vidro como por exemplo, o coeficiente de expansão térmica linear, $\alpha$, resistência mecânica, $P$, do módulo de elasticidade na tensão $\mathrm{E}$, do coeficiente de Poisson, $v$, e por último, mas não menos importante, da condutividade térmica (difusividade térmica), $k$, que é um critério da velocidade relativa pelo qual o calor atravessa o material aquecido. Entretanto, a resistência $\mathfrak{R}$ também depende da uniformidade do vidro, a continuidade e o estado de sua superficie, grau de recozimento, espessura das paredes, o tamanho do recipiente, ou seja do produto final em si.

Um material vítreo quebra mais facilmente sobre resfriamento rápido (abaixo de $\mathrm{T}_{\mathrm{g}}$ ) do que sobre aquecimento rápido. No caso de um material para laser, por exemplo um vidro dopado com $\mathrm{Nd}^{3+}$, que é colocado em uma cavidade laser ressonante, por exemplo na forma de anel, e é bombeada por um laser de argônio de alta potência, para emitir laser em um determinado comprimento, é necessário estar refrigerado para não afetar o desempenho da emissão laser. Normalmente uma dessas faces é refrigerada por água gelada, ou seja está sujeita ao choque térmico, devido ao aquecimento pelo laser de bombeio e ao resfriamento pela água gelada. Ao resfriamos rapidamente essa face do vidro estamos provocando no material uma tensão, por outro lado se o aquecermos rapidamente estamos provocando nele compressão. Os vidros são mais sensíveis à tensão do que à compressão. A resistência do vidro à tensão é geralmente muito menor (10 a 16 vezes) do que a compressão (Volf, 1988).

A resistência ao choque térmico $\mathfrak{R}$ é sempre entendida como resistência ao resfriamento rápido, sendo expressada de duas maneiras:

1. A maior diferença de temperatura que um material é capaz de resistir sem quebrar.

2. A maior diferença de temperatura na qual um material apenas quebrará.

$\mathrm{O}$ coeficiente de expansão térmica, $\alpha$, é a propriedade principal que afeta a resistência do vidro ao choque térmico. A resistência térmica, $\mathfrak{R}$, levando em consideração outras propriedades físicas, de acordo com a lei de Hooke é dada por:

$$
\Re=\chi \frac{P(1-v)}{\alpha \cdot 10^{6} E}
$$


em que: $\mathrm{P}$ é a resistência mecânica, $v$ é o coeficiente de Poisson, $\alpha$ é o coeficiente de expansão térmica $\left(10^{6} \mathrm{~K}^{-1}\right)$, E é o módulo de Young, $\chi$ é uma constante igual a unidade em primeira aproximação.

Entretanto na literatura a resistência ao choque térmico, $\mathfrak{R}$, para materiais laseres é reportada em termos da condutividade térmica, $\mathrm{x}$, tenacidade à fratura, $K_{I C}$, coeficiente de Poisson, $v$, coeficiente de expansão térmica linear, $\alpha$, módulo de Young E, e o raio das trincas no material, é dada por (Payne, 1995).

$$
\Re=\frac{\kappa K_{I C}(1-v)}{\alpha E \sqrt{l}}
$$

O parâmetro $\Re$ serve como figura de mérito para aplicações de alta potência, e está diretamente relacionado à carga máxima térmica que uma superficie resfriada de uma barra de um material laser pode contrair-se sem que haja fratura.

\subsection{Eficiência Quântica}

A eficiência quântica da fluorescência, $\eta$, é uma das propriedades mais importantes de materiais fluorescentes. A determinação de seu valor absoluto é um tanto quanto dificil. Há vários métodos na literatura para determinar $\eta$, como por exemplo o método de esfera integradora cuja desvantagem a necessidade de calibração do detector e inacurácia nos resultados uma vez que a luz da fluorescência é policromática; o método de fluorescência é dependente do tempo de vida e do decaimento da fluorescência, tornando-o inadequado para os sistemas de energia de multi-níveis, uma vez que o comportamento destes parâmetros não obedecem uma forma exponencial. Alguns métodos de técnicas fototérmicas são também usados para a determinação de eficiência quântica não radiativa (Baesso et al., 1998).

A determinação de $\eta$ usando a técnica de lente térmica foi introduzida por Brannon e Magde (1978). Posteriormente esta técnica foi usada para determinar $\eta$ de soluções fluorescentes (Lesiecki e Drake, 1982) e polímeros fluorescentes (Shen e Snook 1989). 
Nesses experimentos foram usadas configurações com feixe único ou modo casado, porém os resultados eram analisados através do modelo parabólico, que não é realístico, uma vez que não prevê os anéis observados em um campo distante durante os experimentos.

Sampaio (1997) usa pela primeira vez o modelo descasado lente térmica para determinar a eficiência quântica de vidros dopados com $\mathrm{Nd}^{3+}$, introduzindo um novo parâmetro na equação que descreve a variação da intensidade no centro do feixe de prova, equação 4.39, proposta por Baesso e Shen (1994). Esse novo parâmetro leva em consideração a fração de energia que não é convertida em calor. $O$ parâmetro $\theta$ da equação 4.39 é escrito como:

$$
\theta=-\frac{P_{e} \alpha L_{e f}}{K \lambda_{p}} \phi \frac{d s}{d T}
$$

com $\phi$ sendo igual a fração de energia convertida em calor. Para materiais que não possuem fluorescência $\phi=1$, ou seja a Eq. 4.39 continua sendo válida. No caso de materiais fluorescentes, como os dopados com terras raras, $\phi$ é escrito como:

$$
\phi=1-\eta \frac{\lambda_{e}}{\left\langle\lambda_{e m}\right\rangle}
$$

$\eta \quad \rightarrow \quad$ Eficiência quântica radiativa,

$\lambda_{\mathrm{e}} \quad \rightarrow$ Comprimento de onda do feixe de excitação,

$\left\langle\lambda_{e m}\right\rangle \rightarrow$ Comprimento de onda médio da fluorescência,

Em nosso grupo desenvolvemos duas maneiras de determinar a eficiência quântica utilizando a espectroscopia de lente térmica. A primeira é utilizando a amostra base como referência e o segundo método é determinando o efeito térmico em vários comprimentos de onda.

No primeiro método, supomos que o parâmetro $\frac{1}{K \lambda_{p}} \frac{d s}{d T}$ da equação 4.45 é aproximadamente o mesmo tanto para a amostra dopada quanto para a amostra base. Chamando $\Theta_{b}=\theta / P \alpha L_{e f}$, o sinal de lente térmica normalizado pela potência de excitação, absorção e espessura efetiva para a amostra base e $\Theta_{d}=\theta / P \alpha L_{e f}$ o sinal de lente térmica 
normalizado pela potência de excitação, absorção e espessura efetiva para a amostra dopada, temos que a fração de energia convertida em calor, é dada por: $\phi=\Theta_{d} / \Theta_{b}$. Desta forma a equação 4.45 pode ser reescrita como:

$$
\frac{\Theta_{d}}{\Theta_{b}}=1-\eta \frac{\lambda_{e}}{\left\langle\lambda_{e m}\right\rangle}
$$

conseqüentemente a eficiência quântica é dada por:

$$
\eta=\left(1-\frac{\Theta_{d}}{\Theta_{b}}\right) \frac{\left\langle\lambda_{e m}\right\rangle}{\lambda_{e}}
$$

A principal dificuldade deste método está em de medir o coeficiente de absorção óptica da amostra base, que é um parâmetro crucial na normalização de $\Theta_{b}$, quanto maior for a transparência da amostra maior será o erro na determinação da eficiência quântica. Uma alternativa para contornar esse problema seria adicionar ao vidro base pequenas quantidades de metais de transição, como por exemplo $\mathrm{Fe}^{3+}$, que não apresenta fluorescência, e portanto seria ideal para servir como referência, uma vez que facilitaria a medição do coeficiente de absorção óptica. Porém a introdução de metais de transição em vidros óxidos induz mudanças estruturais na rede vítrea e conseqüentemente nas propriedades térmica. Baesso et al. (1994) reportam os valores de $K$ e $d s / d T$ para vidros soda-lime, sem dopante e dopado com $\mathrm{Fe}^{3+}$. No caso do vidro base a condutividade térmica é de $10 \times 10^{-3} \mathrm{~W} \mathrm{~cm}^{-1} \mathrm{~K}^{-1}$ e ds/dT igual $2.1 \times 10^{-6} \mathrm{~K}^{-1}$, por outro lado a amostra dopada com $2 \%$ de ferro (em peso) a condutividade térmica é de $12 \times 10^{-3} \mathrm{~W} \mathrm{~cm}^{-1} \mathrm{~K}^{-1} \mathrm{e}$ ds/dT igual 4.7 x $10^{-6} \mathrm{~K}^{-1}$, em ambos os casos $\lambda_{p}$ foi $632.8 \mathrm{~nm}$. Desta forma o parâmetro $\frac{1}{K \lambda_{p}} \frac{d s}{d T}$ da equação 4.45 é de $3.32 \mathrm{~W}^{-1}$ para a amostra base e $6.19 \mathrm{~W}^{-1}$ para a amostra dopada com $2 \%$ de $\mathrm{Fe}_{2} \mathrm{O}_{3}$. Ou seja há uma diferença de aproximadamente $52 \%$. No caso dos vidros aluminato de cálcio essa discrepância é ainda maior. Para a amostra sem dopante $\frac{1}{K \lambda_{p}} \frac{d s}{d T}$ $=11.1 \mathrm{~W}^{-1}$, enquanto que para a amostra dopada com $1 \%$ em peso de $\mathrm{Fe}_{2} \mathrm{O}_{3}$ o valor é de 3.6 $\mathrm{W}^{-1}$, ou seja uma diferença de $300 \%$. Por essa razão não é possível usar um vidro aluminato 
de cálcio dopado com $\mathrm{Fe}^{3+}$ já que a suposição de que o parâmetro $\frac{1}{K \lambda_{p}} \frac{d s}{d T}$ não é válida quando comparado com o vidro sem dopante.

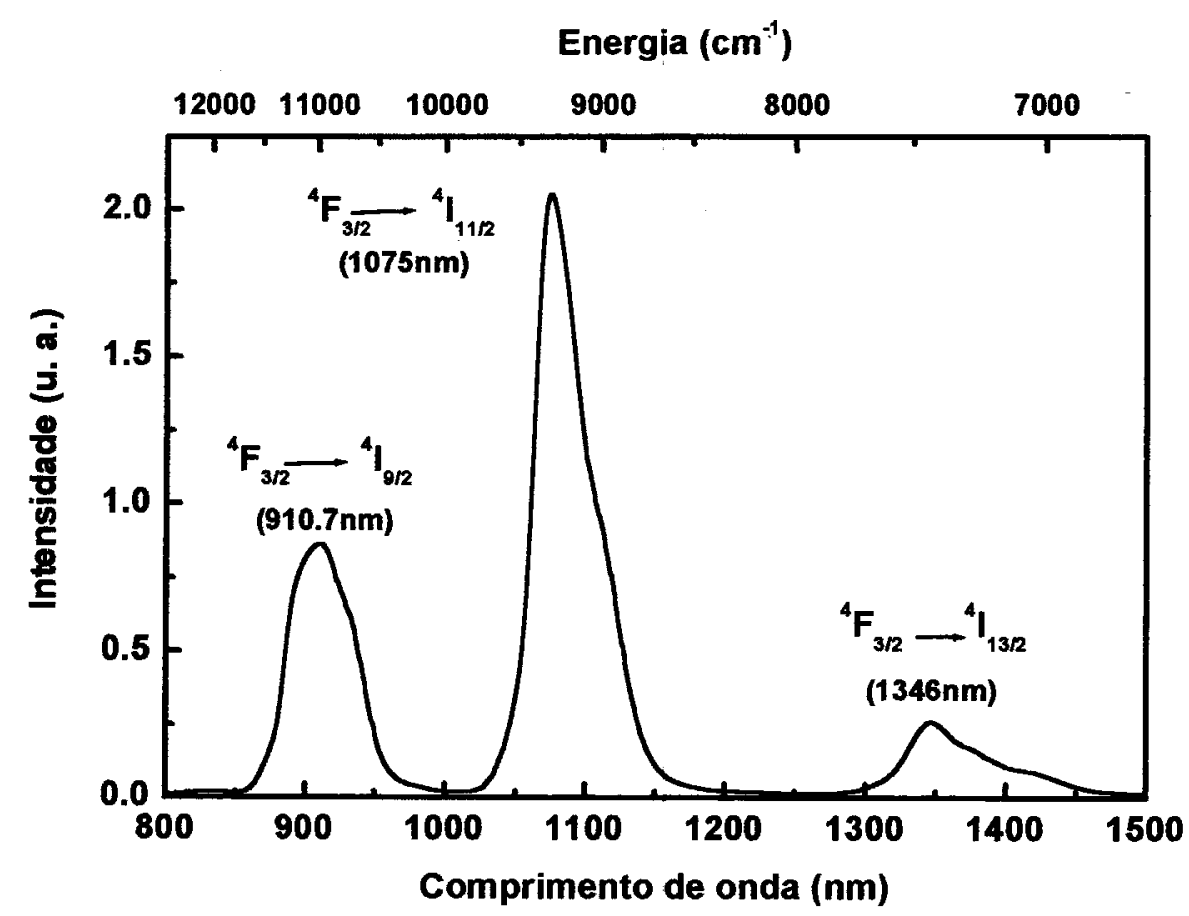

Figura 4.16 - Espectro de fluorescência de uma amostra de vidro aluminato de cálcio dopado com $2 \%$ de $\mathrm{Nd}_{2} \mathrm{O}_{3}$, com laser de excitação em $514 \mathrm{~nm}$, a $300 \mathrm{~K}$, $\lambda_{e}$ em $514.5 \mathrm{~nm}$. (Pecoraro, 1999).

$\mathrm{O}$ comprimento de onda médio da fluorescência, $\left\langle\lambda_{e m}\right\rangle$, foi obtido com base nos espectros de fluorescência das amostras investigadas por Pecoraro (1999). Esta média é feita baseada na razão de ramificação, "branching ratio", que é definida como a fração do processo de decaimento espontâneo total, da transição de um nível $a$ par um nível $b$. No caso do neodímio, devido às regras de seleção, as possíveis transições são quatro: ${ }^{4} \mathrm{~F}_{3 / 2} \rightarrow$ ${ }^{4} \mathrm{I}_{9 / 2},{ }^{4} \mathrm{~F}_{3 / 2} \rightarrow{ }^{4} \mathrm{I}_{11 / 2},{ }^{4} \mathrm{~F}_{3 / 2} \rightarrow{ }^{4} \mathrm{I}_{13 / 2} \mathrm{e}^{4} \mathrm{~F}_{3 / 2} \rightarrow{ }^{4} \mathrm{I}_{15 / 2}$, cujos comprimentos de ondas de emissão são respectivamente $910.7 \mathrm{~nm}, 1075 \mathrm{~nm}, 1346 \mathrm{~nm}$ e $1580 \mathrm{~nm}$. Para a amostra de vidro aluminato de cálcio dopada com $2 \%$ peso de $\mathrm{Nd}_{2} \mathrm{O}_{3}$, cujo espectro de fluorescência a $300 \mathrm{~K}$ é mostrada na figura 4.16. Para essa amostra temos que as branching ratios do nível ${ }^{4} \mathrm{~F}_{3 / 2}$ 
para os níveis ${ }^{4} \mathrm{I}_{9 / 2},{ }^{4} \mathrm{I}_{11 / 2},{ }^{4} \mathrm{I}_{13 / 2}$ e ${ }^{4} \mathrm{I}_{15 / 2}$ são respectivamente $0.42,0.49,0.08,0.006$. Desta forma temos que $\left\langle\lambda_{e m}\right\rangle=0.42 \times 910.7+1075 \times 0.49+0.08 \times 1346+0.006 \times 1580=1026$ $\mathrm{nm}$.

Tabela 4.6 - Propriedades espectroscópicas de vidros aluminato de cálcio dopados com $\mathrm{Nd}_{2} \mathrm{O}_{3}$. Comparação com os resultados reportados por Pecoraro et al. (1999).

\begin{tabular}{|c|c|c|c|c|c|c|}
\hline \multirow{2}{*}{$\begin{array}{c}\mathrm{Nd}_{2} \mathrm{O}_{3} \\
\text { (peso \%) }\end{array}$} & \multirow{2}{*}{$\begin{array}{c}\tau \\
(\mu s) \\
\end{array}$} & \multicolumn{4}{|c|}{ Branching ratios } & \multirow{2}{*}{$\begin{array}{r}\left\langle\lambda_{e m}\right\rangle \\
n \mathrm{~nm}\end{array}$} \\
\hline & & ${ }^{4} I_{9 / 2}$ & ${ }^{4} I_{11 / 2}$ & ${ }^{4} I_{13 / 2}$ & ${ }^{4} \mathrm{I}_{15 / 2}$ & \\
\hline 0,5 & 320 & 0,36 & 0,54 & 0,09 & 0,006 & 1039 \\
\hline 1,5 & 282 & 0,39 & 0,52 & 0,08 & 0,005 & 1030 \\
\hline 2,0 & 260 & 0,42 & 0,49 & 0,08 & 0,006 & 1026 \\
\hline 3,0 & 215 & 0,32 & 0,57 & 0,10 & 0,006 & 1048 \\
\hline 3,5 & 190 & 0,33 & 0,56 & 0,09 & 0,006 & 1033 \\
\hline 4,0 & 170 & 0,33 & 0,57 & 0,10 & 0,006 & 1057 \\
\hline 4,5 & 153 & 0,34 & 0,56 & 0,09 & 0,006 & 1042 \\
\hline 5,0 & 137 & 0,34 & 0,56 & 0,10 & 0,006 & 1056 \\
\hline
\end{tabular}

Um método alternativo ao discutido anteriormente é determinar a eficiência quântica através do sinal de lente térmica, $\theta$, normalizado pela potência de excitação, absorção e espessura efetiva em função do comprimento de onda. Substituindo a equação 4.46 em 4.45 temos que:

$$
\theta=-\frac{P_{e} \alpha L_{e f}}{K \lambda_{p}}\left(1-\eta \frac{\lambda_{e}}{\left\langle\lambda_{e m}\right\rangle}\right) \frac{d s}{d T}
$$

Chamando $\frac{1}{K \lambda_{p}} \frac{d s}{d T}$ de $\beta$ e $\Theta=\frac{\theta}{P_{e} \alpha L_{e f}}$ temos a seguinte equação: 


$$
\Theta=\left(1-\eta \frac{\lambda_{e}}{\left\langle\lambda_{e m}\right\rangle}\right) \beta
$$

\subsection{Tempo de Vida da fluorescência}

O tempo de vida, $\tau$, do nível ${ }^{4} \mathrm{I}_{13 / 2}$ foi medido usando um fotodetector de germânio acoplado a um osciloscópio, marca Tektronix TDS 210. Para excitação da amostra foi utilizado um laser de He-Ne, marca Melles Griot, de $10 \mathrm{~mW}$ de potência, operando em $1523 \mathrm{~nm}$. A exposição da amostra, na ordem de $50 \mathrm{~ms}$, foi controlada através de um chopper. Os dados experimentais foram ajustados através de uma função de decaimento exponencial, dada por $y=A e^{-t / \tau}$, em que $y$ é o sinal dado em unidades arbitrárias, A é a amplitude do sinal em $\mathrm{t}=0, t$ é o tempo e $\tau$ é o tempo de vida 


\section{Resultados}

\subsection{Difração de Raios-X}

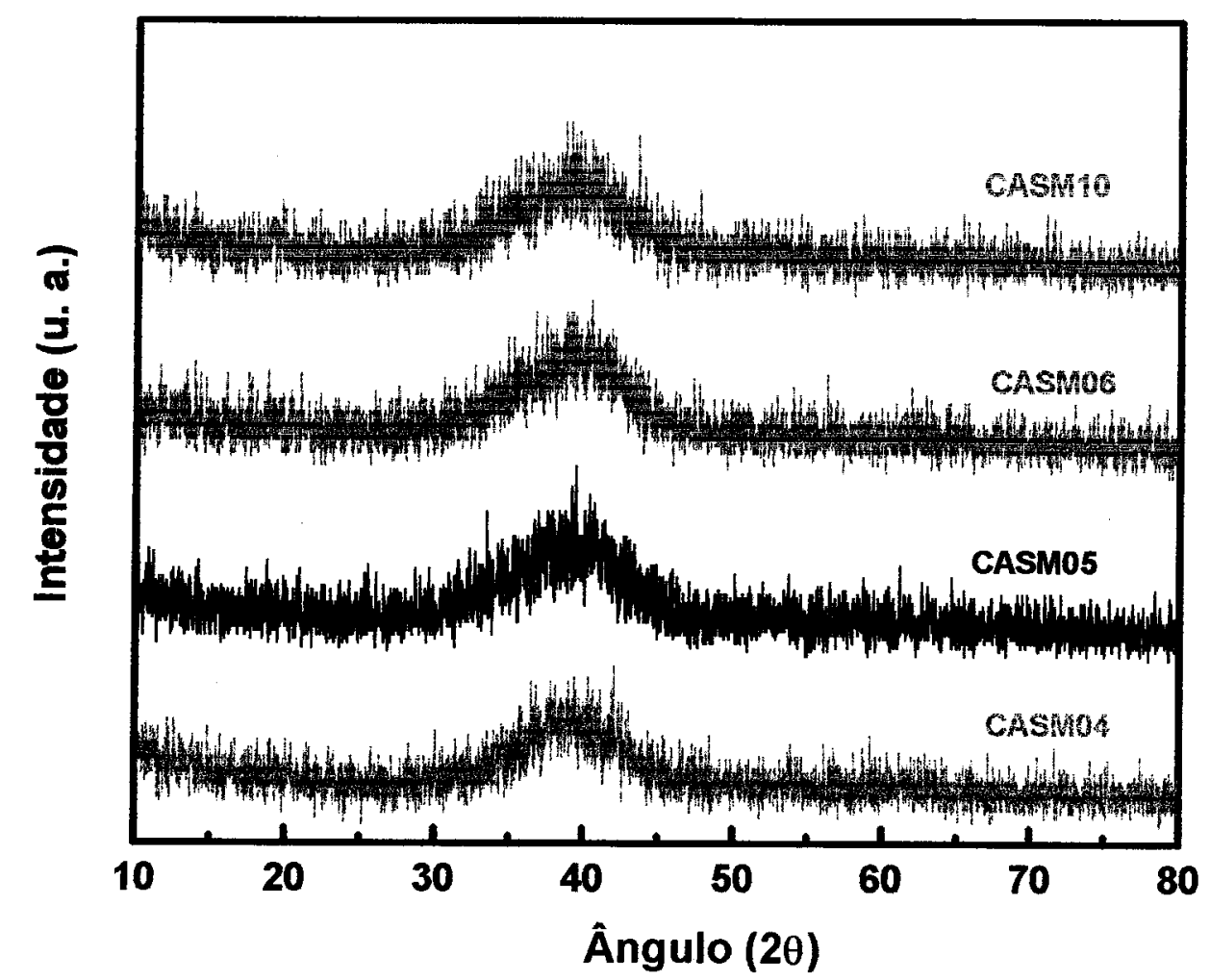

Figura 5.1 - Difratogramas das amostras de vidros aluminato de cálcio dopados com ions terras raras, obtidos através de difração de raios- $X$. 
$\mathrm{Na}$ figura 5.1 são apresentados os difratogramas de raios-X para as amostras CASM04, CASM05, CASM06 e CASM10. Podemos verificar que não houve cristalização das amostras, uma vez que esses difratogramas não revelaram a presença de picos característicos de materiais cristalinos, apresentando apenas o halo característico dos materiais amorfos. Os resultados das demais amostras foram semelhantes.

\subsection{Densidade}

Nas tabelas a seguir são apresentados os resultados relacionados à densidade e ao volume molar dos vidros aluminato de cálcio fundidos ao ar e a vácuo. Nessas tabelas o usamos o acrônimo para identificar a amostra, bem como a concentração de dopante usada. $\mathrm{Al} / \mathrm{Ca}$ é a razão molar entre os principais componentes do vidro $\mathrm{Al}_{2} \mathrm{O}_{3}$ e $\mathrm{CaO}$, (esses valores serão usados posteriormente); $\rho$ é a densidade do vidro; $\bar{n}_{M}$ é o número médio de cátions; $\bar{n}_{0}$ é o número médio de oxigênios; $\bar{W}_{g}$ peso molar do vidro; $V_{M}$ é o volume molar do vidro, $V_{1 g}$ é o volume molar de oxigênios.

Tabela 5.1 - $\rho$ é a densidade do vidro; $\bar{n}_{M}$ é o número médio de cátions; $\bar{n}_{0}$ é o número médio de oxigênios; $\bar{W}_{g}$ peso molar do vidro; $V_{M}$ é o volume molar do vidro, $V_{1 g}$ é o volume molar de oxigênios.

\begin{tabular}{cccccccc}
\hline Amostra & $\begin{array}{c}\% \\
\mathrm{Nd}_{2} \mathrm{O}_{3}\end{array}$ & $\rho$ & $\bar{n}_{M}$ & $\bar{n}_{0}$ & $\bar{W}_{g}$ & $V_{M}$ & $V_{1 g}$ \\
\hline Fosfato00 & - & 3,093 & 1,598 & 2,548 & 100,72 & 32,56 & 12,78 \\
Fosfato01 & 2,0 & 3,083 & 1,615 & 2,588 & 102,60 & 33,28 & 12,86 \\
Borato00 & - & 3,091 & 1,700 & 2,400 & 79,82 & 25,82 & 10,76 \\
Borato01 & 1,7 & 3,202 & 1,704 & 2,408 & 80,75 & 25,22 & 10,47 \\
Silicato00 & - & 2,459 & 1,152 & 1,777 & 60,54 & 24,62 & 13,85 \\
Silicato01 & 2,0 & 2,499 & 1,153 & 1,775 & 61,46 & 24,59 & 13,86 \\
\hline
\end{tabular}


Tabela 5.2 - $\mathrm{Al} / \mathrm{Ca}$ é a razão molar $\mathrm{Al}_{2} \mathrm{O}_{3}$ entre $\mathrm{CaO} ; \rho$ é a densidade do vidro;; $\bar{n}_{M}$ é o número médio de cátions; $\bar{n}_{0}$ é o número médio de oxigênios; $\bar{W}_{g}$ peso molar do vidro; $V_{M}$ é o volume molar do vidro, $V_{1 g}$ é o volume molar de oxigênios.

\begin{tabular}{lccccccccc}
\hline Amostra & $\begin{array}{c}\% \\
\mathrm{Er}_{2} \mathrm{O}_{3}\end{array}$ & $\% \mathrm{Yb}_{2} \mathrm{O}_{3}$ & $\mathrm{Al} / \mathrm{Ca}$ & $\rho$ & $\bar{n}_{M}$ & $\bar{n}_{0}$ & $\bar{W}_{g}$ & $V_{M}$ & $V_{1 g}$ \\
\hline CASM00 & - & - & 0,467 & 2,928 & 1,2711 & 1,6211 & 67,75 & 23,14 & 14,27 \\
CASM01 & - & 1,0 & 0,470 & 2,960 & 1,2732 & 1,6260 & 68,33 & 23,08 & 14,20 \\
CASM02 & - & 3,0 & 0,447 & 3,007 & 1,2659 & 1,6122 & 69,04 & 22,96 & 14,24 \\
CASM03 & - & 5,0 & 0,424 & 3,057 & 1,2585 & 1,5982 & 69,63 & 22,78 & 14,27 \\
CASM04 & 0,5 & - & 0,467 & 2,946 & 1,2795 & 1,6401 & 68,75 & 23,34 & 14,23 \\
CASM05 & 1,0 & - & 0,466 & 2,957 & 1,2717 & 1,6229 & 68,27 & 23,09 & 14,23 \\
CASM06 & 2,0 & - & 0,466 & 2,973 & 1,2731 & 1,6265 & 69,93 & 23,52 & 14,25 \\
CASM07 & 4,0 & - & 0,435 & 3,027 & 1,2627 & 1,6064 & 69,50 & 22,96 & 14,27 \\
CASM08 & 6,0 & - & 0,412 & 3,076 & 1,2533 & 1,5893 & 70,02 & 22,76 & 14,26 \\
CASM09 & 7,0 & - & 0,400 & 3,099 & 1,2509 & 1,5839 & 70,30 & 22,68 & 14,32 \\
CASM10 & 8,0 & - & 0,389 & 3,123 & 1,2475 & 1,5773 & 70,95 & 22,72 & 14,37 \\
CASM11 & 2,0 & 3,0 & 0,424 & 3,053 & 1,2586 & 1,5984 & 69,74 & 22,94 & 14,29 \\
CASM12 & 2,0 & 4,0 & 0,412 & 3,073 & 1,2548 & 1,5912 & 70,08 & 22,79 & 14,33 \\
CASM13 & 0,5 & 2,0 & 0,453 & 2,992 & 1,2678 & 1,6158 & 68,86 & 23,01 & 14,24 \\
CASM14 & 1,0 & 2,0 & 0,447 & 3,002 & 1,2659 & 1,6122 & 69,02 & 22,99 & 14,26 \\
CASM15 & 2,0 & 2,0 & 0,435 & 3,027 & 1,2623 & 1,5952 & 69,15 & 22,84 & 14,32 \\
CASM16 & 3,0 & 2,0 & 0,424 & 3,036 & 1,2585 & 1,5983 & 69,72 & 22,96 & 14,37 \\
CASM17 & 4,0 & 2,0 & 0,412 & 3,074 & 1,2548 & 1,5912 & 70,08 & 22,80 & 14,33 \\
CASM18 & 5,0 & 2,0 & 0,400 & 3,099 & 1,2509 & 1,5839 & 70,42 & 22,72 & 14,35 \\
CASM19 & 2,0 & 1,5 & 0,442 & 3,008 & 1,2650 & 1,6110 & 69,46 & 23,09 & 14,33 \\
\hline
\end{tabular}


Tabela 5.3- Al/Ca é a razão molar $\mathrm{Al}_{2} \mathrm{O}_{3}$ entre $\mathrm{CaO} ; \rho$ é a densidade do vidro; $\bar{n}_{M}$ é o número médio de cátions; $\bar{n}_{0}$ é o número médio de oxigênios; $\bar{W}_{g}$ peso molar do vidro; $V_{M}$ é o volume molar do vidro, $V_{1 g}$ é o volume molar de oxigênios.

\begin{tabular}{cccccccccc}
\hline Amostra & $\begin{array}{c}\% \\
\mathrm{Nd}_{2} \mathrm{O}_{3}\end{array}$ & $\begin{array}{c}\% \\
\mathrm{Fe}_{2} \mathrm{O}_{3}\end{array}$ & $\mathrm{Al} / \mathrm{Ca}$ & $\rho$ & $\bar{n}_{M}$ & $\bar{n}_{0}$ & $\bar{W}_{g}$ & $V_{M}$ & $V_{1 g}$ \\
\hline CASM20 & 0,5 & - & 0,476 & 2,936 & 1,2751 & 1,6296 & 68,16 & 23,21 & 14,24 \\
CASM21 & 1,0 & - & 0,470 & 2,959 & 1,2734 & 1,6264 & 68,32 & 23,09 & 14,20 \\
CASM22 & 1,5 & - & 0,464 & 2,973 & 1,2717 & 1,6232 & 68,47 & 23,03 & 14,19 \\
CASM23 & 2,0 & - & 0,458 & 2,979 & 1,2700 & 1,6200 & 68,65 & 23,04 & 14,23 \\
CASM24 & 2,5 & - & 0,452 & 2,998 & 1,2683 & 1,6167 & 68,80 & 22,95 & 14,20 \\
CASM25 & 3,0 & - & 0,447 & 2,999 & 1,2666 & 1,6135 & 68,98 & 23,00 & 14,26 \\
CASM27 & 4,0 & - & 0,435 & 3,008 & 1,263 & 1,6068 & 69,28 & 23,03 & 14,33 \\
CASM28 & 4,5 & - & 0,429 & 3,012 & 1,2614 & 1,6037 & 69,46 & 23,06 & 14,38 \\
CASM29 & 5,0 & - & 0,423 & 3,024 & 1,2596 & 1,6003 & 69,64 & 23,03 & 14,39 \\
CASM30 & - & 1,0 & 0,455 & 2,931 & 1,2690 & 1,6170 & 67,88 & 23,16 & 14,32 \\
\hline
\end{tabular}

Tabela 5.4 - $\mathrm{Al} / \mathrm{Ca}$ é a razão molar $\mathrm{Al}_{2} \mathrm{O}_{3}$ entre $\mathrm{CaO} ; \rho$ é a densidade do vidro; $\bar{n}_{M}$ éo número médio de cátions; $\bar{n}_{0}$ é o número médio de oxigênios; $\bar{W}_{g}$ peso molar do vidro; $V_{M}$ é o volume molar do vidro, $V_{1 g}$ é o volume molar de oxigênios.

\begin{tabular}{lccccccccc}
\hline Amostra & $\begin{array}{c}\% \\
\mathrm{Nd}_{2} \mathrm{O}_{3}\end{array}$ & $\begin{array}{c}\% \\
\mathrm{Er}_{2} \mathrm{O}_{3}\end{array}$ & $\mathrm{Al} / \mathrm{Ca}$ & $\rho$ & $\bar{n}_{M}$ & $\bar{n}_{0}$ & $\bar{W}_{g}$ & $V_{M}$ & $V_{1 g}$ \\
\hline CASM31 & - & - & 0,458 & 2,938 & 1,271 & 1,610 & 67,70 & 23,04 & 14,31 \\
CASM32 & 1,0 & - & 0,469 & 2,933 & 1,273 & 1,626 & 68,31 & 23,29 & 14,32 \\
CASM33 & 2,0 & - & 0,459 & 2,971 & 1,270 & 1,620 & 68,62 & 23,10 & 14,26 \\
CASM34 & 3,0 & - & 0,448 & 2,987 & 1,267 & 1,614 & 68,95 & 23,08 & 14,30 \\
CASM35 & 4,0 & - & 0,435 & 3,008 & 1,263 & 1,607 & 69,24 & 23,02 & 14,32 \\
CASM36 & 5,0 & - & 0,452 & 3,028 & 1,292 & 1,649 & 71,21 & 23,52 & 14,26 \\
CASM37 & 6,0 & - & 0,413 & 3,045 & 1,256 & 1,594 & 69,85 & 22,94 & 14,39 \\
CASM38 & - & 1,0 & 0,436 & 2,949 & 1,262 & 1,600 & 67,93 & 23,03 & 14,40 \\
CASM39 & - & 2,0 & 0,459 & 2,990 & 1,270 & 1,620 & 68,81 & 23,01 & 14,21 \\
CASM40 & - & 3,0 & 0,416 & 3,001 & 1,255 & 1,587 & 68,43 & 22,80 & 14,37 \\
CASM41 & - & 4,0 & 0,404 & 3,022 & 1,251 & 1,579 & 68,80 & 22,77 & 14,42 \\
CASM42 & - & 5,0 & 0,423 & 3,034 & 1,259 & 1,599 & 69,97 & 23,06 & 14,42 \\
CASM43 & - & 6,0 & 0,382 & 3,092 & 1,244 & 1,566 & 69,60 & 22,51 & 14,37 \\
CASM44 & - & 7,0 & 0,372 & 3,095 & 1,241 & 1,560 & 70,02 & 22,63 & 14,50 \\
CASM45 & - & 8,0 & 0,360 & 3,120 & 1,236 & 1,551 & 70,06 & 22,46 & 14,48 \\
\hline
\end{tabular}




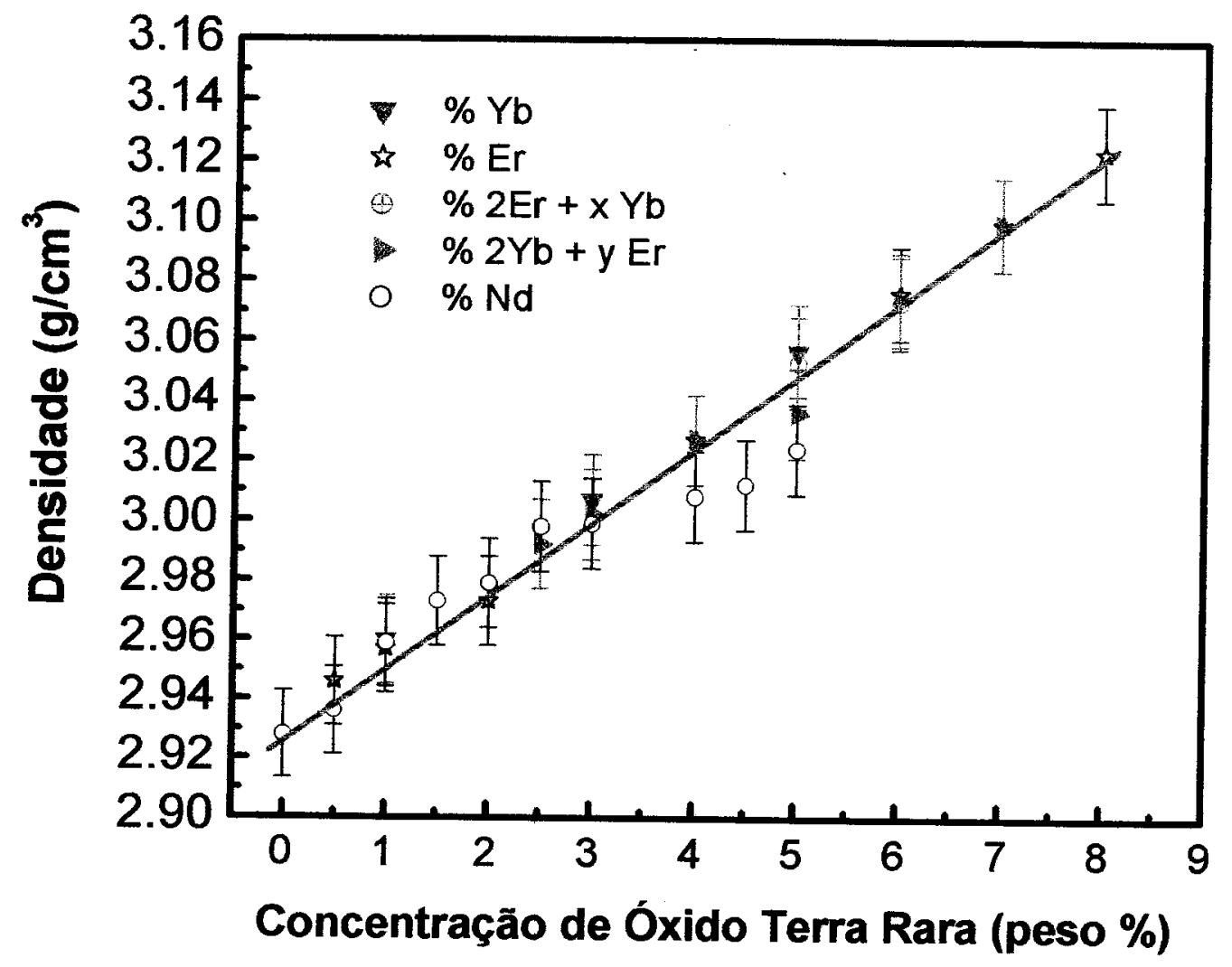

Figura 5.2 - Densidade dos vidros aluminato de cálcio em função da concentração de óxidos terras raras. A reta não está associada a nenhum ajuste teórico, foi desenhada apenas para guiar os olhos.

$\mathrm{Na}$ figura 5.2 podemos observar o comportamento da densidade dos vidros aluminato de cálcio em função da concentração de óxidos terras raras. Conforme aumentase a concentração de $\mathrm{Yb}_{2} \mathrm{O}_{3}, \mathrm{Er}_{2} \mathrm{O}_{3}$ ou $\mathrm{Nd}_{2} \mathrm{O}_{3}$, ocorre um aumento também na densidade. Enquanto que para a amostra base (CASM00) o valor da densidade é de $2.92 \mathrm{~g} / \mathrm{cm}^{3}$, para a amostra dopada com $8 \%$ (em peso) de $\mathrm{Er}_{2} \mathrm{O}_{3}$ (CASM10) é de $3.12 \mathrm{~g} / \mathrm{cm}^{3}$, ou seja há uma aumento de aproximadamente 7\%. Esse resultado é esperado uma vez que a alumina possui um peso molar muito menor, 101.9612, em relação aos óxidos terras raras substitucionais $\mathrm{Yb}_{2} \mathrm{O}_{3}, \mathrm{Er}_{2} \mathrm{O}_{3}$ e $\mathrm{Nd}_{2} \mathrm{O}_{3}$ cujos pesos molares são respectivamente 394.08, 382,52 e 336.48. 
$\mathrm{Na}$ figura 5.3 podemos observar que o volume molar de oxigênios é aproximadamente constante para os vidros aluminato de cálcio dopados com $\mathrm{Nd}_{2} \mathrm{O}_{3}$ até aproximadamente $3 \%$ de concentração, a partir daí há um aumento crescente do volume molar de oxigênios. No caso das amostras dopadas com érbio esse aumento começa a ser

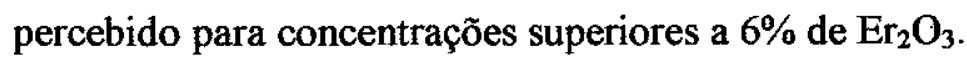

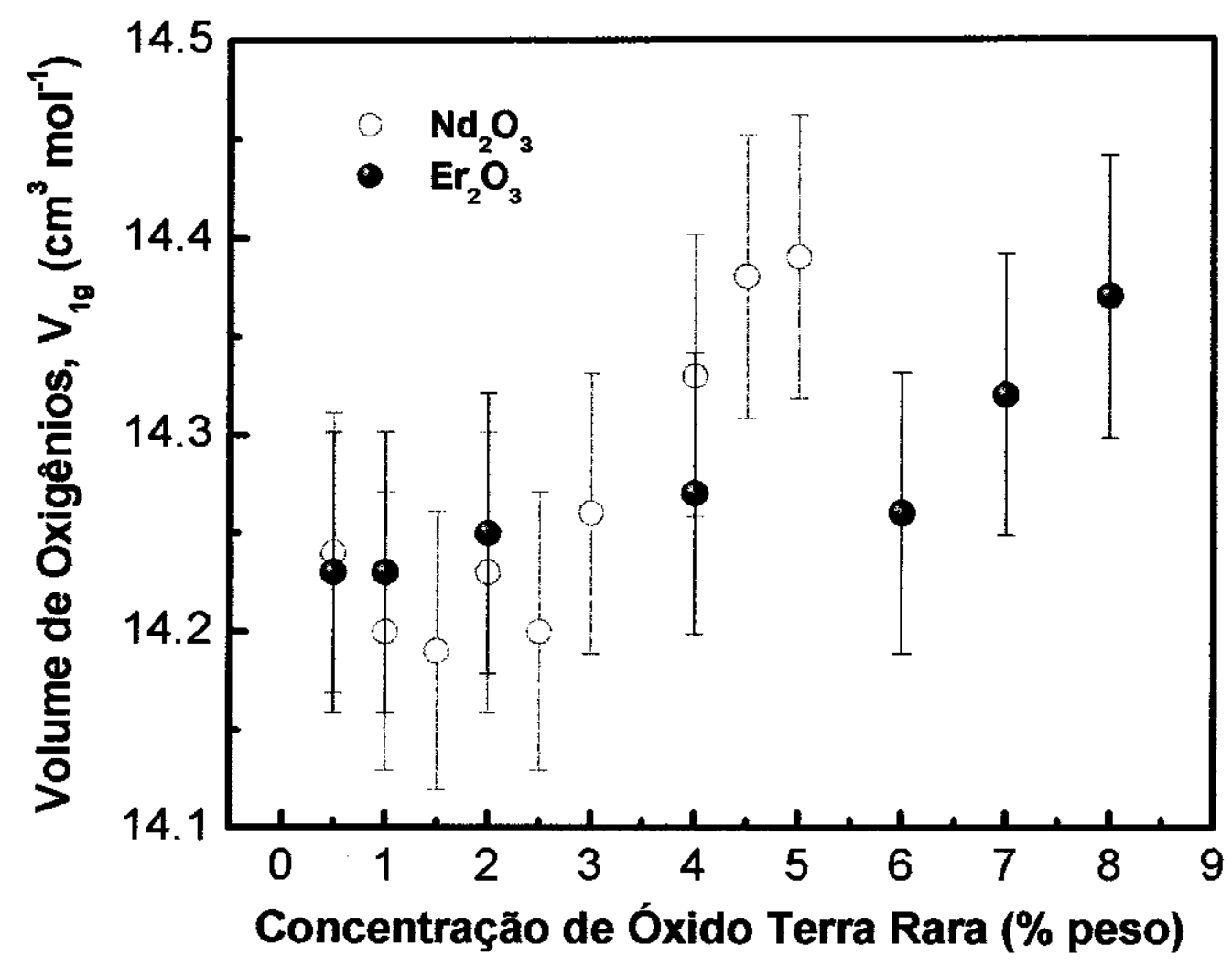

Figura 5.3 - Volume de oxigênios para vidros aluminato de cálcio dopados com $\mathrm{Nd}_{2} \mathrm{O}_{3}$ e $\mathrm{Er}_{2} \mathrm{O}_{3}$. Amostras fundidas a vácuo.

Conforme mencionado nos parágrafos precedentes, vemos que para baixas concentrações de óxidos terras raras o volume de oxigênios dos vidros aluminato de cálcio possuem um comportamento praticamente constante e paralelo ao eixo das abscissas, cujo significado físico é o de que os íons terras raras entraram na rede do vidro ocupando os espaços vazios. Por outro lado quando há uma concentração maior desses íons a curva 
tende a ser ascendente, indicando que os íons terras raras provocam uma expansão da rede vítrea, já que os espaços vazios não comportam uma concentração excessivia desses íons.

Vate ressaltar que esses resultados corroboram com o que, for observado experimentalmente durante a fusão das amostras. A vitrificação é mais facilmente conseguida para amostras com baixa concentração de dopante, aproximadamente $3 \%$, a partir da qual há necessidade de uma taxa maior de resfriamento para a obtenção de vidro, conforme já mencionado na seção preparação de amostras.

Resultados semelhantes foram encontrados para amostras fundidas ao ar. A figura 5.4 mostra o comportamento para uma série de vidros aluminato de cálcio dopados com $\mathrm{Er}_{2} \mathrm{O}_{3}$ fundidos ao ar. Para as amostras dopadas com $\mathrm{Nd}_{2} \mathrm{O}_{3}$ esse comportamento se repetiu.

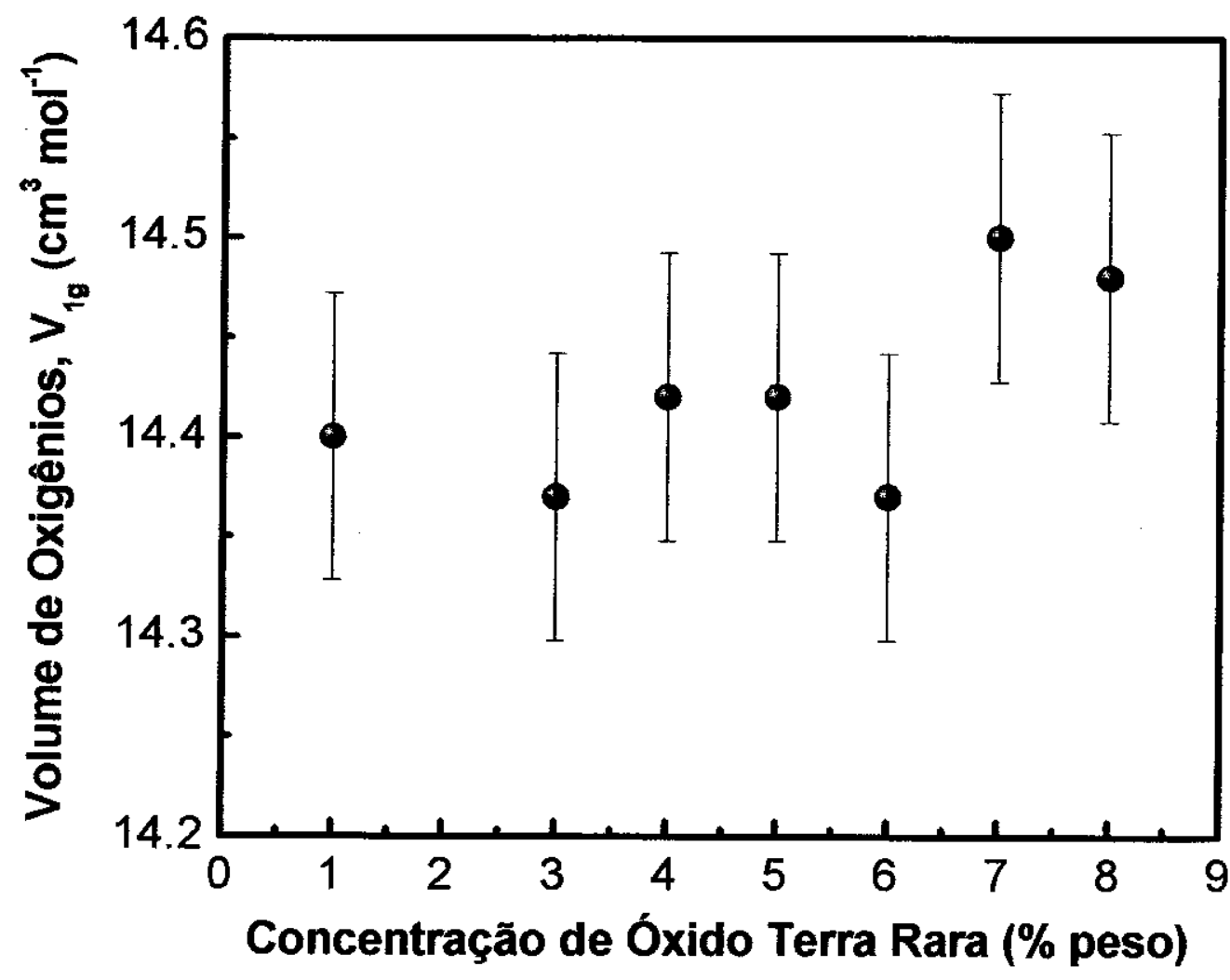

Figura 5.4 volume de oxigênios para o vidro aluminato de cálcio dopados com $\mathrm{Er}_{2} \mathrm{O}_{3}$ fundidos ao ar. 
Ao fazermos o gráfico dos valores de $\mathrm{V}_{1}$ versus a concentração em mol (por exemplo $\mathrm{Nd}_{2} \mathrm{O}_{3}$ ), é possível obter três comportamentos de curva.

Se a curva for completamente paralela ao eixo das abscissas, significa que todos os modificadores de rede adicionados ao vidro entraram nos espaços vazios da rede.

Quando a curva for ascendente é uma indicação de que a rede do vidro foi expandida pela entrada de um outro elemento, em outras palavras, o volume unitário $V_{1}$ por átomo grama de oxigênio é aumentado pela entrada de outro elemento.

Uma curva decrescente significa que a massa das partículas conduz a uma concentração da rede do vidro, particulamente para os elementos de pequeno raio efetivo $\mathrm{r}_{\mathrm{i}}$, tais como $\mathrm{Li}(\mathrm{I}), \mathrm{Mg}(\mathrm{II})$ e $\mathrm{B}(\mathrm{II})$. Esta é a explicação do porquê a densidade de alguns óxidos, em vidros, é diferente daquela do óxido de fato, por esta razão nem sempre a densidade calculada teoricamente condiz com aquela obtida experimentalmente.

Analisando a figura 5.4 podemos perceber que os resultados aqui apresentados para o volume molar de oxigênios dos vidros aluminato de cálcio dopados com terras raras estão de bom acordo com aqueles reportados por Huang e Behrman, uma vez que para baixas concentrações de sílica, $<10 \mathrm{~mol} \%$ e razão molar 0.5 o valor do volume molar de oxigênios é de aproximadamente $14.3 \mathrm{~cm}^{3} \mathrm{~mol}^{-1}$.

Esses resultados podem ser comparados com os reportados por Huang e Behrman (1991), que investigaram o volume molar de oxigênios em função da concentração de $\mathrm{SiO}_{2}$ mantendo a razão $\mathrm{Al}_{2} \mathrm{O}_{3}$ constante. Podemos verificar que há um ponto de mínimo no volume molar de oxigênios para uma concentração de $\mathrm{SiO}_{2}$ de aproximadamente $52 \%$, com a razão $\mathrm{Al}_{2} \mathrm{O}_{3}$ igual a 1.25. Segundo Huang e Behrman o deslocamento do ponto de mínimo no volume molar pode ser explicado assumindo que os íons de alumínio estão na coordenação tetraédrica, de modo que os íons de cálcio estão associados ao tetraedro $\left(\mathrm{AlO}_{4}\right)^{-}$para compensar o excesso de carga. A ligação silício-oxigênio deveria ser somente "quebrada" pelo excesso de cálcio (incluindo todos os íons de cálcio não associados ao tetraedro alumínio-oxigênio). Para os íons de cálcio estarem associados aos tetraedro alumínio-oxigênio, durante o processo de formação de vidro, os ions de cálcio deveriam estar difusos nas proximidades dos íons de alumínio. Na figura 5.6 é mostrado o comportamento do volume molar em função da concentração de íons terras raras. 


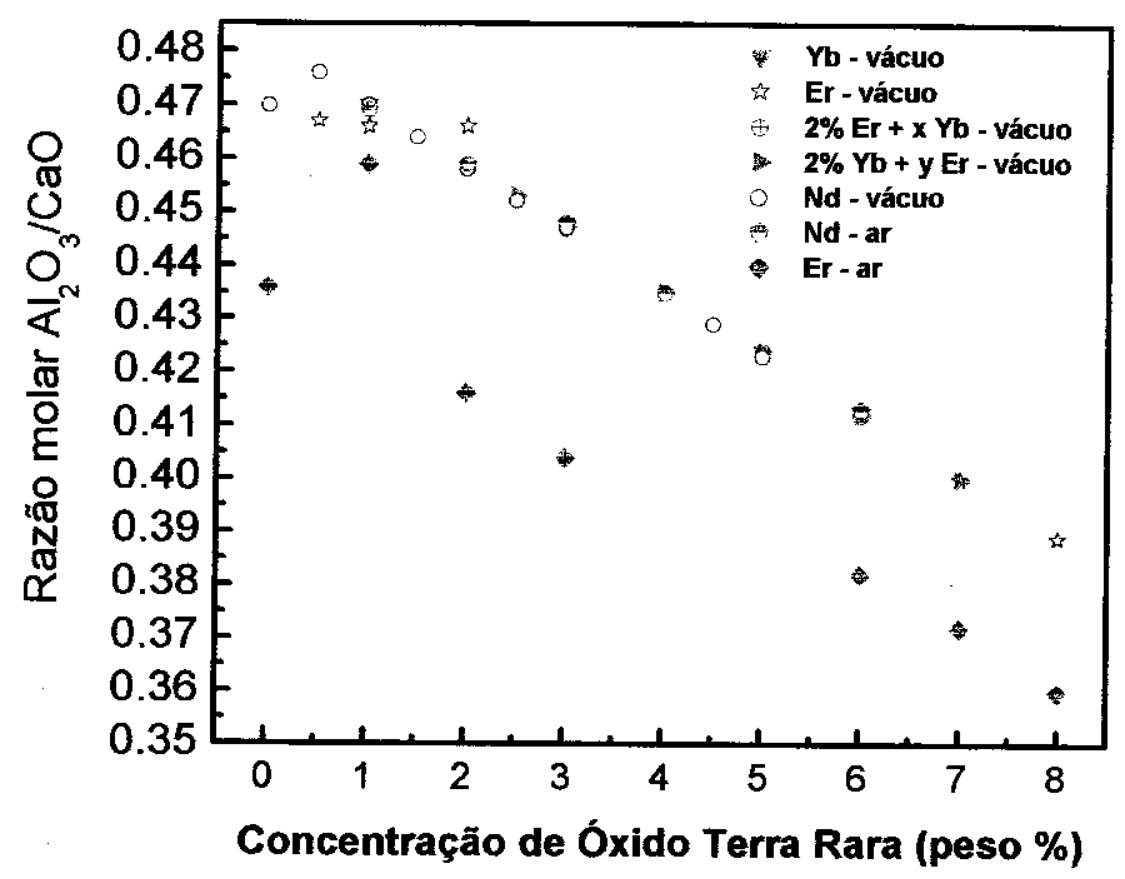

Figura 5.5 - Razão molar $\mathrm{Al}_{2} \mathrm{O}_{3} / \mathrm{CaO}$ dos vidros aluminato de cálcio dopados com ions terras raras.

$\mathrm{Na}$ figura 5.5 é mostrado o comportamento da razão molar $\mathrm{Al}_{2} \mathrm{O}_{3} / \mathrm{CaO}$ para os vidros aluminato de cálcio dopados com óxidos terras raras. Podemos perceber que a série de vidros aluminato de cálcio dopados com $\mathrm{Er}_{2} \mathrm{O}_{3}$ possui uma razão mais baixa do que os demais vidros devido a diferença composicional que é dada na tabela 5.21. Por esta razão é que o valor do volume molar de oxigênios é um pouco maior do que nos demais séries de vidros. Segundo Huang e Behrman quando a razão $\mathrm{Al}_{2} \mathrm{O}_{3} / \mathrm{CaO}$ é menor que a unidade, alguns dos tetraedros alumínio-oxigênio podem estar não associados aos íons de cálcio. $\mathrm{O}$ excesso de carga pode ser compensado pela formação de ozônide e/ou vacâncias de oxigênios. Em nossos vidros essa razão além de ser menor que 1, é reduzida em aproximadamente $20 \%$, de 0.47 para 0.38 .

$\mathrm{Na}$ figura 5.6 são mostrados os resultados para o volume molar dos vidros aluminato de cálcio dopados com óxidos terras raras. $\mathrm{O}$ volume molar apresenta uma diminuição de aproximadamente $4 \%$. 


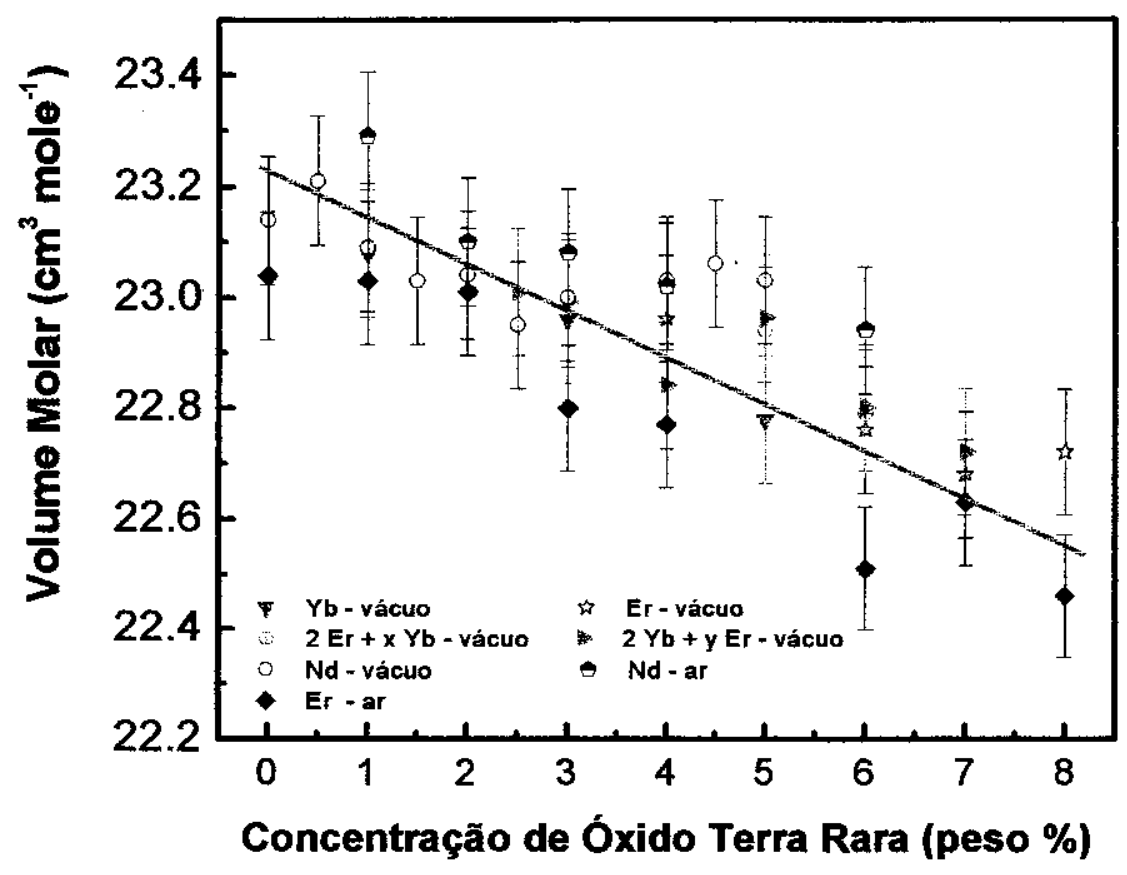

Figura 5.6 - Comportamento do volume molar dos vidros aluminato de cálcio dopados com diferentes concentrações de óxidos terras raras.

\subsection{Propriedades Elásticas}

$\mathrm{Na}$ tabela 5.5 são apresentados os resultados obtidos para amostras preparadas ao ar e a vácuo. Podemos observar que não há mudanças significativas nas propriedades elásticas quando é introduzido na rede do vidro íons terras raras. $\mathrm{O}$ módulo longitudinal, $\mathrm{L}$, para as amostras foi de aproximadamente $140 \mathrm{GPa}$, o módulo ao cisalhamento, G, aproximadamente igual a $40 \mathrm{GPa}$, o módulo de compressibilidade, $\mathrm{K}$, aproximadamente 84 $\mathrm{GPa}$, o módulo de Young, E, foi de aproximadamente $107 \mathrm{GPa}$, a impedância acústica, $Z$, de aproximadamente $21 \mathrm{GPa}$ e a temperatura de Debye foi de aproximadamente $360 \mathrm{~K}$. O erro estimado para essas medidas é de $2.5 \%$. 


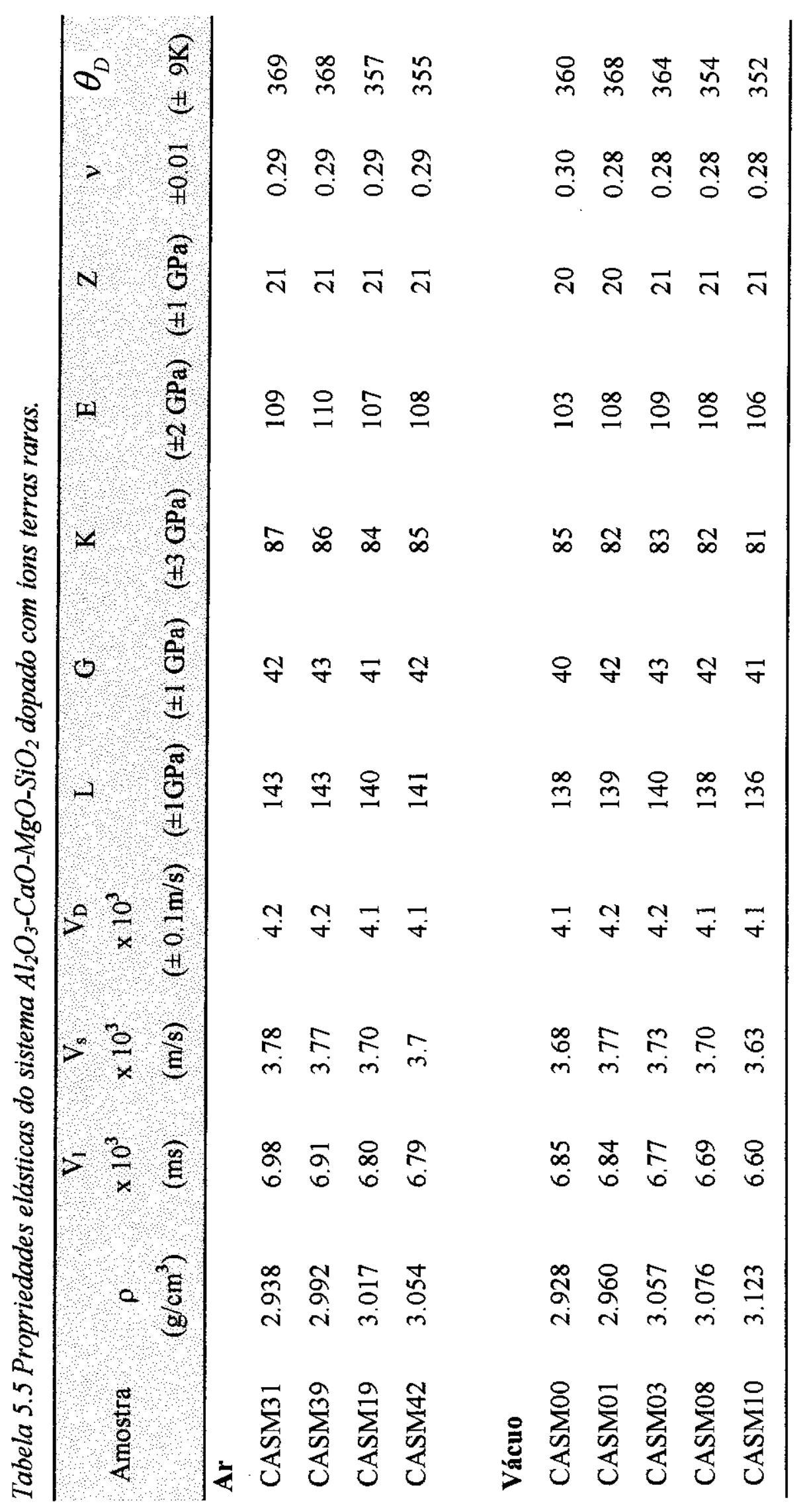


O valor das propriedades elásticas aqui apresentadas estão de bom acordo com um trabalho recente sobre as propriedades elásticas de vidros aluminatos (Haeri et al., 1998). Os vidros aluminato apresentam velocidades ultra-sônicas maiores do que em vidros silicatos, particularmente a velocidade longitudinal que é $15 \%$ maior. Esta comparação é interessante pois é consenso na literatura que o alumínio é coordenado tetraedralmente quando na presença do $\mathrm{Ca}$, coordenação esta similar a do Si na rede vítrea.

Somente vidros silicatos alcalinos terrosos e aluminosilicatos, tais como (Ca, $\mathrm{Mg}) \mathrm{SiO}_{3}$ e $\mathrm{CaAl}_{2} \mathrm{Si}_{2} \mathrm{O}_{8}$ possuem velocidades comparadas a dos vidros aluminato puros. As velocidades ultra-sônicas aqui apresentadas são ainda maiores do que as reportadas por Haeri et. al (1998), além de que as nossas amostras foram obtidas via método de fusão convencional e as reportadas por eles através de splat quenching. A comparação das propriedades elásticas pode ser feita em termos da estrutura do vidro. $O$ modulo de compressibilidade, $\mathrm{K}$, do $\mathrm{SiO}_{2}$ e vidros silicatos alcalinos e aluminosilicatos $\left(\mathrm{K}_{2} \mathrm{Si}_{3} \mathrm{O}_{7}\right.$, $\mathrm{Na}_{2} \mathrm{Si}_{2} \mathrm{O}_{6}, \mathrm{NaAlSi}_{3} \mathrm{O}_{8}$ ) situa-se entre 36.5-41.9 GPa. A compressibilidade dos vidros aluminato de cálcio dopados com terras raras é muito menor $(\mathrm{K}=85 \mathrm{GPa})$, similar as composições dos vidros silicatos alcalinos terrosos e aluminosilicatos $\left(\mathrm{CaSiO}_{3}, \mathrm{MgSiO}_{3}\right.$, $\left.\mathrm{CaAl}_{2} \mathrm{Si}_{2} \mathrm{O}_{8}\right)$. Os vidros aluminatos, $\mathrm{Y}_{2} \mathrm{O}_{3}-\mathrm{Al}_{2} \mathrm{O}_{3}$ são ainda menos compressíveis $(\mathrm{K}=109$ GPa). A primeira vista, a observação de que os vidros aluminato de cálcio possuem melhores propriedades mecânicas em relação a outros sistemas vítreos é um tanto quanto surpreendente, uma vez que as ligações $\mathrm{Si}-\mathrm{O}$, em vidros silicatos, são muito mais fortes e conseqüentemente rijas em relação às ligações Al-O. Por outro lado a maior intensidade e rijeza entre as ligações $\mathrm{Ca}-\mathrm{O}$ e $\mathrm{Mg}$-O, faz com que os vidros alcalinos terrosos sejam menos compressíveis do que os vidros silicatos alcalinos, que possuem ligações $\mathrm{Na}-\mathrm{O}$ ou $\mathrm{K}-\mathrm{O}$ mais fracas. É esperado que vidros que contenham os grupos $\mathrm{AlO}_{4}$ possuam uma rede fraca, entretanto a presença dos cátions $\mathrm{Ca}^{2+}$ aumenta a rijeza, tomando-os resistentes à compressão, e fazendo com que o módulo de compressão seja duas vezes maior do que o do $\mathrm{SiO}_{2}$, resultado semelhante ao reportado por Hwa et al. (1997), concluindo que os vidros aluminato de cálcio possuem uma estrutura muito rígida.

Além disso Hwa, chama a atenção quanto a razão $G /(L-2 G)$ ser menor que a unidade, fato que não é usual para os vidros silicatos que possuem valor maior que a 
unidade. Esta razão é um indicador do tipo de forças de campo. Quando a razão $G /(L-2 G)$ for igual a 1 , as forças são centrais, caso seja diferente de 1 , as forças são não centrais.

Os nossos resultados para o coeficiente de Poisson é de 0.28/029, corroborando com os dados reportados por Hawa, que variam entre 0.280 a $0.322 . \mathrm{O}_{\mathrm{SiO}_{2}}$ apresenta coeficiente de Poisson igual a 0.166 . O aito valor do coeficiente de Poisson nos vidros aluminato de cálcio pode ser explicado levando em consideração o tipo da das ligações que são iônicas (Hwa et al., 1997), em comparação ao $\mathrm{SiO}_{2}$ em que as ligações são predominantemente covalentes (Brassington et al., 1981; Soga e Ota, 1983).

Na tabela 5.6 são comparados os módulos de elasticidade para vários sistemas vítreos.

Tabela 5.6 - Dados comparativos dos módulos de elasticidade de alguns sistemas vítreos (Volf et al., 1995).

\begin{tabular}{lcccccc}
\hline Sistema vítreo & $\begin{array}{c}\rho \\
\left(\mathrm{g} / \mathrm{cm}^{3}\right)\end{array}$ & $\begin{array}{c}V_{L} \\
\left(\times 10^{3} \mathrm{~m} / \mathrm{s}\right)\end{array}$ & $\begin{array}{c}V S \\
\left(\times 10^{3} \mathrm{~m} / \mathrm{s}\right)\end{array}$ & $\begin{array}{c}\mathrm{L} \\
(\mathrm{GPa})\end{array}$ & $\begin{array}{c}\mathrm{G} \\
(\mathrm{GPa})\end{array}$ & $\begin{array}{c}\mathrm{K} \\
(\mathrm{GPa})\end{array}$ \\
\hline $\mathrm{SiO}_{2}$ & 2,204 & 5,95 & 3,76 & 78,1 & 31,2 & 36,5 \\
$\mathrm{~K}_{2} \mathrm{Si}_{3} \mathrm{O}_{7}$ & 2,42 & 4,9 & 2,94 & 58 & 21 & 30 \\
$\mathrm{Na}_{2} \mathrm{Si}_{2} \mathrm{O}_{6}$ & 2,494 & 5,44 & 3,11 & 73,9 & 24,1 & 41,9 \\
$\mathrm{NaAlSi}_{3} \mathrm{O}_{8}$ & 2,369 & 5,74 & 3,51 & 78 & 29,2 & 39,1 \\
$\mathrm{CaAl}_{2} \mathrm{Si}_{2} \mathrm{O}_{8}$ & 2,693 & 6,7 & 3,79 & 121 & 38,7 & 69,2 \\
$\mathrm{CaSiO}_{3}$ & 2,880 & 6,39 & 3,55 & 118 & 36,3 & 69,2 \\
$\mathrm{MgCaSi}_{2} \mathrm{O}_{6}$ & 2,863 & 6,73 & 3,72 & 130 & 39,7 & 76,9 \\
$\mathrm{MgSiO}_{3}$ & 2,761 & 6,98 & 3,89 & 134 & 41,8 & 78,8 \\
\hline
\end{tabular}

O único trabalho reportando as propriedades mecânicas dos vidros aluminato de cálcio em função da temperatura foi reportado por Florence (1955). Nesse artigo são apresentados os resultados para o módulo de Young, módulo ao cisalhamento e coeficiente de Poisson. Da temperatura ambiente, $20{ }^{\circ} \mathrm{C}$, até a temperatura de $750{ }^{\circ} \mathrm{C}$, o módulo de Young diminui de $105 \mathrm{GPa}$ para $93 \mathrm{GPa}$, aproximadamente, $11 \%$; o módulo ao cisalhamento diminui de $41 \mathrm{GPa}$ para $36 \mathrm{GPa}$, aproximadamente $12 \%$, em contra partida o 
coeficiente de Poisson aumenta $3 \%$ de 0.289 para 0.298 . Na tabela 5.7 são apresentados os resuitados no intervalo de temperatura investigado.

Um dos trabalhos mais completos investigando a variação das propriedades mecânicas dos vidros aluminato de cálcio é reportado por Onoda e Brown (1970). O módulo de Young varia entre 89.6 a $122.6 \mathrm{GPa}$, enquanto que a resistência mecânica os varia 2.89 a $4.48 \mathrm{GPa}$.

Tabela 5.7 - Módulo de Young, E; Módulo de cisalhamento, G; Coeficiente de Poisson em funçâo da temperatura para o vidro aluminato de cálcio $41.2 \mathrm{Al}_{2} \mathrm{O}_{3}, 42 \mathrm{CaO}, 16.8 \mathrm{BaO} \%$ peso) (Florence et al., 1955)

\begin{tabular}{cccc}
\hline $\begin{array}{c}\text { Temperatura } \\
\left({ }^{\circ} \mathrm{C}\right)\end{array}$ & $\begin{array}{r}\text { Módulo de } \\
\text { Young, } \mathrm{E} \\
(\mathrm{GPa})\end{array}$ & $\begin{array}{c}\text { Módulo ao } \\
\text { Cisalhamento, } \mathrm{G} \\
(\mathrm{GPa})\end{array}$ & $\begin{array}{c}\text { Coeficiente } \\
\text { de Poisson, } v\end{array}$ \\
\hline 20 & 105,2 & 40,80 & 0,289 \\
65 & 104,5 & 40,59 & 0,287 \\
110 & 104,1 & 40,39 & 0,289 \\
210 & 102,8 & 39,76 & 0,293 \\
300 & 101,7 & 39,35 & 0,292 \\
410 & 99,95 & 38,71 & 0,291 \\
500 & 98,91 & 38,28 & 0,292 \\
600 & 97,47 & 37,67 & 0,294 \\
700 & 95,60 & 36,88 & 0,296 \\
730 & 95,24 & 36,65 & 0,299 \\
750 & 93,40 & 35,98 & 0,298 \\
\hline
\end{tabular}

\subsection{Dureza}

Na tabela 5.8 são apresentados os resultados para as diferentes concentrações de óxidos terras raras, sendo $1 \mathrm{Yb}$ equivalente $1 \%$ (em peso) de $\mathrm{Yb}_{2} \mathrm{O}_{3}, 3 \mathrm{Yb}$ equivalente a $3 \%$ (em peso) de $\mathrm{Yb}_{2} \mathrm{O}_{3}$ e assim por diante. 
Tabela 5.8 - Dureza Vickers para os vidros aluminato de cálcio dopados com óxidos terras raras.

\begin{tabular}{cccccc}
\hline Amostra & $\begin{array}{c}\% \\
\text { dopante }\end{array}$ & $\begin{array}{c}\mathrm{HV} \\
\left(\mathrm{Kg} / \mathrm{mm}^{2)}\right.\end{array}$ & Amostra & $\begin{array}{c}\% \\
\text { dopante }\end{array}$ & $\begin{array}{c}\mathrm{HV} \\
\left(\mathrm{Kg} / \mathrm{mm}^{2}\right)\end{array}$ \\
\hline CASM00 & - & $865 \pm 25$ & CASM20 & $0.5 \mathrm{Nd}$ & $862 \pm 25$ \\
CASM01 & $1 \mathrm{Yb}$ & $837 \pm 18$ & CASM21 & $1.0 \mathrm{Nd}$ & $851 . \pm 19$ \\
CASM02 & $3 \mathrm{Yb}$ & $814 \pm 29$ & CASM22 & $1.5 \mathrm{Nd}$ & $847 \pm 16$ \\
CASM03 & $5 \mathrm{Yb}$ & $807 \pm 24$ & CASM23 & $2.0 \mathrm{Nd}$ & $832 \pm 20$ \\
CASM04 & $0.5 \mathrm{Er}$ & $852 \pm 21$ & CASM24 & $2.5 \mathrm{Nd}$ & $824 \pm 21$ \\
CASM05 & $1 \mathrm{Er}$ & $831 \pm 23$ & CASM25 & $3.0 \mathrm{Nd}$ & $819 \pm 22$ \\
CASM06 & $2 \mathrm{Er}$ & $824 \pm 19$ & CASM26 & $3.5 \mathrm{Nd}$ & $815 \pm 22$ \\
CASM07 & $4 \mathrm{Er}$ & $815 \pm 15$ & CASM27 & $4.0 \mathrm{Nd}$ & $804 \pm 20$ \\
CASM08 & $6 \mathrm{Er}$ & $800 \pm 20$ & CASM28 & $4.5 \mathrm{Nd}$ & $800 \pm 16$ \\
CASM09 & $7 \mathrm{Er}$ & $793 \pm 19$ & CASM29 & $5.0 \mathrm{Nd}$ & $798 \pm 22$ \\
CASM10 & $8 \mathrm{Er}$ & $781 \pm 23$ & CASM15 & $2 \mathrm{Er}+2 \mathrm{Yb}$ & $808 \pm 11$ \\
CASM11 & $2 \mathrm{Er}+3 \mathrm{Yb}$ & $785 \pm 10$ & CASM16 & $2 \mathrm{Er} r_{2}+3 \mathrm{Yb}$ & $804 \pm 17$ \\
CASM12 & $2 \mathrm{Er}+4 \mathrm{Yb}$ & $776 \pm 22$ & CASM17 & $2 \mathrm{Er}+4 \mathrm{Yb}^{2}$ & $798 \pm 10$ \\
CASM13 & $2 \mathrm{Er}+0.5 \mathrm{Yb}$ & $815 \pm 14$ & CASM18 & $2 \mathrm{Er}+5 \mathrm{Yb}$ & $795 \pm 13$ \\
CASM14 & $2 \mathrm{Er}+1 \mathrm{Yb}$ & $811 \pm 14$ & - & - & - \\
\hline
\end{tabular}


Na figura 5.7 são mostrados os resultados obtidos para a dureza Vickers dos vidros aluminato de cálcio em função da concentração de óxidos terras raras. Podemos perceber que há um decréscimo de aproximadamente $11 \%$ entre a amostra base, CASM00, cujo valor de $\mathrm{HV}=865 \pm 25 \mathrm{~kg} / \mathrm{mm}^{2}$, e a amostra dopada com $8 \%$ (em peso) de $\mathrm{Er}_{2} \mathrm{O}_{3}, \mathrm{CASM10}$, $\mathrm{HV}=781 \pm 23 \mathrm{~kg} / \mathrm{mm}^{2}$. As barras de erro nessa figura refere-se ao desvio padrão para as diferentes medidas, que é de aproximadamente $3 \%$. Esse erro pode estar atribuído a não planicidade da superficie das amostras, o que pode afetar a focalização da indentação pelo microscópio do durômetro, pode também ser devido a possíveis defeitos no próprio vidro, tensões internas, não homogeneidade, etc...

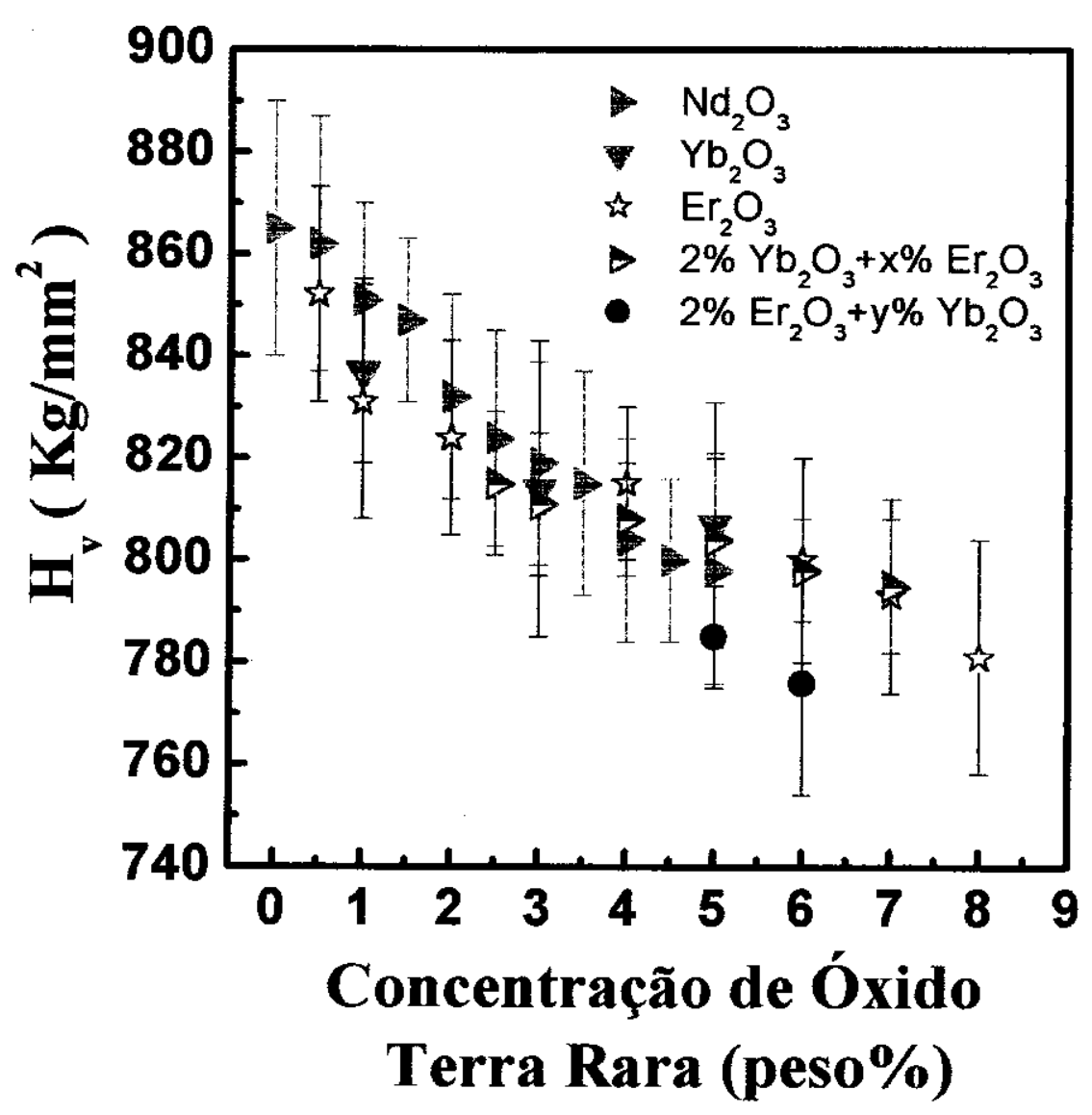

Figura 5.7 - Dureza Vickers para os vidros aluminato de cálcio em função da concentração de óxidos terras raras. 
Esse decréscimo apresentado na dureza Vickers é esperado uma vez que em nossas amostras o óxido terra rara entra na composição do vidro substituindo a $\mathrm{Al}_{2} \mathrm{O}_{3}$. Esse comportamento é uma indicação de que os íns terra raras ao ocupar os interstícios da rede vitrea diminuindo as forças das ligações químicas. Se levarmos em consideração a barra de erros, podemos perceber que a dureza é constante até aproximadamente $3 \%$ (em peso) de óxido terra-rara, corroborando com os resultados apresentados no capítulo anterior sobre o volume molar.

\subsection{Tenacidade à Fratura}

Tabela 5.9 - Resultados obtidos para a determinação de $K_{I C}$. P é a carga, $H_{V}$ é a dureza Vickers, a é o raio da diagonal da indentação, c é o raio da diagonal da indentação $+o$ comprimento da trinca, e lé o comprimento da trinca, E é o módulo de Young e $K_{I C}$ é a tenacidade à ruptura.

\begin{tabular}{cccccccc}
\hline $\begin{array}{c}\text { Sistema } \\
\text { Vítreo }\end{array}$ & $\begin{array}{c}\mathrm{P} \\
(\mathrm{kgf})\end{array}$ & $\begin{array}{c}\mathrm{H}_{\mathrm{V}} \\
(\mathrm{GPa})\end{array}$ & $\begin{array}{c}a \\
(\mu \mathrm{m})\end{array}$ & $\begin{array}{c}c \\
(\mu \mathrm{m})\end{array}$ & $\begin{array}{c}l \\
(\mu \mathrm{m})\end{array}$ & $\begin{array}{c}\mathrm{E} \\
(\mathrm{GPa})\end{array}$ & $\begin{array}{c}\mathrm{K}_{\mathrm{IC}} \\
\left(\mathrm{MPa} \mathrm{m}^{1 / 2}\right)\end{array}$ \\
\hline Aluminato & 0,30 & 8,0 & 13,2 & 30,8 & 17,8 & 110,0 & 1,4 \\
Silicato & 0,30 & 5,6 & 15,7 & 34,6 & 20,4 & 87,0 & 1,2 \\
Borato & 0,30 & 6,8 & 14,3 & 36,5 & 21,9 & 81,0 & 1,1 \\
Fosfato & 0,10 & 3,0 & 12,4 & 25,6 & 14,7 & 64,4 & 0,7 \\
Fluoreto & 0,10 & 2,5 & 13,5 & 29,1 & 16,1 & 55,0 & 0,6 \\
Telureto & 0,05 & 2,8 & 9,0 & 18,6 & 11,6 & 38,0 & 0,4 \\
chalcogeneto & 0,05 & 4,3 & 7,4 & 15,5 & 9,5 & 22,0 & 0,4 \\
\hline
\end{tabular}

Como discutido anteriormente, no caso de medidas de dureza é necessário que a indentação seja perfeita, diminuindo dessa forma os erros. Entretanto para medir $\mathrm{K}_{\mathrm{IC}}$ é necessário visualizar as trincas que saem da indentação, sendo necessário aumentar o tempo que a carga fica em contato com a superfície da amostra, ou aumentar a carga. Na presente investigação escolhemos aumentar a carga, no caso dos vidros aluminato de cálcio a carga utilizada foi de $0.3 \mathrm{kgf}$ durante $30 \mathrm{~s}$. Foram feitas pelo menos cinco indentaçöes em cada medida, pois cerca de $40 \%$ delas apresentam fissuras na superfície, conforme mostrado na 
figura 3.7, impossibilitando a visualização das trincas. Os resultados apresentados na tabela 5.9 säo a média dos valores obtidos para cada amostra.

Podemos perceber que o vidro aluminato de cálcio possui o maior valor de $\mathrm{K}_{\mathrm{IC}}$, que é de $1.31 \mathrm{MPa} \mathrm{m}^{1 / 2}$ graças principaimente a sua dureza e ao alto módulo de elasticidade, conforme equação 3.24. Por outro lado os vidros chalcogenetos são os que possuem menor $\mathrm{K}_{\mathrm{IC}}$, que principalmente devido a seu baixo módulo de elasticidade.

\subsection{Análise Térmica Diferencial}

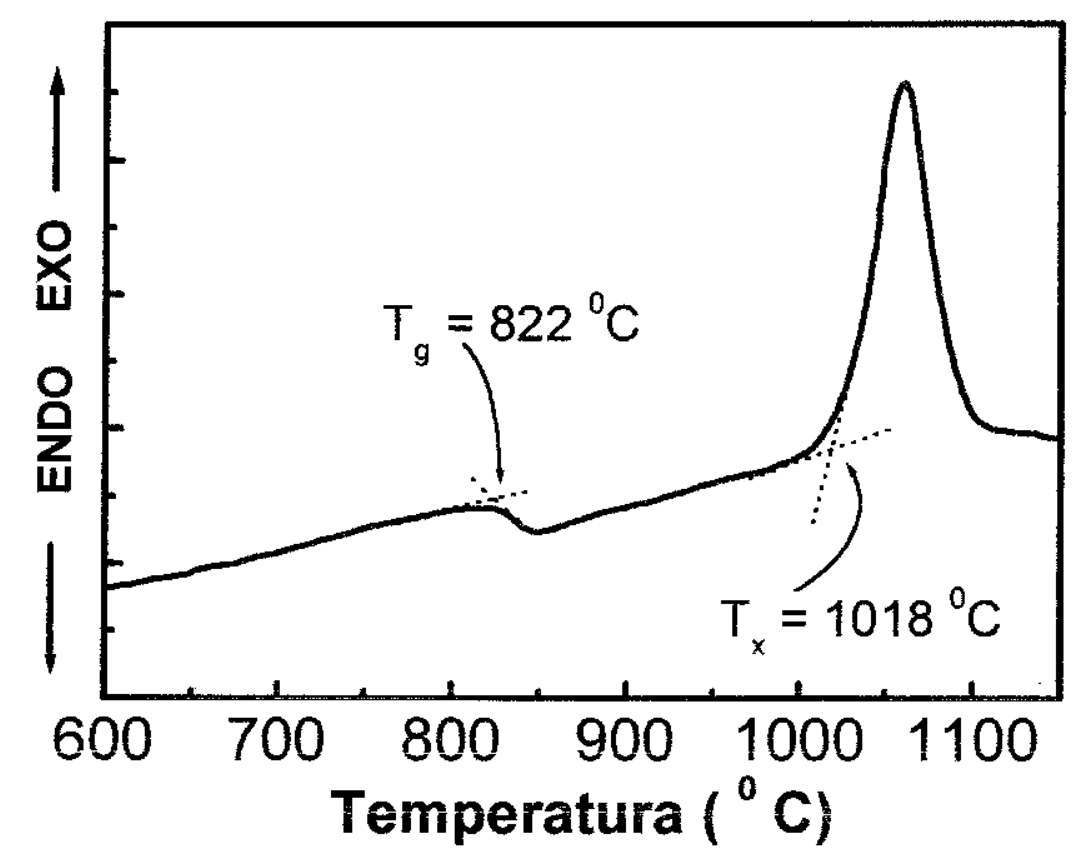

Figura 5.8 - Curva de DTA para amostra de vidro aluminato de cálcio dopada com $2 \%$ de $\mathrm{Er}_{2} \mathrm{O}_{3}$

Na figura 5.8 é mostrada a região onde ocorre os eventos térmicos dos vidros aluminato de cáicio. A temperatura de transiçâo vítrea desses vidros é aproximadamente em torno de $800^{\circ} \mathrm{C}$, enquanto que a temperatura de cristalização está próxima a $1000{ }^{\circ} \mathrm{C}$. Mais especificamente no caso dessa amostra dopada com $22 \%$ de $\operatorname{Er}_{2} \mathrm{O}_{3}$ o valor de $\mathrm{T}_{\mathrm{g}}$ é de 822 
${ }^{\circ} \mathrm{C}$ e de $\mathrm{T}_{\mathrm{x}}$ é de $1018{ }^{\circ} \mathrm{C}$. A diferença entre $\mathrm{T}_{\mathrm{x}}$ e $\mathrm{T}_{\mathrm{g}}$ é de $196{ }^{\circ} \mathrm{C}$, o que indica uma boa estabilidade térmica desses vidros.

$\mathrm{Na}$ figura 5.9 temos as curvas para quatro amostras de vidro aluminato de cálcio, o vid̀ro CASM00, amostra base, CASM04 corresponde à amostra dopada com $0.5 \%$ de $\mathrm{Er}_{2} \mathrm{O}_{3}, \mathrm{CASM} 07$ dopada com $4 \%$ de $\mathrm{Er}_{2} \mathrm{O}_{3}$ e CASM10 corresponde à amostra dopada com $8 \%$ de $\mathrm{Er}_{2} \mathrm{O}_{3}$. O que fica aparentemente visivei nestas curvas é o desiocamento do pico de cristalização bem como da região de transformação vítrea. A temperatura de cristalização, $\mathrm{T}_{\mathrm{x}}$, da amostra CÁSM00 é de $1058{ }^{\circ} \mathrm{C}$ enquanto que para amostra CASM10 é de $955^{\circ} \mathrm{C}$, ou seja uma diferença $103{ }^{\circ} \mathrm{C}$. No caso da temperatura de transição vítrea, $\mathrm{T}_{\mathrm{g}}$, da amostra CASM00 é de $841^{\circ} \mathrm{C}$ enquanto que da amostra CASMio de $782^{\circ} \mathrm{C}$, uma diferença de 59 ${ }^{\circ} \mathrm{C}$. Portanto a entrada de $\mathrm{Er}_{2} \mathrm{O}_{3}$ na rede vítrea influencia de maneira mais significativa $\mathrm{T}_{\mathrm{x}}$ do que $T_{g}$.

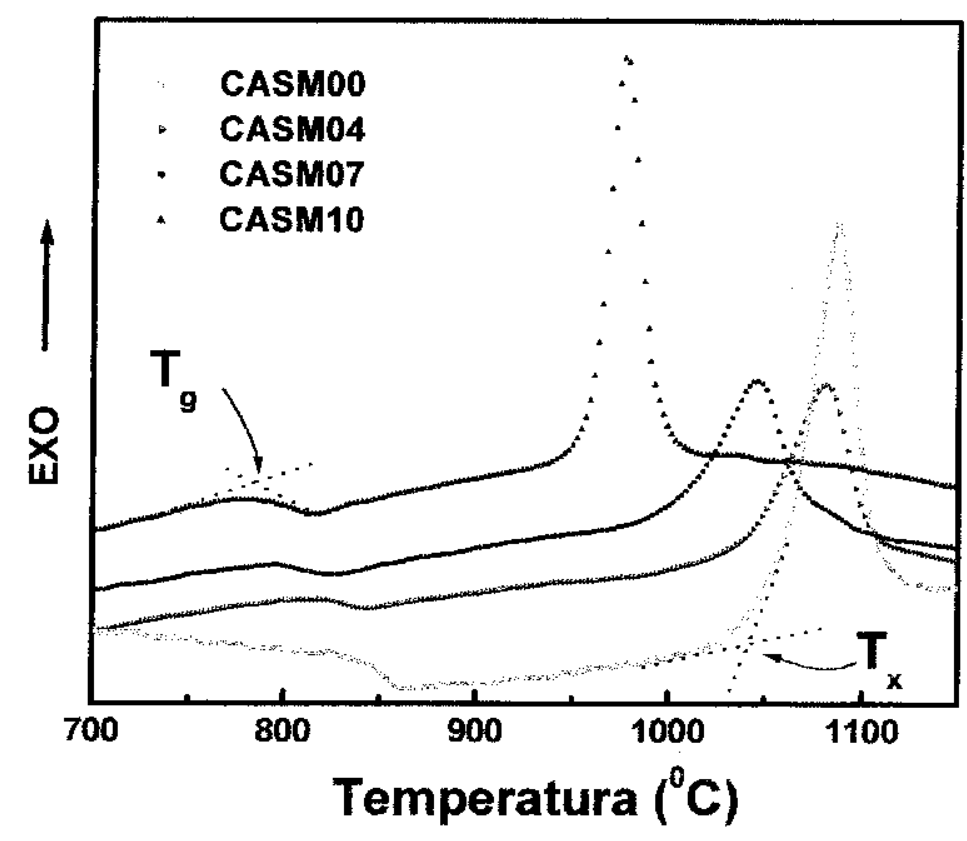

Figura 5.9 - curvas de DTA mostrando o deslocamento dos eventos térmicos, $T_{g}$ e $T_{x}$ na direção de temperaturas menores. 
$\mathrm{Na}$ tabela 5.10 encontram-se os valores para os eventos térmicos das várias séries de vidros aluminato de cálcio preparadas a vácuo.

Tabela 5.10 - Eventos térmicos vidros aluminato de cálcio dopados com óxidos terras raras. $T_{g}$ (iemperatura de transição vítrea), $T_{x}$ (iemperatura de crisialização).

\begin{tabular}{|c|c|c|c|c|c|}
\hline Amostra & $\begin{array}{c}\% \\
\text { dopante }\end{array}$ & $\begin{array}{l}\text { Massa } \\
(\mathrm{mg})\end{array}$ & $\begin{array}{c}\mathrm{T}_{\mathrm{g}} \\
\left({ }^{\circ} \mathrm{C}\right)\end{array}$ & $\begin{array}{c}\mathrm{T}_{\mathrm{x}} \\
\left({ }^{0} \mathrm{C}\right)\end{array}$ & $\begin{array}{l}T_{x}-T_{g} \\
\left({ }^{0} C\right)\end{array}$ \\
\hline CASM00 & - & 120,32 & 841 & 1058 & 217 \\
\hline CASM04 & $0,5 \mathrm{Er}_{2} \mathrm{O}_{3}$ & 83,16 & 821 & 1038 & 197 \\
\hline CASMOS & $1,0 \mathrm{Er}_{2} \mathrm{O}_{3}$ & 130,68 & 817 & 1035 & 218 \\
\hline CASM06 & $2,0 \mathrm{Er}_{2} \mathrm{O}_{3}$ & 122,58 & 822 & 1018 & 196 \\
\hline CASMOT & $4,0 \mathrm{Er}_{2} \mathrm{O}_{3}$ & 80,20 & 798 & 1000 & 202 \\
\hline CASM08 & $6,0 \mathrm{Er}_{2} \mathrm{O}_{3}$ & 166,76 & 791 & 979 & 188 \\
\hline CASM09 & $7,0 \mathrm{Er}_{2} \mathrm{O}_{3}$ & 163,45 & 787 & 958 & 171 \\
\hline CASM10 & $8,0 \mathrm{Er}_{2} \mathrm{O}_{3}$ & 245,00 & 782 & 955 & 173 \\
\hline CASM01 & $1,0 \mathrm{Yb}_{2} \mathrm{O}_{3}$ & 202,35 & 813 & 1029 & 216 \\
\hline CASMO2 & $3,0 \mathrm{Yb}_{2} \mathrm{O}_{3}$ & 202,60 & 803 & 993 & 190 \\
\hline CASMÖ3 & $5,0 \mathrm{Yb}_{2} \mathrm{O}_{3}$ & 207,67 & 788 & 982 & 194 \\
\hline CASM11 & $2 \mathrm{Er}_{2} \mathrm{O}_{3}+3 \mathrm{Yb}_{2} \mathrm{O}_{3}$ & 201,00 & 794 & 979 & 185 \\
\hline CASMI2 & $2 \mathrm{Er}_{2} \mathrm{O}_{3}+4 \mathrm{Yb}_{2} \mathrm{O}_{3}$ & 182,00 & 790 & 976 & 186 \\
\hline CASM13 & $2 \mathrm{Yb}_{2} \mathrm{O}_{3}+0,5 \mathrm{Er}_{2} \mathrm{O}_{3}$ & 154,35 & 807 & 1006 & 199 \\
\hline CASM14 & $2 \mathrm{Yb}_{2} \mathrm{O}_{3}+1,0 \mathrm{Er}_{2} \mathrm{O}_{3}$ & 182,25 & $\overline{79} 8$ & 1006 & 208 \\
\hline CASM15 & $2 \mathrm{Yb}_{2} \mathrm{O}_{3}+2,0 \mathrm{Er}_{2} \mathrm{O}_{3}$ & 180,20 & 792 & 983 & 191 \\
\hline CASM16 & $2 \mathrm{Yb}_{2} \mathrm{O}_{3}+3,0 \mathrm{Er}_{2} \mathrm{O}_{3}$ & 209,49 & 798 & 969 & 171 \\
\hline CASM17 & $2 \mathrm{Yb}_{2} \mathrm{O}_{3}+4.0 \mathrm{Er}_{2} \mathrm{O}_{3}$ & 258,00 & 791 & 972 & 181 \\
\hline CASM18 & $2 \mathrm{Yb}_{2} \mathrm{O}_{3}+5,0 \mathrm{Er}_{2} \mathrm{O}_{3}$ & 175,86 & 785 & 969 & 184 \\
\hline
\end{tabular}


Na figura 5.10 é mostrado o comportamento da diferença entre $T_{x}$ e $T_{g}$. Podemos verificar que conforme aumenta-se a concentração de terra rara, tanto $T_{x}$ quando $T_{g}$ diminuem da mesma forma.

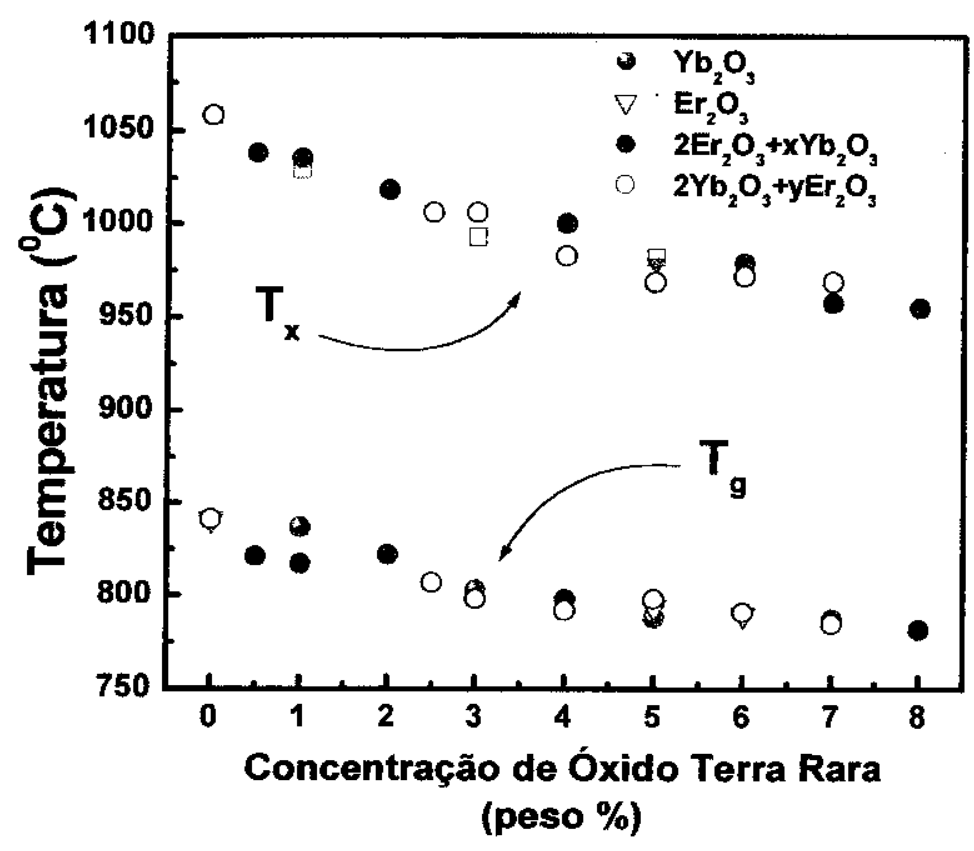

Figura 5.10 - Variação dos parâmetros térmicos $T_{g}$ e $T_{x}$ dos vidros aluminato de cálcio dopados em função da concentração de óxido terras raras.

A diferença entre $T_{x}$ e $T_{g}$ é usada freqüentemente na literatura (Hrubý, 1972) para predizer ou explicar a tendência à cristalização, um pequeno intervalo entre $T_{g}$ e $T_{x}$ indica que o vidro contém unidades estruturais com alta tendência à cristalização, ou seja, com alta temperatura liquidus que não é favorável à formação de vidro. Por outro lado, um curto intervalo entre $T_{x}$ e $T_{m}$ indica que a fase cristalina formada em $T_{x}$ tem um baixo ponto de fusão, conseqüentemente a temperatura original tem uma baixa temperatura solidus. Levando isto em consideração Hrubý (1972) formulou três regas: 1) Todos os vidros na temperatura $T_{g}$ estão em estados estruturais comparáveis; 2) $O$ intervalo entre $T_{x}-T_{g}$ é diretamente proporcional à tendência de formação de vidro; 3) $O$ intervalo entre $T_{m}-T_{x}$ é indiretamente proporcional à tendência de formação de vidro. Estas relações podem ser 
combinadas em uma simples relação que é uma medida numérica da tendência à formação de vidro, que é dada por:

$$
W=\frac{T_{x}-T_{g}}{T_{m}-T_{x}}
$$

Podemos observar dos dados da tabela 5.10 que a diferença entre $T_{x}$ e $T_{g}$ é praticamente constante, aproximadamente $189 \pm 16{ }^{\circ} \mathrm{C}$. Para a amostra CASM00 essa diferença foi de $217^{\circ} \mathrm{C}$, enquanto que para a CASM10 foi de $161{ }^{\circ} \mathrm{C}$. Em relação a alguns sistemas vítreos o intervalo entre $T_{x}$ e $T_{g}$ é relativamente alto.

Como já mencionado anteriormente, no intervalo composicional estudado, a temperatura de fusão, $\mathrm{T}_{\mathrm{m}}$, de vidros aluminato de cálcio dopados com $\mathrm{Nd}_{2} \mathrm{O}_{3}$ permanece praticamente constante (Sampaio, 1997). Levando isso em consideração, a fim de estimarmos o valor de $\mathrm{W}$ para os vidros dopados com $\mathrm{Er}_{2} \mathrm{O}_{3}, \mathrm{Yb}_{2} \mathrm{O}_{3}$ e suas combinações o valor de $\mathrm{T}_{\mathrm{m}}=1325^{\circ} \mathrm{C}$ com margem de erro de $5 \%$. Usando a equação 5.1 e os valores da tabela 5.10, encontramos para o vidro CASM00, $W=0.81$ enquanto que para o CASM09 o valor de $W=0.47$.

Segundo Hrubý, se o valor de $W$ for próximo a 0.1 , a preparação do vidro é muito dificil e requer um controle rigoroso da maioria das condições experimentais, necessitando uma taxa de resfriamento da ordem de $10^{2}{ }^{0} \mathrm{C} / \mathrm{s}$. Se o valor for igual a 0.5 a formação de vidro será facilmente obtida pelo resfriamento livre do material fundido ao ar. Para valores acima de 1.0 tem-se um vidro com estrutura polimérica com alto peso molecular. No caso das amostras de vidro aluminato de cálcio dopados com $\mathrm{Er}_{2} \mathrm{O}_{3}$ esse valor variou de 0.8 , CASM00, a 0.4 para amostra CASM10. Esses resultados corroboram com o que foi observado durante a fusão das amostras, ou seja amostras com baixa concentração de terra rara vitrificou-se muito mais facilmente do que aquelas com alto teor de terra rara. $\mathrm{Na}$ figura 5.11 temos o comportamento de W em função da concentração de $\operatorname{Er}_{2} \mathrm{O}_{3}$ para os vidros aluminato de cálcio. As setas indicam as amostras que cristalizaram-se parcialmente. 


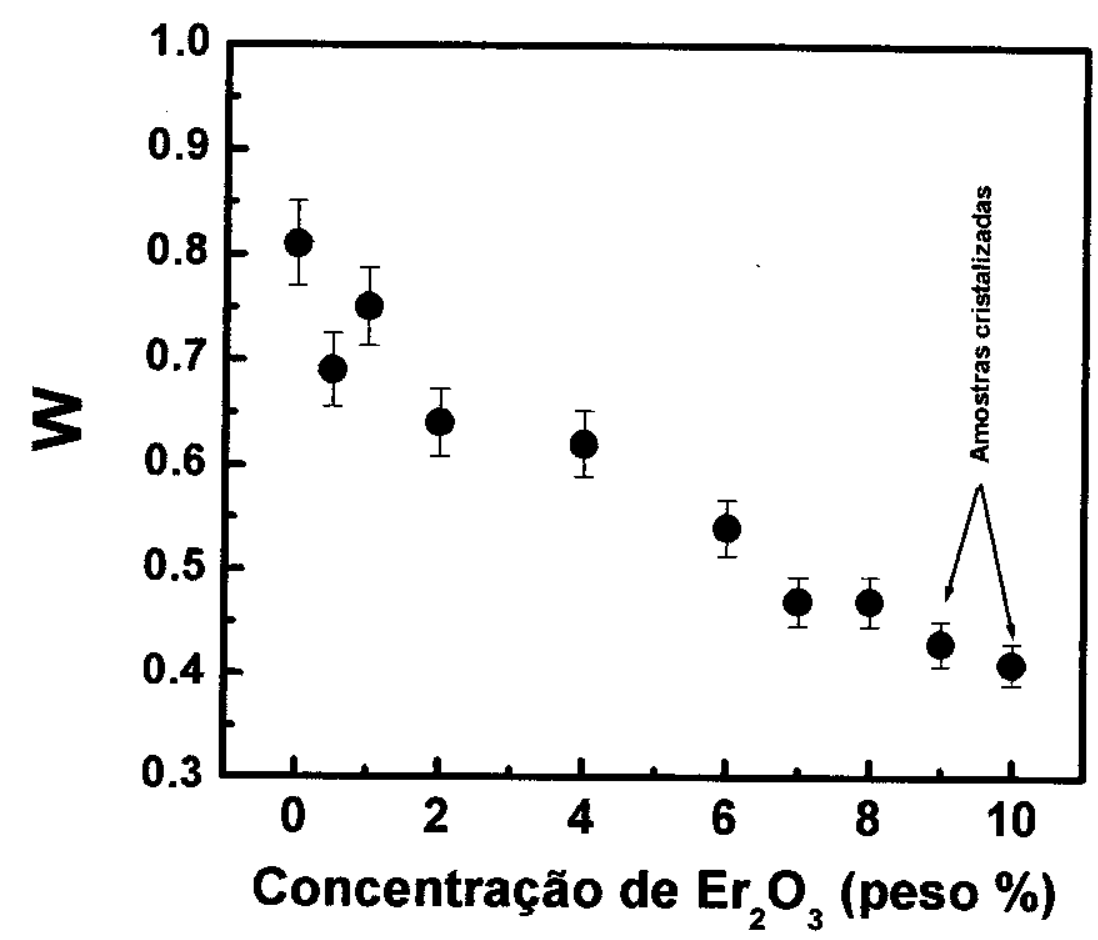

Figura 5.11 - Tendência à cristalização dos vidros aluminato de cálcio em função do aumento da concentração de $\mathrm{Er}_{2} \mathrm{O}_{3}$.

A diminuição nos valores de $\mathrm{T}_{\mathrm{g}}$ de apoximadamente $62{ }^{\circ} \mathrm{C}$ entre amostra base, CASM00, e a amostra dopada com $10 \%$ (em peso) de $\mathrm{Er}_{2} \mathrm{O}_{3}, \mathrm{CASM08}$, pode ser explicada da seguinte maneira. A intensidade de campo entre os íons de terra rara e oxigênios é mais fraca do que as entre as ligações de Al com os oxigênios da sua vizinhança, sendo portanto mais fácil de quebrá-las, desta forma uma menor energia térmica é requerida para que a viscosidade necessária a formação de vidro ocorra.

Conforme o diagrama de fase parcial do sistema $\mathrm{CaO}: \mathrm{Al}_{2} \mathrm{O}_{3}$, figura 5.12, podemos observar que conforme diminui-se a concentração de $\mathrm{Al}_{2} \mathrm{O}_{3}$ e devido ao alto ponto de fusão dô $\mathrm{CaO}$, ocồre umin aumento significativo da temperatura liquidus. Uma diminuição de $10 \%$ na concentração (em peso) de $\mathrm{Al}_{2} \mathrm{O}_{3}$ corresponde a um aumento de $258{ }^{\circ} \mathrm{C}$ na temperatura de fusão do vidro. É evidente que no caso dos vidros aluminato de cálcio aqui investigados, que é um sistema quaternário, esse aumento de temperatura não é tão abrupto devido aos outros componentes, $\mathrm{SiO}_{2}$ e $\mathrm{MgO}$, porém podemos imaginar que essa seja uma indicação de que para podermos obter vidro, quando a concentração de alumina diminui 
razoavelmente, é necessário um aumento maior de temperatura de fusão. Além de utilizar altas taxas de resfriamento, da ordem de centenas de graus, como por exemplo o método de splat quenching.

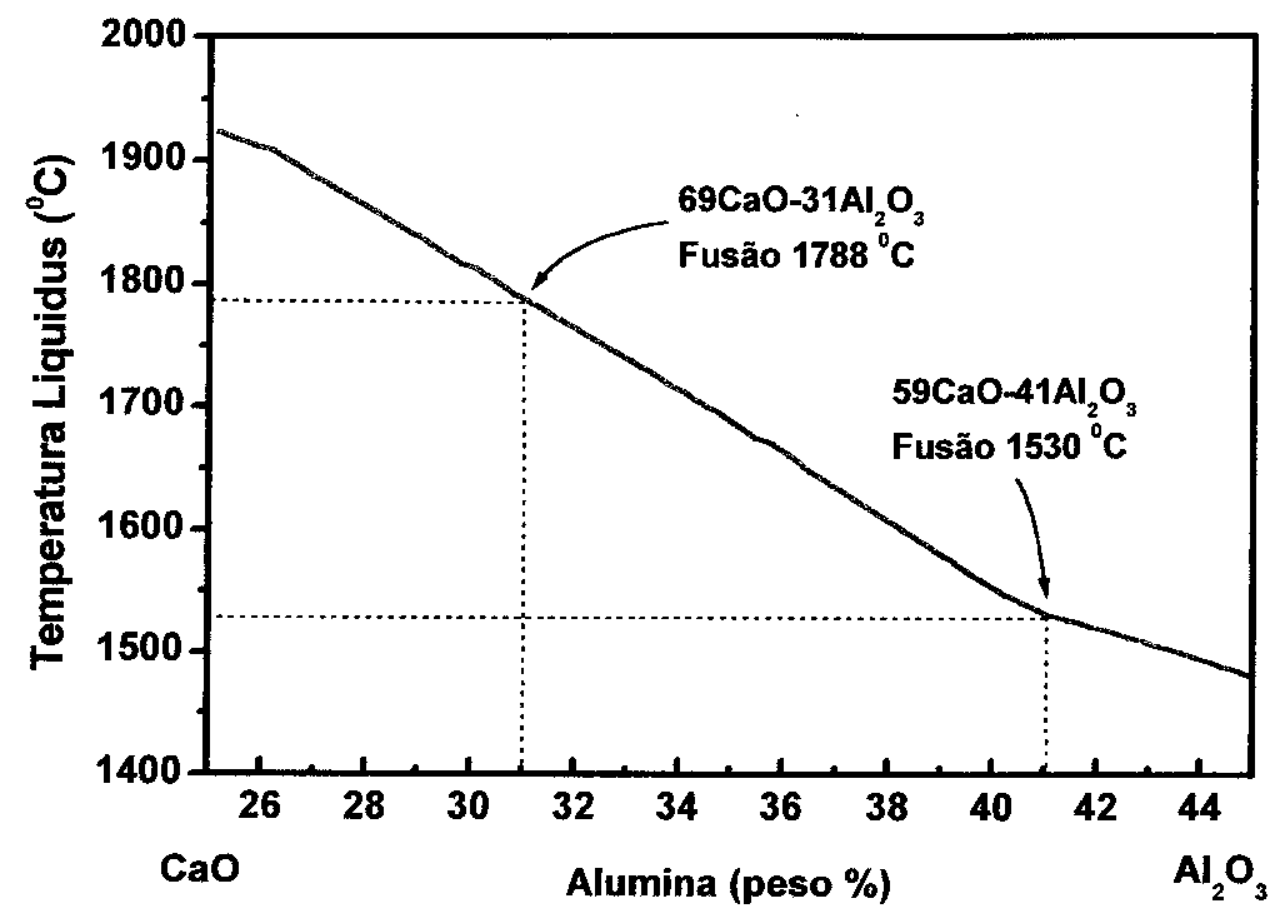

Figura 5.12 - Diagrama parcial do sistema $\mathrm{CaO}: \mathrm{Al}_{2} \mathrm{O}_{3}$ (Rawson, 1967).

\subsection{Calor Específico}

A figura 5.13 mostra a curva de decaimento de $\Delta \mathrm{T}$ em função do tempo, entre o substrato de silício e o reservatório térmico, cuja potência dissipada foi de $566.6 \mu \mathrm{W}$. Fazendo-se o ajuste dos dados experimentais com a equação 4.19, obtemos os valores de $\Delta \mathrm{T}=0.097 \pm 0.001$ e $\tau=7.24 \pm 0.06$. Usando esses valores e a equação 4.21 , temos que a capacidade térmica do substrato é de $42.29 \mathrm{~J} / \mathrm{K}$.

Esse procedimento foi repetido três vezes. Em seguida foi feita a média aritimética dos valores da capacidade térmica do substrato. Obteve-se $\mathrm{C}_{\mathrm{sub}}=(42.99 \pm 0.01) \times 10^{-3}$ $\mathrm{J} / \mathrm{K}$. Os dados obtidos para o substrato são mostrados na tabela 5.11. 


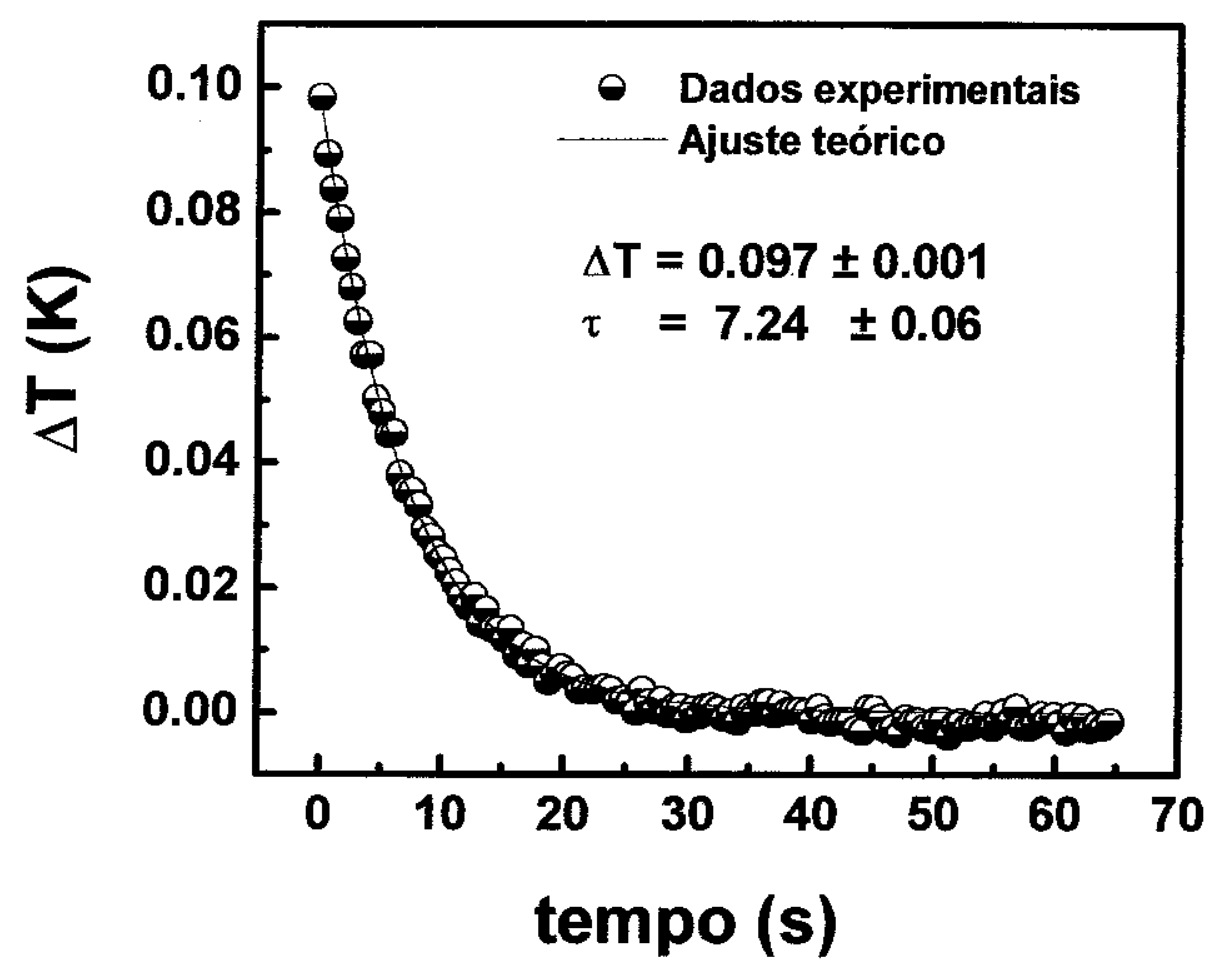

Figura 5.13 - curva de decaimento da diferença de temperatura entre o substrato de silício e o reservatório térmico em função do tempo. Os pontos abertos representam os dados experimentais e a linha contínua o ajuste teórico obtido. A ordem de grandeza do erro é de $1 \%$.

Tabela 5.11 - dados experimentais da capacidade térmica do substrato.

\begin{tabular}{ccccccc}
\hline $\begin{array}{c}\text { Temperatura } \\
(\mathrm{K})\end{array}$ & $\begin{array}{c}\text { corrente } \\
(\mathrm{mA})\end{array}$ & $\begin{array}{c}\text { tensão } \\
(\mathrm{mV})\end{array}$ & $\begin{array}{c}\mathrm{P} \\
(\mu \mathrm{W})\end{array}$ & $\begin{array}{c}\tau \\
(\mathrm{s})\end{array}$ & $\begin{array}{c}\Delta \mathrm{T} \\
(\mathrm{K})\end{array}$ & $\begin{array}{c}\mathrm{C} \\
(\mathrm{mJ} / \mathrm{K})\end{array}$ \\
\hline 297,29 & 3,135 & 0,23798 & 746,07 & 7,2978 & 0,12659 & 43,01 \\
297,351 & 2,85 & 0,21411 & 610,21 & 7,2214 & 0,10366 & 42,51 \\
297,38 & 2,75 & 0,20602 & 566,56 & 7,38378 & 0,09626 & 43,46 \\
\hline
\end{tabular}

A figura 5.14 mostra a curva de decaimento de $\Delta \mathrm{T} \times \mathrm{t}$ com 256 pontos, para uma amostra de vidro aluminato de cálcio dopado com $4.0 \%$ (peso) de $\mathrm{Nd}_{2} \mathrm{O}_{3}$. $\mathrm{O}$ ajuste dos dados experimentais pela equação teórica é indicado pela linha continua. Este ajuste nos 
fornece $\Delta \mathrm{T}=0.097 \mathrm{~K}$ e $\tau=13.63 \mathrm{~s}$. A potência dissipada no aquecedor foi de $\mathrm{P}=637.8$ $\mu \mathrm{W}$. Desta forma a capacidade térmica do substrato + amostra, $\mathrm{C}_{\text {total }}=89.62 \times 10^{-3} \mathrm{~J} / \mathrm{K}$. Como o valor da capacidade térmica do substrato foi de $\mathrm{C}_{\mathrm{sub}}=42.99 \times 10^{-3} \mathrm{~J} / \mathrm{K}$, temos que a capacidade térmica da amostra de vidro aluminato de cálcio $C_{a m o}=46.63 \times 10^{-3} \mathrm{~J} / \mathrm{K}$. Como a massa da amostra foi de $51.04 \times 10^{-3} \mathrm{mg}$, obtemos o valor do calor específico a pressão constante $c_{\mathrm{p}}=0.914 \mathrm{~J} \mathrm{~K}^{-1} \mathrm{~g}^{-1}$.

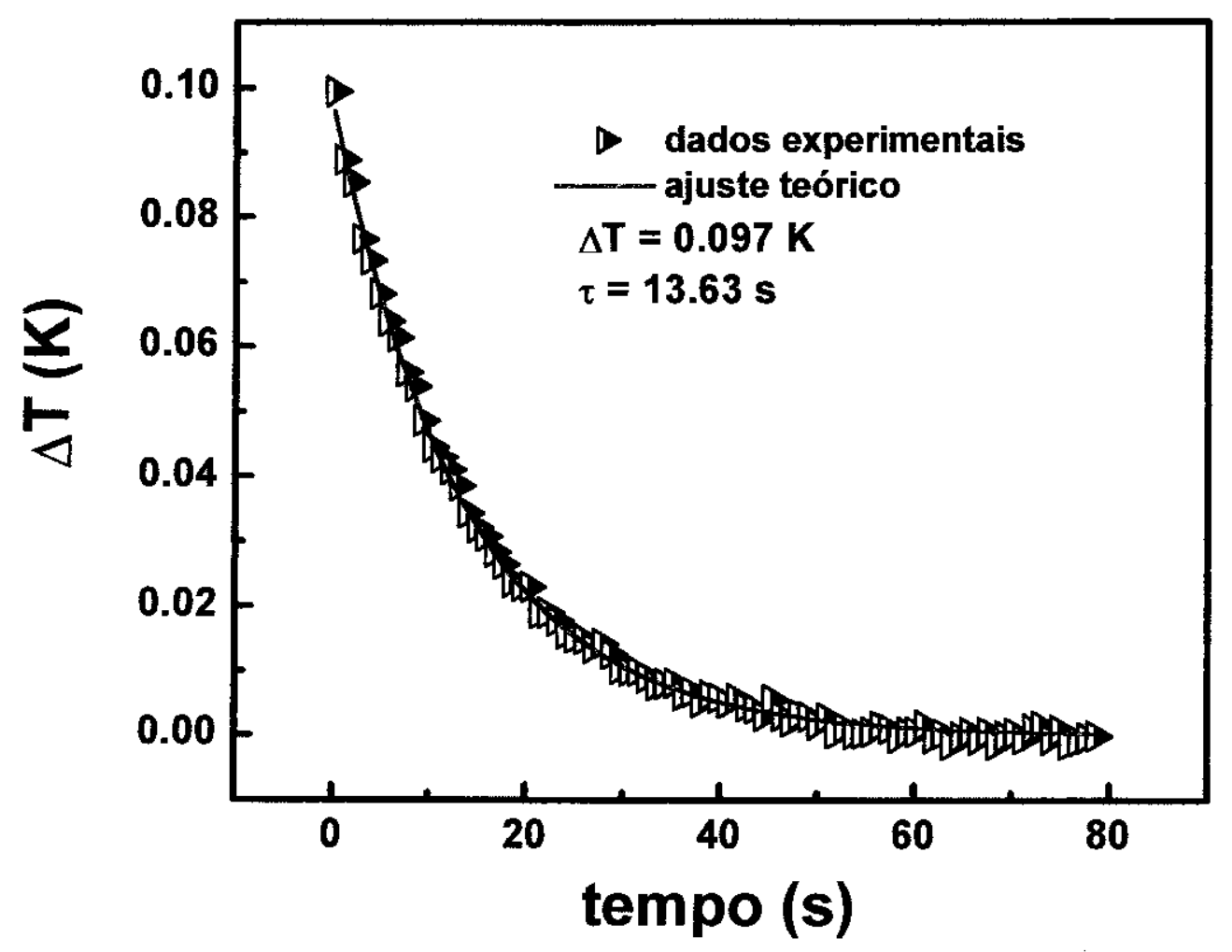

Figura 5.14 - Curva de decaimento da diferença de temperatura entre o substrato de silício + amostra de vidro aluminato de cálcio dopado com $4.0 \%$ (peso) $\mathrm{Nd}_{2} \mathrm{O}_{3}$. A curva contínua representa o ajuste. Potência dissipada foi de $P=637.8 \mu \mathrm{W}$, com $\Delta T=0.097 \mathrm{~K}$ e $\tau=$ $13.63 s$

Seguindo esse procedimento foi possivel obter o calor específico das amostras de vidro aluminato de cálcio dopados com $\mathrm{Nd}_{2} \mathrm{O}_{3}$, apresentados na tabela 5.12, enquanto que na tabela 5.13 são apresentados o calor específico para vidros aluminato de cálcio dopados com Er e $\mathrm{Yb}$, nessas medidas utilizou-se um calorímetro no qual a capacidade térmica do substrato foi de $\mathrm{C}_{\text {sub }}=52.33 \times 10^{-3} \mathrm{~J} / \mathrm{K}$. 
A figura 5.15 mostra o comportamento do calor específico dos vidros aluminato de cálcio dopados em função da concentração de óxidos terras raras. Podemos observar que o comportamento do calor específico é praticamente constante, próximo à $0.92 \mathrm{~J} \mathrm{~g}^{-1} \mathrm{~K}^{-1}$, sendo independente da concentração e do tipo de óxido terra rara que entra na composição do vidro.

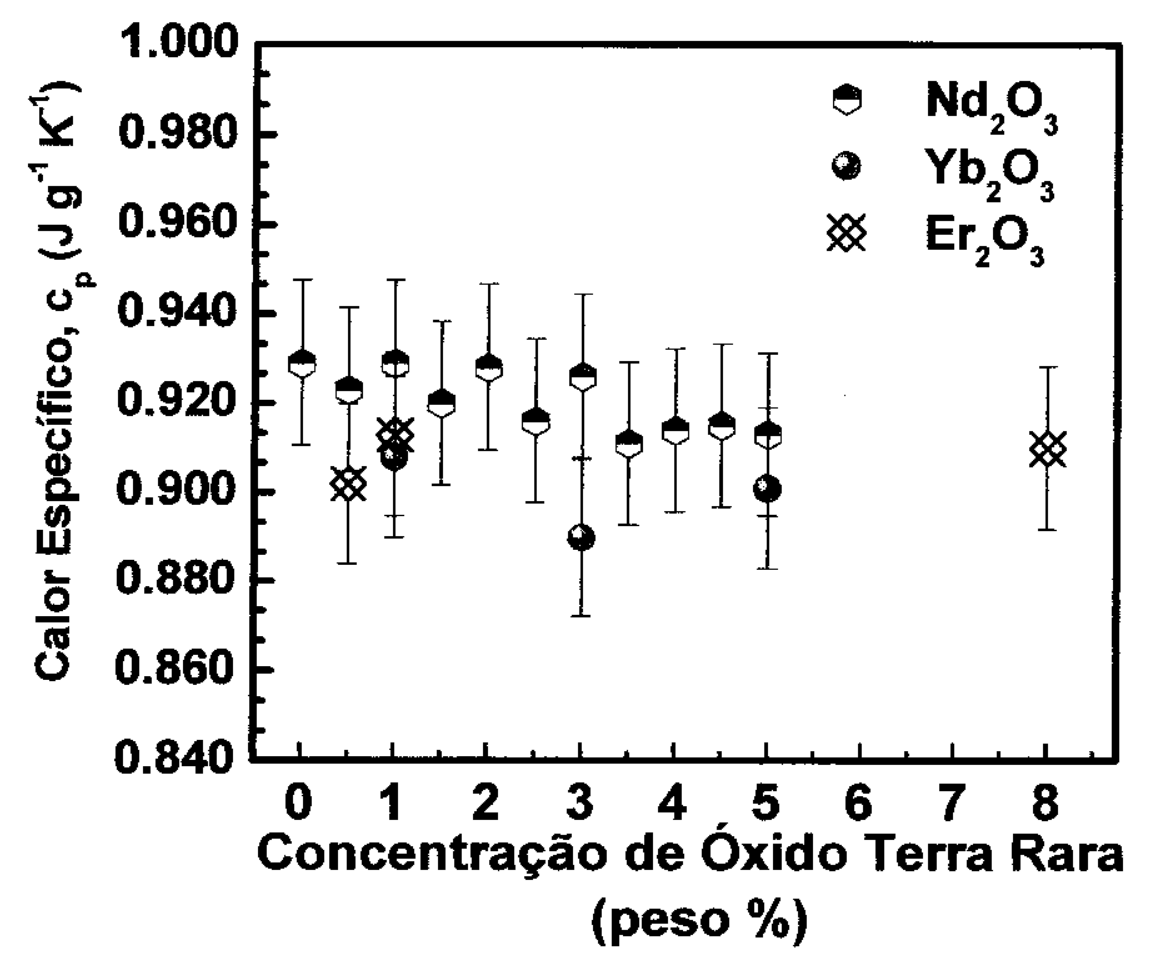

Figura 5.15 - Calor específico dos vidros aluminato de cálcio em função da concentração de óxidos terras raras. 


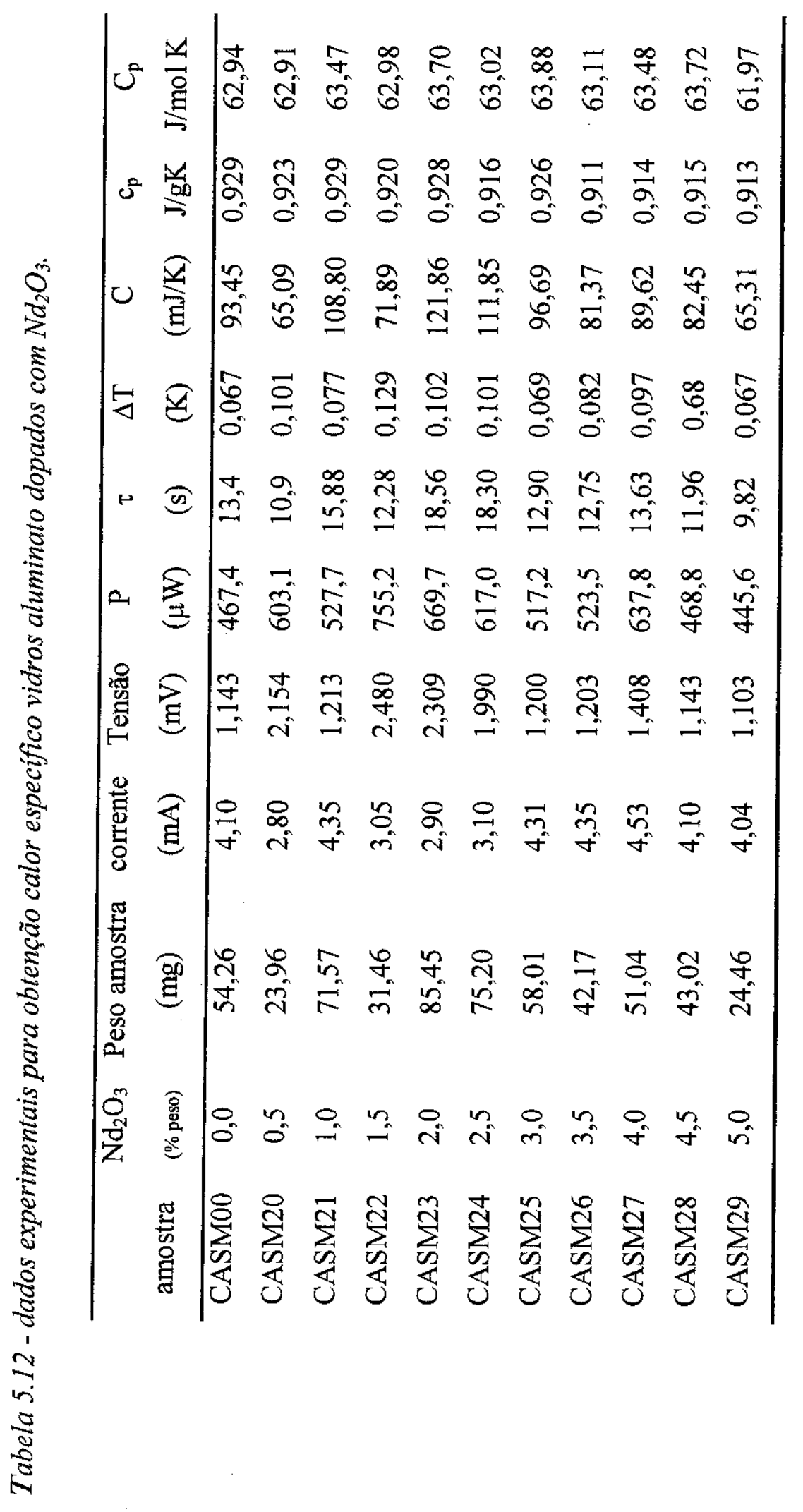


Tabela 5.13 - dados experimentais para obtenção do calor específico para vidros aluminato de cálcio dopados com diferentes concentraçães de Yb e Er.

\begin{tabular}{lccccccccccc} 
Amostra & $\begin{array}{c}\% \\
\text { dopante }\end{array}$ & $\begin{array}{c}\text { Peso } \\
\text { amostra } \\
(\mathrm{mg})\end{array}$ & $\begin{array}{c}\text { corrente } \\
(\mathrm{mA})\end{array}$ & $\begin{array}{c}\text { Tensão } \\
(\mathrm{mV})\end{array}$ & $\begin{array}{c}\mathrm{P} \\
(\mu \mathrm{W})\end{array}$ & $\begin{array}{c}\tau \\
(\mathrm{s})\end{array}$ & $\begin{array}{c}\Delta \mathrm{T} \\
(\mathrm{K})\end{array}$ & $\begin{array}{c}\mathrm{C} \\
(\mathrm{mJ} /\end{array}$ & $\begin{array}{c}\mathrm{c}_{\mathrm{p}} \\
\mathrm{J} / \mathrm{gK}\end{array}$ & $\begin{array}{c}\mathrm{C}_{\mathrm{p}} \\
\mathrm{J} / \mathrm{mol} \mathrm{K}\end{array}$ \\
\hline $\mathrm{CASM01}$ & $1 \mathrm{YB}_{2} \mathrm{O}_{3}$ & 27,99 & 2,00 & 1,869 & 373,9 & 13,2 & 0,064 & 77,8 & 0,908 & 62,04 \\
$\mathrm{CASM02}$ & $3 \mathrm{YB}_{2} \mathrm{O}_{3}$ & 24,72 & 1,90 & 1,779 & 338,1 & 12,7 & 0,059 & 74,3 & 0,890 & 61,45 \\
$\mathrm{CASM03}$ & $5 \mathrm{YB}_{2} \mathrm{O}_{3}$ & 33,89 & 1,90 & 1,810 & 344,0 & 13,8 & 0,057 & 82,9 & 0,901 & 62,74 \\
$\mathrm{CASM04}$ & $05 \mathrm{Er}_{2} \mathrm{O}_{3}$ & 28,06 & 2,00 & 1,805 & 360,9 & 12,9 & 0,060 & 77,7 & 0,902 & 62,01 \\
$\mathrm{CASM05}$ & $1 \mathrm{Er}_{2} \mathrm{O}_{3}$ & 25,60 & 2,20 & 1,985 & 436,7 & 12,8 & 0,074 & 75,7 & 0,913 & 62,33 \\
$\mathrm{CASM10}$ & $8 \mathrm{Er}_{2} \mathrm{O}_{3}$ & 23,10 & 2,20 & 3,022 & 664,8 & 27,1 & 0,246 & 73,4 & 0,910 & 64,56
\end{tabular}

\section{8 Índice de Refração}

Nas tabelas 5.14, 5.15 e 5.16 são fornecidos os resultados obtidos para o índice de refração e as propriedades a ele relacionadas. Os índices de refração são dados para cada comprimento. A diferença $n_{F}-n_{c}$ é a dispersão óptica média entre $486.1 \mathrm{~nm}$ e $656.3 \mathrm{~nm}$. $v_{\mathrm{d}}$ é o número de Abbe, calculado a partir da equação 4.27. П é a refração molar calculada a partir da equação 4.26 , na qual usamos o valor do volume molar, $V_{M}$ das tabelas 2.6 a 2.8 . $V_{\phi}$ e $V_{f}$ foram calculados a partir das equações 4.28 e 4.29. No caso das medidas em função da temperatura, a obtenção do ângulo de desvio da luz foi feita fazendo a média de pelo menos cinco medidas em cada uma das temperaturas. Entre uma temperatura e outra a diferença foi de $5{ }^{\circ} \mathrm{C}$. Esperando-se aproximadamente 10 minutos entre estes pontos para alcançar o equilíbrio térmico. 


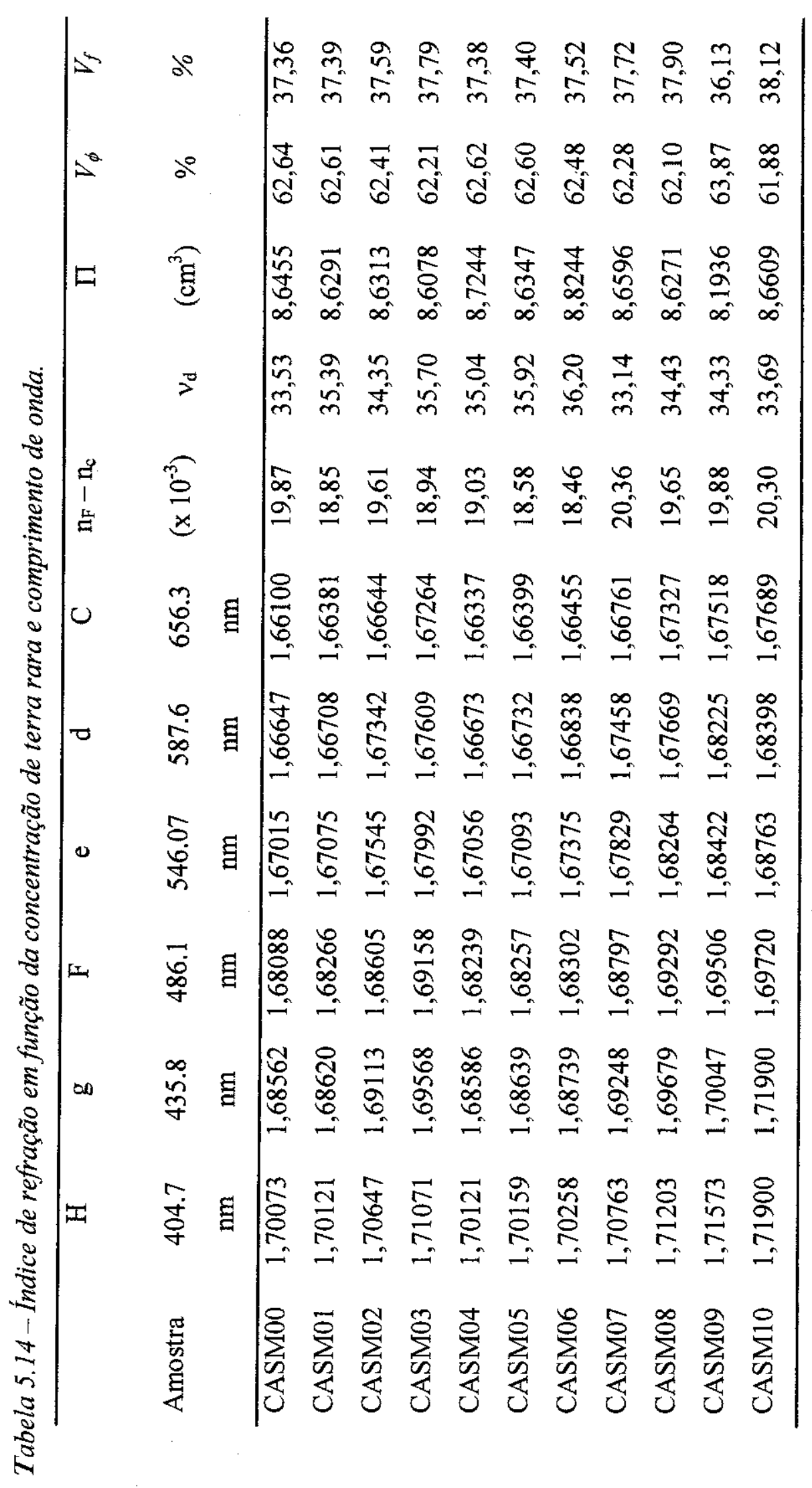




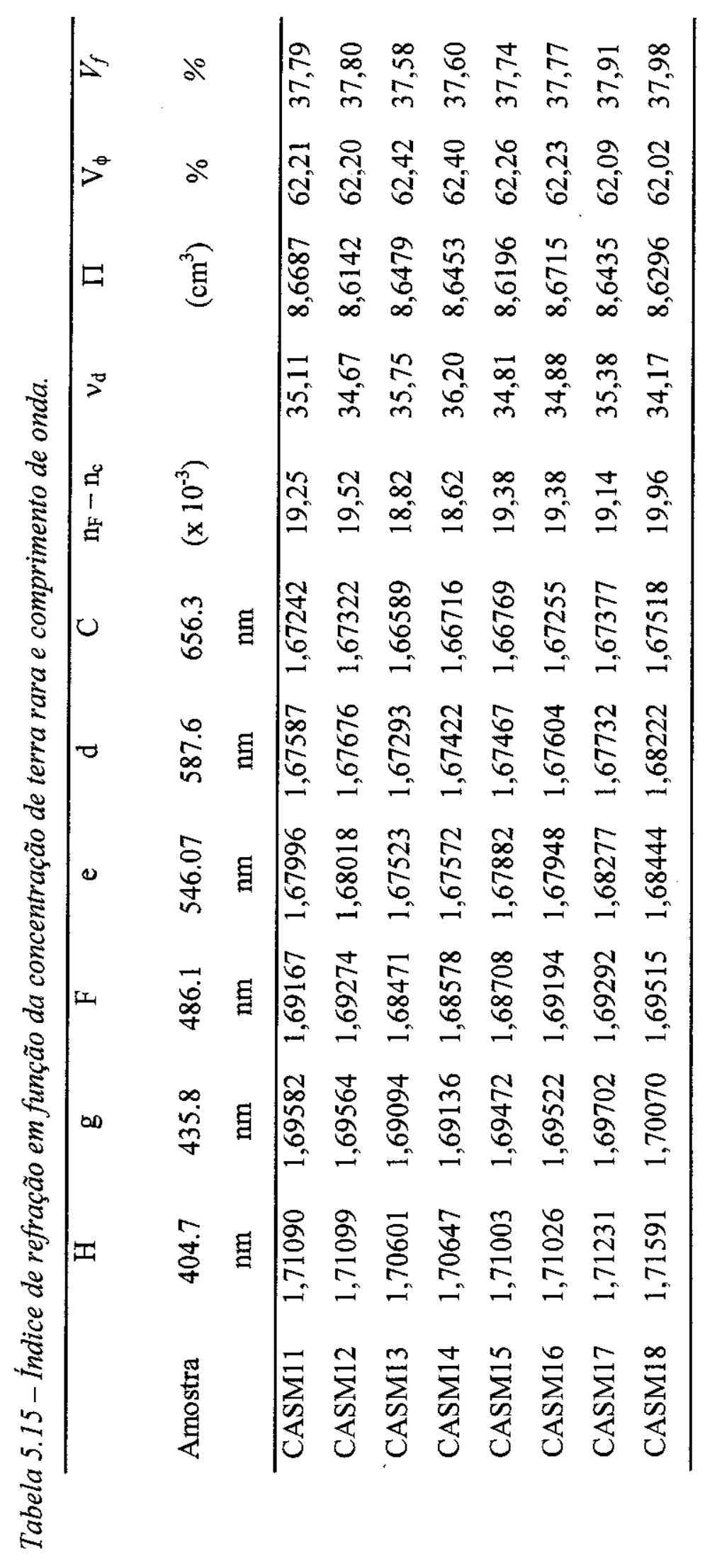




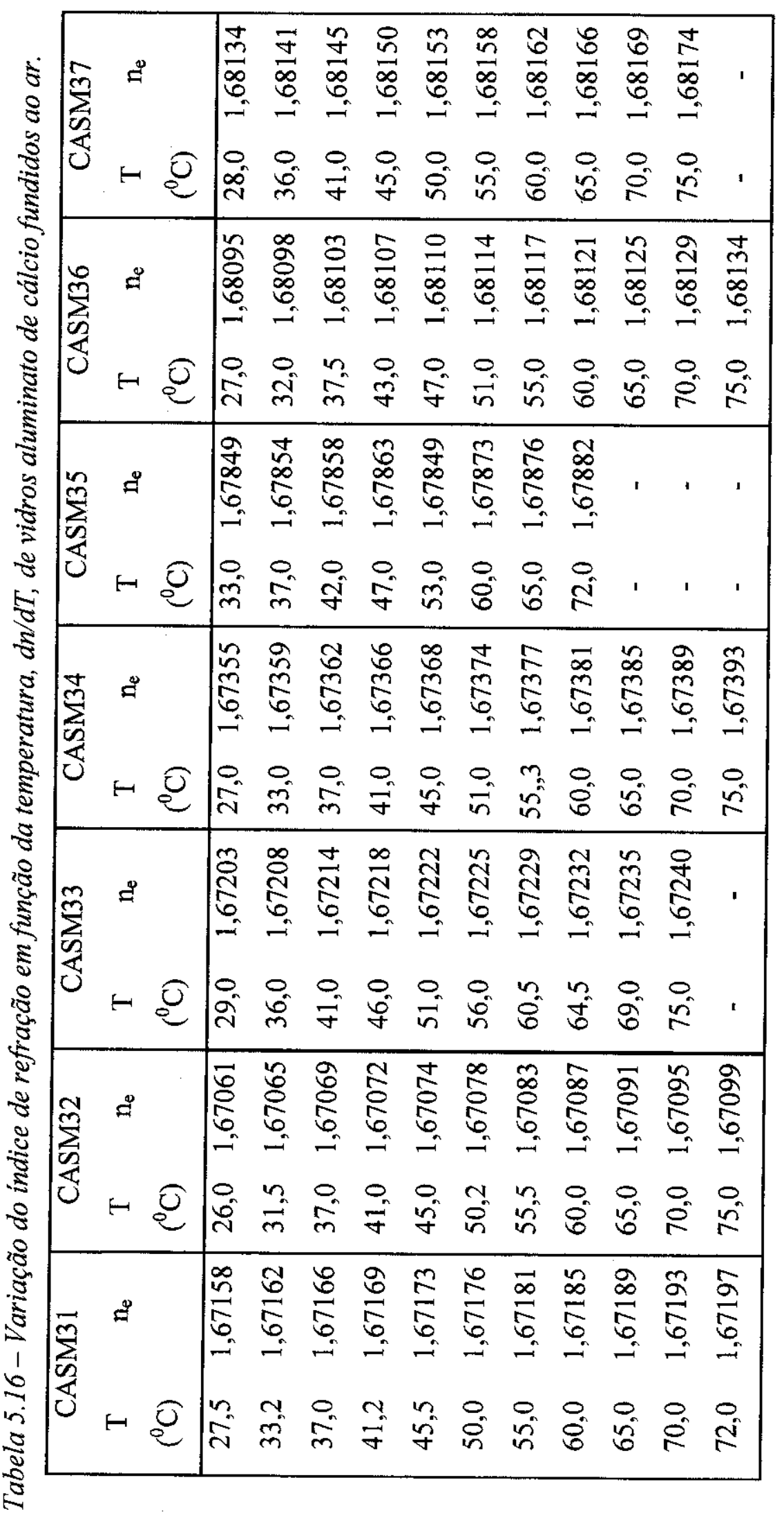




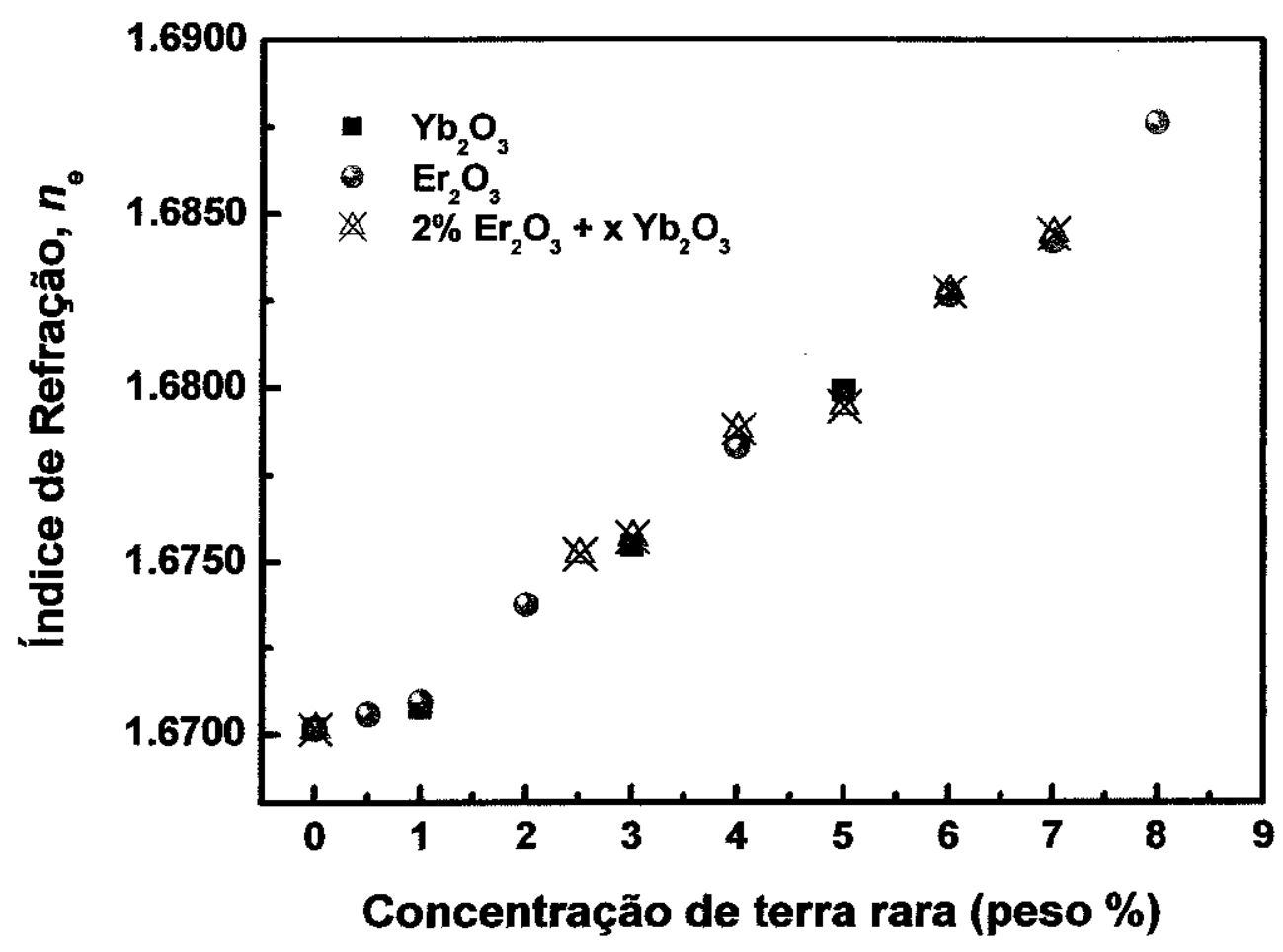

Figura 5.16 - Índice de refração para vidros aluminato de cálcio em função da concentração com óxido terras raras. Os dopantes são indicados na figura.

Na figura 5.16 é mostrada o comportamento do índice de refração dos vidros aluminato de cálcio em função da concentração de óxidos terras raras. Podemos perceber que há um aumento linear do índice de refração, independente da natureza do íon terra rara. As amostras de 0.5 e $1.0 \%$ (em peso) de terra rara apresenta um pequeno desvio da linearidade, o qual é atribuído ao método de preparação da amostra conforme já discutido no capítulo 2 .

Essa independência em relação ao dopante pode ser devido ao fato de que o papel principal sobre essa propriedade é desempenhado pelos formadores de rede, no caso $\mathrm{Al}_{2} \mathrm{O}_{3}$, e $\mathrm{SiO}_{2}$. Conforme reportado por Shelby (1985) e posteriormente por Huang e Behrman (1991), o índice de refração nos vidros aluminato de cálcio é dependende da concentração de $\mathrm{SiO}_{2}$ e da razão molar $\mathrm{Al}_{2} \mathrm{O}_{3} / \mathrm{CaO}$. Vidros com alta concentração de $\mathrm{SiO}_{2}$ possuem índice de refração mais baixo, próximo a 1.55, enquanto que para concentrações baixas de $\mathrm{SiO}_{2}$ e razão molar $\mathrm{Al}_{2} \mathrm{O}_{3} / \mathrm{CaO}<1$ esse valor é de 1.65 . Os dados aqui apresentados estão de bom acordo com 
aqueles reportados por Shelby (1985) e Huang/Behrman (1991). Oprea et al. (1992) reportam também que um aumento na concentração de $\mathrm{CaO}$ induz um aumento no índice de refração dos vidros aluminato de cálcio, sugerindo que a estrutura interna desses vidros muda mesmo com pequenas quantidades de $\mathrm{CaO}$.

De acordo com os modelos estruturais propostos na literatura (King e Shelby, 1996) para os vidros aluminato de cálcio, quando a razão molar $\mathrm{Al}_{2} \mathrm{O}_{3} / \mathrm{CaO}$ é menor que 1 há a ocorrência de formação de oxigênios non-bridging (NBO). No caso de nossas amostras essa razão é de 0.466 para a amostra CASM00 e de 0.388 para a amostra CASM10. O Comportamento do índice de refração em função dessa razão é mostrada na figura 5.17 .

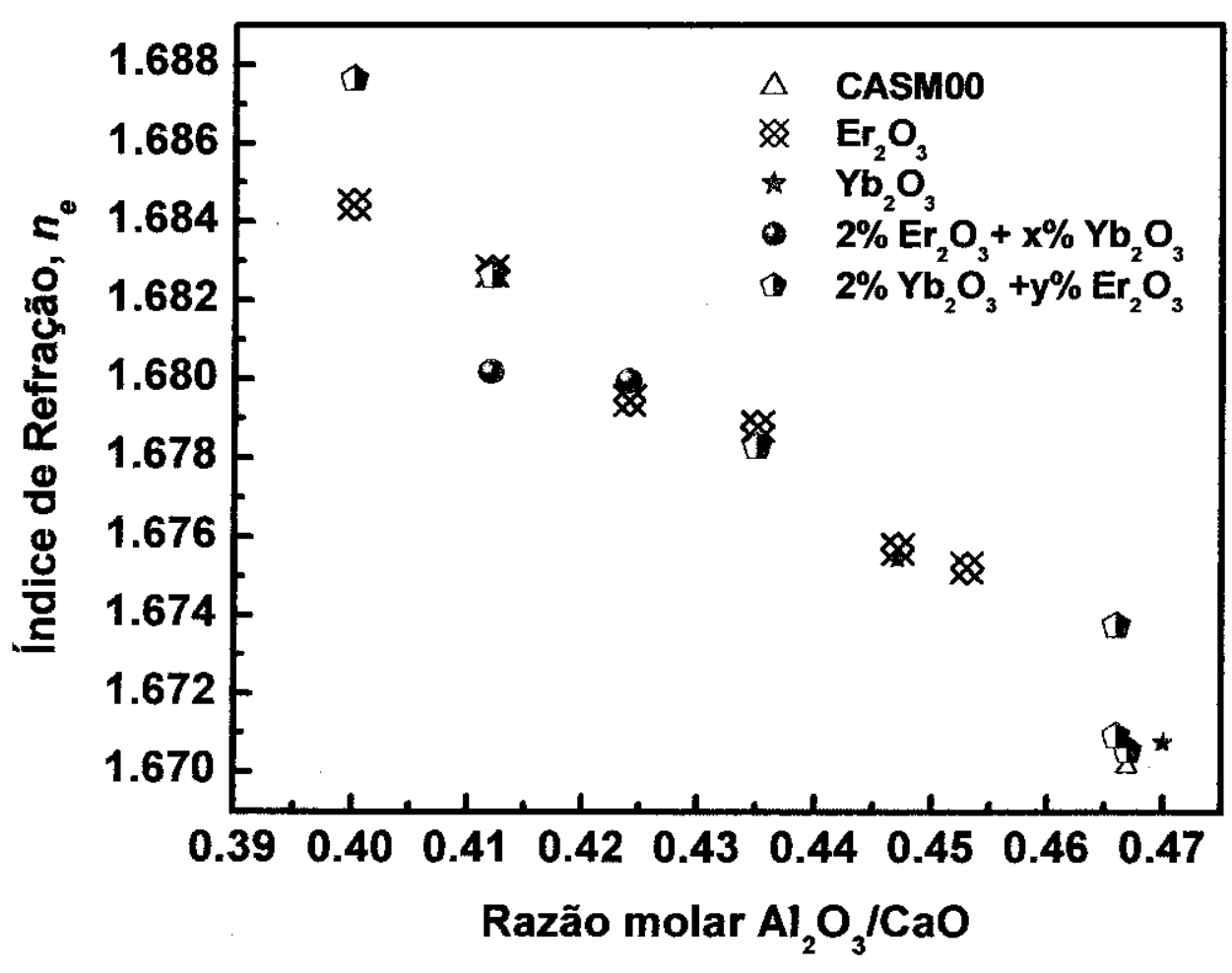

Figura 5.17 - Índice de refração dos vidros aluminato de cálcio dopados com óxidos terras raras (indicado na figura) em função da razão molar $\mathrm{Al}_{2} \mathrm{O}_{3} / \mathrm{CaO}$. 
Como o decréscimo da razão $\mathrm{Al}_{2} \mathrm{O}_{3} / \mathrm{CaO}$ que é de aproximadamente $20 \%$ podemos supor que há um aumento de $N B O$ 's, de forma que haja um aumento na polarizabidade, cuja conseqüência é um aumento no índice de refração (Sampaio, 2000).

Em nossas amostras a diferença do índice de refração entre a amostra base, CASM00, $\mathrm{n}_{\mathrm{e}}=1.67015$, e a amostra CASM10, dopada com $8 \%$ (em peso) de $\mathrm{Er}_{2} \mathrm{O}_{3}, \mathrm{n}_{\mathrm{e}}=1.68763$, foi de aproximadamente $1 \%$. Ou seja, uma variação bem abaixo daquelas observadas em outras propriedades, tais como $T_{g}$ e HV que foi de aproximadamente $10 \%$.

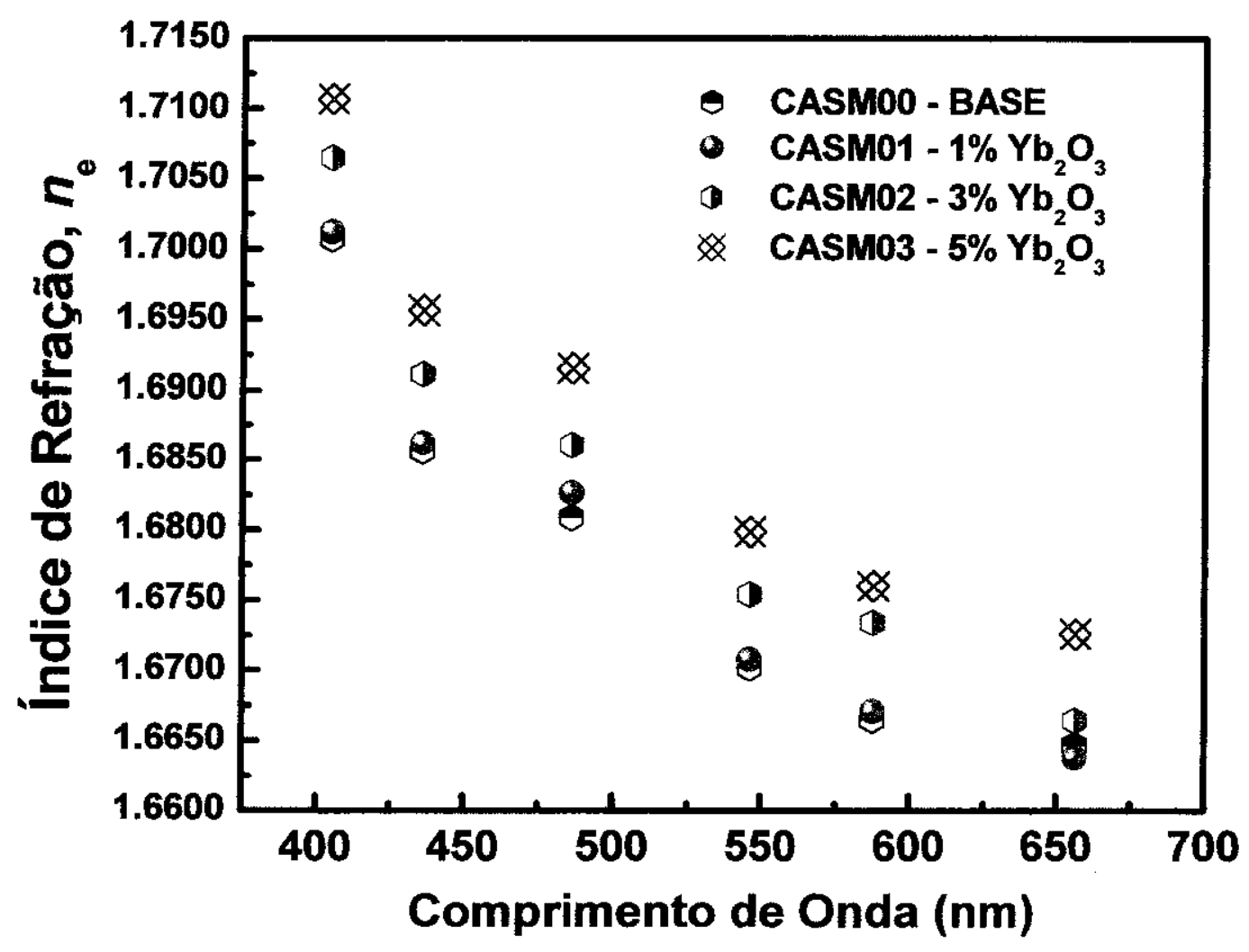

Figura 5.18 - Índice de refração de vidros aluminato de cálcio em função do comprimento de onda na região visivel do espectro eletromagnético.

Na figura 5.18 podemos verificar que conforme aumenta-se o comprimento de onda, o índice de refração dos vidros aluminato de cálcio diminuem monotonamente. Uma investigação em comprimentos de ondas mais longos, até a região do infravermelho médio foi reportada por Hafner et al. (1958), como mostra a figura 5.19. 


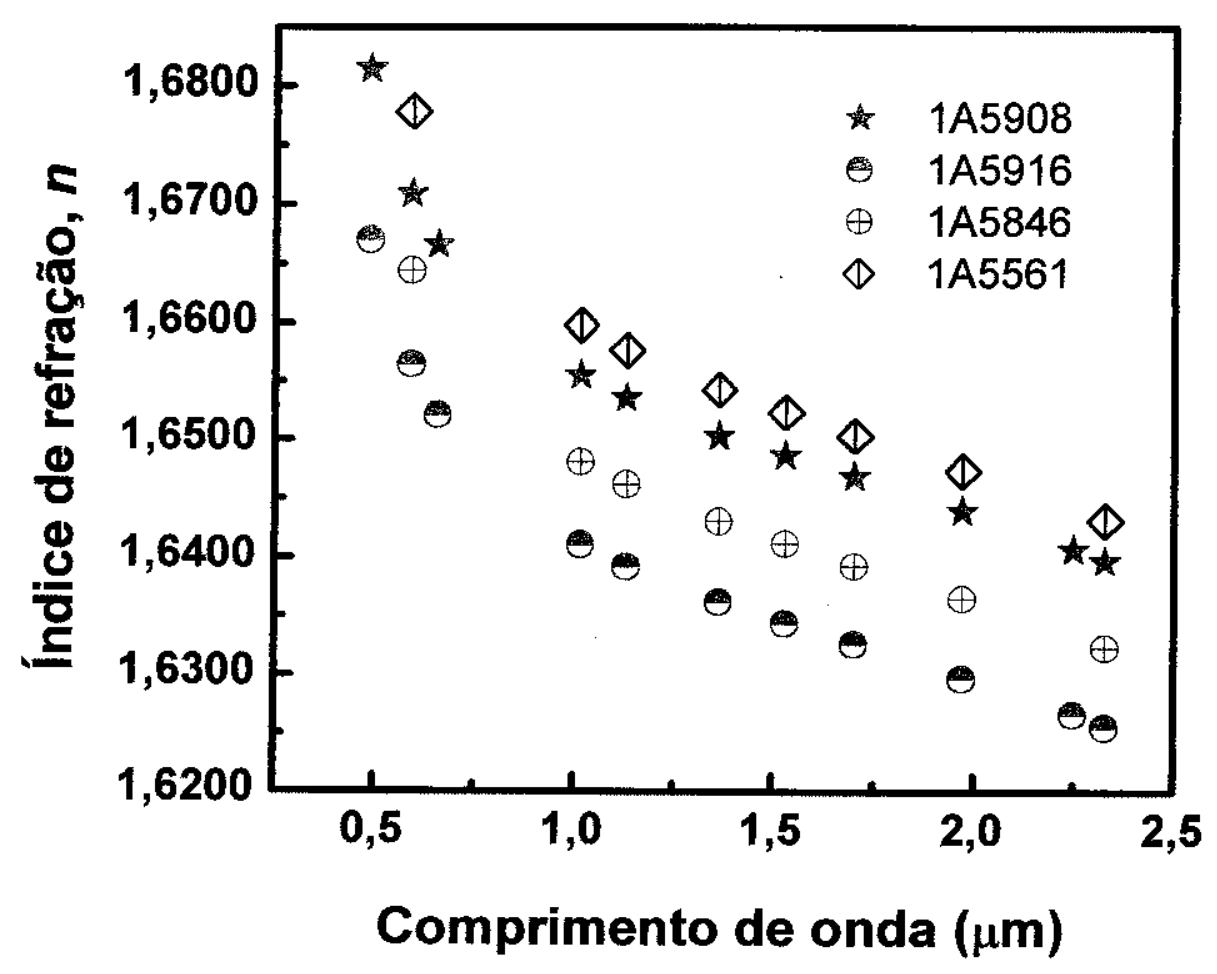

Figura 5.19 - Índice de refração de vidros aluminato de cálcio em função do comprimento de onda. $\mathrm{LA5908)} 58.5 \mathrm{CaO}, 27.5 \mathrm{Al}_{2} \mathrm{O}_{3}, 8.4 \mathrm{MgO}, 5.6 \mathrm{SiO}_{2} . \mathrm{IA5916)} 32.5 \mathrm{CaO}, 57.5 \mathrm{Al}_{2} \mathrm{O}_{3}, 2 \mathrm{MgO}$, $2 \mathrm{BaO}, 2 \mathrm{La}_{2} \mathrm{O}_{3}, 7.5 \mathrm{Na}_{2} \mathrm{O}, 2.5 \mathrm{~K}_{2} \mathrm{O}, 0.5 \mathrm{Fe}_{2} \mathrm{O}_{3} . \mathrm{IA5846)} 32.5 \mathrm{CaO}, 57.5 \mathrm{Al}_{2} \mathrm{O}_{3}, 2 \mathrm{MgO}, 2 \mathrm{BaO}$, $\left.2 \mathrm{La}_{2} \mathrm{O}_{3}, 7.5 \mathrm{Na}_{2} \mathrm{O}, 2.5 \mathrm{~K}_{2} \mathrm{O}, 2 \mathrm{Fe}_{2} \mathrm{O}_{3} \mathrm{IA} 5561\right) 32.5 \mathrm{CaO}, 57.5 \mathrm{Al}_{2} \mathrm{O}_{3}, 2 \mathrm{MgO}, 2 \mathrm{BaO}, 2 \mathrm{La}_{2} \mathrm{O}_{3}$, $7.5 \mathrm{Na}_{2} \mathrm{O}, 2.5 \mathrm{~K}_{2} \mathrm{O}, 5 \mathrm{Fe}_{2} \mathrm{O}_{3}$ (Hafner et al, 1958).

A figura 5.20 mostra que quando fazemos uma aproximação simplificada, considerando os íons como esferas sólidas, o espaço livre na rede do vidro, calculado através da equação 5.4, diminui conforme aumenta-se a concentração de óxido terra rara. $\mathrm{O}$ que suporta a suposição de que os íons terras raras induz relaxamento da rede do vidro, que por sua vez induz uma diminuição entre as ligações químicas, promovendo uma diminuição nas propriedades térmicas, como $\mathrm{T}_{\mathrm{g}}$, e nas propriedades mecânicas como $\mathrm{HV}$. 


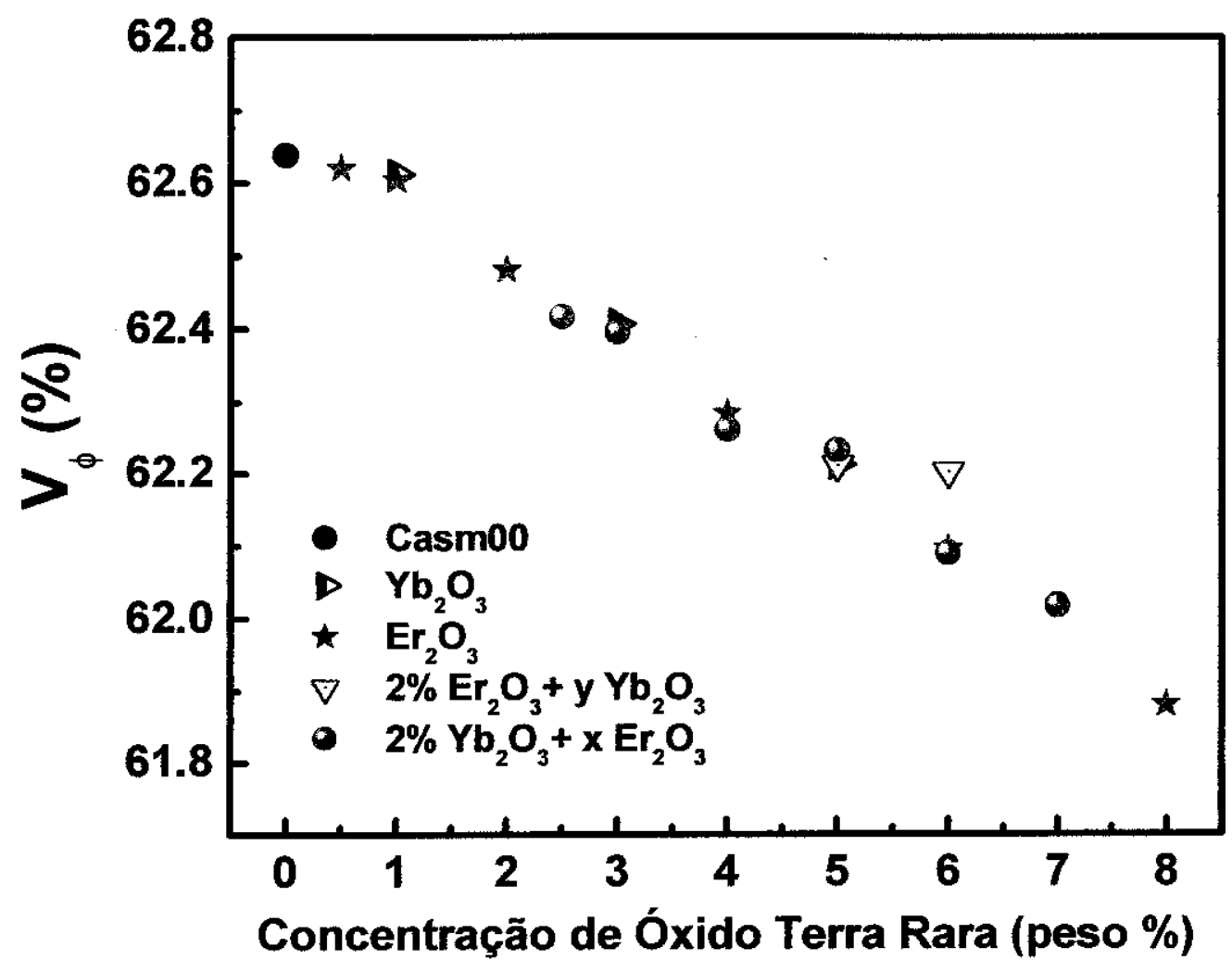

Figura 5.20 - Espaço livre no vidro em relação a todos os íons no vidro, em função da concentração de ions terras raras. Os ions são considerados de uma forma simplificada, como esferas sólidas.

Além dos cátions, os ânions exercem uma influência adicional sobre o índice de refração dos vidros. No caso dos vidros de $\mathrm{B}_{2} \mathrm{O}_{3}$, preparado em condições normais e contendo água, seu índice de refração $n_{\mathrm{D}}$ é igual a 1,4684, enquanto que para os vidros de $\mathrm{B}_{2} \mathrm{O}_{3}$ sem água possuem um índice de refração igual a 1,4581. Da mesma forma o índice de refração dos vidros silicatos aumenta quanto é acrescido valores crescentes do grupo $\mathrm{OH}^{-}$e a diferença afeta a quarta casa decimal. $O$ vidro de sílica ao contrário apresenta uma pequena diminuição, porém perceptível, do índice de refração quando o teor de $\mathrm{OH}$ cresce. No caso dos vidros aluminato de cálcio a diferença se dá na terceira casa decimal. Um exemplo é o vidro 
CASM00 que possui um índice de refração $n_{\mathfrak{e}}=1,67015$ (amostra preparada a vácuo), e o vidro CASM31 que possui um índice de refração $n_{\mathrm{e}}=1,67158$ (amostra preparada ao ar).

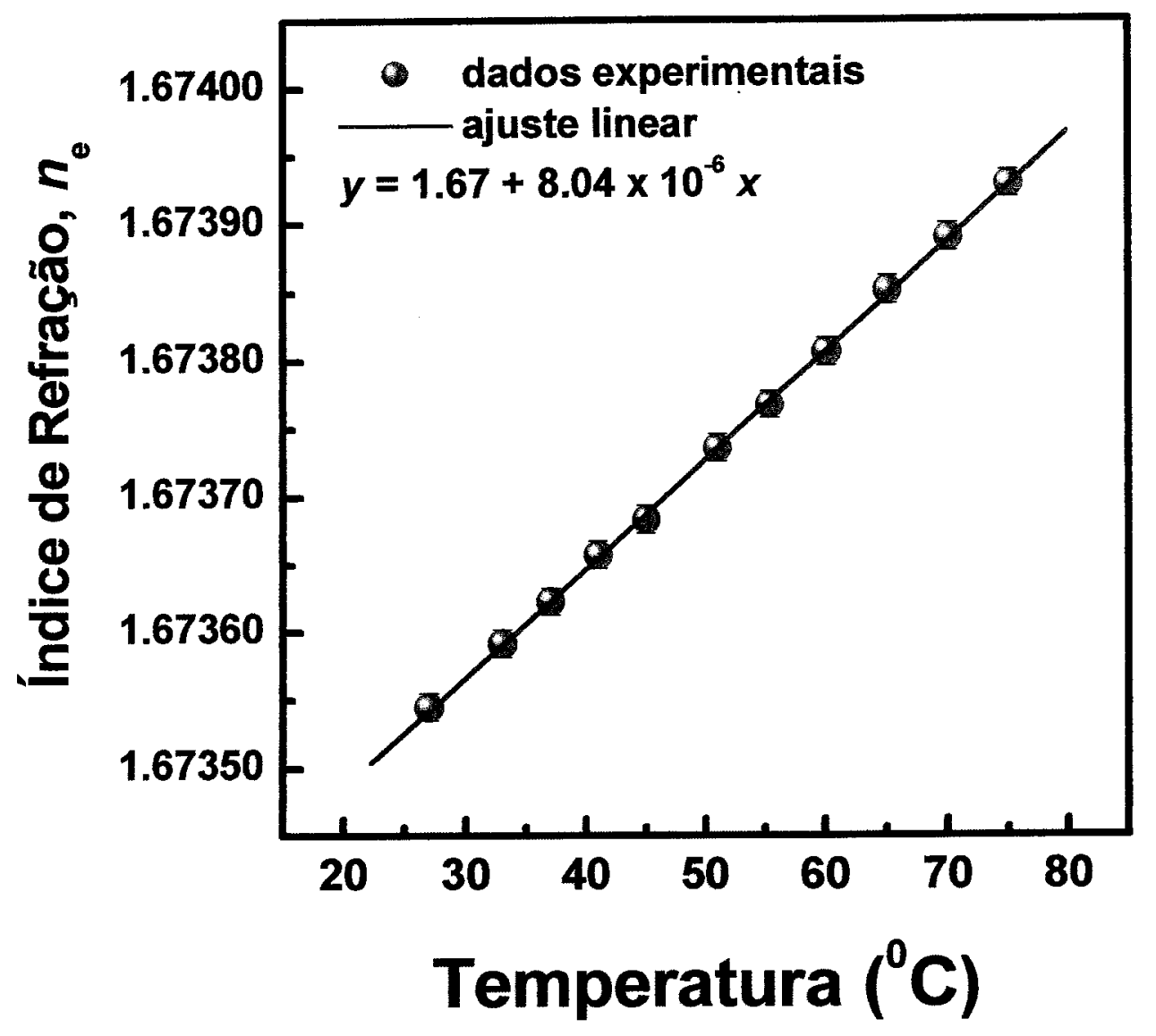

Figura 5.21 - Índice de refração em função da temperatura para uma amostra de vidro aluminato de cálcio dopado com $3 \%$ de $\mathrm{Nd}_{2} \mathrm{O}_{3}$-amostra fundida a vácuo (CASM34).

Na figura 5.21 é mostrado o comportamento do índice de refração de uma amostra de vidro aluminato de cálcio dopado com $3 \%$ de $\mathrm{Nd}_{2} \mathrm{O}_{3}$ fundida a vácuo (CASM34). Podemos notar que o índice de refração aumenta linearmente com a temperatura. Fazendo-se o ajuste linear dos dados experimentais podemos obter a variação do índice de refração em função da temperatura, dn/dT. No caso desta amostra obtivemos dn/dT igual a $8.04 \times 10^{-6} \mathrm{~K}^{-1}$. Este resultado está de bom acordo com o reportado por Waxler e Cleek (1973) cujo valor foi de 7.5 
x $10^{-6} \mathrm{~K}^{-1}$ determinado através da técnica de interferometria. A composição da amostra por ele investigada, $41.5 \mathrm{Al}_{2} \mathrm{O}_{3}: 48.5 \mathrm{CaO}: 5 \mathrm{SiO}_{2}: 5 \mathrm{MgO}\left(\%\right.$ em peso), e índice de refração $\mathrm{n}_{\mathrm{D}}=$ 1.67155 , muito próxima da nossa CASM00.

$\mathrm{Na}$ figura 5.22 é mostrado o comportamento de $d n / d T$ para os vidros aluminato de cálcio dopados com $\mathrm{Nd}_{2} \mathrm{O}_{3}$ fundidos ao ar. Não é observado nenhum aumento significativo, salvo para a amostra dopada com $6 \%$ (em peso) de $\mathrm{Nd}_{2} \mathrm{O}_{3}$, entretanto este desvio está dentro do erro de $2.5 \%$.

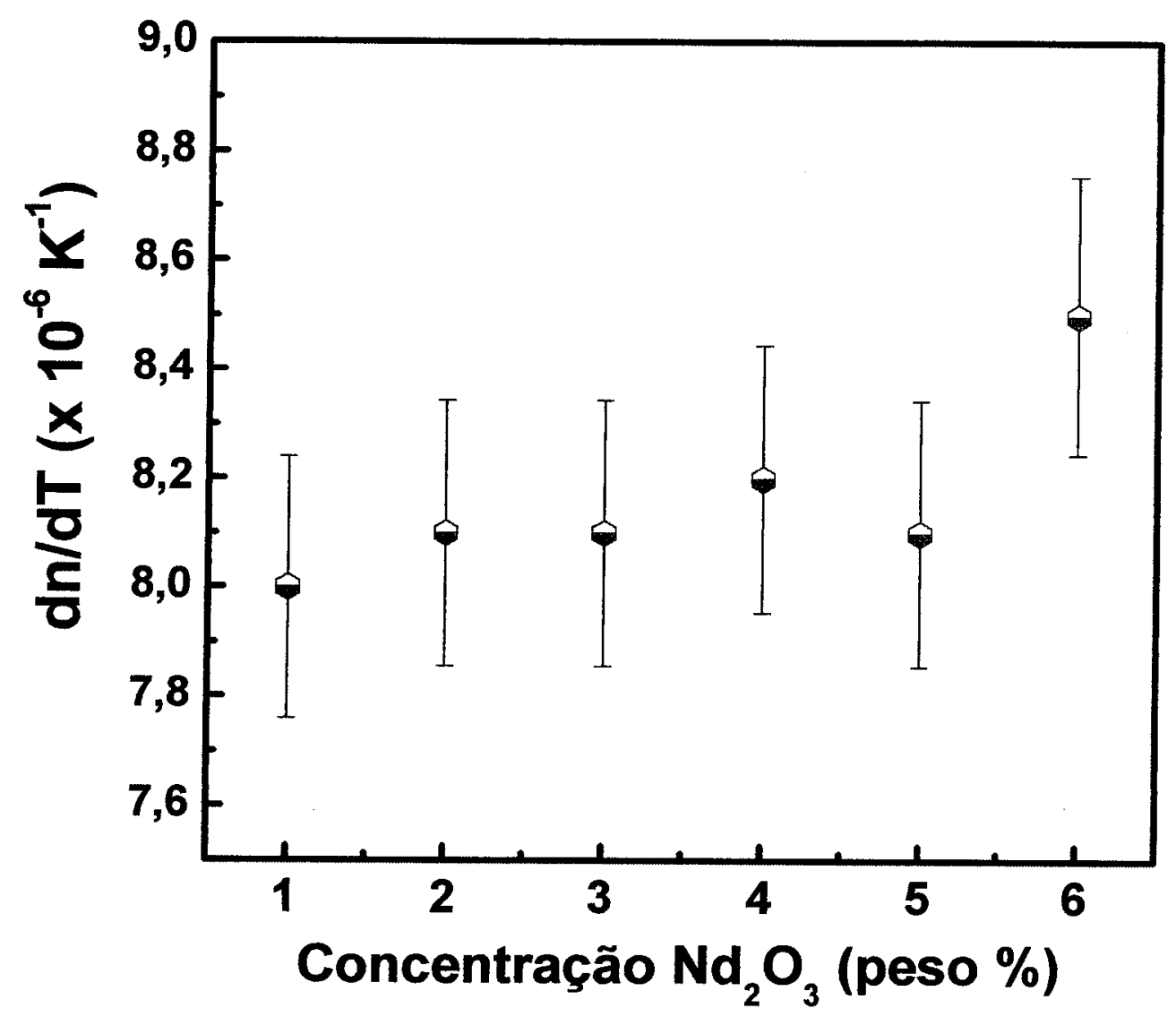

Figura 5.22 - dn/dT em função da concentração de $\mathrm{Nd}_{2} \mathrm{O}_{3}$ em vidros aluminato de cálcio preparados ao ar. 


\subsection{Transmitância Óptica}

Na figura 5.23 é comparada a curva de transmitância óptica de uma amostra de vidro aluminato de cálcio fundido á vácuo (curva sólida) e de uma amostra fundida ao ar (curva pontilhada). Podemos notar que há um deslocamento do início da transmitância óptica para comprimentos de onda maiores para amostras fundidas ao ar. No caso da amostra fundida a vácuo a transmissão inicia-se em $261 \mathrm{~nm}$ enquanto que para a amostra fundida ao ar inicia-se em $313 \mathrm{~nm}$, ou seja, há um deslocamento de $52 \mathrm{~nm}$. Esse deslocamento foi observado para as demais amostras quando levado em consideração a atmosfera de fusão.

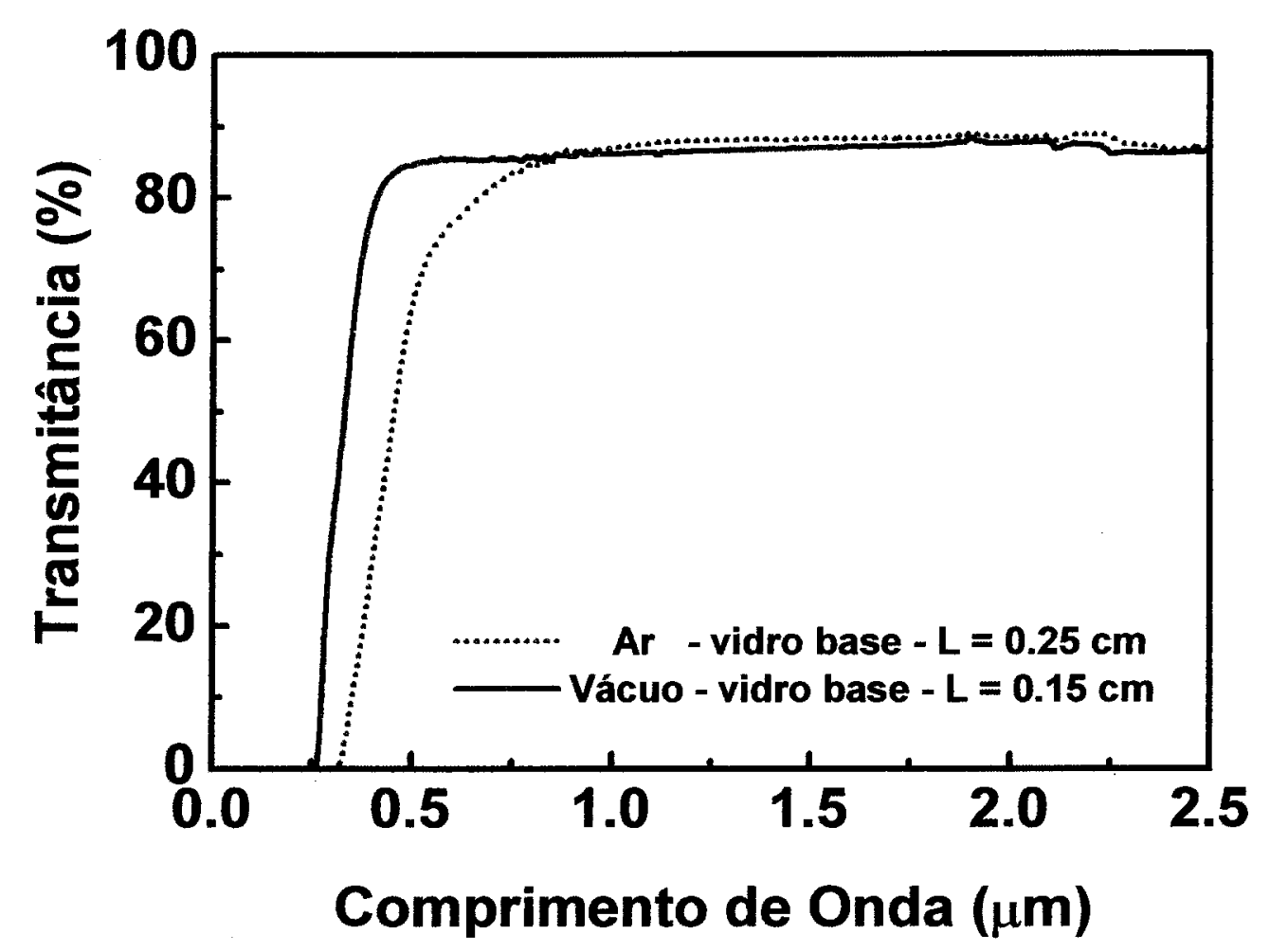

Figura 5.23 - Curvas de transmitância óptica na região do visível e infravermelho próximo do vidro aluminato de cálcio puro fundido em diferentes atmosferas. A curva pontilhada referese a uma amostra com $0.25 \mathrm{~cm}$ de espessura fundida ao ar, enquanto que a curva sólida refere-se a amostra com $0.15 \mathrm{~cm}$ de espessura fundida á vácuo.

Vale aqui ressaltar que as amostras preparadas a vácuo diferem na coloração em relação as amostras preparadas ao ar. As amostras de vidro aluminato de cálcio, vidro base, 
quando fundidas a vácuo possui uma coloração azul/verde claro, quase transparente. A variação entre essa coloração quando os vidros são preparados a vácuo foram investigadas por Argüelo et al. (1981), e atribuido a formação de radicais $O_{3}^{-}$devido à exposição a radiação ultravioleta. Por outro lado as amostras preparadas ao ar possuem uma coloração amarelada para o caso dos vidros puro. Quando as amostras são dopadas com $\mathrm{Nd}_{2} \mathrm{O}_{3}$ a coloração muda de azul claro para um tom entre o azul e vinho intenso, quando fundidas a vácuo e ao ar, respectivamente, essa variação na cor é também dependente da concentração de dopante. No caso das amostras dopadas com $\mathrm{Er}_{2} \mathrm{O}_{3}$ a coloração muda de rosa, amostras fundidas a vácuo, para salmão quando fundidas ao ar; fato semelhante ocorre também para as amostras dopadas com $\mathrm{Er}_{2} \mathrm{O}_{3}$ e co-dopadas com $\mathrm{Yb}_{2} \mathrm{O}_{3}$ já que o $\mathrm{Yb}^{3+}$ não possue banda de absorção na região do visível.

Shelby (1985) reporta que vidros aluminato de cálcio, fundidos ao ar, cuja concentração molar de $\mathrm{CaO}$ é maior que $48 \%$ possuem uma coloração amarelada, enquanto que os vidros com concentração menor de $\mathrm{CaO}$ são menos coloridos. Segundo Shelby, em geral, a intensidade da coloração amarela aumenta com o aumento de $\mathrm{CaO}$; os vidros sem sílica possuem uma coloração intensa, isto também foi observado em nossos estudos. Esta coloração, afirma Shelby, não está associada a nenhuma banda de absorção específica, mas tem como resultado um aumento da absorção em toda a região do visível que diminui gradualmente com o comprimento de onda.

Uma suposição para essa coloração poderia ser atribuída a íons de $\mathrm{Pt}^{+4}$ dissolvidos no vidro durante a fusão. A fim de verificar essa possibilidade realizou-se em uma amostra de vidro aluminato de cálcio fundido em cadinho de platina e em atmosfera ambiente, medidas de espectrometria de energia dispersiva (EDS) usando uma microssonda eletrônica, marca JEOL, modelo $840 \mathrm{~A}$, cujo limite de detecção é de $\pm 0.1 \%$. O resultado foi negativo para esse limite de detecção. Entretanto não é descartada a possibilidade de que haja alguns traços de $\mathrm{Pt}^{+4}$ dissolvido na amostra, porém seria necessário o uso de um equipamento mais sensível. Um outro resultado fornecido pela análise de ESD foi a obtenção das porcentagens quantitativos dos elementos formadores do vidro. As porcentagens em átomos (peso) encontradas foram para o $\mathrm{Al}-36.5 \%$ (29.3\%), $\mathrm{Si}-13.8 \%$ (11.5\%), $\mathrm{Ca}-49.7 \%$ (59.2\%), os demais componentes não foram detectados devido às limitações da microssonda. 
Uma outra suposição que podemos fazer em relação ao deslocamento do início da banda de absorção na região do ultravioleta e o amarelo intenso, nas amostras fundidas ao ar, é de que uma pequena parcela dos íons de $\mathrm{Ca}^{2+}$ que contribuem para a compensação de cargas do grupo $\left(\mathrm{AlO}_{4}\right)$ combinam com os radicais $\mathrm{OH}^{-}$presentes no vidro, conforme mostra a forte banda de absorção da figura 5.24, formando $\left(\mathrm{CaO}_{2}\right)^{2-}+\mathrm{H}_{2} \uparrow$ que agem como centro de cores, absorvendo em toda a região do visível.

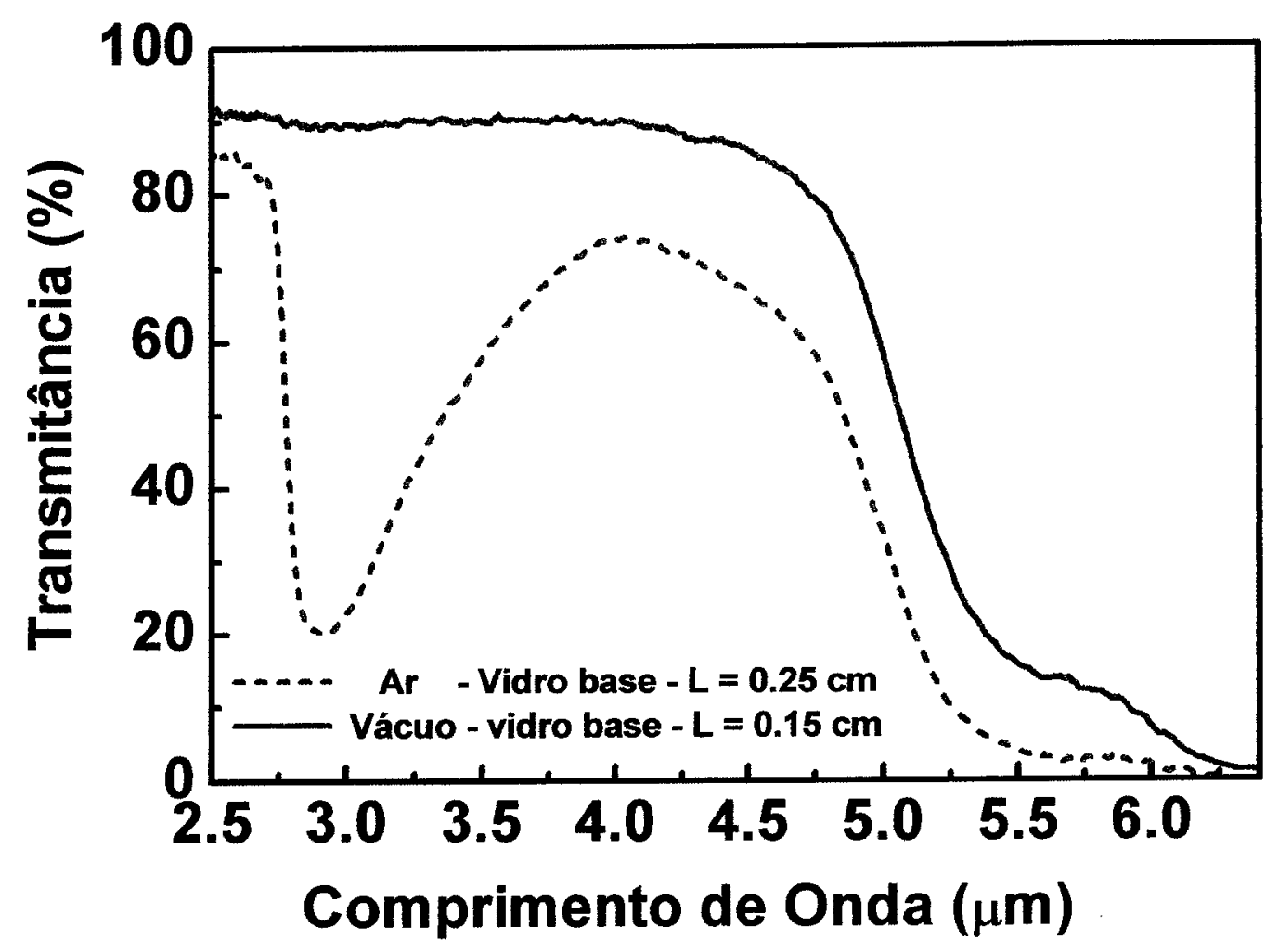

Figura 5.24 - Curvas de transmitância óptica na região do infravermelho médio para o vidro aluminato de cálcio em diferentes atmosfera de fusão. A curva pontilhada refere-se a uma amostra com $0.25 \mathrm{~cm}$ de espessura, cuja atmosfera de fusão foi ao ar e a curva sólida referese a uma amostra com $0.15 \mathrm{~cm}$ de espessura fundida a vácuo.

Na figura 5.25 é comparada a transmitância óptica de duas amostras de vidro aluminato de cálcio, dopadas com $2 \%$ (em peso) de $\mathrm{Nd}_{2} \mathrm{O}_{3}$ fundidas em atmosferas diferentes. A curva sólida refere-se a amostra fundida a vácuo e com espessura de $0.347 \mathrm{~cm}$, por outro lado a 
curva pontilhada refere-se a fundida ao ar, cuja espessura é de $0.327 \mathrm{~cm}$. Podemos perceber que para a amostra fundida ao ar a absorção é mais intensa desde a região do ultravioleta até a região do visível, apenas a partir de aproximadamente $720 \mathrm{~nm}$ é que a transmitância começa a ser mais próxima. As bandas que aparecem nesta figura refere-se as absorç̃es características do íon $\mathrm{Nd}^{3+}$.

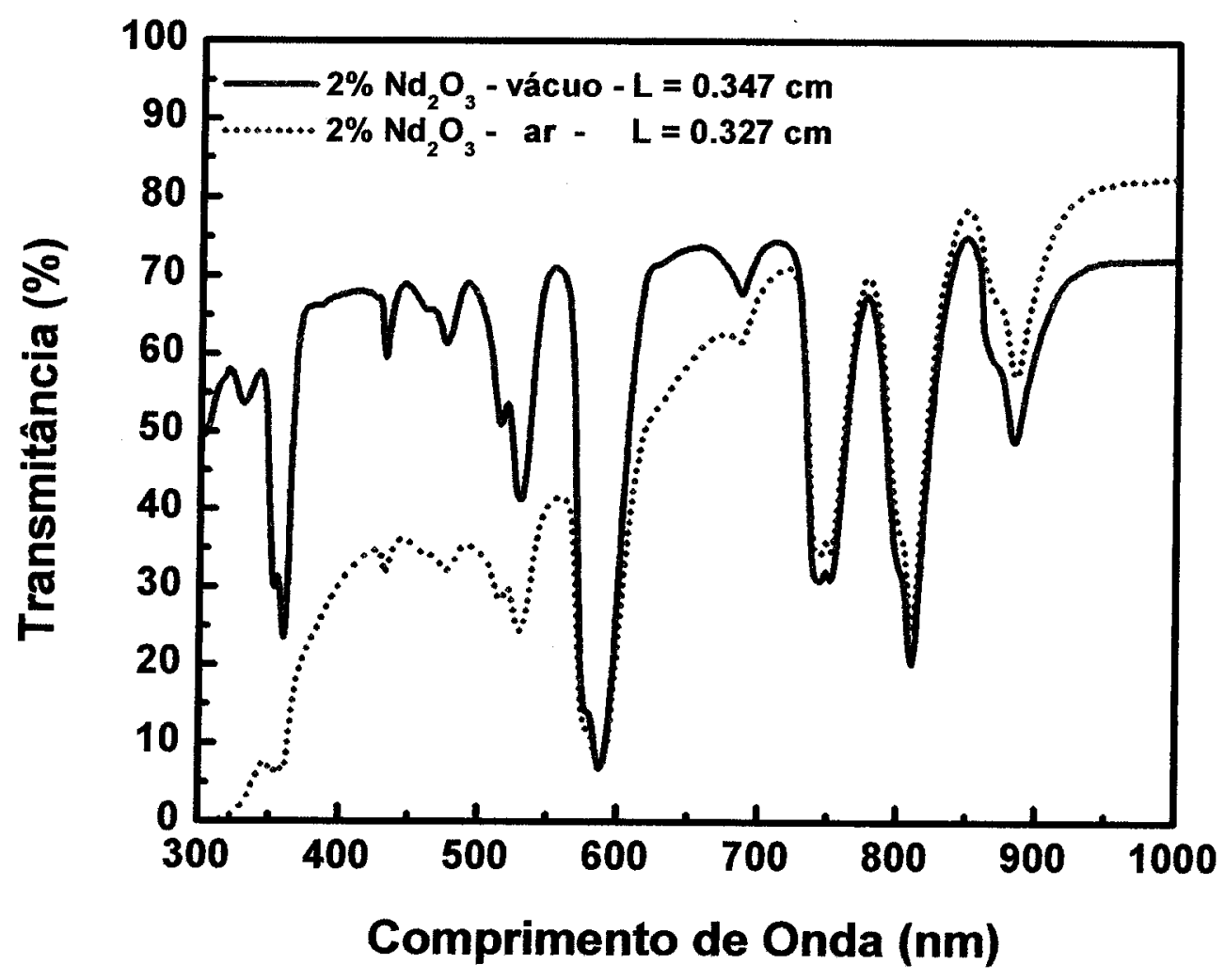

Figura 5.25 - Curvas de transmitância óptica na região do visível e infravermelho próximo para amostras de vidro aluminato de cálcio dopado com $2 \%$ (em peso) de $\mathrm{Nd}_{2} \mathrm{O}_{3}$ fundidas em atmosferas diferentes. A curva pontilhada refere a uma amostra com $0.327 \mathrm{~cm}$ de espessura fundida ao ar, enquanto que a curva sólida refere-se a uma amostra com $0.347 \mathrm{~cm}$ de espessura fundida a vácuo.

$\mathrm{Na}$ figura 5.26 é comparada a transmitância óptica para duas amostras de vidro aluminato de cálcio, dopadas com $2 \%$ (em peso) de $\mathrm{Er}_{2} \mathrm{O}_{3}$ fundidas em atmosferas diferentes. A curva sólida refere-se a amostra fundida a vácuo e com espessura de $0.32 \mathrm{~cm}$, enquanto que a curva pontilhada refere-se à amostra fundida ao ar e com espessura de $0.248 \mathrm{~cm}$. Aqui 
igualmente as amostras dopadas com $\mathrm{Nd}_{2} \mathrm{O}_{3}$, podemos perceber que as amostras fundida ao ar possuem uma absorção mais intensa desde a região do ultravioleta até a região do visível. As bandas que aparecem nesta figura refere-se as absorções características do íon $\mathrm{Er}^{3+}$.

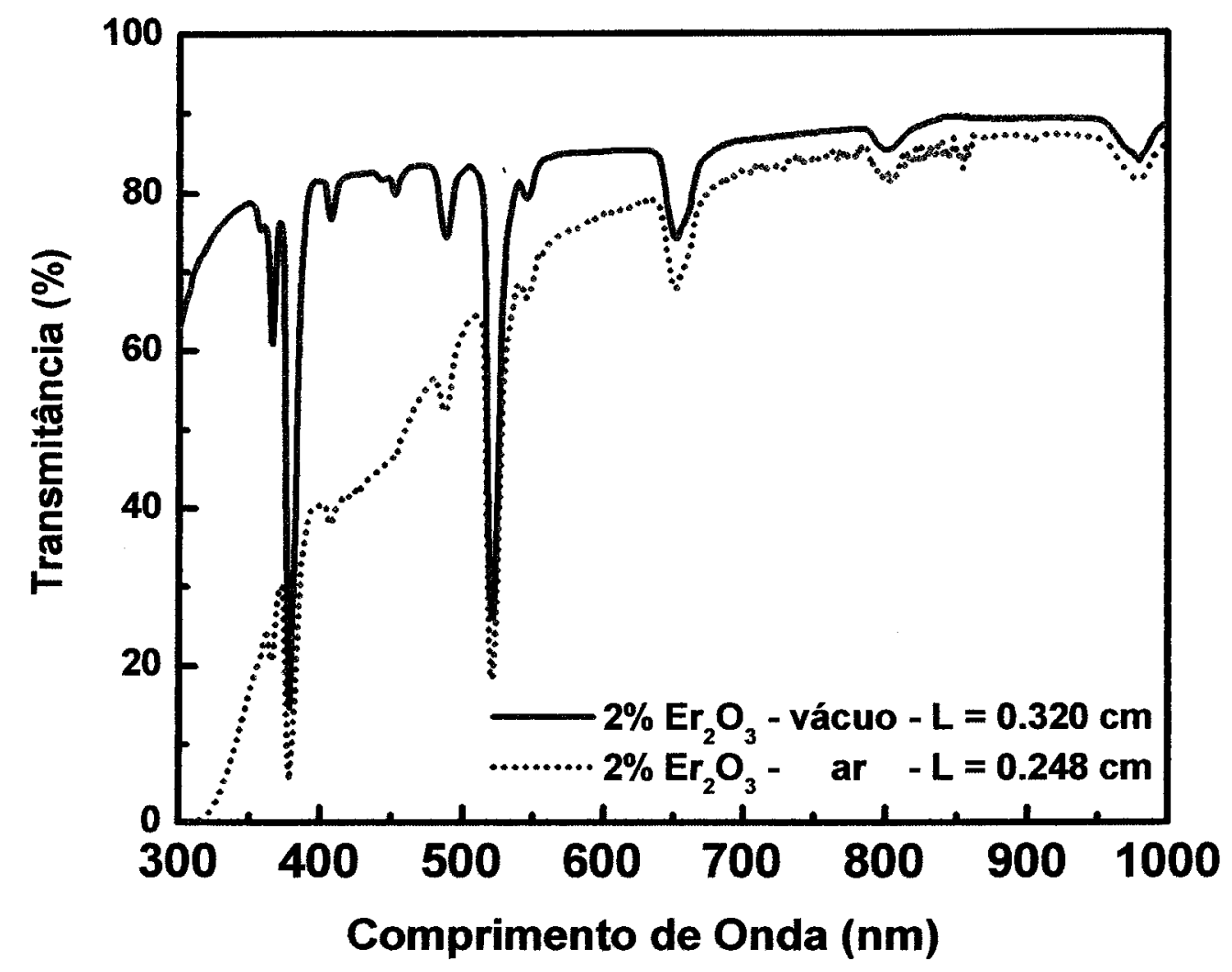

Figura 5.26 - Curvas de transmitância óptica na região do visível e infravermelho próximo para amostras de vidro aluminato de cálcio dopado com $2 \%$ (em peso) de $\mathrm{Er}_{2} \mathrm{O}_{3}$ fundidas em atmosferas diferentes. A curva pontilhada refere-se a uma amostra com $0.248 \mathrm{~cm}$ de espessura fundida ao ar, enquanto que a curva sólida refere-se a uma amostra com $0.320 \mathrm{~cm}$ de espessura fundida a vácuo.

Na figura 5.27 é comparada a transmitância óptica de uma amostra de vidro aluminato de cálcio dopada com $2 \%$ (em peso) de $\mathrm{Er}_{2} \mathrm{O}_{3}$ e com $0.32 \mathrm{~cm}$ de espessura, representada pela curva sólida, com uma amostra de vidro aluminato de cálcio dopada com $2 \%$ (em peso) de $\mathrm{Er}_{2} \mathrm{O}_{3}$ e co-dopada com $2 \%$ (em peso) de $\mathrm{Yb}_{2} \mathrm{O}_{3}$ e com $0.255 \mathrm{~cm}$ de espessura, representada pela curva pontilhada. Ambas as amostras foram fundidas a vácuo. Podemos perceber que a amostra co-dopada com $\mathrm{Yb}_{2} \mathrm{O}_{3}$ apresenta uma banda de absorção mais intensa em torno de 
$980 \mathrm{~nm}$, propriedade que é freqüentemente usada para melhorar a eficiência de bombeio de laseres que operam nesse comprimento de onda.

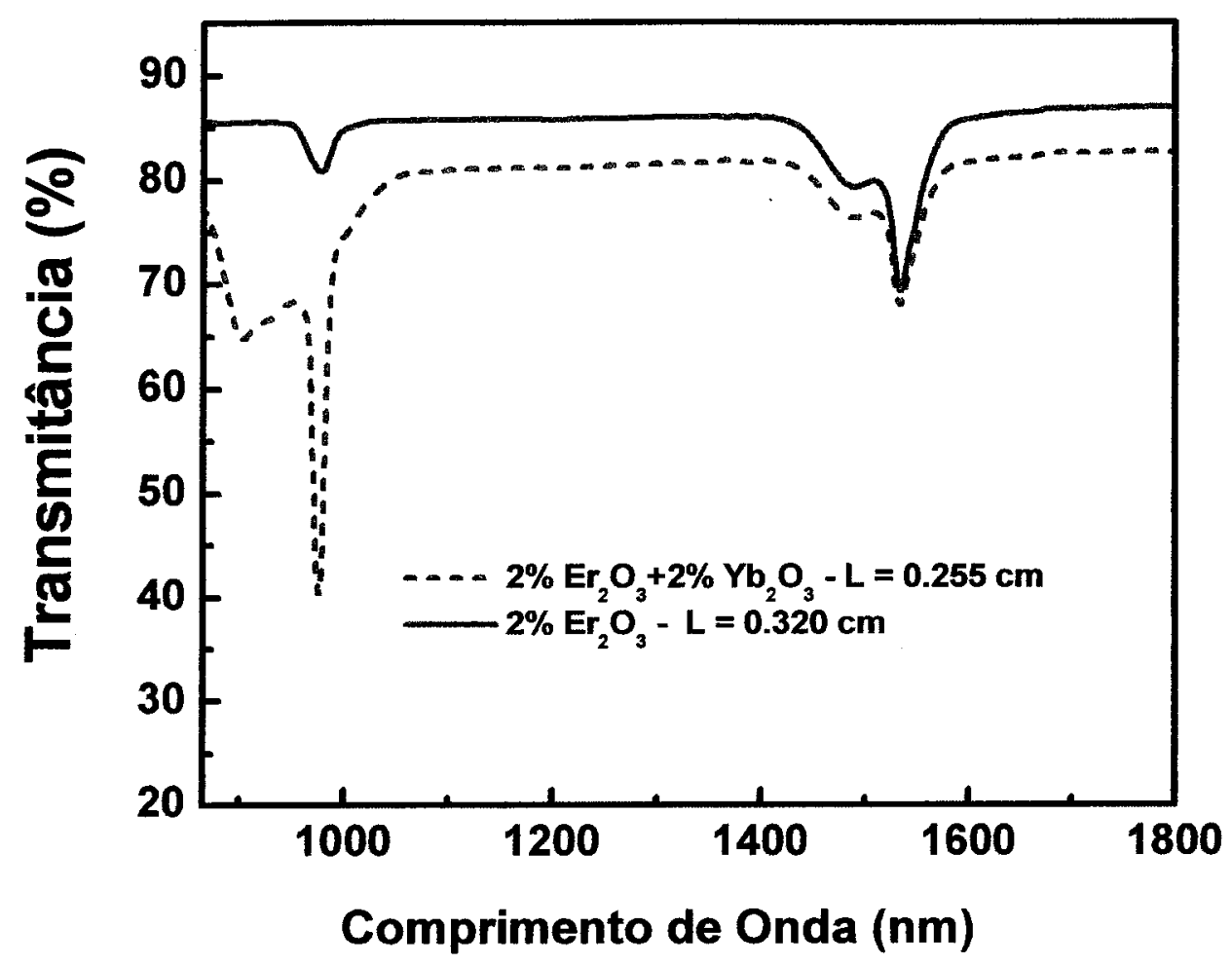

Figura 5.27 - Curvas de transmitância óptica na região do infravermelho próximo/médio de duas amostras de vidro aluminato de cálcio fundidas a vácuo. A curva sólida refere-se a amostra com $0.320 \mathrm{~cm}$ de espessura dopada com $2 \%$ (em peso) de $\mathrm{Er}_{2} \mathrm{O}_{3} ; \mathrm{A}$ curva pontilhada refere-se a uma amostra com $0.255 \mathrm{~cm}$ de espessura dopada com $2 \%$ (em peso) de $\mathrm{Er}_{2} \mathrm{O}_{3}$ e codopada com $2 \%$ (em peso) de $\mathrm{Yb}_{2} \mathrm{O}_{3}$.

A figura 5.28 mostra as curvas transmitância óptica de várias amostras de vidros aluminato de cálcio fundidas a vácuo e ao ar. As fortes bandas de absorção centrada em 2800 $\mathrm{nm}$ refere-se aos radicais $\mathrm{OH}^{-}$presentes nas amostras. Podemos perceber que o corte no infravermelho ocorre em $5500 \mathrm{~nm}$ para todas as amostras. 


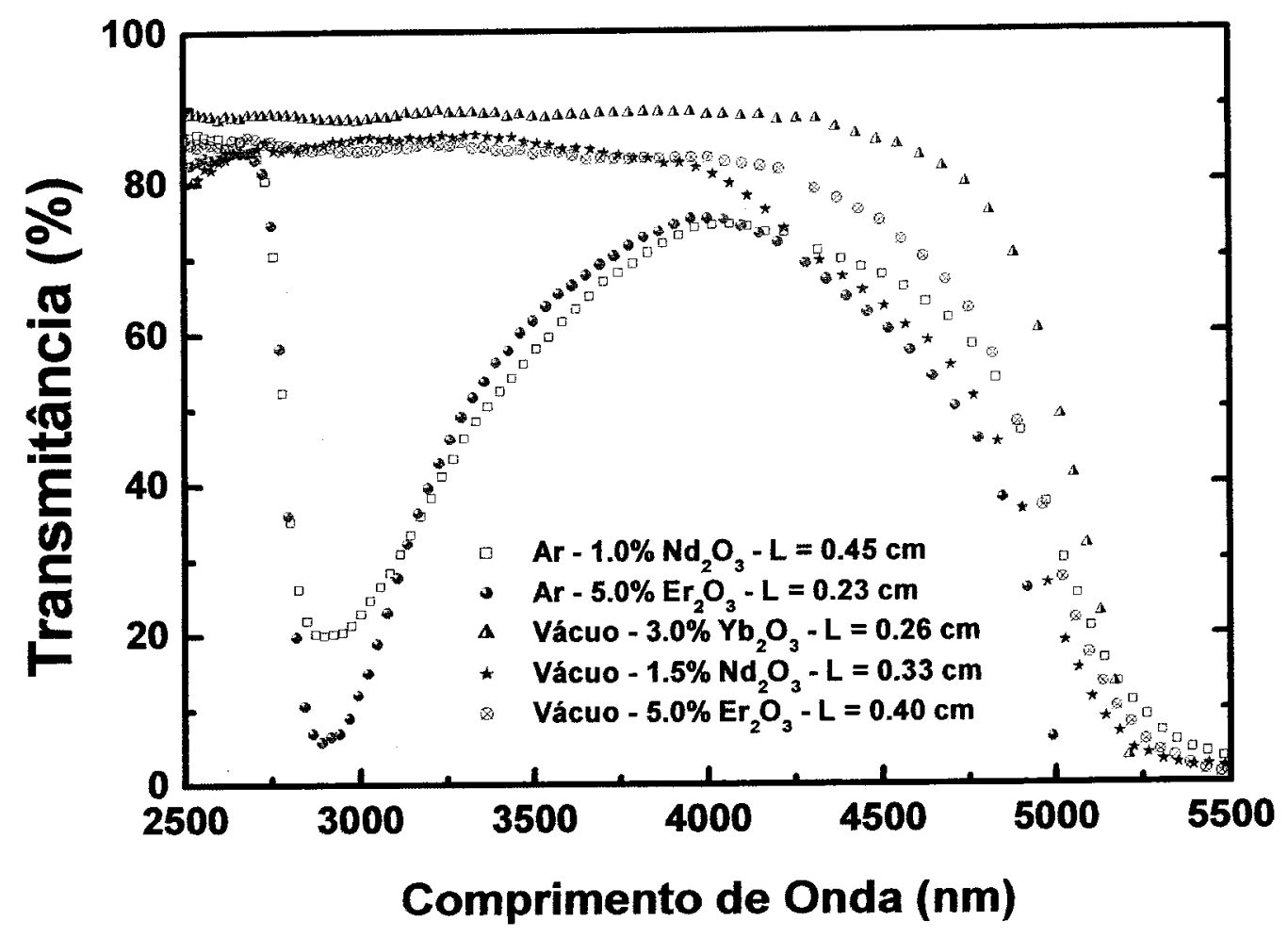

Figura 5.28 - Curvas de transmitância óptica na região do infravermelho médio para várias amostras de vidro aluminato de cálcio dopadas com $\mathrm{Er}_{2} \mathrm{O}_{3}, \mathrm{Nd}_{2} \mathrm{O}_{3}$ e $\mathrm{Yb}_{2} \mathrm{O}_{3}$. Na figura são indicadas as espessuras e a atmosfera de fusão para cada amostra.

\subsection{Propriedades Termo-Ópticas}

Nas tabelas 5.19 a 5.27 são apresentados os valores da concentração de íons de $\mathrm{Er}^{3+}$ ou $\mathrm{Nd}^{3+}, \mathrm{L}$ (espessura da amostra), $\alpha$ (coeficiente de absorção óptica), $\alpha \mathrm{L}_{\text {ef }}$ (produto entre o coeficiente de absorção óptica e a espessura efetiva), $\theta / \mathrm{P}$ é o sinal de lente térmica normalizado obtido no estado estacionário ou transiente, $\Theta_{\mathrm{ef}}$ é o sinal de lente térmica normalizado pela potência, coeficiente de absorção óptica e espessura efetiva, $t_{c}$ (Constante de tempo característica da lente térmica), $\Theta$ é o sinal de lente térmica normalizado pela potência, coeficiente de absorção óptica e espessura e D é a difusividade térmica, (-) valores não 
medidos. Os valores apresentados são a média aritimética dos vários transientes obtidos para cada amostra

O sinal de lente térmica no estado estacionário foi obtido usando a equação 4.40 . No caso da amostra de vidro aluminato de cálcio dopado com $4 \%$ de $\mathrm{Er}_{2} \mathrm{O}_{3}$ fundida a vácuo, com o feixe de excitação em $804 \mathrm{~nm}$ e o feixe de prova em $632.8 \mathrm{~nm}$. Da tabela 4.5 temos que $\mathrm{m}=$ 8.943 e V $=1.848$. o que resulta em:

$$
\theta=2\left[1-\sqrt{\frac{I(t)}{I(0)}}\right] \frac{1}{\operatorname{atan} 0.977}=2.047\left[1-\sqrt{\frac{I(t)}{I(0)}}\right]
$$

Os valores do atan é dado em radianos.

$\mathrm{Na}$ tabela 5.17 temos os dados dos outros transientes obtidos para a amostra de vidro aluminato de cálcio dopado com $4 \% \mathrm{Er}_{2} \mathrm{O}_{3}$ com diferentes potências aplicadas.

Tabela 5.17 Dados experimentais do efeito de lente térmica no estado estacionário para amostra de vidro aluminato de cálcio dopado com $4 \%$ de $\mathrm{Er}_{2} \mathrm{O}_{3}$, fundida a vácuo. Laser de excitação em $804 \mathrm{~nm}$ e laser de prova em $632.8 \mathrm{~nm}$.

\begin{tabular}{cccc}
\hline $\begin{array}{c}\text { Potência } \\
\text { Watts }\end{array}$ & $\begin{array}{c}\mathrm{I}(0) \\
\text { Volts }\end{array}$ & $\begin{array}{c}\mathrm{I}(\mathrm{t}) \\
\text { Volts }\end{array}$ & $\begin{array}{c}\theta \\
\text { rad }\end{array}$ \\
\hline 0,035 & 514 & 530 & 0,03162 \\
0,056 & 513 & 537 & 0,04734 \\
0,076 & 514 & 545 & 0,06082 \\
0,09 & 514 & 552 & 0,07432 \\
0,112 & 513 & 560 & 0,09172 \\
0,135 & 514 & 568 & 0,10484 \\
0,156 & 514 & 578 & 0,12370 \\
0,177 & 514 & 586 & 0,13867 \\
0,2 & 513 & 595 & 0,15754 \\
0,222 & 513 & 603 & 0,17231 \\
0,242 & 514 & 612 & 0,18663 \\
0,261 & 514 & 621 & 0,20300 \\
\hline
\end{tabular}


Na figura 5.29 temos os valores de $\theta$ em função da potência. Fazendo-se o ajuste linear $y=a+b x$, obtemos o valor de $\theta / \mathrm{P}$, que neste caso é $0.755 \mathrm{rad} \mathrm{W}^{-1}$.

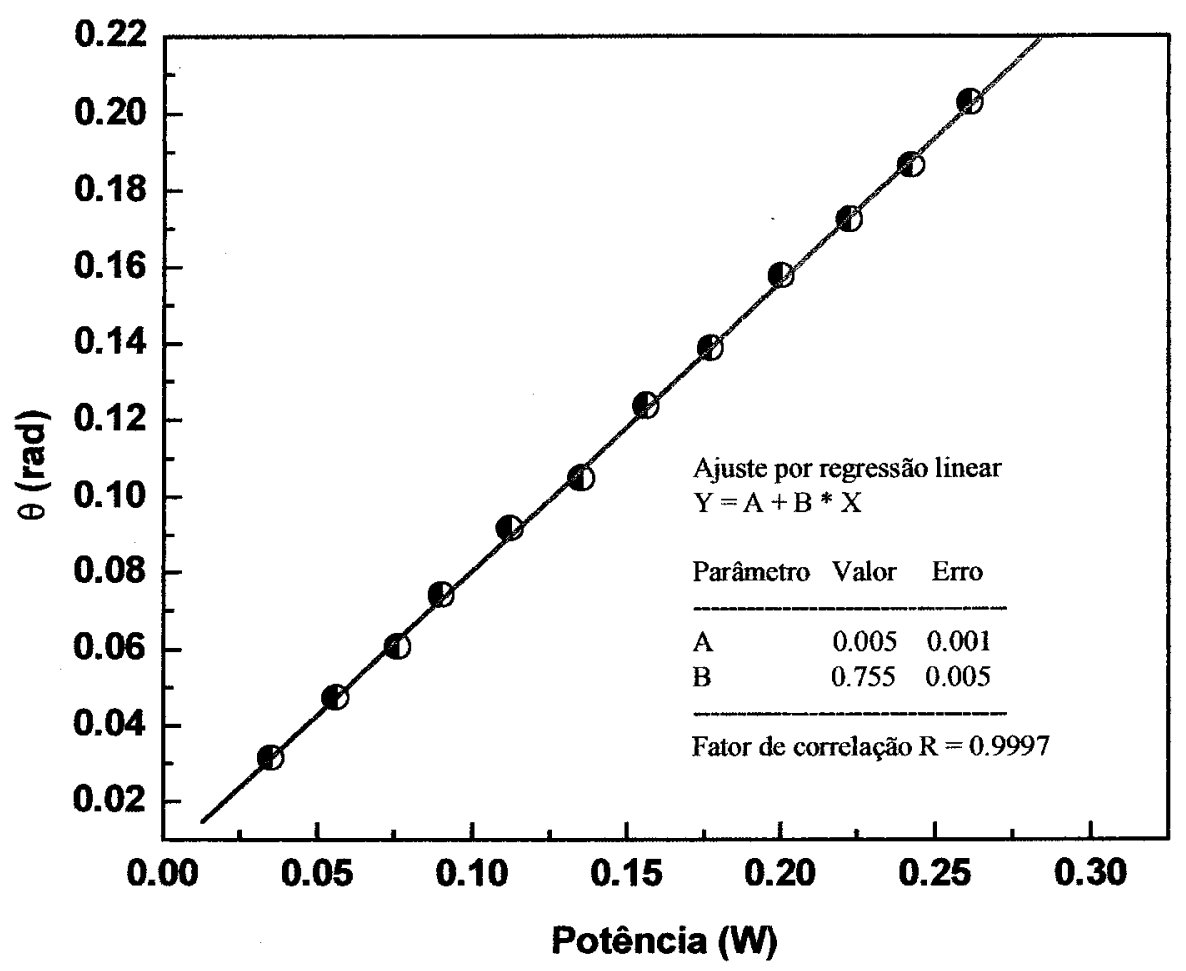

Figura 5.29 - Obtenção do valor de $\theta P$ para amostra de vidro aluminato de cálcio dopado com $4 \% \mathrm{Er}_{2} \mathrm{O}_{3}$. Amostra fundida a vácuo. Laser prova em $632.8 \mathrm{~nm}$ e laser excitação em 804 $n m$.

A difusividade térmica foi obtida através da equação 4.41 , tomando os valores médios de $t_{c}$ conforme exemplificado na tabela 5.18

Tabela 5.18 - dados experimentais obtidos através do transiente para amostra de vidro aluminato de cálcio dopado com $4.0 \%$ de $\mathrm{Er}_{2} \mathrm{O}_{3}$

\begin{tabular}{rccc}
\hline Potência $(\mathrm{W})$ & $\theta(\mathrm{rad})$ & $-\theta / \mathrm{P}\left(\mathrm{rad} \mathrm{W} \mathrm{C}^{-1}\right)$ & $\mathrm{t}_{\mathrm{c}}(\mathrm{ms})$ \\
\hline $104 \times 10^{-3}$ & $-0,0848 \pm 0,001$ & 0,817 & $1,888 \pm 0,004$ \\
$80 \times 10^{-3}$ & $-0,066 \pm 0,001$ & 0,825 & $1,885 \pm 0,004$ \\
$91 \times 10^{-3}$ & $-0,075 \pm 0,001$ & 0,824 & $1,859 \pm 0,004$ \\
& & & \\
& Média aritimética & $0,822 \pm 0,004$ & $1,88 \pm 0,01$ \\
\hline
\end{tabular}




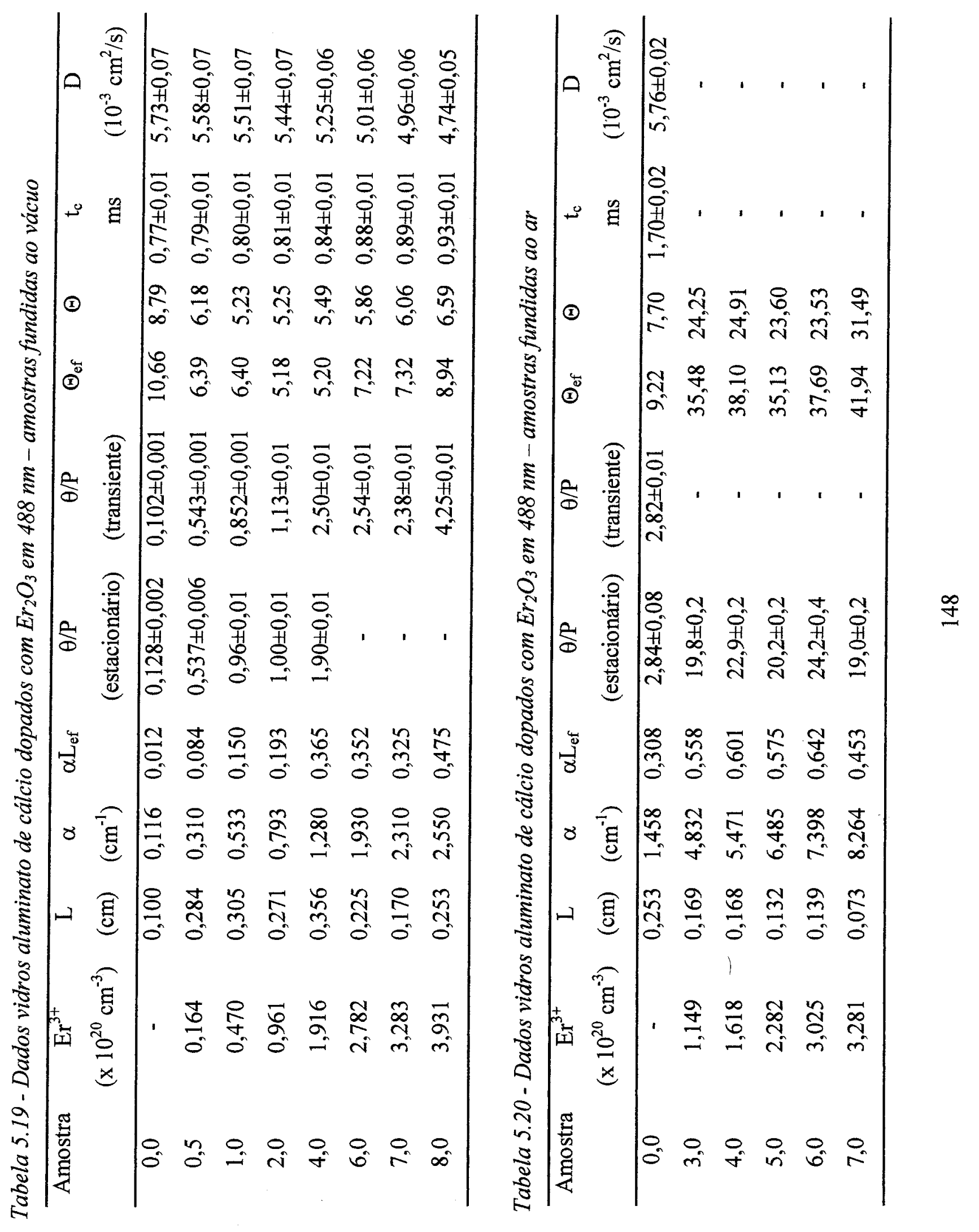




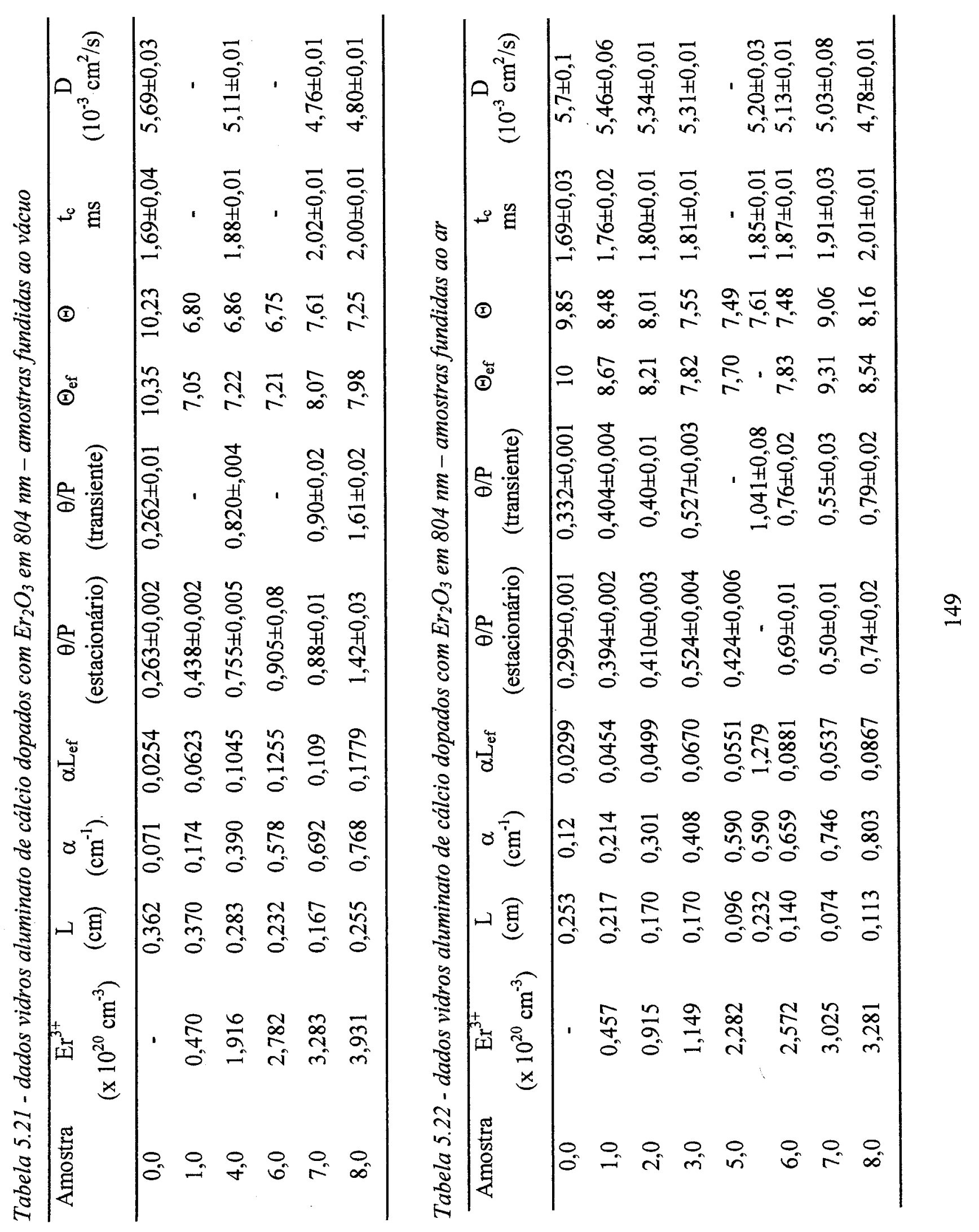



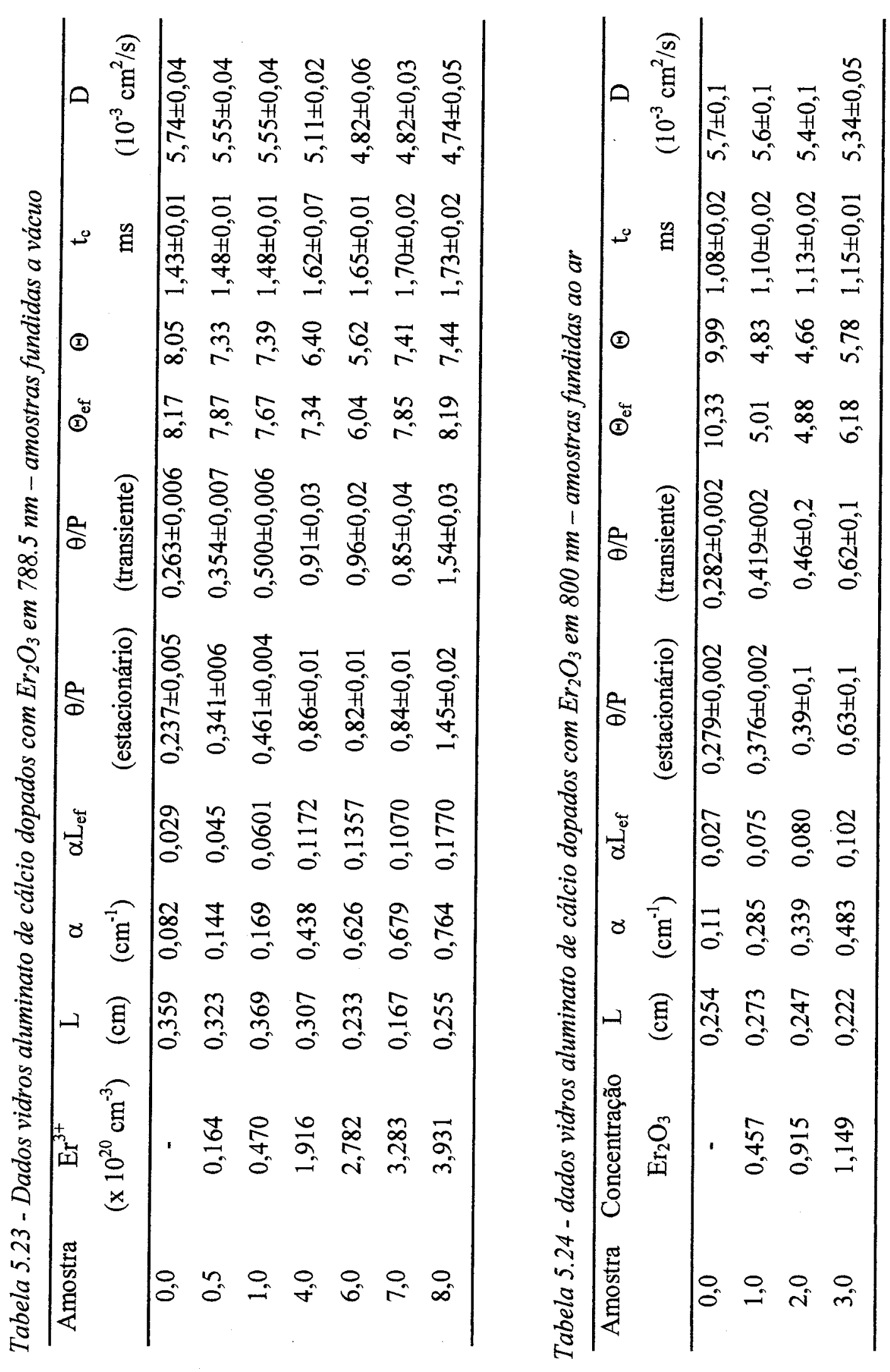


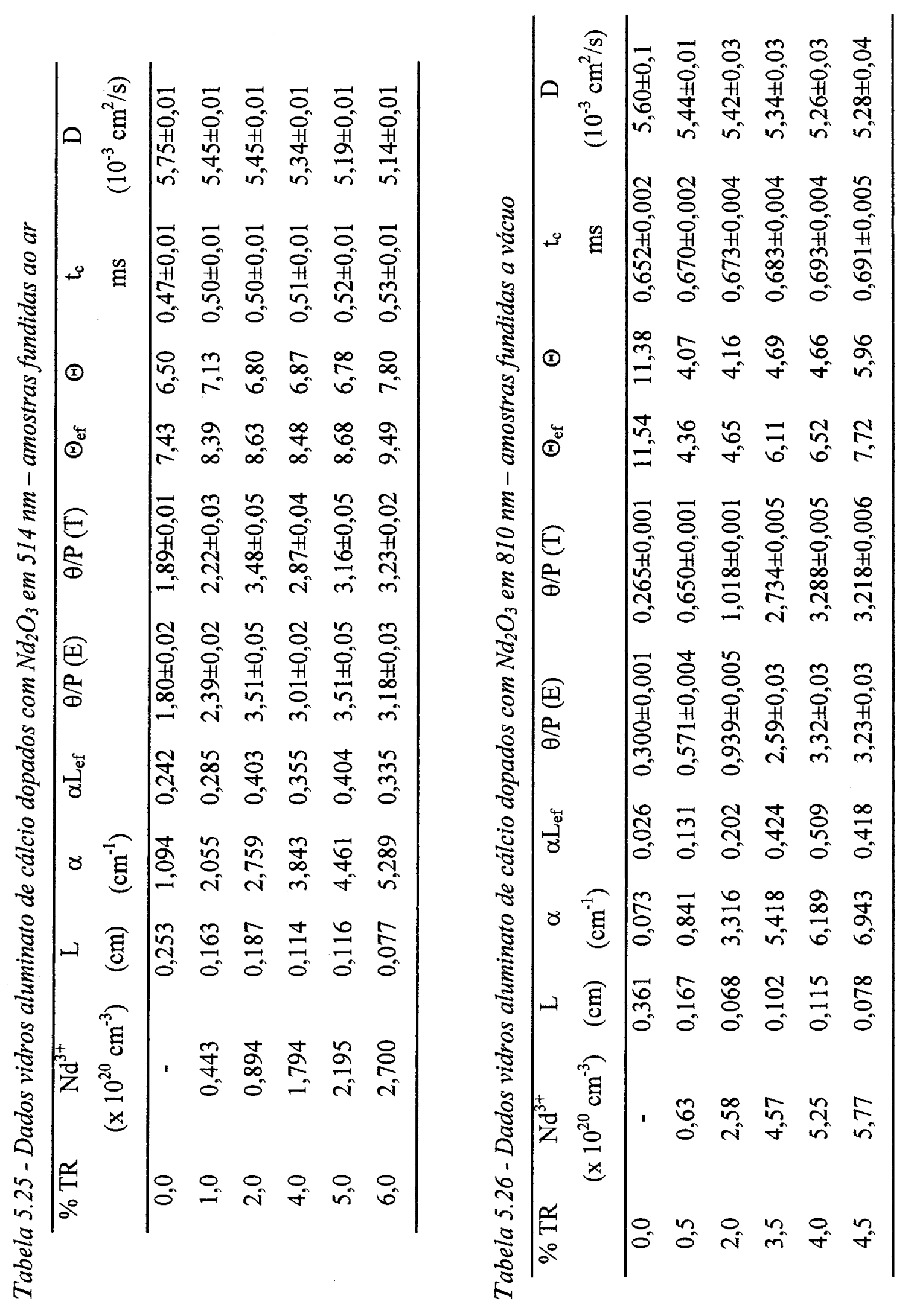




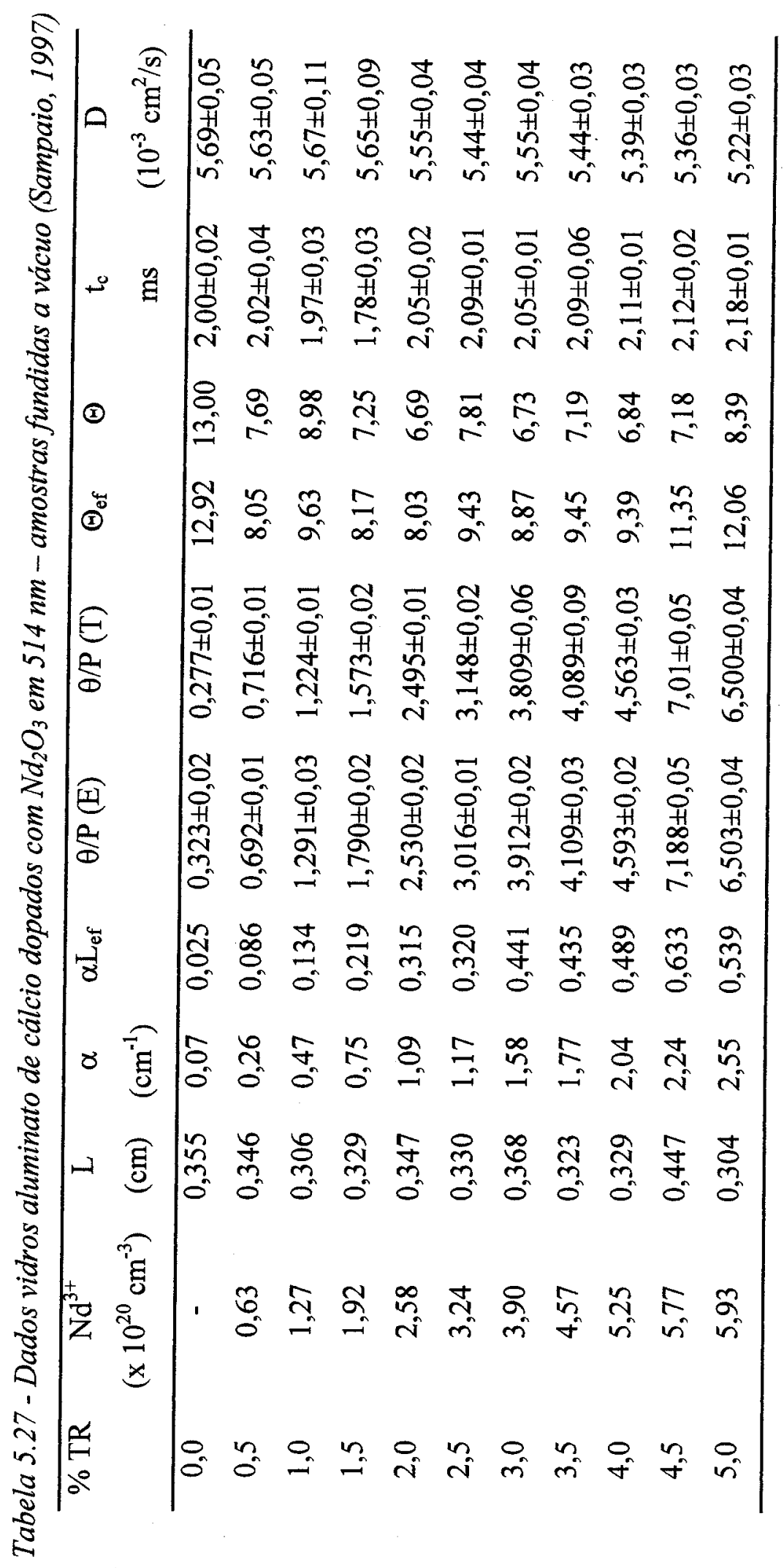


Na figura 5.30 é mostrado o comportamento da difusividade térmica dos vidros aluminato de cálcio em função da concentração de $\mathrm{Er}_{2} \mathrm{O}_{3} \mathrm{e}$ da atmosfera de fusão.

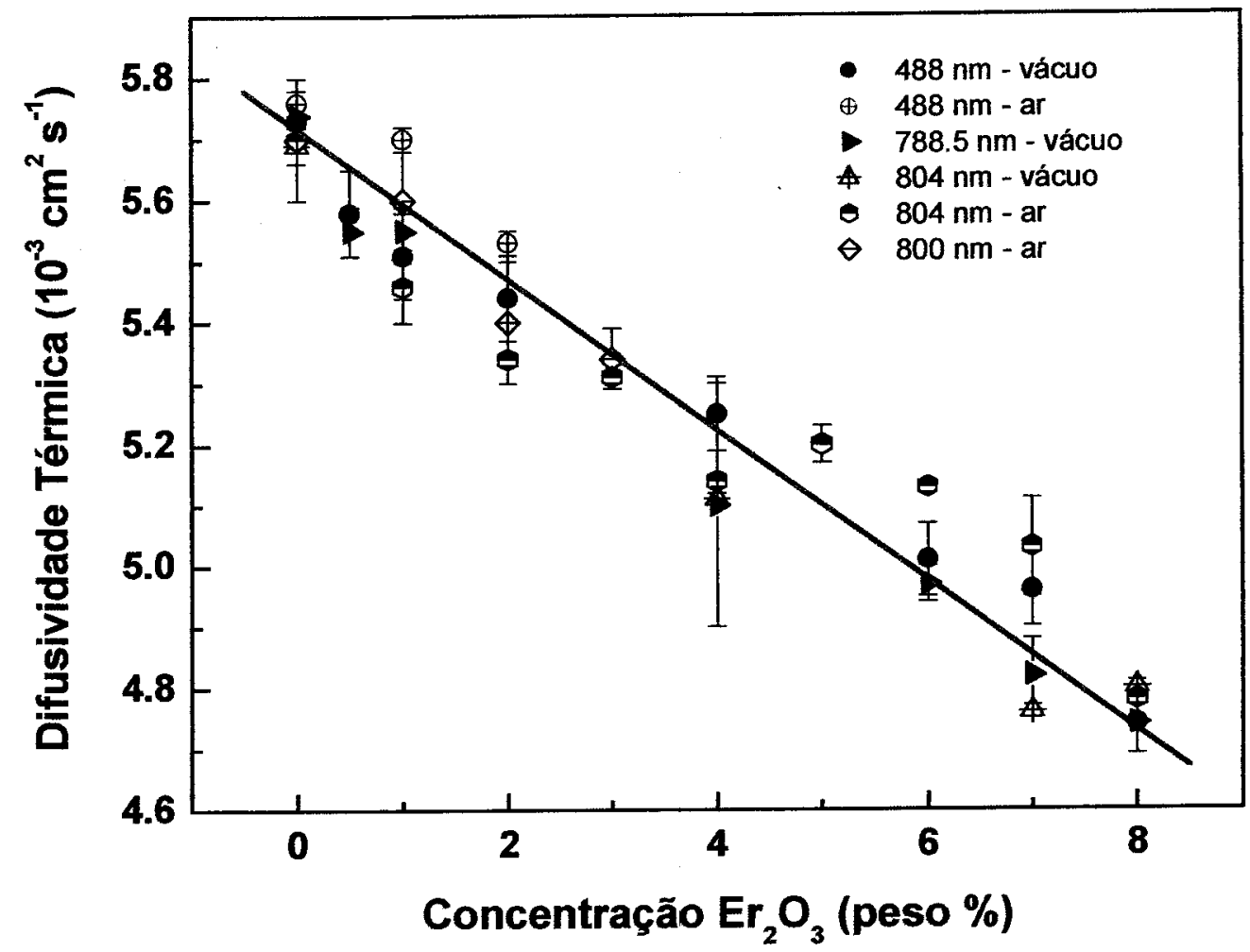

Figura 5.30 - Difusividade em função da concentração de $\mathrm{Er}_{2} \mathrm{O}_{3}$. Amostras preparadas a vácuo e ao ar. Comprimento de onda da medida é indicada na figura.

Durante os experimentos percebemos que um outro fator que pode influenciar nos resultados da difusividade térmica está na variação do diâmetro do feixe do laser de excitação, principalmente nas medidas feitas no laser de titânio-safira. Isso pode ser resolvido fazendo um melhor alinhamento do laser. Para amostras espessas, D pode diferir em relação às amostras mais finas, provavelmente isso ocorra porque a posição em que o sinal de LT foi maximizado, não coincida com a posição da cintura do feixe do laser. Isso pode ser resolvido fazendo pequenas variações da posição da amostras. Outros fatores que influenciam nessa medida é a não homogeneidade da amostras. Para amostras com estrias ou com qualidade óptica não muito boa, há uma variação de até $20 \%$ nesses valores. 
No caso das amostras dopadas com érbio a difusividade diminui de $5.7 \times 10^{-3} \mathrm{~cm}^{2} \mathrm{~s}^{-1}$, CASM00, para aproximadamente $4.7 \times 10^{-3} \mathrm{~cm}^{2} \mathrm{~s}^{-1}$, amostra CASM10, ou seja $18 \% \mathrm{de}$

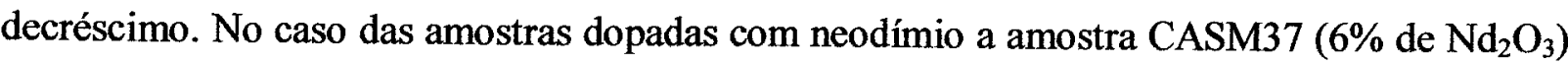
tem uma difusividade térmica de $5.1 \times 10^{-3} \mathrm{~cm}^{2} \mathrm{~s}^{-1}$, ou seja há um decréscimo $11 \%$. Estes resultados estão de bom acordo com os reportados anteriormente por Sampaio (1997) e Baesso et al. (1999) Comparando os dados das tabelas 5.19 a 5.27 podemos verificar que essa diminuição na difusividade independe do tipo do terra rara, sendo mais dependente da substituição de $\mathrm{Al}_{2} \mathrm{O}_{3}$ por terra-rara. Esse comportamento pode ser uma indicação de que os íns terra rara agem como modificadores de rede, esta suposição é baseada no trabalho de Mansanares et al. (1989) que investigaram a difusividade térmica de vidros soda-lime dopados com ferro, cuja conclusão é de que quando o íon $\mathrm{Fe}^{3+}$ atua como formador de rede ocorre um aumento na difusividade térmica, por outro lado quando o íon $\mathrm{Fe}^{3+}$ atua como modificador de rede ocorre um decréscimo na difusividade térmica. A diminuição na conectividade da rede devido à presença dos íons terras raras induzem barreiras térmicas adicionais na estrutura do vidro, e conseqüentemente diminuem a difusão de calor através da amostra.

Quando comparamos a difusividade térmica de vários tipos de vidros. Podemos observar que essa propriedade decresce na seguinte ordem são os vidros aluminato de cálcio, $5.7 \times 10^{-3} \mathrm{~cm}^{2} \mathrm{~s}^{-1}$; vidros silicatos $5.5 \times 10^{-3} \mathrm{~cm}^{2} \mathrm{~s}^{-1}$; vidros boratos $3.9 \times 10^{-3} \mathrm{~cm}^{2} \mathrm{~s}^{-1}$; vidros fluoretos $2.7 \times 10^{-3} \mathrm{~cm}^{2} \mathrm{~s}^{-1}$; vidros chalcogenetos $2.5 \times 10^{-3} \mathrm{~cm}^{2} \mathrm{~s}^{-1} \mathrm{e}$ vidros fosfatos $2.2 \times 10^{-3}$ $\mathrm{cm}^{2} \mathrm{~s}^{-1}$.

Lima et al. (1999) investigaram a influência do cobalto sobre a difusividade de vários vidros fluoretos usando espectroscopia de lente térmica. No caso dos vidros ZBLAN dopados com $\mathrm{CoF}_{2}$ a difusividade térmica permaneceu constante, aproximadamente $2.6 \times 10^{-3} \mathrm{~cm}^{2} \mathrm{~s}^{-1}$, independente da concentração desse haleto. $\mathrm{A}$ introdução de íons de $\mathrm{Co}^{2+}$ não influencia a difusividade térmica desses vidros pois esse sistema vitreo tem uma estrutura mais aberta em relação aos vidros óxidos, principalmente devido aos elementos pesados que compõem a sua estrutura, tais como $\mathrm{La}, \mathrm{Ba}, \mathrm{Pb}, \mathrm{Zr}$, Hf, e portanto são menos susceptivel à introdução de elementos leves como por exemplo os metais de transição. Por outro lado, Baesso et al. (1994) reporta que vidros soda-lime dopados com pequenas quantidades de $\mathrm{Fe}_{2} \mathrm{O}_{3}$ apresenta um 
aumento significativo na difusividade térmica. Esse é um indício de que o $\mathrm{Fe}^{3+}$ atua como formador de rede nesses vidros.

Com base nos resultados apresentados anteriormente, densidade, calor específico e difusividade térmica, podemos calcular a condutividade térmica, que é dada por $k=\rho c D$, cujos resultados para os vidros aluminato de cálcio dopados com $\mathrm{Nd}_{2} \mathrm{O}_{3}$ e $\mathrm{Er}_{2} \mathrm{O}_{3}$ são apresentados na figura 5.31 .

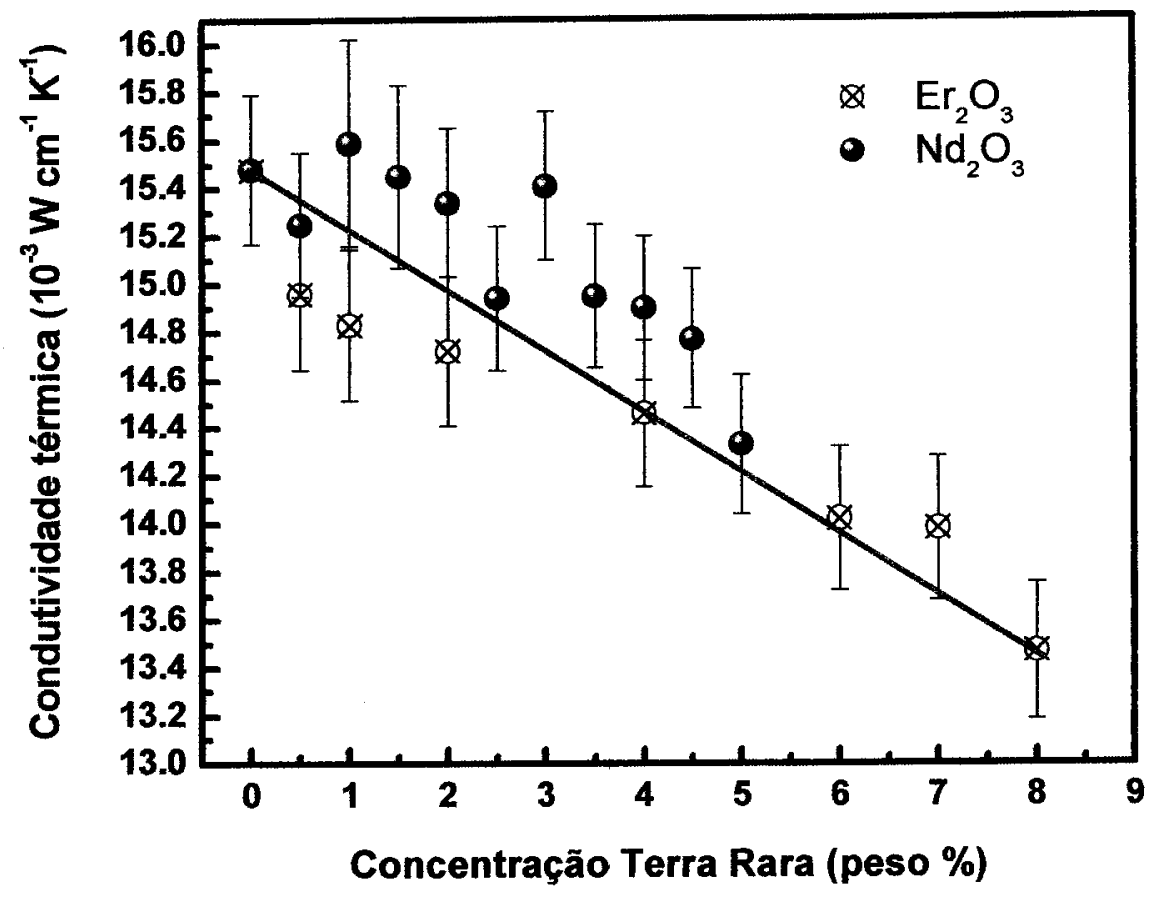

Figura 5.31 - Condutividade térmica de vidros aluminato de cálcio em função da concentração de terra rara. Curva desenhada para guiar os olhos.

A amostra base, CASM00, possui condutividade térmica de $15.5 \times 10^{-3} \mathrm{~W} \mathrm{~cm}^{-1} \mathrm{~K}^{-1}$, enquanto que a amostra mais dopada com 8 peso\% de $\mathrm{Er}_{2} \mathrm{O}_{3}$, CASM10, tem uma condutividade térmica de $13.5 \times 10^{-3} \mathrm{~W} \mathrm{~cm}^{-1} \mathrm{~K}^{-1}$, ou seja uma diminuição de aproximadamente $13 \%$. Podemos verificar na figura 5.31 que essa diminuição é independente do terra rara. Essa diminuição na condutividade pode ser explicada supondo que quando o átomo de terra rara entra na estrutura do vidro atuando como modificador de rede, este promove uma abertura na rede vítrea, que desempenha o papel de barreiras térmicas, 
dificultanto no processo de condução de calor pelo material. Esse resultado corrobora com os resultados obtidos para a variação do volume molar.

Usando o mesmo método descrito anteriormente, obtivemos também, a fim de comparação, a condutividade térmica de vários outros sistemas vítreos que são mostrados na figura 5.32.

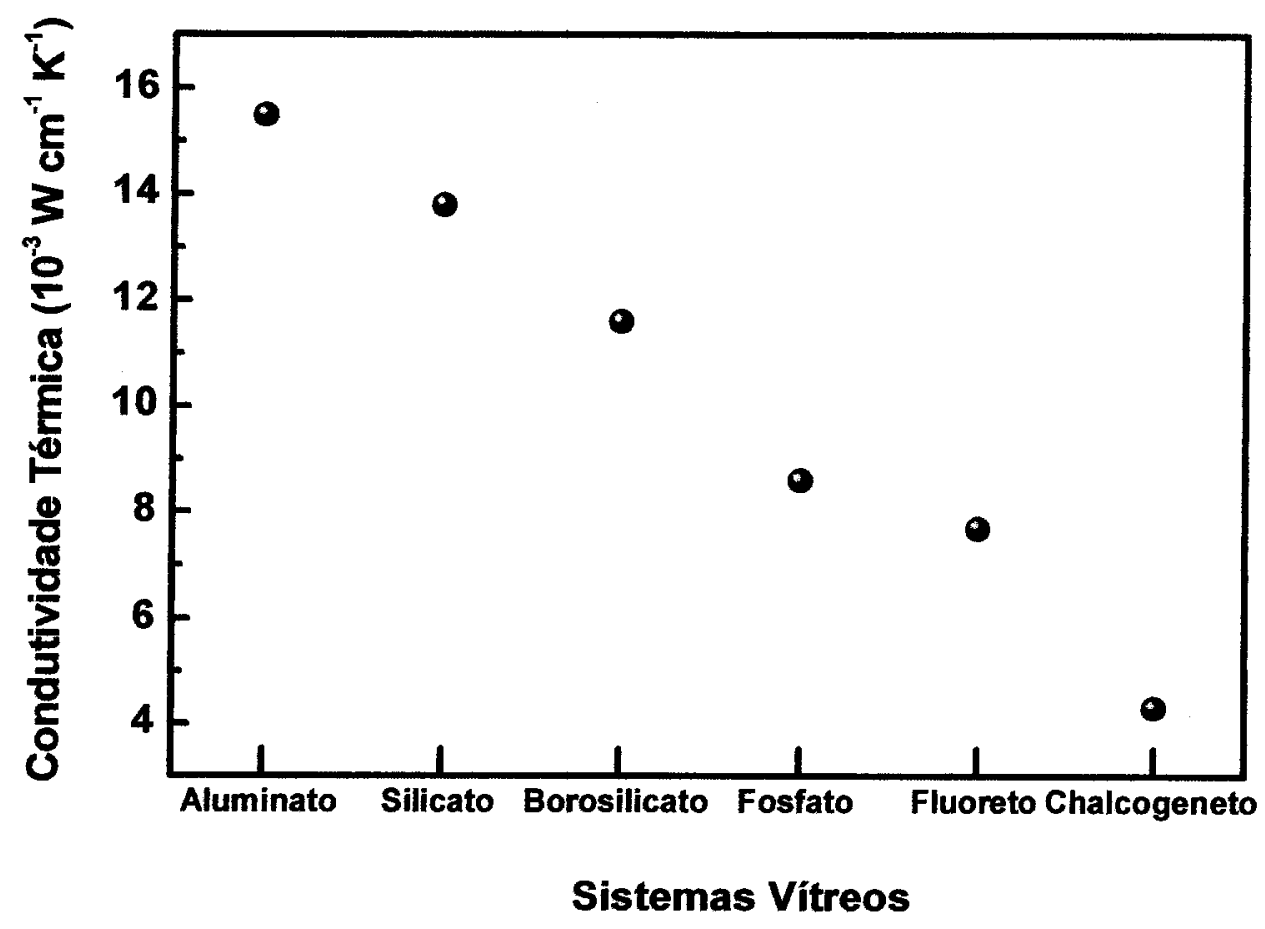

Figura 5.32 - Comparação da condutividade térmica entre vários sistemas vítreos.

$\mathrm{O}$ sistema aluminato de cálcio possui o maior valor nessa propriedade, aproximadamente $15.5 \times 10^{-3} \mathrm{~W} \mathrm{~cm}^{-1} \mathrm{~K}^{-1}$ enquanto que o menor valor é apresentado pelos vidros chalcogenetos, $4.3 \times 10^{-3} \mathrm{~W} \mathrm{~cm}^{-1} \mathrm{~K}^{-1}$. Essa diferença pode ser atribuída ao peso/raio iônico dos átomos que compõem cada um dos sistemas vitreos. Quanto mais fechada for a estrutura da rede vítrea mais fácil será conduzir o calor através do material. 


\subsection{Resistência ao choque térmico}

$\mathrm{Na}$ tabela 5.28 são comparados os resultados obtidos da resistência ao choque térmico para diferentes sistemas vítreos. Os parâmetros, $\alpha, \kappa, v$ e $E$ foram obtidos da literatura (Payne et al., 1995; Klocek, 1991; Krupke et al., 1986; Lima et al., 1999; Lima et al., 2001).

Tabela 5.28 comparação da resistência ao choque térmico de vários sistemas vitreos

\begin{tabular}{|c|c|c|c|c|c|c|c|}
\hline Sistema vitreo & $\begin{array}{c}\alpha \\
\left(10^{-6} K^{-1}\right)\end{array}$ & $\begin{array}{c}\mathrm{k} \\
(\mathrm{W} / \mathrm{mK})\end{array}$ & $\begin{array}{c}\mathrm{K}_{\mathrm{IC}} \\
\left(\mathrm{MPa} \mathrm{m}^{1 / 2}\right)\end{array}$ & $\checkmark$ & $\begin{array}{l}l \\
\mu \mathrm{m}\end{array}$ & $\begin{array}{c}\mathrm{E} \\
(\mathrm{GPa}) \\
\end{array}$ & $\begin{array}{c}\Re \\
(W / m)\end{array}$ \\
\hline Aluminato & 9,8 & 1,55 & 1,4 & 0,29 & 17,8 & 110,0 & 339 \\
\hline Silicato & 8,0 & 1,20 & 1,2 & 0,24 & 20,4 & 87,0 & 358 \\
\hline borato & 8,3 & 0,90 & 1,1 & 0,21 & 21,9 & 81,0 & 244 \\
\hline Fosfato & 9,8 & 0,86 & 0,7 & 0,24 & 14,7 & 64,4 & 197 \\
\hline Telureto & 13,0 & 0,60 & 0,4 & 0,24 & 16,1 & 38,0 & 117 \\
\hline Fluoreto & 17,2 & 0,77 & 0,6 & 0,31 & 11,6 & 55,0 & 86 \\
\hline Calcogeneto & 19,0 & 0,59 & 0,4 & 0,26 & 9,5 & 22,0 & 142 \\
\hline$Y A G^{*}$ & 6,7 & 10,0 & 1,40 & 0,28 & 25,0 & 282 & 1067 \\
\hline$Y L F^{*}$ & 13,8 & 5,8 & 0,27 & 0,33 & 25,0 & 75,0 & 203 \\
\hline
\end{tabular}

*Cristais para efeito de comparação.

Podemos verificar os vidros aluminato de cálcio possuem resistência ao choque térmico semelhante a dos vidros silicatos, i. e., $339 \mathrm{~W} / \mathrm{m}$, enquanto que o menor valor é característica do vidro fluoreto, $86 \mathrm{~W} / \mathrm{m}$. O fato dos vidros aluminato de cálcio apresentar uma maior resistência deve-se a sua alta tenacidade à fratura e alta condutividade térmica. $O$ que não ocorre por exemplo com os vidros fluoretos. Também são apresentados na tabela 5.28, a caráter informativo, a resistência ao choque térmica de dois cristais o YAG, que é consagrado material para laser, e o cristal YLF. Podemos verificar que o YAG em relação aos vidros possuem uma alta resistência ao choque térmico, isso deve-se principalmente a sua alta condutividade térmica, que é privilegiada devido a periodicidade da rede cristalina. 


\subsection{Eficiência Quântica}

$\mathrm{Na}$ figura 5.33 é mostrado o comportamento da eficiência quântica, comparando o método de Judd-Ofelt com os médidos através da espectroscopia de lente térmica. Podemos verificar que a eficiência quântica é aproximadamente igual através dos dois métodos.

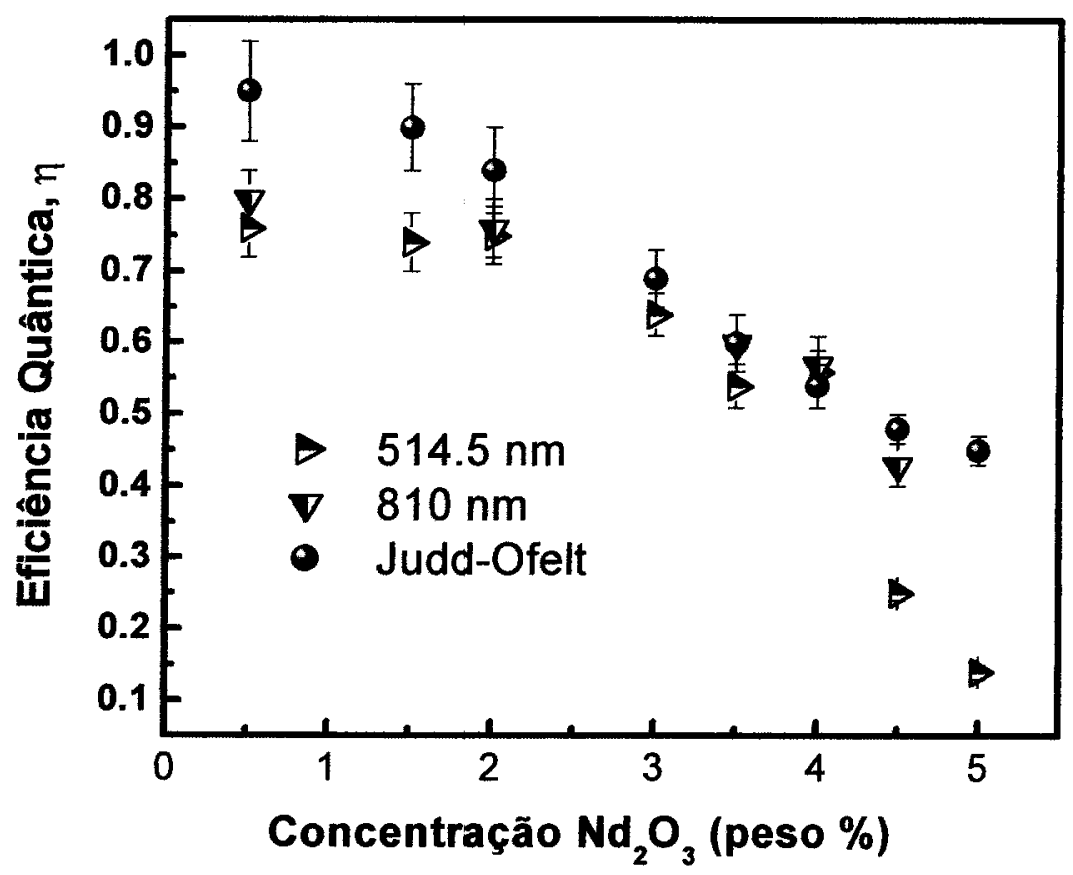

Figura 5.33 - Comportamento da eficiência quântica dos vidros aluminato de cálcio em função da concentração de $\mathrm{Nd}_{2} \mathrm{O}_{3}$.

Na figura 5.34 são apresentados os resultados do sinal de lente térmica normalizado pela potência, coeficiente de absorção óptica e espessura, em função do comprimento de onda para uma amostra de vidro aluminato de cálcio dopado $2 \%$ de $\mathrm{Nd}_{2} \mathrm{O}_{3}$ (amostra fundida a vácuo). Ajustando os dados $\Theta, \lambda_{e}$, e $\left\langle\lambda_{e m}\right\rangle$ obtidos experimentalmente, através da equação 4.49 , podemos determinar $\eta$ e $\beta$ e conseqüentemente ds/dT. 


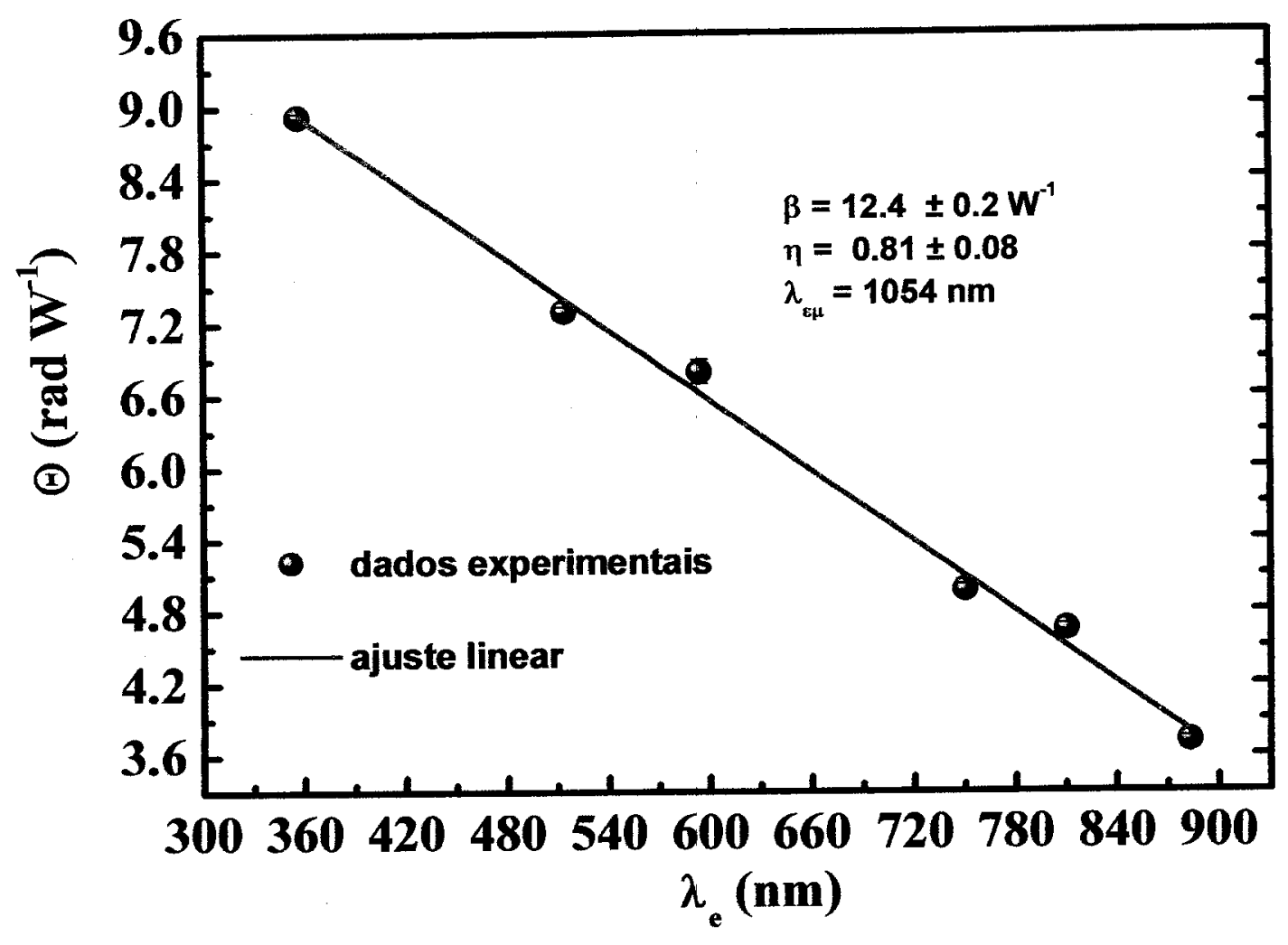

Figura 5.34 - Efeito de lente térmica normalizado em função do comprimento de onda do laser de excitação. A reta representa o ajuste através da Eq. 6.19.

Comparando os resultados da eficiência quântica, $0.81 \pm 0.01$, para a amostra de vidro aluminato de cálcio dopada com $2 \%$ em peso de $\mathrm{Nd}_{2} \mathrm{O}_{3}$, podemos verificar que o valor obtido em função do comprimento de onda está de bom acordo com os demais resultados obtidos através do método de Judd-Ofelt, que foi de $0.84 \pm 0.06$ e do que utiliza o vidro base como referência $0.75 \pm 0.04$. Além disso o método em função do comprimento permitiu calcular o valor de ds/dT independente da amostra base. Sabendo que a condutividade térmica para essa amostra é de $(15.3 \pm 0.3) \times 10^{-3} \mathrm{~W} \mathrm{~cm}^{-1} \mathrm{~K}^{-1}$ e o laser de excitação em $632.8 \times 10^{-7} \mathrm{~cm}$, temos que $\mathrm{ds} / \mathrm{dT}=(12.0 \pm 0.4) \times 10^{-6} \mathrm{~K}^{-1}$.

Foram também realizados os cálculos para a obtenção da eficiência quântica de vidros aluminato de cálcio dopados com $\mathrm{Er}^{3+}$ através do primeiro método, ou seja, usando o vidro 
base como referência. Na figura 5.35 é ilustrado o diagrama parcial dos níveis de energia do the $\mathrm{Er}^{3+}$.

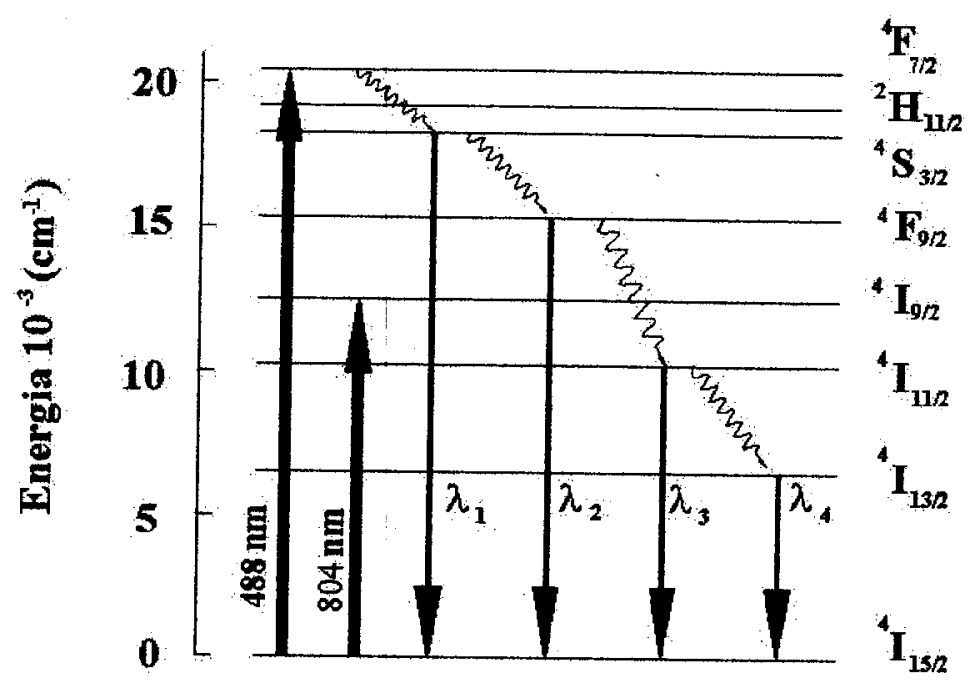

Figura 5.35 - Níveis de energia parcial do érbio.

Um íon de $\mathrm{Er}^{3+}$ ao ser excitado por um laser operando em $488 \mathrm{~nm}$, ocorre a ressonância do nivel de energia ${ }^{4} \mathrm{~F}_{7 / 2}$. Após esta excitação, o sistema decai rapidamente para o nível ${ }^{4} \mathrm{~S}_{3 / 2}$ $\left(\mathrm{em} \approx 1.8 \times 10^{4} \mathrm{~cm}^{-1}\right)$ gerando várias linhas de fluorescência, sendo $\lambda_{1}=547 \mathrm{~nm}$ referente a transição ${ }^{4} \mathrm{~S}_{3 / 2} \rightarrow{ }^{4} \mathrm{I}_{15 / 2} ; \lambda_{2}=652 \mathrm{~nm}$, referente a transição transição ${ }^{4} \mathrm{~F}_{9 / 2} \rightarrow{ }^{4} \mathrm{I}_{15 / 2} ;$ e $\lambda_{3}=980$ $\mathrm{nm}$, referente a transição transição ${ }^{4} \mathrm{I}_{11 / 2} \rightarrow{ }^{4} \mathrm{I}_{15 / 2}$. A eficiência quântica de ca uma dessas transições é muito baixa, conforme reportado por Zou e Izumitani (1993c), respectivamente, $3.27 \%, 1.5 \%$ e $2.1 \%$. Entretanto, nos vidros óxidos, somente a transição ${ }^{4} I_{13 / 2} \rightarrow{ }^{4} I_{15 / 2}$ $\left(\lambda_{4} \sim 1.54 \mu \mathrm{m}\right)$ apresenta alta eficiência quântica (Hewak, 1993), sendo que a maioria dos outros níveis decaem por cascata multifônons $\left({ }^{4} \mathrm{~S}_{3 / 2} \rightarrow{ }^{4} \mathrm{~F}_{9 / 2} \rightarrow{ }^{4} \mathrm{I}_{9 / 2} \rightarrow{ }^{4} \mathrm{I}_{1 / 2} \rightarrow{ }^{4} \mathrm{I}_{13 / 2}\right)$. Levando isso em consideração, tomamos em primeira aproximação $\left\langle\lambda_{e m}\right\rangle$ igual a $1.54 \mu \mathrm{m}$. Usando os dados de $\Theta_{\text {ef }}$ das tabelas 5.21 a 5.24 pudemos calcular a eficiência quântica dos vidros dopados com $\mathrm{Er}^{3+}$.

$\mathrm{Na}$ figura 5.36 é mostrado o comportamento da eficiência quântica dos vidros aluminato de cálcio em função da concentração de $\mathrm{Er}_{2} \mathrm{O}_{3}$ e em função da atmosfera de fusão. 


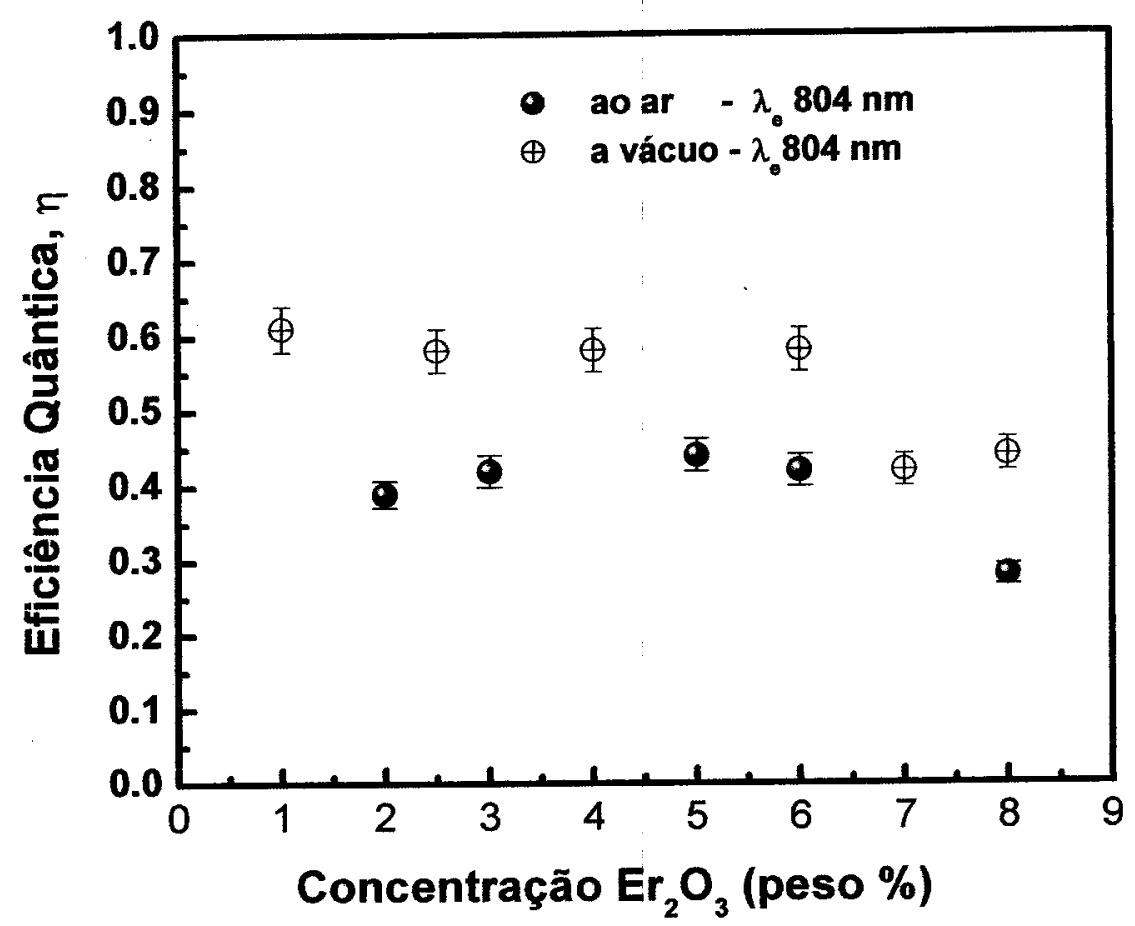

Figura 5.36 - Eficiência quântica dos vidros aluminato de cálcio em função da concentração de $\mathrm{Er}_{2} \mathrm{O}_{3}$.

Em relação a esses resultados podemos discutir vários aspectos desse comportamento. O primeiro se refere a diferença absoluta de $33 \%$ entre a eficiência quântica das amostras fundidas a vácuo e ao ar. Essa diferença é esperada já que as amostras fundidas ao ar possuem em sua estrutura radicais $\mathrm{OH}$ que contribuem para a relaxação multifônons e conseqüentemente possuem uma eficiência quântica mais baixa. Porém o fato que chama a atenção é o baixo valor da eficiência quântica das amostras fundidas a vácuo. Era esperado que a eficiência quântica das amostras menos dopadas fosse alto, aproximadamente $90 \%$, porém podemos verificar na figura 5.36 que esse valor foi de $60 \%$. Surge então algumas questões do porquê isso ocorre. Uma suposição é de que o érbio seja pouco sensibilizado quanto excitado nos comprimentos de onda nos quais os experimentos foram feitos. Na figura 5.26 foi mostrado o espectro de transmitância dos vidros aluminato de cálcio dopado com 
$\mathrm{Er}_{2} \mathrm{O}_{3}$, onde verificamos que a absorção óptica em $804 \mathrm{~nm}$, das amostras fundidas ao ar é sensivelmente maior do que as fundidas a vácuo.

$\mathrm{Na}$ região de comprimentos de onda mais curtos temos uma maior contribuição do coeficiente de absorção óptica da matriz, o que interfere na normalização do sinal de lente térmica, e conseqüentemente na determinação da eficiência quântica. Isso pode ser verificado na tabela 5.20, em que o sinal de lente térmica das amostras dopadas é muito maior do que o da amostra base, impossibilitando a determinação da eficiência quântica do $\mathrm{Er}^{3+}$ nessa matriz vítrea, fato semelhante ocorre com as amostras dopadas com $\mathrm{Nd}_{2} \mathrm{O}_{3}$ fundidas ao ar, vide tabela 5.25. Porém quando analisamos a eficiência quântica das amostras dopadas com $\mathrm{Er}_{2} \mathrm{O}_{3}$ em que a excitação ocorreu em $488 \mathrm{~nm}$, os valores de $\eta$ são maiores que a unidade, com eficiência de até $160 \%$. Esse enorme erro deve-se principalmente ao erro na medida do coeficiente de absorção óptica que é baixo.

Uma vez que esta é a primeira vez que a técnica de lente térmica está sendo empregada como ferramenta para medir a eficiência quântica de vidros dopados com $\mathrm{Er}^{3+}$, podemos afirmar, de nossa experiência, que há necessidade de entender melhor como funcionam os mecanismos de absorção do $\mathrm{Er}^{3+}$ nesse e em outros sistemas vítreos. Provavelmente excitando a amostra em comprimentos de ondas próximos às bandas de absorção mais intensa desse íon, como por exemplo $525 \mathrm{~nm}$ ou $1540 \mathrm{~nm}$, possamos minimizar o erro observado. Uma vez que a eficiência de transferência de energia $\mathrm{Yb} \rightarrow$ Er é de aproximadamente $86 \%$ (Souza et al. 2000) nos vidros aluminato de cálcio dopados com Er e co-dopados com $\mathrm{Yb}$, seria interessante realizar medidas excitando estas amostras em $980 \mathrm{~nm}$. 


\subsection{Tempo de Vida da fluorescência}

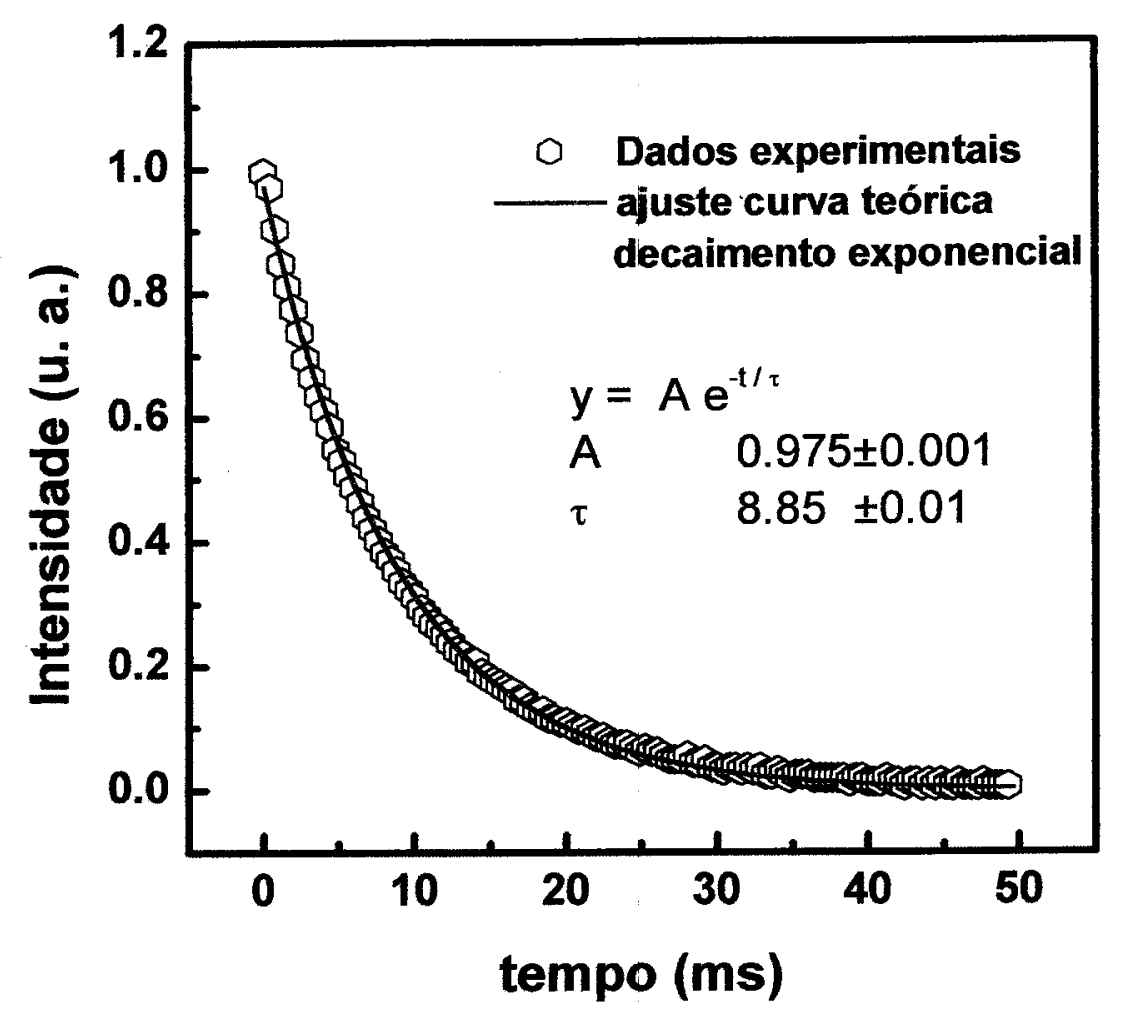

Figura 5.37 - Decaimento exponencial do tempo de vida de uma amostra de vidro aluminato de cálcio dopado com $0.5 \%$ de $\mathrm{Er}_{2} \mathrm{O}_{3}$.

$\mathrm{Na}$ figura 5.37 é mostrado a curva de decaimento para uma amostra de vidro aluminato de cálcio dopado com 0.5 peso $\%$ de $\mathrm{Er}_{2} \mathrm{O}_{3}$. Através do ajuste obtivemos $\tau=8.85 \pm 0.01 \mathrm{~ms}$.

Este procedimento foi seguido para as demais amostras de vidros aluminato de cálcio dopado com $\mathrm{Er}_{2} \mathrm{O}_{3}$. Para a amostra dopada com $0.5 \%$ de $\mathrm{Er}_{2} \mathrm{O}_{3}$ o tempo de vida foi de $8.85 \pm$ $0.01 \mathrm{~ms}$, ocorrendo um valor máximo para a amostra dopada com $2.0 \%$ de $\operatorname{Er}_{2} \mathrm{O}_{3}$, aproximadamente $13.6 \pm 0.4 \mathrm{~ms}$, e em seguida decrescendo até a amostra dopada com $8 \%$ de $\mathrm{Er}_{2} \mathrm{O}_{3}$, cujo tempo de vida foi de $8.2 \pm 0.2 \mathrm{~ms}$. Os resultados são mostrados na figura 5.38 , e estão de bom acordo com os reportados anteriormente por Zou e Izumitami (1993). Esse 
aumento inicial no tempo de vida pode ser atribuído ao efeito de captura de radiação "radiation trapping".

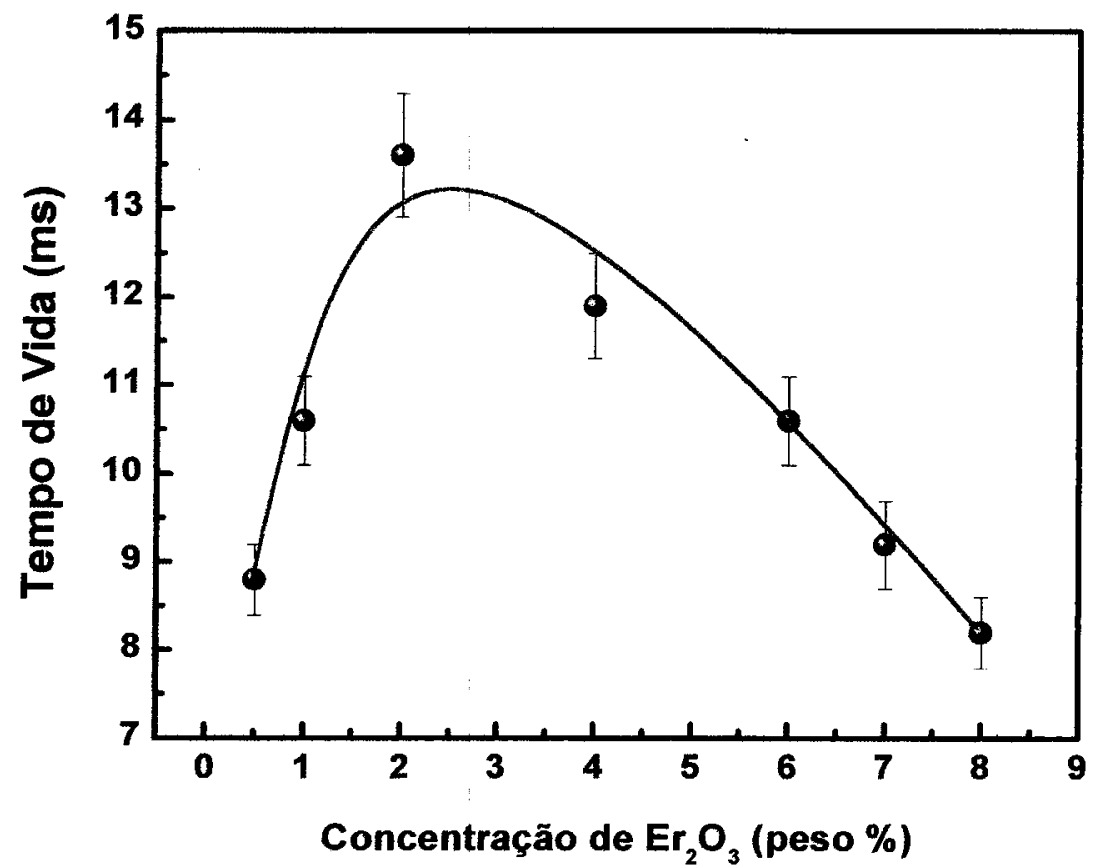

Figura 5.38 - Tempo de vida da fluorescência em função da concentração de $\mathrm{Er}_{2} \mathrm{O}_{3}$. Curva desenhada para guiar os olhos. 


\section{Conclusões e Perspectivas de trabalhos futuros}

\subsection{Conclusões}

Nesta tese investigamos a influência da adição de íons terra rara na composição de vidros aluminato de cálcio com baixa concentração de sílica. Foi possível introduzir nesses vidros até $8 \%$ (em peso) de $\mathrm{Er}_{2} \mathrm{O}_{3}$, e $5 \%$ de $\mathrm{Nd}_{2} \mathrm{O}_{3}$. No caso das amostras fundidas ao ar esse valor foi de $6 \%$ (em peso) de $\mathrm{Nd}_{2} \mathrm{O}_{3}$. As amostras apresentaram boa qualidade óptica, ou seja, por inspeção visual as amostras não apresentaram estrias, cordas e tiveram uma boa transparência.

A densidade do vidro base foi de $2.92 \mathrm{~g} / \mathrm{cm}^{3}$, enquanto que do vidro com a maior quantidade de dopante, $8 \%$ (em peso) de $\mathrm{Er}_{2} \mathrm{O}_{3}$ foi de $3.13 \mathrm{~g} / \mathrm{cm}^{3}$. O volume molar manteve-se constante para baixas concentrações $(<3 \%$ em peso) de terra rara, enquanto que para concentrações mais altas houve um aumento nessa propriedade, indicando que os íons terras raras promovem expansão da rede vítrea, levando conseqüentemente a devitrificação.

As propriedade elásticas tiveram pequenas variações, dentro do erro da técnica da utilizada: o módulo de Young, E, foi de aproximadamente $105 \mathrm{GPa}$, o coeficiente de Poisson de 0.29 e a temperatura de Debye foi de aproximadamente $360 \mathrm{~K}$ Conclui-se desse resultado que os módulos de elasticidade são mais dependente dos elementos formadores de rede do que dos elementos modificadores, como os íons terras raras. 
Os vidros aluminato de cálcio apresentam uma alta dureza, que pode ser atribuída a alta concentração de $\mathrm{Al}_{2} \mathrm{O}_{3}$ em sua composição. Conforme substituímos o $\mathrm{Al}_{2} \mathrm{O}_{3}$ por óxido terra rara, observamos um decréscimo nessa propriedade, que diminui de $860 \mathrm{Kg} / \mathrm{mm}^{2}$, amostra

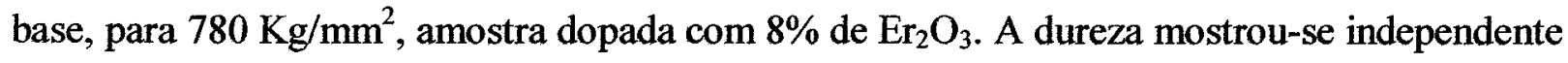
do tipo de terra rara.

Os vidros aluminato de cálcio possuem uma alta tenacidade à fratura, cerca de 3 vezes maior que os vidro chalcogeneto. Concluímos que devido as suas excelentes propriedades mecânicas, os vidros aluminato de cálcio são apropriadas para aplicações em que a robustez seja um pré-requisito.

Os vidros aluminato de cálcio apresentaram alto valor na temperatura de transição vítrea, $\mathrm{T}_{\mathrm{g}}$, de aproximadamente $840{ }^{\circ} \mathrm{C}$, que decresce conforme aumenta-se a concentração de íons terras raras. A temperatura de cristalização, $T_{x}$, também diminui a medida que aumenta-se a concentração de terra rara. A diferença entre $T_{x}$ e $T_{g}$ diminui em aproximadamente $20 \%$. Os vidros aluminato de cálcio possuem resistência ao choque térmico semelhante aos vidros silicatos. Devido as ótimas propriedades térmicas destes vidros concluímos os vidros aluminato de cálcio são ideais para operar em ambientes hostis, como por exemplo uma cavidade laser.

Pudemos verificar que conforme aumenta-se a concentração de dopante ocorre um aumento do índice de refração, sendo que esse aumento independente do tipo de terra rara. Esse aumento no índice de refração é explicado levando em consideração o aumento da polarizabilidade eletrônica devido à formação de oxigênios non-bridging. $\mathrm{O}$ índice de refração do vidro base em $546.1 \mathrm{~nm}$ foi de 1.67015. O índice de refração em função da temperatura, $\mathrm{dn} / \mathrm{dT}$, apresentou ser aproximadamente $8.0 \times 10^{-6} \mathrm{~K}^{-1}$.

$O$ corte da transmitância na região do infravermelho não é influenciado pela adição de ions terras raras na composição do vidro, cuja transmitância máxima ocorre em $5.5 \mu \mathrm{m}$. O método de fusão a vácuo mostrou-se eficiente para eliminação da forte banda de absorção da água que ocorre próxima a $3.0 \mu \mathrm{m}$.

A difusividade térmica apresentou um decréscimo de aproximadamente $8 \%$. Essa é uma indicação de que os íons terras raras entram na estrutura do vidro como modificadores de rede, 
reduzindo a conectividade da rede vítrea e induzindo barreiras térmicas, e que tem como conseqüência a diminuição da difusão de calor através do material.

O método apresentado de obtenção da eficiência quântica mostrou-se eficaz, principalmente quando feito em função do comprimento de onda, já que não há a necessidade de usar amostra de referência. Os resultados foram satisfatórios para o caso das amostras dopadas com $\mathrm{Nd}_{2} \mathrm{O}_{3}$, pois são semelhantes aos calculados através do método de Judd-Ofelt. Para concentrações até $2 \%$ (em peso) de $\mathrm{Nd}_{2} \mathrm{O}_{3}$, a eficiência quântica foi de aproximadamente $80 \%$.

Entretanto no caso das amostras dopadas com $\mathrm{Er}_{2} \mathrm{O}_{3}$ verificamos que há necessidade de aperfeiçoar a técnica, e entender melhor os processos de transferência de energia, absorção e emissão desse íon.

Com base na tese aqui apresentada podemos afirmar que os vidros aluminato de cálcio são excelentes candidatos para servir como hospedeiro para meio ativo de laser de estado sólido.

\subsection{Perspectivas de trabalhos futuros}

Em se tratando de vidros aluminato de cálcio podemos dizer que há muito ainda a ser estudado. Abaixo relacionamos alguns tópicos que podem ser fontes de futuras investigações, tanto do ponto de vista acadêmico quanto tecnológico:

- Investigação da introdução de outros terras raras nas composições dos vidros aluminato de cálcio, tais como, Ho, Pr, Sm, Eu, Gd, Tb, Dy, Tm e estudar os processos de cristalização.

- Investigação de composições sem a presença de $\mathrm{SiO}_{2}$, como por exemplo $\mathrm{BaO}, \mathrm{SrO}$ e $\mathrm{CaF}_{2}$ e verificar se a cristalização ocorre da mesma forma como ocorreu com as amostras já estudadas.

- Introduzir na composição desses vidros elementos que atuem como formadores de rede pesados tais como $\mathrm{Pb}, \mathrm{W}, \mathrm{Ba}, \mathrm{La}$, etc... a fim de reduzir a energia de fônons desses vidros e dessa forma melhorar as propriedades espectroscópicas. 
- Investigação através da técnica de EXAFS como que ocorre a cristalização desses vidros, quais são os mecanismos presentes, como é que estão localizados os átomos na estrutura do vidro. O que ocorre quando entra um íon terra rara na estrutura do vidro, qual é a distância critica para que isso ocorra.

- Estudar sistemas vítreos híbridos, ou seja, tentar otimizar uma composição em que seja possível harmonizar as propriedades térmicas e mecânicas dos vidros aluminatos com as propriedades ópticas de outros sistemas vítreos, como por exemplo os fluoretos e chalcogenetos. Para isso seria interessante estudar vidros nos sistemas aluminato-fosfato, aluminato-borato, aluminato-fluoreto, aluminato-telureto, aluminato-silicato, e as suas variações.

- Desenvolver vidros aluminato de cálcio através do processo sol-gel, já que poderia-se conseguir uma melhor homogeneidade desses vidros, além de diminuir o gasto com energia, uma vez que a formação desses vidros ocorreria em temperaturas bem abaixo da temperatura de fusão convencional que é de aproximadamente $1400{ }^{\circ} \mathrm{C}$. E principalmente pelo fato de termos poucos trabalhos que discutem a preparação desses vidros preparados por esse método.

- Introduzir óxidos leves e pesados e verificar como ocorre a formação de vidro. 


\section{Referências Bibliográficas}

Alper, A. M., McNally, R.N., Ribbe, P. G., Doman, R.C. In: Phase diagram for ceramists. Editado por Levin, E. M., Robbins, C. R., McMurdie, H. F. The American Ceramic Society, Westerville, (1952) Fig. 259.

Argüelo, Z. P., Bilac, S. A., Cisneros, J. I., Tomyiama, M., Miranda, L. C. M. On the colour variation of a calcium aluminate glass. Glass Tecnology 22 (1981) 186-189.

Azechi, L. S., da Costa, R. F., Medina, A. N., Gandra, F. C. G. Projeto de um calorímetro utilizando o método de relaxação térmica, Rev. Física e Instrumentação, 10 [2] (1995) 7075.

Baesso, M. L., Bento, A. C., Andrade, A. A., Sampaio, J. A., Pecoraro, E., Nunes, L. A. O., Catunda, T., Gama, S. Absolute thermal lens method to determine fluorescence quantum efficiency and concentration quenching of solids. Physical Review B 57 [17] (1998) 1054510549.

Baesso, M. L., Bento, A. C., Duarte, A. R., Neto, A. M., Miranda, L. C. M., Sampaio, J. A., Catunda, T., Gama, S., Gandra, F. C. G. $\mathrm{Nd}_{2} \mathrm{O}_{3}$ doped low silica calcium aluminosilicate glasses: Thermomechanical properties. J. Appl. Phys. 85 [12] (1999) 8112-8118.

Baesso, M. L., Bento, A. C., Fagundes de Souza, D., Sampaio, J. A. Low silica aluminate glass as a fluorescent source includes silica glass doped with rare earth ions to enhance transmission. BR9903163-A - Patent (2001). 
Baesso, M. L., Shen, J., e Snook, R. D. Mode-Mismatched thermal lens determination of temperature coefficient of optical path length in soda lime glass at different wavelengths. $\mathrm{J}$. Appl. Phys. 75 [8] (1994) 3732-3737.

Baesso, M. L. Influência dos metais de transição em vidros aluminato de cálcio e soda-lime. Tese de mestrado, Unicamp, Campinas (1987) pp. 87.

Brannon, J. H., Magde, J. Absolute quantum yield determination by thermal blooming fluorescein. J. Phys. Chem. 82 (1979) 705-709.

Brassington, M. P., Tu, H. L., Miller, A. J., Saunders, G. A. Elastic-Constants of a fluorozirconate glass. Matt. Res. Bull 16 (1981) 613-621.

Bussem, W., Eitel, A.: Structure of pentacalcium trialuminate. Z. Kristallogr., 95 [3-4] (1936) 175-188.

Chung, W. J., Yoo, J. R., Kim, Y. S., Heo J. Mechanism of Blue Up-Conversion in $\mathrm{Tm}^{3+} / \mathrm{Nd}^{3+}$ doped Calcium Aluminate Glasses, J. Am. Ceram. Soc. 80 [6] (1997) 1485-1490.

Davy, J. R. Development of calcium aluminate glasses for use in the infrared spectrum to 5 um. Glass Technology, 19 (1978) 32-36.

Dutt, D. A., Higby, P. L., e Griscom, D. L. A structural model for low silica content calcium aluminosilicate glasses. Phys. Chem. Of Glasses, 33 (1992) 51-55.

Evleth, E.M. Ground and excited-state correlations in rupture of oxygen-oxygen bonds in peroxides. J. Am. Chem. Soc. 98 (1976) 1637.

Fanderlik, I. Optical properties of glass, Prague, Elsevier, (1983) 320 pp.

Fang, R. L., Swofford, in: Ultrasensitive Laser Spectroscopy, Editado por D. S. Kliger, Academic Press, New York, 1983, p. 176.

Florence, J. M., Glaze, F. W., e Black, M. H. Infrared transmitance of some calcium and germanate glasses. J. Res. Nat. Bureau Standards, 55 [4] (1955) 231-237.

Guillemet, C. Comportament mécanique du verre, Verre, 3 [6] (1997) 10-16.

Hafner, H. C., Kreidl, N. J., e Weidel, R. A. Optical properties of some calcium aluminate glasses. J. Am. Ceram. Soc., 41 [8] (1958) 315-323.

Hannon, A. C., Parker, J. M. The structure of aluminate glasses by neutron diffraction. J. Non-Cryst. Solids, 174 (2000) 102-109. 
Hawa, L. G., Chen, C. C, Hwang, S. L. Optical properties of calcium-aluminate oxide glasses Chin. J. Phys. 35 (1997) 78.

Hewak, D., Glass and Rare-Earth Doped Glasses for Optical Fibers, Short Run Press (1993).

Higby, P. L., Ginter, R. J., Aggarwal, I. D., Friebele, E. J. Glass formation and thermal properties of low-silica calcium aluminosilicate glasses. J. Non-Cryst. Solids, 126 (1990) 209-215.

Holloway, D. G: The physical properties of glass, Wykeham Publications Ltd., London, (1973) pp. 220.

Hosono, H., e Abe, Y. Photosensivity and structural defects in dopant-free ultravioletsensitive calcium aluminate glasses, J. Non-Cryst. Solids $95 \& 96$ (1987a) 717-724.

Hosono, H., Kinoshita, T., e Kawazoe, H. Long lasting phosphorescence properties of $T^{3+}$ activated reduced calcium aluminate glasses. J. Phys. Condens. Matter 10 (1998) 95419547.

Hosono, H., Y. Abe. Photochromism of reduced calcium aluminate glasses. Mat. Res. Bull., 23 (1988) 171-176.

Hosono, H., Yamazaki, K., e Abe, Y. Dopant-free ultraviolet-sensitive calcium aluminate glasses. J. Am. Ceram. Soc., 68 [11] (1985) C-304-C305.

Hosono, H., Yamazaki, K., e Abe, Y. Photosensitive characteristcs of dopant-free, ultravioletsensitive calcium aluminate glasses. J. Am. Ceram. Soc., 70 [12] (1987b) 867-870.

Hosono, H.,. Yamazaki, K, e Abe, Y. Photosensitive mechanism of dopant-free, ultravioletsensitive calcium aluminate glasses. J. Am. Ceram. Soc., 70 [12] (1987) 870-873.

Hrubý, A. Evaluation of glass-forming tendency by means of DTA. Czech. J. Phys. B 22 (1972) 1187-1193.

Huang, C., e Behrman, E. C. Structure and properties of calcium aluminosilicate glasses. J. Non-Cryst. Solids, 128 (1991) 310-321.

Hwa, L., G. Rayleigh-Brillouin scattering in calcium aluminosilicate glasses. J. Raman Spectroscopy, 29 (1998) 269-272.

Jacobs, R. R., Weber, M. J. Dependence of the ${ }^{4} F_{3 / 2} \rightarrow{ }^{4} I_{1 / 2}$ Induced-Emission Cross Section for $\mathrm{Nd}^{3+}$ on Glass Composition, IEEE Journal of Quantum Eletronics, QE-12 [2] (1976) $102-111$. 
Kerns, L., Weinberg, M. C., Myers, S., e Assink, R. Al coordination in sol-gel and conventional calcium aluminate glasses. J. Non-Cryst. Solids, $232-234$ (1998) 86-92.

King, W. A., Shelby, J. E. Strontium calicium aluminate glasses. Phys. Chem. Glasses, 37 (1996) 1-3.

Kinoshita, T., Yamazaki, M., Kawazoe, H., e Hosono, H. Long lasting phosphorescence and photostimulated luminescence in Tb-ion-activated reduced calcium aluminate glasses. J. Appl. Phys., 86 [7] (1999) 3729-3733.

Krupke, W. F., Shinn, M. D., Marion, J. E., Caird, J. A., Stokowski, S. E.: Spectroscopic, optical, and thermomechanical properties of neodymium-doped and chromium-doped gadolinium scandium gallium garnet. J. Op. Soc. of Am. B - Optical Physics, 3 [1] (1986) 102-114.

Klemm, W. Über die Bildung von diamenteindrücken in Glasoberflächen. Glastechn. 19 (1941) 386-390.

Klocek, P. Handbook of optical materials, Marcel Dekker, Inc., New York (1991) pp.189.

Leedecke, C. J. e Ballard, C. P. Eletrical properties of calcium aluminate glasses. Am. Ceram. Soc. Bull., 59 [3] (1980) 383-383.

Lesiecki, M. L., Drake, J. M. Use of the thermal lens technique to measure the luminescent quantum yields of dyes in pmma for luminescent solar concentrators Appl. Opt. 21 [3] (1982) 557-560.

Li, Z., Ghosh, A., Kobayashi, A. S.; Bradt, C. R. Indentation Fracture Toughness of Sintered Silicon Carbide in the Palmqvist Crack Regime, J. Am. Ceram. Soc., 72, 6 (1989) p. 904.

Lines, M. E., MacChessney, J. B., Lyons, K. B., Bruce, A. J., Miller, A. E., Nassao, K. Calcium aluminate glasses as potencial ultralow-loss optical materials at $1.5-1.9 \mu \mathrm{m}$. J. Non-Cryst. Solids, 107 (1989) 251-260.

Mason, W. P. Physical acoustic properties of solids, D. Van Nostrand Company, Inc. (1958)

Massazza, F. (1959). In Phase diagram for ceramists. Editado por Levin, E. M., Robbins, C. R., McMurdie, H. F. The American Ceramic Society, Westerville, Fig. 294.

McMillan, P. F. McMillan, Tese doutorado, Universidade Estadual do Arizona-EUA, 1981.

McMillan, P. e Piriou, B. Raman Spectroscopy of calcium aluminate glasses and crystals. J. Non-cryst. Solids, 55 (1983) 221-242. 
McMillan, P. F., Petuskey, W. T., Coté, B., Massiot, D., Landron, C., Coutures J., P. A structural investigation of $\mathrm{CaO}-\mathrm{Al}_{2} \mathrm{O}_{3}$ glasses via ${ }^{27} \mathrm{Al} \mathrm{MAS}-\mathrm{NMR}$. J. Non-Cryst. Solids, 195 (1996) $261-71$.

McMillan, P., Piriou, B. e Navrotsky, A. A. Raman spectroscopy study of glasses along the joins silica-calcium aluminate, silica-sodium aluminate, and silica potassium aluminate, Geochimica et Cosmochimica Acta, 46 (1982) 2021-2037.

Morikawa, H., Marumo, F., Koyama, T., Yamane, M., e Oyobe, A. Structural analysis of $12 \mathrm{CaO} .7 \mathrm{Al}_{2} \mathrm{O}_{3}$ glass. J. Non-Cryst. Solids, 56 (1983) 355-360.

Novotný V., Vich M., Kubista P. Silikáty 23 (1979) 51.

Ogata, Y., Tomizawa, K., e Furuta, K. Peroxides, ed., S. Patai, Wiley, (1983) p. 711.

Onoda Jr., G. Y., Brown, S. D. Low-silica glasses based on calcium aluminates. I. Am. Ceram. Society, 53 [6] (1970) 311-316.

Ohlweiler, O. A. Química Analítica Quantitativa, $3^{\text {a }}$. edição, Rio de Janeiro, (1982) pp. 273.

Oprea, C., Togan, D, Popescu, C. Structure and properties of glasses with a low amount of $\mathrm{SiO}_{2}$ in a quaternary system of $\mathrm{Al}_{2} \mathrm{O}_{3}-\mathrm{SiO}_{2}-\mathrm{CaO}-\mathrm{MgO}$. Thermochimica acta, 194 (1992) 165-173.

Ota, R., Soga, N.: Elastic properties of fluoride glasses under pressure and temperature. J. Non-Cryst. Solids 56 (1983) 105-110.

Paradis, P. F., Babin, F., Gagné, J. M., Lévesque, S. Analysis of the fluorescence of a Nddoped $50 \% \mathrm{CaO}-50 \% \mathrm{Al}_{2} \mathrm{O}_{3}$ glass, pumped at $810 \mathrm{~nm}$, between 1050 and $1100 \mathrm{~nm}$. J. Opt. Soc. Am. B 14 [5] (1997) 1009-1012.

Paul, A. : Chemistry of Glasses, Chapman and Hall, 2a. Ed., London, (1990) 367 pp.

Payne, S. A., Marshall, C. D., Bayramian, A., Wilke, H. Laser properties of a new averagepower Nd-doped phosphate glass. Appl. Phys. B 61 (1995) 257-266.

Pecoraro, E., Sampaio, J. A., Nunes, L. A. O., Gama, S., Baesso, M. L. Spectroscopic properties of water free $\mathrm{Nd}_{2} \mathrm{O}_{3}$-doped low silica calcium aluminosilicate glasses, J. NonCryst. Solids 277 (2000) 73-81.

Pecoraro, E.: Estudo espectroscopico de vidros a base de aluminato de calcio dopados com $\mathrm{Nd}^{3+}$ e de vidros a base de fluoreto de chumbo dopados com $\mathrm{Pr}^{3+}$ e $\mathrm{Pr}^{3+} / \mathrm{Yb}^{3+}$, Tese de doutorado, São Carlos (1999), IFSC, USP. 
Petkov, V., Billinge, S. J. L., Shastri, S. D., Himmel, B. Polyhedral units and network connectivity in calcium aluminosilicate glasses from high-energy X-ray diffraction. Phys. Rev. Letters, 85 (2000) 3436-3439.

Ponton, C. B., Rawlings, R. D., Vickers Indentation Fracture Tougness Test Pat 1 - Review of Literature and Formulation of Standardised Indentation Toughness Equations, Materials Science and Technology, 5, (1989) pp. 865.

Purt, G (1960). In Phase diagram for ceramists. Editado por Levin, E. M., Robbins, C. R., McMurdie, H. F. The American Ceramic Society, Westerville, Fig. 206.

Qiu, J., Hirao, K. Long Lasting Phosphorescence in $\mathrm{Eu}^{2+}$-Doped Calcium aluminoborate Glasses, Solid State Communications, 106 [12] (1998) 795-798.

Rawson, H., Inorganic Glass-Forming System. London, Academic Prss (1967) 317.

Salmang, H: Die physikalischen und chemischen grundlagen der glasfabrikation. Springer, Berlim Göttigen Heidelberg (1957).

Sampaio, J. A., Catunda, T., Coelho, A. A., Gama, S., Bento, A. C., Miranda, L. C. M., Baesso, M. L.: Thermo-mechanical and optical properties of calcium aluminosilicate glasses doped with $\mathrm{Er}^{3+}$ and $\mathrm{Yb}^{3+}$. J. Non-Cryst. Solids 273 [2-3] (2000) 239-245.

Sampaio, J. A., Catunda, T., Gama, S., Baesso, M. L.: Thermo-optical properties of OH-free erbium-doped low silica calcium aluminosilicate glasses measured by thermal lens technique. J. Non-Cryst. Solids 284 (2001) 210-216.

Sampaio, J. A., Investigação de vidros aluminato de cálcio dopados com íons terras, Tese de Mestrado, Unicamp (1997).

Scholze, H.: Le verre - Nature, Structure et proprietés, $2^{\mathrm{a}}$. edição, Institut du verre (1980), Tradução de GLAS, Natur, Struktur und Eigenschaften, Springer-Verlag, Berlin/Heidelber (1977).

Schroeder, T. F., Carpenter, H. W., Carniglia, S. C.: Technical Report R-8079, Contract N00019-69-C-0150, U. S. Department of the Navy, Naval Air Systems Command, Washington, DC (1969).

Shand, E. B.: Glass Engineering Handbook, 2ª edição, McGraw-Hill Book Company, New York (1958). 